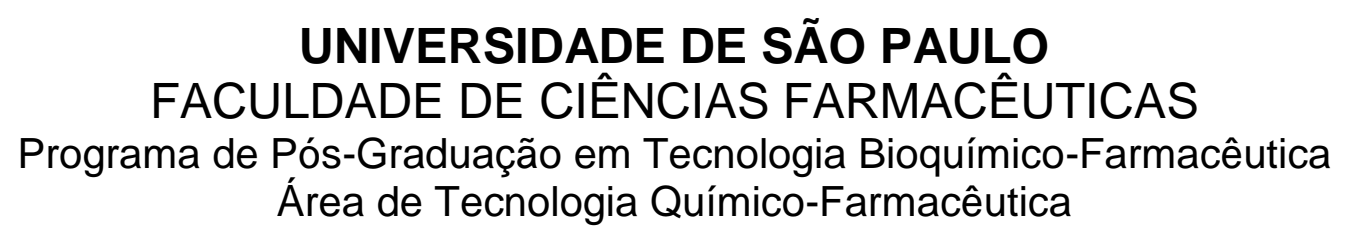

Planejamento, síntese e avaliação da atividade de derivados 5-nitro-2-tiofilidênicos com estrutura azometínica e oxadiazolínica frente a microorganismos causadores de infecções hospitalares

Leandro de Sá Bortolozzo

Dissertação para obtenção do grau de MESTRE

Orientador :

Prof. Dr. Leoberto Costa Tavares 


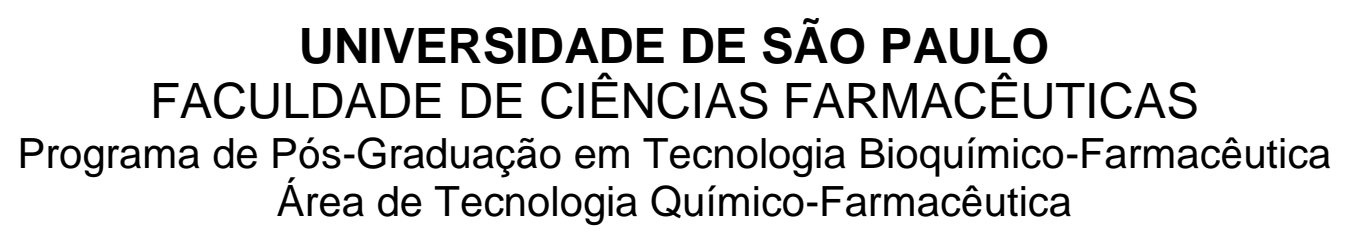

Planejamento, síntese e avaliação da atividade de derivados 5-nitro-2-tiofilidênicos com estrutura azometínica e oxadiazolínica frente a microorganismos causadores de infecções hospitalares

Leandro de Sá Bortolozzo

Dissertação para obtenção do grau de MESTRE

Orientador :

Prof. Dr. Leoberto Costa Tavares 
Ficha Catalográfica

Elaborada pela Divisão de Biblioteca e

Documentação do Conjunto das Químicas da USP.

\footnotetext{
Bortolozzo, Leandro de Sá
B 739p Planejamento, sintese e avaliação da atividade de derivados 5-nitro-2-tiofilidênicos com estrutura azometínica e oxadiazolínica frente a micro-organismos causadores de infecções hospitalares / Leandro de Sá Bortolozzo. -- São Paulo, 2013. $184 \mathrm{p}$.

Dissertação (mestrado) - Faculdade de Ciências Farmacêuticas da Universidade de São Paulo. Departamento de Tecnologia Bioquímico-Farmacêutica.

Orientador: Tavares, Leoberto Costa

1. Fármaco : Planejamento: Química farmacêutica 2. Síntese : Química orgânica 3. Ensaios biológicos: Farmacologia 4. Quimiometria I. T. II. Tavares, Leoberto Costa, orientador.
}

$$
615.19 \text { CDD }
$$




\section{Planejamento, síntese e avaliação da atividade de derivados 5-nitro-2-tiofilidênicos com estrutura azometínica e oxadiazolínica frente a micro- organismos causadores de infecções hospitalares}

Comissão Julgadora

da

Dissertação para obtenção do grau de Mestre

Prof. Dr. Leoberto Costa Tavares

Orientador

Profa. Dra. Elza Masae Mamizuka

(USP - Membro titular)

Profa. Dra. Daniela Gonçales Rando

(UNIFESP - Membro Titular) 
Dedico este trabalho as pessoas que me ensinaram o sentido das palavras amor e simplicidade, aos meus avós Zoilo e Ercilia Bortolozzo que eu amo tanto.

A minha alma gêmea Lucilia Vilela de Melo pelo companheirismo, cumplicidade, afeto, carinho, paciência e amor em todos os momentos. 


\section{Agradecimentos}

A realização deste trabalho em muito se deve à colaboração e apoio de diversas pessoas, as quais transmito os mais sinceros agradecimentos:

À Deus, em primeiro lugar, por me dar força, ânimo e sabedoria.

Ao meu orientador, Prof. Dr. Leoberto Costa Tavares, pelos ensinamentos, amizade, apoio, respeito e incentivo em todos os momentos da realização desse trabalho. Agradeço a oportunidade que me foi dada.

À amiga e Profa. Dra. Kerly Fernanda Mesquita Pasqualoto pela indicação ao LPDF, mas principalmente pela força e confiança depositada.

Ao Dr. Salomão Dória Jorge, pela amizade, apoio, brincadeiras, ensinamentos e grande contribuição no desenvolvimento deste trabalho.

À amiga e doutoranda Fanny Palace-Berl, pelo apoio, ensinamento e discussões de grande valor no desenvolvimento do trabalho.

Ao companheiro de mestrado Rodrigo Rocha Zorzi, pelo auxílio constante, horas de conversas e pela convivência.

Ao grande amigo Michael Jefferson Amorim de Oliveira, pelos muitos cafés expressos e conversas.

Ao técnico João Sussumu Murayama, agradeço a atenção, disponibilidade e toda a ajuda prestada sempre que necessário. Aos amigos Adelson Neto e André Siqueira.

À Prof. Dra. Marina Ishii pela doação de cepas microbiológicas utilizadas neste trabalho, pela amizade, atenção e ensinamentos.

À Prof. Dra. Marina Baquerizo Martinez, Silvia Regina dos Santos e Cristiane Mika, pela doação das cepas de S. aureus ATCC 29213 e E.faecalis ATCC 29212 utilizada neste trabalho.

À Profa. Michelle Carneiro Polli, pelos ensinamentos de Química Farmacêutica, ainda na Universidade São Francisco. Ao Prof.Dr. Roberto Parise Filho, também pelos ensinamentos e constante incentivo no desenvolvimento de minha pesquisa.

Aos meus pais, Joel e Jozemar, pela compreensão e apoio. Aos meus irmãos Lucas e Laís pelo apoio. As minhas tias Noeli e Célia pelas constantes ajudas no decorrer de minha vida.

Ao Programa de Pós-Graduação em Tecnologia Bioquímico-Farmacêutica da Faculdade de Ciências Farmacêuticas da Universidade de São Paulo, pela oportunidade e apoio na realização do presente trabalho.

Ao Jorge, Elaine, e Mirian da Secretaria de Pós-Graduação, Joarez e Elza, da Secretaria do Departamento de Tecnologia Bioquímico-Farmacêutica, pela atenção e solicitude.

À CAPES, pela bolsa sem a qual não teria sido possível a realização deste trabalho.

A todos aqueles que de alguma forma, direta ou indiretamente, contribuíram para a realização deste trabalho. 
"Lembrar que estarei morto em breve é a ferramenta mais importante que já encontrei para me ajudar a tomar grandes decisões. Porque quase tudo - expectativas externas, orgulho, medo de passar vergonha ou falhar - caem diante da morte, deixando apenas o que é mais importante. Não há razão para não seguir seu coração." 
Bortolozzo, L.S. Design, synthesis and activity evaluation of 5-nitro-2-thiophylidene derivatives with azomethine and oxadiazole structures against microorganisms related to hospital infections. São Paulo, 2013. 185p. (Dissertation - Faculdade de Ciências Farmacêuticas, Universidade de São Paulo).

\section{RESUMO}

A incidência de infecções hospitalares tem aumentado substancialmente, resultando no aumento de morbidade e mortalidade nas últimas décadas. Embora as infecções hospitalares estejam intimamente ligadas à assepsia e à higiene do ambiente nosocomial, não se pode deixar de considerar a susceptibilidade já instaurada dos doentes acometidos por estas infecções. Os avanços tecnológicos relacionados à procedimentos invasivos, diagnósticos ou terapêuticos, ajudaram na disseminação das infecções microbianas. Em decorrência desta evolução, surgiram micro-organismos multirresistentes ao atual arsenal de agentes farmacológicos utilizados rotineiramente na quimioterapia, tornando estas infecções grave problema de Saúde Pública. A necessidade de pesquisar novas alternativas para o combate destes micro-organismos é evidente, sendo que derivados nitroheterocíclicos apresentam-se como alternativa bastante viável para estudos de novos compostos com potencial atividade antimicrobiana. Baseado nestes fatos o presente trabalho propõe o planejamento, síntese e avaliação da atividade antimicrobiana de derivados tiofilidênicos com estruturas azometínica e oxadiazolínica frente a microorganismos responsáveis por algumas das principais infecções hospitalares instauradas em hospitais em todo o mundo. A escolha dos grupos substituintes dos compostos planejados foi baseada no digrama de Craig, tendo sido planejado e sintetizados vinte derivados tiofilidênicos, estruturalmente identificados e avaliados quanto à atividade antimicrobiana frente às cepas padrão de Staphylococcus aureus (ATCC 29213) e multirressitente (VISA 3), Escherichia coli (ATCC 25922), Candida albicans (ATCC 573Y), Klebsiella pneumoniae (ATCC 70060), Enterococcus faecalis (ATCC 29212), Enterobacter cloacae (ATCC 23355) e Serratia marcescens (ATCC 14756). Observou-se que os compostos sintetizados apresentaram atividade bastante promissora frente às bactérias Gram positivas ( $S$. aureus ATCC 29213, S. aureus VISA 3 e E. faecalis ATCC 29212) e para o fungo (C. albicans ATCC 573Y), enquanto que para bactérias Gram negativas não foi observado atividade antibacteriana significativa. Estudos de Relação Estrutura Atividade (REA) foram realizados, com objetivo de determinar quais propriedades físico-químicas auxiliam na atividade biológica. Pode-se observar que o equilíbrio lipo-hidrofílico, juntamente com as propriedades eletrônicas, estereoquímicas e topológicas foram as propriedades que contribuíram para a atividade antimicrobiana dos compostos estudados. Revelando esta classe de compostos como promissora opção no delineamento de novos fármacos no combate às infecções hospitalares com caráter de multirresistência.

Palavras Chave: Atividade antibacteriana; Planejamento de fármacos; Nitrocompostos; Infecções hospitalares. 
Bortolozzo, L.S. Design, synthesis and activity evaluation of 5-nitro-2-thiophylidene derivatives with azomethine and oxadiazole structures against microorganisms related to hospital infections. São Paulo, 2013. 185p. (Dissertation - Faculdade de Ciências Farmacêuticas, Universidade de São Paulo).

\section{ABSTRACT}

Incidence of nosocomial infections has increased substantially, resulting in increased morbidity and mortality in recent decades. Although nosocomial infections are closely connected to asepsis and hygiene of the nosocomial environment, one cannot fail to consider the already established susceptibility of patients affected by these infections. Technological progress related to invasive procedures, diagnostic or therapeutic, helped in spreading microbial infections. However, as a consequence of this advancement, microorganisms that are multidrug resistant to the current arsenal of pharmacologic agents used in antibiotic therapy emerged and these infections became a serious public health problem. The need for new alternatives to fight these microorganisms is evident and nitroheterocyclic derivatives are considered as viable for studies of new compounds with potential antimicrobial activity. Based on those events the present study proposes the design, synthesis and antimicrobial activity of thiophylidene derivatives with azomethine and oxadiazole structures against microorganisms responsible for some of the main nosocomial infections observed in hospitals worldwide. The choice of the substituent groups of compounds was based on the Craig diagram, having been designed and synthesized twenty thiophylidene derivatives, structurally identified and evaluated for antimicrobial activity against the strains standard Staphylococcus aureus (ATCC 29213) and mutiresistant (VISA 3), Escherichia coli (ATCC 25922), Candida albicans (ATCC 573Y), Klebsiella pneumoniae (ATCC 70060), Enterococcus faecalis (ATCC 29212), Enterobacter cloacae (ATCC 23355) and Serratia marcescens (ATCC 14756). It was observed that the synthesized compounds show very promising activity on the Gram positive bacteria ( $S$. aureus ATCC 29213, S. aureus VISA 3 and E. faecalis ATCC 29212) and against the fungus (C. albicans ATCC 573Y), while for Gram negative bacteria significant antibacterial activity was not observed. Structure Activity Relationship (SAR) Studies were performed with the objective of determining which physicochemical properties help in the biological activity. It can be observed that the lipophilic-hydrophilic balance, together with the stereochemistry, electronic and topological properties were contributed to the antimicrobial activity of the studied substances. Revealing this class of compounds as a promising option in designing of new drugs to fight nosocomial infections with multidrug resistance character.

Key Words: Antibacterial activity; Drug design; Nitrocompounds; Nosocomial infections. 


\section{Lista de Figuras}

Figura 1. Principais mecanismos de resistência microbiana.......................................... 4

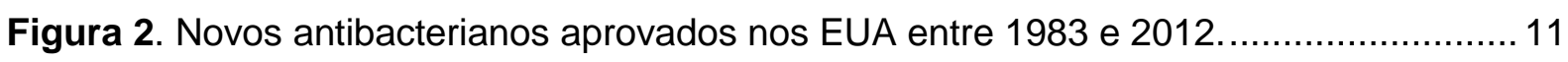

Figura 3. Ranitidina planejada por modificações moleculares da cimetidina. ..................... 15

Figura 4. Fases importantes na ação de fármacos................................................. 17

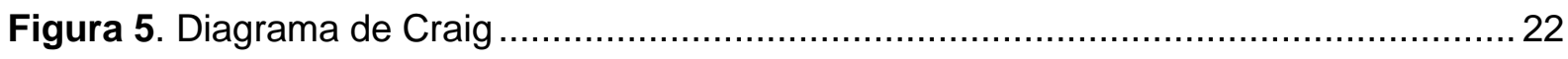

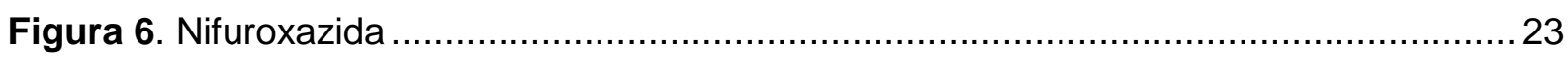

Figura 7. Fármacos nifurtimox, nitrofural e nitrofurantoína, em destaque as subestruturas responsáveis pela ação antimicrobiana.................................................. 23

Figura 8. Processo de redução do grupo nitro via aeróbia e via anaeróbia. ....................... 25

Figura 9. Diferença estrutural entre os derivados nitrocompostos................................ 26

Figura 10. Novos derivados nitrotiofênicos e suas atividades antimicrobianas...................2 27

Figura 11. Estrutura química da nifuroxazida e dos derivados tiofênicos com estruturas azometínica (Série A) e oxadiazolínica (Série B). Em destaque, os locais de modificação estrutural planejados neste estudo e os substituintes selecionados.

Figura 12. Formação das bezidrazidas substituídas. 31

Figura 13. Obtenção de derivados tiofilidênicos azometínicos (Série A). .......................... 32

Figura 14. Obtenção de derivados tiofilidênicos oxadiazolínicos (Série B) ......................... 32

Figura 15. Procedimento de determinação da CIM. (a) Adição de meio de cultura e de soluções-mãe; (b) Adição de inóculo. 36

Figura 16. Procedimento geral adotado para diluição dos compostos na fase II. (a) Adição das primeiras soluções de compostos; (b) Primeira diluição dos compostos. .... 37

Figura 17. Mecanismo de esterificação de Fischer. 43

Figura 18. Mecanismo de reação de amonólise. 44 
Figura 19. Ilustração dos dois possíveis caminhos sintéticos para formação das benzidrazidas substituídas.

Figura 20. Mecanismo de reação de obtenção de bases de Schiff.

Figura 21. Espectro de $\mathrm{RMN}{ }^{1} \mathrm{H}$ do composto 5-nitro-2-tiofilideno 4-nitrobenzidrazida (série $\left.\mathrm{A}-\mathrm{NO}_{2}\right)$

Figura 22. Espectro de $\mathrm{RMN}{ }^{13} \mathrm{C}$ do composto 5-nitro-2-tiofilideno 4-nitrobenzidrazida. 50

Figura 23. Mecanismo de reação para obtenção dos derivados tiofilidênicos oxadiazolínicos.

Figura 24. Espectro de RMN ${ }^{1} \mathrm{H}$ do composto 2-[5-nitro-tiofiliden-2-il]-3-acetil-5-[4-nitro-fenil]2,3-diidro-1,3,4-oxadiazolinas. 56

Figura 25. Espectro de $\mathrm{RMN}{ }^{13} \mathrm{C}$ do composto 2-[5-nitro-tiofiliden-2-il]-3-acetil-5-[4-nitrofenil]-2,3-diidro-1,3,4-oxadiazolinas.

Figura 26. Derivados não obtidos pela via sintética proposta. 61

Figura 27. RMN ${ }^{1} \mathrm{H}$ Realizado neste trabalho com o objetivo da tentativa de identificação do derivado - série $\mathrm{A}-\mathrm{COCH}_{3}$.

Figura 28. $\mathrm{RMN}{ }^{1} \mathrm{H}$ do derivado série $\mathrm{A}-\mathrm{COCH}_{3}$, após cromatográfica em coluna líquida. 62

Figura 29. Confirmação do ácido 4-butilbenzoíco por $\mathrm{RMN}{ }^{1} \mathrm{H}$, após tentativa de obtenção do composto série $\mathrm{B}-\mathrm{n}-\mathrm{C}_{4} \mathrm{H}_{9}$.

Figura 30. Confirmação do ácido 4-t-butilbenzoíco por $\mathrm{RMN}{ }^{1} \mathrm{H}$, após tentativa de obtenção do composto série $\mathrm{B}-\mathrm{t}-\mathrm{C}_{4} \mathrm{H}_{9}$. 63

Figura 31. Curva exponencial da inibição de crescimento em diferentes concentrações do composto série $\mathrm{A}-\mathrm{NO}_{2}$, frente a $\mathrm{S}$. aureus ATCC 29213 realizado na fase I. .... 77

Figura 32. Representação da construção dos modelos moleculares $3 D(A-I$ e $B-I)$ a partir das coordenadas cartesianas das estruturas cristalografadas. 80

Figura 33. Modelo molecular 3D do composto A-I. (*) átomos utilizados na sobreposição e cálculo dos valores de RMSD. 
Figura 34. Mapas de potencial eletrostático (MPEs), dos compostos A-IV, A-I, A-II e A-X, utilizando GaussView 3.0

Figura 35. MPEs, dos compostos B-IV, B-I e B-X, utilizando GaussView 3.0. 84

Figura 36. Mapas de distribuição de orbitais moleculares de HOMO e LUMO calculados com o método HF/3-21G* para os compostos derivados tiofênicos de estrutura azometínica (série A). 86

Figura 37. Mapas de distribuição de orbitais moleculares de HOMO e LUMO calculados com o método HF/3-21G* para os compostos derivados tiofênicos de estrutura oxadiazolínica (série B).

Figura 38. Mapas de potencial lipofílico (MLPs), dos compostos A-I, A-X, A-II, A-IV. 88

Figura 39. Mapas de potencial lipofílico (MLPs), dos compostos B-I, B-X, e B-IV. 89

Figura 40. Valores de $I_{90}$ em potência $(\log 1 / C)$ dos compostos série $A$ e $B$ frente aos micro-organismos selecionados para os estudos subsequentes

Figura 41. Exemplos de gráficos de dispersão das variáveis $x 34, x 5$ em relação à atividade frente a $C$. albicans (y) e seus coeficientes de correlação de Pearson (R). 93

Figura 42. Dendograma dos compostos série A e B estudados frente a $S$. aureus. 96

Figura 43. Dendograma dos descritores estudados frente a $S$. aureus. 97

Figura 44. Escores entre PC1 e PC2, grupo dos compostos avaliados frente a $S$. aureus.. 98

Figura 45. Distância residual das amostras em relação à distância de Mahalanobis para o micro-organimo $S$. aureus. 99

Figura 46. Dendograma dos compostos série A e B estudados frente a C. albicans. 100

Figura 47. Dendograma dos descritores estudados frente a $C$. albicans. 100

Figura 48. Escores entre PC1 e PC2, grupo dos compostos avaliados frente a $C$. albicans. 102

Figura 49. Distância residual das amostras em relação à distância de Mahalanobis para a análise de C.albicans. 102

Figura 50. Dendograma dos compostos série A e B estudados frente a E. faecalis. 103 
Figura 51. Dendograma dos descritores estudados frente a $E$. faecalis. 104

Figura 52. Escores entre PC1 e PC2, grupo dos compostos avaliados frente a $E$. faecalis. 105

Figura 53. Distância residual das amostras em relação à distância de Mahalanobis para o micro-organismo E. faecalis. 106 


\section{Lista de tabelas}

Tabela 1. Exemplos de mecanismos de resistência e as suas bases genéticas 5

Tabela 2. Micro-organismos mais comuns em infecções hospitalares no Brasil. 7

Tabela 3. Antibióticos empregados na atual terapêutica de infecções hospitalares. 10

Tabela 4. Porcentagem de dimetilsulfóxido (DMSO) limitante para não inibição do crescimento dos micro-organismos utilizados nos ensaios microbiológicos. ... 35

Tabela 5. Relação de rendimentos de benzidrazidas 4-R-substituídas obtidas com respectivos rendimentos descritos na literatura.

Tabela 6. Rendimentos parciais e totais obtidos na síntese dos derivados 5-nitro-2-tiofilideno benzidrazidas substituídas - série A.

Tabela 7. Obtenção de derivados tiofilidênicos azometínicos R-substituídos (série A): faixa de fusão e massa molar.

Tabela 8. Principais sinais de $R M N{ }^{1} \mathrm{H}$ (ppm) em DMSO $d_{6}$ de derivados tiofilidênicos azometínicos 4-R-substituídas (série A)

Tabela 9. Principais sinais de $R M N{ }^{13} \mathrm{C}$ (ppm) em DMSO $d_{6}$ de derivados tiofilidênicos azometínicos 4-R-substituídas (série A). 52

Tabela 10. Análise elementar dos derivados tiofilidênicos oxadiazolínicos 4-R-substituídas (série A)

Tabela 11. Rendimentos parciais e totais das etapas de preparação dos derivados tiofilidenos oxadiazolínicos 4-R-substituídos (série B).

Tabela 12. Principais sinais de $\mathrm{RMN}^{1} \mathrm{H}$ (ppm) em DMSO d6 de derivados tiofilidênicos oxadiazolínicos 4-R-substituídas (série B).

Tabela 13. Principais sinais de $R M N{ }^{13} \mathrm{C}$ (ppm) em DMSO $d_{6}$ de derivados tiofilidênicos oxadiazolínicos 4-R-substituídas (série B).

Tabela 14. Análise elementar dos derivados tiofilidênicos oxadiazolínicos4-R-substituídas (série B)

Tabela 15. Concentração inibitória mínima, CIM $(\mu \mathrm{M}$ e $\mu \mathrm{g} / \mathrm{ml})$, de 5-nitro-2-tiofilideno benzidrazidas 4-R-substituídas (Série A) e dos derivados tiofilidênicos 
oxadiazolínicos4-R-substituídas (Série B) frente à cepa de S. aureus ATCC 29213.

Tabela 16. Concentração inibitória mínima, CIM ( $\mu \mathrm{M}$ e $\mu \mathrm{g} / \mathrm{ml})$, de 5-nitro-2-tiofilideno benzidrazidas 4-R-substituídas (Série A) e dos derivados tiofilidênicos oxadiazolínicos 4-R-substituídas (Série B) frente à cepa de S. aureus VISA 3.

Tabela 17. Concentração inibitória mínima, CIM $(\mu \mathrm{M}$ e $\mu \mathrm{g} / \mathrm{ml})$, de 5-nitro-2-tiofilideno benzidrazidas 4-R-substituídas (Série A) e dos derivados tiofilidênicos oxadiazolínicos 4-R-substituídas (Série B) frente à cepa de $C$. albicans ATCC $573 Y$.

Tabela 18. Concentração inibitória mínima, CIM $(\mu \mathrm{M}$ e $\mu \mathrm{g} / \mathrm{ml})$, de 5-nitro-2-tiofilideno benzidrazidas 4-R-substituídas (Série A) e dos derivados tiofilidênicos oxadiazolínicos 4-R-substituídas (Série B) frente à cepa de E. faecalis ATCC 29212.

Tabela 19. Concentração inibitória mínima, CIM $(\mu \mathrm{M}$ e $\mu \mathrm{g} / \mathrm{ml})$, de 5-nitro-2-tiofilideno benzidrazidas 4-R-substituídas (Série A) e dos derivados tiofilidênicos oxadiazolínicos 4-R-substituídas (Série B) frente à cepa de $K$. pneumoniae ATCC 700603.

Tabela 20. Concentração inibitória mínima, CIM $(\mu \mathrm{M}$ e $\mu \mathrm{g} / \mathrm{ml})$, de 5-nitro-2-tiofilideno benzidrazidas 4-R-substituídas (Série A) e dos derivados tiofilidênicos oxadiazolínicos 4-R-substituídas (Série B) frente à cepa de E. cloacae ATCC 23355.

Tabela 21. Concentração inibitória mínima, CIM $(\mu \mathrm{M}$ e $\mu \mathrm{g} / \mathrm{ml})$, de 5-nitro-2-tiofilideno benzidrazidas 4-R-substituídas (Série A) e dos derivados tiofilidênicos oxadiazolínicos 4-R-substituídas (Série B) frente à cepa de E. coli ATCC 25922.

Tabela 22. Concentração inibitória mínima, CIM $(\mu \mathrm{M}$ e $\mu \mathrm{g} / \mathrm{ml})$, de 5-nitro-2-tiofilideno benzidrazidas 4-R-substituídas (Série A) e dos derivados tiofilidênicos oxadiazolínicos 4-R-substituídas (Série B) frente à cepa de S. marcescens ATCC 14756.

Tabela 23. Concentração Inibitória Mínima (CIM) em diferentes concentrações do composto série A- $\mathrm{NO}_{2}$, frente a $S$. aureus ATCC 29213 realizado na fase I. 
Tabela 24. $I_{90}$ dos compostos da série $A$.

Tabela 25. $I C_{90}$ dos compostos da série $B$.

Tabela 26. Valores dos parâmetros termodinâmicos obtidos para osconfôrmeros de energia mais baixa selecionados do PAC do composto A-I e do composto B-I. 82

Tabela 27. Valores de CHELPG dos compostos A-I, A-IV, A-X AlI, B-I, B-IV e B-X. 85

Tabela 28. Valores dos coeficientes de partição calculados por diferentes metodologias. .. 90

Tabela 29. Descritores calculados e obtidos da literatura para os compostos investigados. 91

Tabela 30. Atividade antimicrobiana representada em potência $(\log 1 / C)$. 92

Tabela 31. Análise de PCA quanto a contribuição das PCs e valores dos pesos dos descritores frente a $S$. aureus. 98

Tabela 32. Resultados obtidos da análise de PCA quanto a contribuição das PCs e valores dos pesos dos descritores frente a $C$. albicans. 101

Tabela 33. Resultados obtidos da análise de PCA quanto a contribuição das PCs e valores dos pesos dos descritores frente a $E$. faecalis. 105 


\section{Lista de Abreviaturas}

ANVISA: Agência Nacional de Vigilância Sanitária

CCD: Cromatografia em camada delgada

$\mathrm{CClH}$ : Comissões de Controle de Infecção Hospitalar

CIM: Concentração inibitória mínima

CLSI: Clinical and Laboratory Standards Institute

DM: Dinamica molecular

DMF: Dimetilformamida

DMSO: Dimetilsulfóxido

DMSO- $\mathrm{d}_{6}$ : Dimetilsulfóxido deuterado

DNA: Desoxyribonucleic acid

DP: Desvio padrão

FDA: Food and Drug Administration (Administração Federal de Alimentos e medicamentos)

HCA: Hierarquical cluster analysis (análise de agrupamentos hierárquicos)

$\mathrm{IH}$ : Infecções hospitalares

KPC: Klebsiella pneumoniae carbapenemase

MLPs: Maps of lipophilicity potential (Mapas de potencial lipofílico)

MPEs: Maps of electrostatic potential (Mapas de potencial eletrostático)

MRSA: Methicillin-resistant Staphylococcus aureus(Staphylococcus aureus resistente a meticilina)

P,D\&I: Pesquisa, desenvolvimento e inovação

PC: Componente principal

PCA: Principal component analysis (análise de componentes principais)

QSAR: Quantitative Structure-Activity Relationships (Relações Quantitativas entre Estrutura Química e Atividade Biológica)

RMN ${ }^{13} \mathrm{C}$ : Ressonância Magnética Nuclear de Carbono 13

RMN ${ }^{1} \mathrm{H}$ : Ressonância Magnética Nuclear de Hidrogênio

RMSD: Root mean square deviation (desvio médio da raiz quadrada)

SAR: Structure-Activity Relationship (Relação Estrutura Atividade)

TMS: Trimetilsilano

UFC: Unidades formadoras de colônias

VRE: Vancomycin-resistant Enterococcus (Vancomicina resistente a Enterococcus)

VRSA: Vancomycin-resistant Staphylococcus aureus (Vancomicina resistente a Staphylococcus aureus)

WHO/OMS: World Health Organization (Organização Mundial da Saúde) 


\section{Sumário}

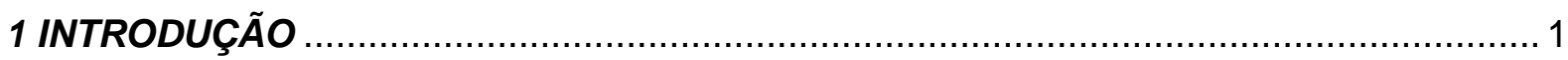

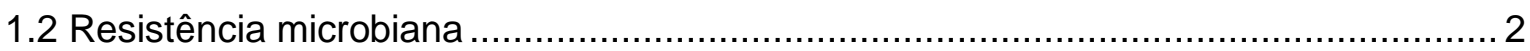

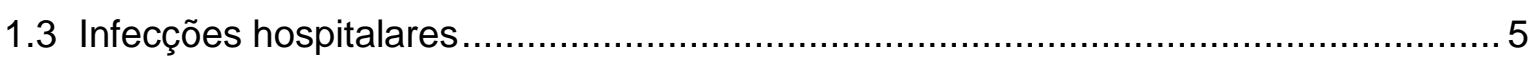

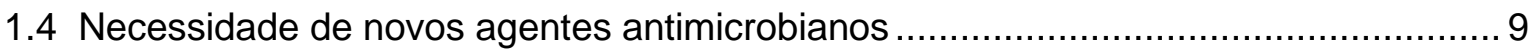

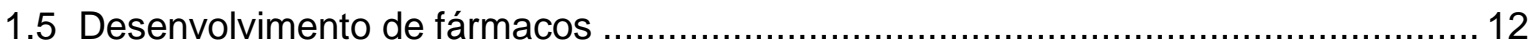

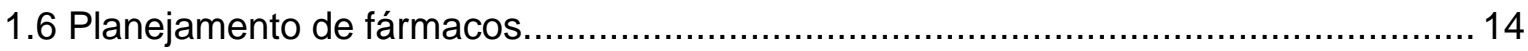

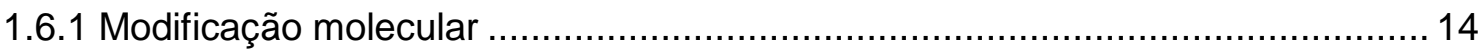

1.6.2 Estudos de relações entre estrutura química e atividade biológica .................... 16

1.6.3 Propriedades físico-químicas que influenciam a ação de fármacos ................... 18

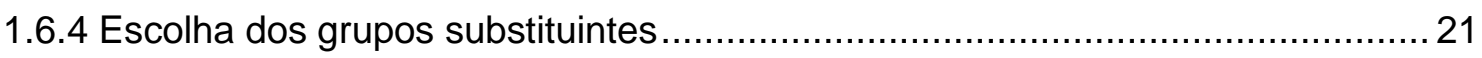

1.7 Composto protótipo e mecanismo de ação .............................................................. 23

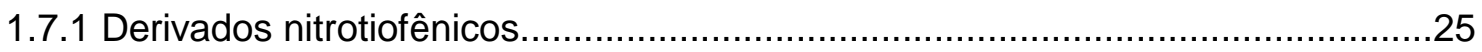

2 OBJETIVO

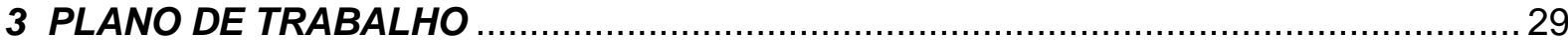

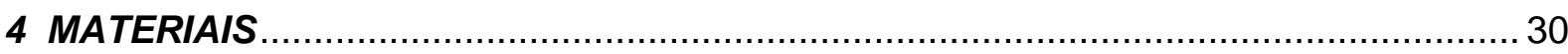

4.1 Reagentes, solventes e meios de cultura ........................................................ 30

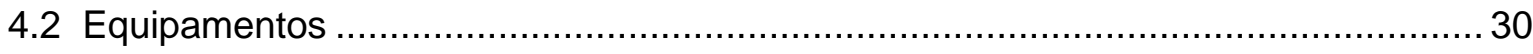

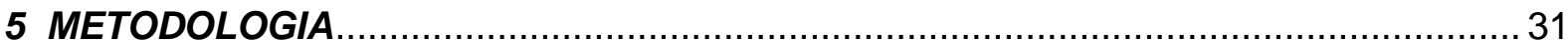

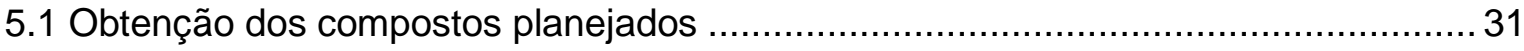

5.1.1 Obtenção de benzidrazidas substituídas ...................................................... 31

5.1.2 Obtenção dos derivados azometínicos (Série A)..............................................

5.1.3 Obtenção dos derivados oxadiazolínicos (Série B) ...................................... 32

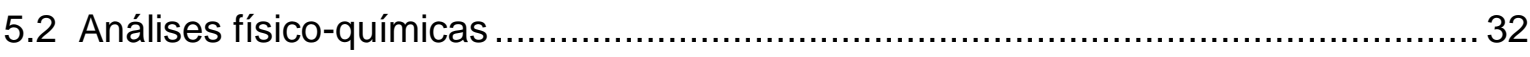

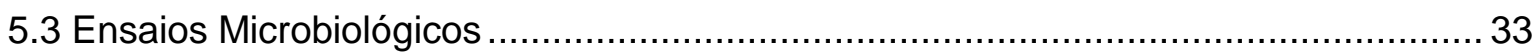

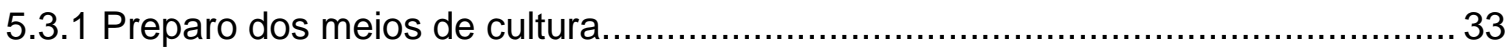

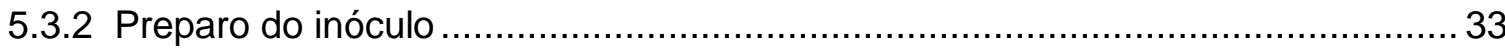


5.3.3 Preparo das soluções de compostos a serem testados

5.3.4 Determinação da concentração inibitória mínima (CIM) …................................ 35

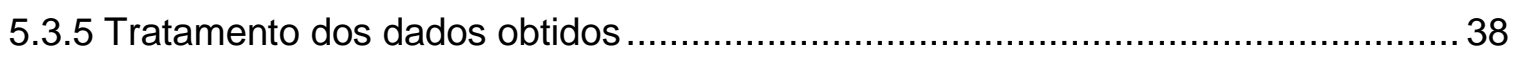

5.4 Estudos de relações estrutura-atividade ........................................................... 38

5.4.1 Construção das moléculas tridimensionais................................................. 39

5.4.2 Cálculo de propriedades moleculares .................................................... 40

5.4.3 Análise exploratória de dados: HCA e PCA........................................................ 41

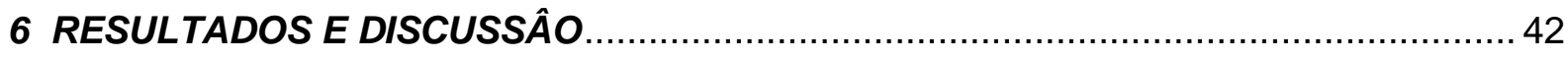

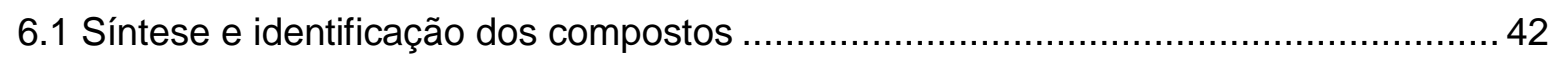

6.1.1 Obtenção de benzidrazidas substituídas ................................................. 42

6.1.2 Obtenção de derivados tiofilidênicos azometínicos ..................................... 46

6.1.3 Obtenção dos derivados tiofilidênicos oxadiazolínicos ................................... 54

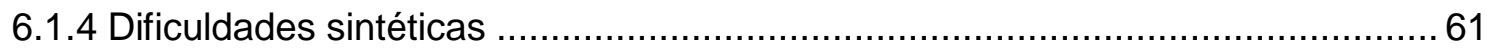

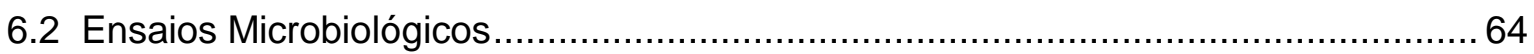

6.2.1 Determinação da concentração inibição mínima (CIM) frente a cepas de $S$. aureus ATCC 29213, S. aureus VISA 3 E. coli ATCC 25922, C. albicans ATCC 573Y, E. faecalis ATCC 29212, K. pneumoniae ATCC 700603 e E. cloacae ATCC 23355 S. marcescens ATCC 14756.

6.2.2 Determinação da concentração inibitória de $90 \%\left(\mathrm{IC}_{90}\right)$ das células bacterianas e fúngicas 76

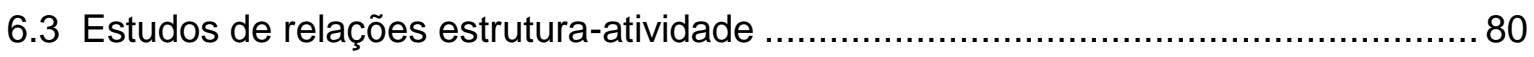

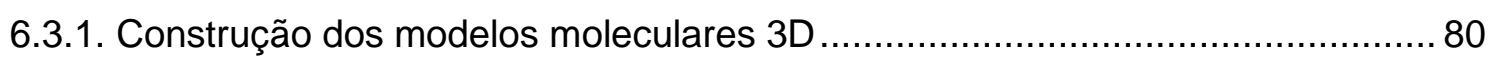

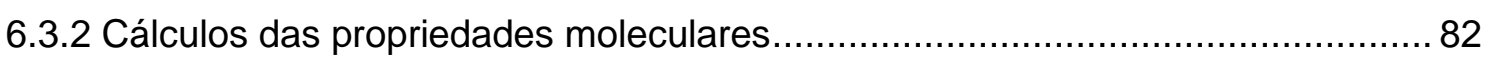

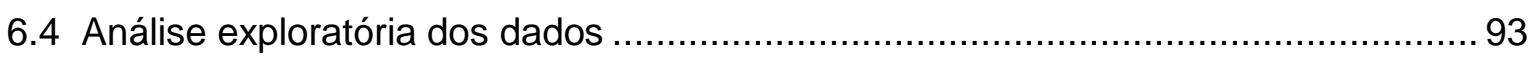

6.4.1 Análise exploratória dos dados obtidos para $S$. aureus.................................96

6.4.2 Análise exploratória dos dados obtidos para C. albicans ................................. 99

6.4.3 Análise exploratória de dados obtidos para E. faecalis ................................. 103

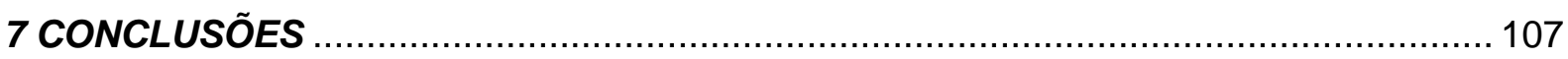


8 PERSPECTIVAS. 108

9 REFERÊNCIAS BIBLIOGRÁFICAS. 110

Anexo 1. Espectros de $R M N{ }^{1} \mathrm{H}$ e $R M N{ }^{13} \mathrm{C}$ dos derivados tiofilidênicos azometínicos. 120

Anexo2. Espectros de $R M N{ }^{1} \mathrm{H}$ e $R M N{ }^{13} \mathrm{C}$ dos compostos derivados tiofilidênicos oxadiazolínicos 142

Anexo 3. Representação gráfica dos confôrmeros e suas energias totais da simulação de dinâmica molecular. 160

Anexo 4. Propriedades calculadas e obtidas em literatura dos compostos das séries A e $B$ 


\section{INTRODUÇÃO}

Infecções hospitalares (IH) tem se destacado pelo aumento frequente de microorganismos resistentes aos principais agentes antimicrobianos utilizados na terapêutica, resultado da íntima relação que o ambiente hospitalar estabelece com os agentes causais destas infecções, sendo estes espaços foco de contaminação e transmissão de diversos micro-organismos, inclusive aqueles com caráter de multirresistência e com maior incidência quando há falta de higienização correta e uso inadequado de agentes antimicrobianos (EAGYE et al., 2009).

No Brasil, as primeiras referências ao controle de contaminação hospitalar surgiram na década de 50, iniciando, a partir daí, preocupação com a implementação de medidas ambientais, técnicas de assepsia e, também, com a identificaçao dos micro-organismos resistentes. Na década de 60, o termo "infecção hospitalar" surgiu em artigos científicos, nos quais se destacavam temas como micro-organismos isolados, perfil de sensibilidade, tipagem de micro-organismos e o emprego correto de antibióticos (HALEY et al., 1985; OLIVEIRA \& MARUYAMA, 2008; WHO,2011).

A partir de 1968 surgiram as primeiras Comissões de Controle de Infecção Hospitalar (CCIH) no país vinculadas, inicialmente, a instituições de ensino. Em 1983, o Ministério da Saúde, pressionado por fatos veiculados na imprensa relacionados a casos de IH, imitiu a Portaria MS № 196/1986 que recomendava aos hospitais brasileiros a criação de CCIH. Contudo, no decorrer dos anos se estabeleceu a Portaria №. 2.616/1998, ainda em vigor, que mantém a obrigatoriedade da existência dessas comissões em ambiente hospitalar (OLIVEIRA \& MARUYAMA, 2008).

Mesmo com o desenvolvimento de medidas para o controle de IH sua prevalência tem aumentado nos últimos anos desordenadamente. No Brasil, dados sobre infecção hospitalar são pouco divulgados, o que dificulta o conhecimento da dimensão do problema no país (MENEZES et al., 2007).

Diante disso, a forma de utilização dos agentes antimicrobianos tornou-se preocupante no Brasil e no mundo. Medidas legais brasileiras foram tomadas com a criação da RDC N44, de 26 de outubro de 2010, com o objetivo de controlar a venda e o consumo dos medicamentos antimicrobianos, buscando assim evitar problemas decorrentes do uso incorreto destes fármacos. Atualmente, o uso indiscriminado de antimicrobianos para infecções de etiologia viral, bacteriana e parasitária, certamente potencializa o desenvolvimento de resistência por estes micro-organismos. Um exemplo deste quadro é o emprego na prática clínica de antimicrobianos de amplo espectro de ação, sendo que um fármaco com menor espectro seria suficiente para erradicar os processos infecciosos 
existentes em determinados casos clínicos (MENEZES et al., 2007; OLIVEIRA \& MARUYAMA, 2008).

A busca por novos agentes antimicrobianos é uma necessidade premente, devido ao aumento da resistência bacteriana, principalmente entre patógenos potencialmente perigosos. Isso tem levado a um aumento na necessidade de novos fármacos e novas classes de antibióticos, tanto para infecções adquiridas em hospitais quanto na comunidade.

Assim, com a atenção voltada para a evolução e gravidade deste problema, o presente trabalho visa à obtenção de compostos análogos à nifuroxazida (5-nitro-2furfurilideno 4- hidroxibenzidrazida), fármaco utilizado nos anos 70 e 80, como primeira ou segunda escolha, no tratamento de infecções intestinais (KOROLKOVAS \& BURCKHALTER, 1988). A nifuroxazida apresenta características que propiciam o emprego de métodos de modificação molecular, tornando estes análogos uma interessante alternativa para o planejamento de novos agentes antimicrobianos com emprego no controle de infecções hospitalares com caráter de multirresistência. Desta forma, aborda-se neste trabalho as etapas de planejamento, síntese e identificação dos compostos, avaliação da atividade antimicrobiana frente a oito cepas diferentes de micro-organismos causadores de infecções hospitalares e o estudo da relação entre a estrutura planejada e a atividade biológica verificada, com o objetivo de identificar compostos com características físicoquímicas que favorecem a atividade biológica destes, tornando-os promissores para o tratamento destas infecções com caráter de multirresistência.

\subsection{Resistência microbiana}

A resistência microbiana é considerada problema de Saúde Pública mundial, tema que tem sido alvo de diversas iniciativas de controle e prevenção. $O$ consumo inadequado de agentes antimicrobianos, causada por doses iandequadas de medicamentos antibióticos, tratamentos incorretos e pela exposição constante de organismos patogênicos oas antimicrobianos nos hospitais, é um dos principais fatores que levam ao aumento da resistência microbiana. A Organização Mundial da Saúde (OMS) e o Centro de Controle e Prevenção de Doenças (Centers for Disease Control and Prevention - CDC) consideram que mais de $50 \%$ das prescrições de antibióticos no mundo são inadequadas, o que impacta diretamente na seleção de micro-organismos resistentes aos agentes antimicrobianos atualmente disponíveis, com consequente aumento do número de casos de $\mathrm{IH}$ de difícil tratamento (FENAFAR, 2013; CDC, 2013).

Atualmente a Agência Nacional de Vigilância Sanitária (ANVISA), juntamente com Organização Pan-Americana da Saúde (OPAS) tem tomado medidas no monitoramento e 
controle da resistência microbiana, com a criação da "Rede Nacional de Monitoramento da Resistência Microbiana em Serviços da Saúde - Rede RM" com o objetivo de conter o uso inadequado de agentes antimicrobianos (ANVISA, 2012). Mesmo com medidas legislativas tomadas pelas agências regulatórias, problemas como a resistência de patógenos a quase todos os agentes antimicrobianos disponíveis, tem se tornado muito comum, especialmente no ambiente hospitalar (MICHAEL \& ANDREW, 2009). O uso inadequado dos antimicrobianos pode selecionar cepas naturalmente resistentes ou aquelas previamente sensíveis, que adquiriram mecanismos de resistência. Um ponto que merece destaque é a disseminação de tais cepas, que ocorre principalmente através do contato físico dos profissionais de saúde e seus pacientes, do ambiente, entre outras formas (MICHAEL \& ANDREW, 2009; GILBERT et al., 2010).

$\mathrm{Na}$ união européia cerca de 25.000 pacientes morrem anualmente de infecções causadas por bactérias multirresistentes e os custos associados estão estimados em 1,5 bilhões de euros por ano. Nos Estados Unidos da América (EUA) os custos com patógenos resistentes aos antimicrobianos ultrapassam os 35 bilhões de dólares por ano (LEUNG, et al. 2011). No ano de 2001 a Organização Mundial da Saúde (OMS) publicou um documento de estratégias de contenção da resistência microbiana (Global strategy for containment of antimicrobial resistance) com uma série de recomendações visando implementar políticas nacionais em resposta aos micro-organismos multirresistentes. Já, em 2005, a OMS advertiu sobre o andamento lento de legislações efetivas no controle para uso racional de antimicrobianos (LEUNG, et al. 2011).

A introdução de antibióticos é uma das intervenções médicas mais importantes no que diz respeito a redução da morbidade e mortalidade humana. No entanto o intenso uso destes fármacos (estimado em 2002 em aproximadamente 200.000 toneladas por ano em todo o mudo) aumentou drasticamente a frequência de resistência entre os patógenos humanos, ameaçando assim uma era pós-antibiótica com a perda das opções terapêuticas (LEUNG, et al. 2011). Ao longo dos anos, a pressão seletiva de diferentes antibióticos resultou em diferentes micro-organismos portadores de resistência a múltiplos fármacos com diferentes mecanismos de ação, dentre os quais destacam-se: Pseudomonas aeruginosa, Acinetobacter baumannii, Escherichia coli e Klebsiella pneumoniae com espectro estendido à enzima beta-lactamase, Enterococos resistentes à vancomicina (VRE, Vancomycin-resistant Enterococcus), Staphylococcus aureus resistente à meticilina (MRSA, Methicillin-resistant Staphylococcus aureus) e resistente à vancomicina (VRSA, Vancomycin -resistant Staphylococcus aureus) (ALEKSHUN \& LEVY, 2007).

Diferentes mecanismos de resistência microbiana são responsáveis por inativar os agentes antimicrobianos. Os mais comums são influenciados pelo princípio evolutivo da 
adaptação genética de organismos às mudanças no seu meio ambiente. Dentre estes, destaca-se 3 grupos distintos: Destruição do antibiótico - enzimas catalisam a degradação do antibiótico ou modificam grupos funcionais farmacologicamente importantes presentes em sua estrutura, criando funçôes inativas para o reconhecimento molecular; Efluxo contínuo do antibiótico - genes mutantes superexpressam proteínas transportadoras de membrana responsáveis pela entrada e saída de substâncias no meio citoplasmático, fazendo com que a retirada do antibiótico para o meio extracelular seja mais rápida que a sua difusão pela membrana bacteriana, mantendo uma concentração insuficiente para atuar como bloqueador de funções celulares; Reprogramação e modificação da estrutura-alvo

- alvos macromoleculares do antibiótico, como ribossomos, proteínas e constituintes da parede celular, são estruturalmente modificados a partir de genes que os expressam, afetando o reconhecimento do fármaco pelo alvo e diminuindo sua potência. Utilizando um destes mecanismos, ou uma combinação deles, cepas de bactérias vêm sobrepujando até os antibióticos mais promissores, independente da classe química as quais pertençam. A Figura 1 ilustra os respectivos mecanismos de resistência e a tabela 1 mostra as principais classes de fármacos utilizados na terapêutica antibacteriana e os respectivos mecanismos de resistência microbiana desenvolvidos pelos micro-organismos. (SILVEIRA et al., 2006; ALEKSHUN \& LEVY, 2007; MICHAEL \& ANDREW, 2009).

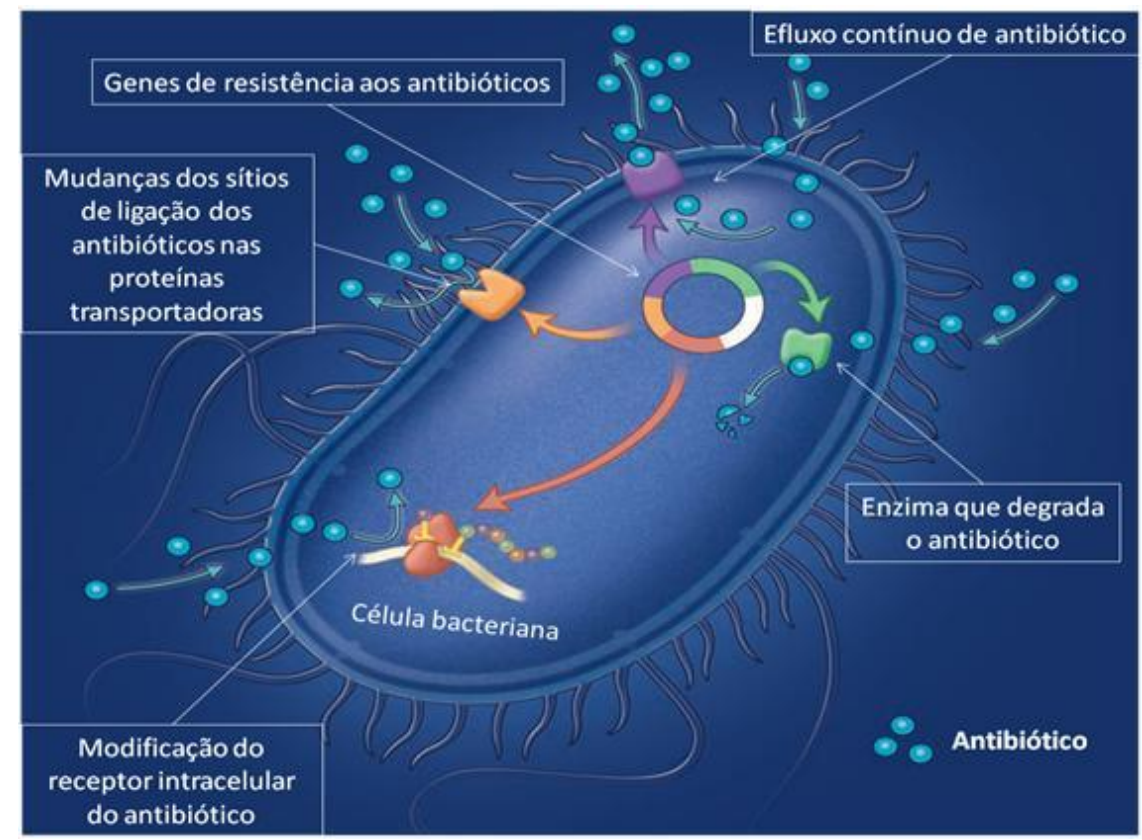

Figura 1. Principais mecanismos de resistência microbiana (Adaptado de SCOTT, 2009; CONLY, 2002; ARIAS \& MURRAY, 2012). 
Tabela 1. Exemplos de mecanismos de resistência e as suas bases genéticas.

\begin{tabular}{|c|c|c|c|}
\hline $\begin{array}{c}\text { Classes de } \\
\text { Antimicrobianos }\end{array}$ & $\begin{array}{l}\text { Mecanismos de } \\
\text { resistência }\end{array}$ & $\begin{array}{c}\text { Bases } \\
\text { genéticas }\end{array}$ & Micro-organismos \\
\hline$\beta$-lactâmicos & $\begin{array}{c}\text { Alteração da } \\
\text { ligação das } \\
\text { penicilinas a } \\
\text { proteínas alvos }\end{array}$ & cromossômica & $\begin{array}{c}\text { Staphylococcus aureus } \\
\text { Streptococcus pneumoniae } \\
\text { Staphylococcus epidermidis } \\
\text { Escherichia coli }\end{array}$ \\
\hline Fluoroquinolonas & $\begin{array}{l}\text { Alteração do } \\
\text { alvo DNA girase }\end{array}$ & cromossômica & $\begin{array}{c}\text { Staphylococcus aureus } \\
\text { Streptococcus pneumoniae } \\
\text { Staphylococcus epidermidis } \\
\text { Enterobactérias }\end{array}$ \\
\hline Aminoglicosídeos & $\begin{array}{l}\text { Modificação } \\
\text { enzimática do } \\
\text { fármaco }\end{array}$ & plasmídeo & $\begin{array}{c}\text { Staphylococcus aureus } \\
\text { Streptococcus pneumoniae } \\
\text { Enterobactérias }\end{array}$ \\
\hline Tetraciclinas & $\begin{array}{l}\text { Bomba do } \\
\text { Efluxo }\end{array}$ & plasmídeo & $\begin{array}{c}\text { Staphylococcus aureus } \\
\text { Streptococcus pneumoniae } \\
\text { Enterobactérias }\end{array}$ \\
\hline Glicopeptídeos & $\begin{array}{l}\text { Alteração de } \\
\text { alvo }\end{array}$ & $\begin{array}{l}\text { cromossômica } \\
\text { e plasmídeo }\end{array}$ & Staphylococcus aureus \\
\hline
\end{tabular}

Diante deste cenário, agentes antimicrobianos que hoje lideram as listas dos mais vendidos, correm o risco de se tornarem inativos, devido ao possível surgimento da resistência microbiana a estes agentes. Desta forma, o conhecimento dos mecanismos bioquímicos e genéticos envolvidos na resistência microbiana é de grande importância para se entender como os micro-organismos podem desenvolvê-la e estudos aprofundados destes mecanismos podem levar ao desenvolvimento de novos fármacos com novos alvos moleculares (SILVEIRA et al., 2006).

\subsection{Infecções hospitalares}

Ambientes hospitalares são grandes reservatórios de micro-organismos patogênicos, de modo que as infecções hospitalares $(\mathrm{IH})$ podem ser adquiridas não apenas por pacientes, mas também por visitantes e funcionários do hospital. Neste sentido a OMS tem identificado a resistência microbiana como uma das maiores ameaças à saúde humana, sendo que as IH estão entre as infecções mais prevalentes, tornando-se importante fator implicado no desfecho desfavorável dos pacientes criticamente enfermos (SOUZA \& FIGUEIREDO, 2008). 
A descoberta de fármacos antibacterianos nas décadas de 1930 e 1940 representou um momento de transformação na história da humanidade. Gerhard Johannes Paul Domagk, um dos microbiologistas mais importantes do século 20, que testemunhou as eras pré-antibiótica e antibiótica, descreveu a descoberta e desenvolvimento de medicamentos antibacterianos como uma "aquisição impressionante do poder" para os médicos e seus pacientes. Agora, 80 anos mais tarde, os desafios colocados por infecções causadas por patógenos multirresistentes continuam a aumentar, causando morbidade e mortalidade, além de aumentar os custos dos cuidados com a saúde (GILBERT et al., 2010).

Adventos tecnológicos como a utilização de procedimentos médicos invasivos relacionados a novas técnicas cirúrgicas e diagnósticas, bem como o uso de terapia antimicrobiana de amplo espectro, trouxeram benefícios imensuráveis aos pacientes, mas, por outro lado, está sendo uma das causas de aumento na incidência de infecções por micro-organismos multirresistentes (SOUZA \& FIGUEIREDO, 2008). No Brasil e no mundo, as $\mathrm{IH}$ estão crescendo tanto em incidência quanto em complexidade, gerando diversas implicações sociais e econômicas. De, aproximadamente, 40 milhões de hospitalizações por ano nos Estados Unidos, estima- se que dois milhões de pacientes (cerca de 5\% do total) adquirem IH, sendo que em 1995, aproximadamente 88 mil mortes foram relacionadas com infecções deste tipo (GILBERT et al., 2010; FONTANA, 2008; FONTANA et al, 2010; BOUCHER et al., 2009).

Diferentes micro-organismos como bactérias, fungos e vírus causam as $\mathrm{IH}$. Nesse universo, o grupo de patógenos que se destaca é o das bactérias que constituem a microbiota humana e que normalmente não trazem risco a indivíduos saudáveis, mas podem causar infecções em indivíduos com estado imunológico comprometidas, sendo denominadas então de bactérias oportunistas (FONTANA, 2008).

O segundo grupo de importância médica nas IH são os fungos, sendo a Candida albicans o agente mais frequentemente isolado em hospitais de todo mundo. Este microorganismo é responsável por cerca de $80 \%$ das infecções fúngicas de origem hospitalar e é a quarta causa de infecção da corrente sanguínea, conduzindo ao óbito em torno de 25 a $38 \%$ dos pacientes que desenvolvem candidemia. Isto se deve ao fato dos fármacos disponíveis, por exemplo, os azóis (fluconazol e itraconazol), não serem mais eficientes frente a $C$. albicans, devido ao desenvolvimento de resistência gênica por este microorganismo (TAMURA et al., 2007; ESPINEL-INGROFF, 2008). No Brasil os microorganismos mais comuns em IH estão destacados na tabela 2. 
Tabela 2. Micro-organismos mais comuns em infecções hospitalares no Brasil.

\begin{tabular}{cc}
\hline Micro-organismo & Locais comuns de isolamento \\
\hline Bactérias Gram negativas & \\
Escherichia coli & \\
Pseudomonas $S P$ & Trato urinário, feridas cirúrgicas, sangue, \\
Klebsiella $S P$ & trato respiratório. \\
Enterobacter $S P$ & \\
Bactérias Gram positivas & \\
Streptococcus $S P$ & \\
Staphylococcus aureus & Trato urinário, trato respiratório, feridas \\
Staphylococcus epidermidis & cirungicas, pele, sangue. \\
Fundida albicans & \\
Outros & \\
Fonte: TAMURA et al., 2007; SOUZA \& FIGUEIREDO, 2008; ESPINEL-INGROFF, \\
2008; FONTANA, 2010.
\end{tabular}

Dois recentes relatórios, um da Sociedade Americana de Doenças Infecciosas (IDSA, Infectious Diseases Society of America) e outra da Agência Europeia de Prevenção e Controle de Doenças (ECDC, European Centre for Disease Control) demonstram que existem poucos candidatos à fármaco que ofereçam benefícios sobre os chamados "patógenos ESKAPE" (Enterococcus faecium, Staphylococcus aureus, Klebsiella pneumoniae, Acinetobacter baumannii, Pseudomonas aeruginosa, e espécies de Enterobacter spp), que atualmente causam a maioria das infecções hospitalares no mundo (GILBERT et al., 2010).

Os dados do Centro para Controle e Prevenção de Doenças dos EUA (CDC, Centers for Disease Control and Prevention) mostram rápido aumento de taxas de infecção por Staphylococcus aureus resistente a meticilina (MRSA, Methicillin-resistant Staphylococcus aureus) e, Enterococcus faecium resistente à vancomicina (VRE, vancomycin-resistant enterococci), e Pseudomonas aeruginosa resistente a fluoroquinolona. Estatísticas mostram que morrem mais pessoas de infecção por MRSA em hospitais dos Estados Unidos do que com AIDS (Síndrome da Imunodeficiência Adquirida) e tuberculose juntas. Além disso, vários outros micro-organismos patogênicos como espécies de Acinetobacter spp, Escherichia coli, entre outras, estão emergindo como agentes infectantes importantes nos ambientes hospitalares (BOUCHER et al., 2009).

Dentre as diversas bactérias encontradas no ambiente hospitalar observa-se uma predominância da espécie Gram positiva de Staphylococcus aureus, considerado o mais importante micro-organismo patogênico de $\mathrm{IH}$. Pode ser encontrado em diversos processos infecciosos, de forma persistente ou transitória, sem causar qualquer sintoma aparente. Desde que consiga ultrapassar a barreira natural, este micro-organismo pode infectar indivíduos tanto na comunidade como no ambiente hospitalar, causando grande número de 
síndromes clínicas. Estas infecções originam processos piogênicos e/ou doenças mediadas por toxinas (GORDON \& LOWY, 2008; RATTI \& SOUSA, 2009). Segundo dados da CDC (Centers for Disease Control and Prevention) Staphylococcus aureus resistente a meticilina (MRSA) e considerada a infecção com maior numero estimado de mortes por ano ultrapassando 11,000 mil mortes (CDC, 2013).

Uma propriedade biológica fundamental do $S$. aureus é a sua capacidade de colonizar assintomaticamente indivíduos saudáveis. O principal modo de transmissão por $S$. aureus é por contato direto, geralmente o contato dérmico com indivíduos colonizados, além de contato com objetos e superfícies contaminadas. A colonização nasal de $S$. aureus é considerada a principal responsável pela colonização da superfície cutânea, tornando-se motivo de preocupação ao se analisar a prevalência desses micro-organismos na população em geral e entre trabalhadores hospitalares (GORDON \& LOWY, 2008).

Outra bactéria de importante destaque neste cenário é a Klebsiella pneumoniae que teve sua primeira cepa resistente identificada em 2001, nos Estados Unidos, e espalhou-se pelos hospitais do mundo todo. Esta bactéria faz parte da família das enterobactérias $(P$. auriginosa e Acinetobacter spp, entre outras) produtoras da enzima Klebsiella pneumoniae carbapenemase mais conhecida como KPC, que confere resistência aos antimicrobianos carbapenêmicos e $\beta$-lactâmicos. Estudos clínicos revelam altas taxas de insucesso do tratamento à estas infecções, relatando uma taxa de mortalidade de 22 a $72 \%$ em pacientes que adquirem estas infecções (DIENSTMANN et al., 2010; PELEG \& HOOPER, 2010).

As enterobactérias produtoras de carbapenemase já foram identificadas em pelo menos 20 estados norte americanos, assim como em outras partes do mundo. Observando uma rápida disseminação destas bactérias, a CLSI (Clinical and Laboratory Standards Institute), em 2009, passou a recomendar a pesquisa da enzima KPC em isolados de enterobactérias com resistência a cefalosporinas e sensibilidade diminuída a carbapenemas. Atualmente, a KPC constitui importante mecanismo de resistência no contexto hospitalar mundial, pois, é capaz de inativar não só os fármacos carbapenêmicos, mas também $\beta$ lactâmicos como as cefalosporinas e as penicilinas. Sua pesquisa é relevante a fim de limitar sua disseminação, contribuindo para a redução dos índices de morbidade e mortalidade ligados a diferentes doenças infecciosas (QUEENAN \& BUSH, 2007; DIENSTMANN et al., 2010).

A maioria dos casos reportados de contaminação por enterobactérias ocorrem em pessoas que frequentaram ou estiveram em hospitais. (DIENSTMANN et al., 2010; FONTANA et al., 2010). Recentemente, tem sido observada maior incidência de bacilos Gram negativos resistentes a cefalosporinas de espectro ampliado no ambiente hospitalar, 
ocasionando assim, o uso de fármacos mais potentes e com expectro de ação ampliado a diversos micro-organismos (SOARES, 2012).

A maior utilização de carbapenemas no ambiente hospitalar acaba por ocasionar maior pressão seletiva sobre a microbiota nosocomial, o que favorece a seleção de subpopulações de micro-organismos com sensibilidade diminuída ou resistente a esses antimicrobianos. A resistência às cefalosporinas de espectro ampliado pode ser decorrente da hiperexpressão de $\beta$-lactamase cromossômica associada à diminuição da permeabilidade da membrana externa ou, ainda, hiperexpressão de bombas de efluxo, que reduzem a concentração do antimicrobiano na célula bacteriana por meio da extrusão do mesmo. Outros mecanismos têm sido descritos, como a produção das metalo-ß-lactamases $(\mathrm{MBL})$, enzimas que hidrolisam todos os betalactâmicos comercialmente disponíveis, sendo a única exceção a monobactama, aztreonam. Atualmente esta enzima tem sido detectada em diferentes micro-organismos, como Acinetobacter spp, Pseudomonas aeruginosa e Klebsiella pneumoniae isolados de diferentes regiões geográficas. Ela é subdividida em 5 classes de MBL (IMP (imipenemase), VIM (Verona imipenemase), SPM (São Paulo metaloB-lactamase), GIM (German imipenemase) e SIM-1 (codificada pelo gene blasIM-1 detectado em sete $A$. baumannii) (MENDES, et al, 2006; QUEENAN \& BUSH, 2007).

Estudos em hospitais brasileiros demonstram que a taxa de mortalidade relacionada à $\mathrm{IH}$ varia conforme a topografia, a doença de base, a etiologia, entre outros. Os coeficientes de letalidade causada por IH sofre grande variação, de 9 a 58\%, chegando a $40 \%$ entre as infecções de corrente sanguínea. O impacto econômico destas infecções resulta em internações prolongadas, novos procedimentos para diagnósticos e terapêuticos (MARRA et al., 2011).

A fácil disseminação das infecções dificulta o controle de epidemias, preocupando os profissionais da saúde já que o tratamento das infecções hospitalares é extremamente difícil, elevando taxas de mortalidade e, algumas vezes, gerando surtos de infecções provocadas por micro-organismos resistentes à maioria dos fármacos disponíveis na terapêutica.

\subsection{Necessidade de novos agentes antimicrobianos}

Diversas razões justificam a necessidade urgente por novos agentes antimicrobianos, entre elas destacam-se: (1) as doenças infecciosas, que são a segunda maior causam de mortalidade do mundo; (2) as altas taxas de resistência microbiana, especialmente em ambientes hospitalares; (3) o decréscimo constante observado no 
número total de novos agentes antimicrobianos aprovados pela FDA (Food and Drug Administration); (4) a necessidade de agentes que atuem por mecanismos de ação diferentes dos fármacos em uso (BOUCHER et al., 2009; IDSA, 2011).

Mesmo o arsenal terapêutico de antimicrobianos dispondo de mais de 100 fármacos atualmente no mercado mundial, a resistência microbiana é evidente em boa parte dos medicamentos disponíveis para uso. Com o grande número de fármacos antimicrobianos a indústria farmacêutica nos últimos anos dispensou poucos recursos para a pesquisa, desenvolvimentos e inovação (P,D\&l) destes agentes, desta forma com o uso rotineiro dos fármacos de amplo espectro, relatos de resistência microbiana acabam se tornando comuns na prática clínica, como mostra a tabela 3 (ANVISA, 2011; IDSA, 2011).

Tabela 3. Antibióticos empregados na atual terapêutica de infecções hospitalares.

\begin{tabular}{|c|c|c|c|c|c|}
\hline Fármaco & Indicações & $\begin{array}{c}\text { Micro- } \\
\text { organismos } \\
\text { envolvidos }\end{array}$ & $\begin{array}{c}\% \text { de } \\
\text { prescrições }\end{array}$ & $\begin{array}{l}\text { Aprovado } \\
\text { pela FDA }\end{array}$ & $\begin{array}{c}1^{\circ} \text { Relato } \\
\text { de } \\
\text { resistência }\end{array}$ \\
\hline Meropenem & $\begin{array}{c}\text { Infecções do } \\
\text { trato } \\
\text { respiratório }\end{array}$ & Enterobacter spp & 31,58 & 1996 & 1998 \\
\hline Teicoplanina & $\begin{array}{l}\text { Infecções da } \\
\text { pele }\end{array}$ & $\begin{array}{c}\text { Staphylococcus } \\
\text { aureus }\end{array}$ & 23,68 & 1985 & 1988 \\
\hline Vancomicina & $\begin{array}{l}\text { Endocardite, } \\
\text { Pneumonia }\end{array}$ & $\begin{array}{c}\text { Staphylococcus } \\
\text { aureus }\end{array}$ & 15,78 & 1981 & 1987 \\
\hline $\begin{array}{c}\text { Anfotericina } \\
\text { B }\end{array}$ & $\begin{array}{l}\text { Doenças } \\
\text { fúngicas }\end{array}$ & $\begin{array}{l}\text { Candida } \\
\text { albicans }\end{array}$ & 7,89 & 1957 & 1982 \\
\hline Ceftazidima & $\begin{array}{l}\text { Infecções } \\
\text { urinárias }\end{array}$ & $\begin{array}{c}\text { Pseudomonas } \\
\text { aeruginosa }\end{array}$ & 7,89 & 1980 & 1990 \\
\hline Polimixina B & $\begin{array}{l}\text { Infecções do } \\
\text { trato urinário }\end{array}$ & $\begin{array}{c}\text { Pseudomonas } \\
\text { aeruginosa }\end{array}$ & 5,27 & 1978 & 1982 \\
\hline
\end{tabular}

A redução na $P, D \& I$ pode ser atribuido à falha de mercado, como a baixa venda de medicamentos desta clase, e falta de incentivos regulatórios. A comercialização de antibióticos não é tão rentável quanto outros fármacos de uso crônico (por exemplo, medicamentos para tratar diabetes ou hipertensão arterial). Além disso, orgãos como a FDA tem atrasado a publicação de orientações que descrevem como as empresas devem projetar antibióticos para ensaios clínicos. Estes desincentivos fazem com que a P,D\&I pelas empresas farmacêuticas torne-se pouco atrativa, se tratando de fármacos antimicrobianos (BOUCHER et al., 2009; IDSA, 2011, BRITO \& CORDEIRO, 2012). 
Nos Estados Unidos, medidas legislativas já foram adotadas, porém a falta de investimento da indústria farmacêutica no desenvolvimento de antimicrobianos tem levado a IDSA (Infectious Diseases Society of America) a aplicar incentivos políticos de desenvolvimento de novos agentes antimicrobianos. Apesar dos esforços, apenas um único antibacteriano, a fidaxomicina, foi aprovado desde o inicio dessa política (figura 2) (BOUCHER et al., 2009; IDSA, 2011).

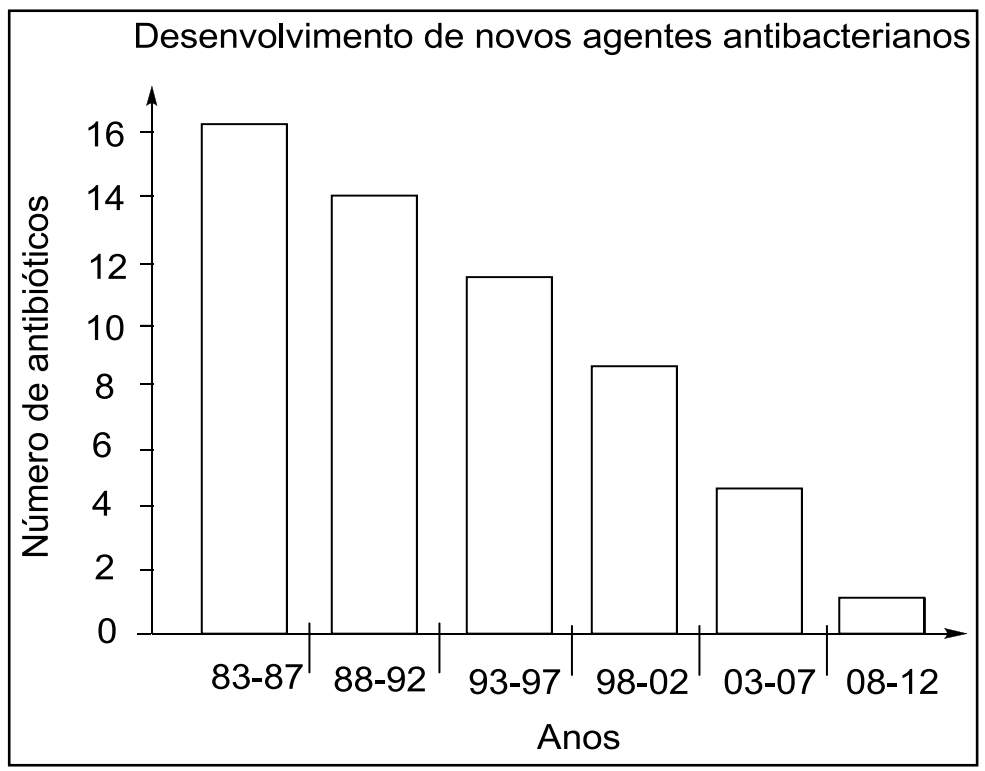

Figura 2. Novos antibacterianos aprovados nos EUA entre 1983 e 2012 (IDSA, 2011).

A IDSA tem como objetivo influenciar a construção de infraestrutura para a P,D\&I de fármacos antimicrobianos, desenvolvendo políticas de incentivo para as companhias farmacêuticas através da iniciativa chamada de "Bad Bugs Need Drugs 10X'20 Ten New Antibiotics by 2020". Esta iniciativa tem como objetivo o desenvolvimento de dez fármacos antimicrobianos até o ano de 2020. Este desafio exige que a indústria, a academia, os institutos de saúde e os órgãos reguladores, trabalhem em conjunto com o objetivo de criar pesquisas efetivas no tratamento destas doenças (BOUCHER et al., 2009; IDSA, 2011).

Os profissionais de P,D\&I responsáveis pelo desenvolvimento de novos fármacos, vêm propondo novas abordagens de planejamento para antibióticos, que vão de produtos naturais, como lipopeptídeos modificados por meio da engenharia genética, a peptídeos antimicrobianos, otimizados pela engenharia de proteínas. Outras abordagens possíveis são investir em tecnologias para aumentar o sistema de defesa do hospedeiro, como um veículo para atacar micróbios (BRITO \& CORDEIRO, 2012). 
O grande desafio destas pesquisas é que o desenvolvimento de novos fármacos no combate a infecções não segue a mesma velocidade de surgimento de resistência microbiana, pois a descoberta de um fármaco para tal finalidade pode levar cerca de uma década ou mais, enquanto que o desenvolvimento de resistência pode levar cerca de 7 a 8 anos, sendo necessário então, investimentos de P,D\&I nesta área (BOUCHER et al., 2009; GILBERT et al., 2010).

\subsection{Desenvolvimento de fármacos}

A pesquisa e desenvolvimento de fármacos antimicrobianos tem sido moldada pelo envolvimento de algumas áreas do conhecimento como a química, a fisiopatologia, a farmacologia, a microbiologia, a bioquímica, a biologia molecular, entre outras. A química foi a primeira e é até hoje, a principal base para o desenvolvimento de fármacos. As outras áreas de conhecimento foram ciências que evoluíram a partir do início do século 20 , impulsionadas pelo próprio desenvolvimento de fármacos, tornando-se ferramentas importantes para a compreensão dos mecanismos de ação fisiológicos e farmacológicos (DREWS, 1995).

A cura e o alívio das doenças podem ser apontados como o objetivo principal do desenvolvimento de fármacos. (DREWS, 1995). Atualmente observam-se recentes avanços no entendimento de doenças graças à genômica, proteômica e metabolômica, mesmo assim a tarefa de descoberta e desenvolvimento seguro e eficaz de fármacos ainda é um grande desafio para os pesquisadores, pois o tempo de pesquisa e desenvolvimento de um fármaco leva em torno de 15 anos e o custo médio está estimado em cerca de 800 milhões de dólares. Este valor incluí o custo das milhares de falhas incluídas neste processo, pois para cada 5.000 a 10.000 compostos que são pesquisados, apenas um chega a receber aprovação como fármaco (PhRMA, 2007).

O primeiro passo no desenvolvimento de um fármaco é a identificação de um alvo terapêutico, seguido do respectivo ensaio experimental que permita identificar moléculas com possível ação no alvo escolhido. O ensaio experimental consiste na avaliação do efeito de milhares de moléculas sobre a plataforma terapêutica selecionada. Com o desenvolvimento tecnológico diversas técnicas têm sido desenvolvidas para acelerar a triagem farmacológica de desenvolvimento de fármacos. Dentre as técnicas mais recentes podemos destacar a triagem biológica automatizada em alta escala (HTS, High-throughput screening), que propicia a avaliação biológica in vitro de milhares ou até mesmo milhões de compostos contra uma proteína alvo ou sistema celular definido (FERREIRA, GLAUCIUS, ANDRICOPULO, 2011; ANVISA, 2012). 
As moléculas selecionadas nesta triagem inicial são posteriormente analisadas de forma a identificar grupos químicos com características comuns. Cada grupo é analisado relativamente à potência, propriedades físico-químicas, custo dos reagentes, capacidade de scale-up, seletividade biológica e propriedade intelectual ao redor da estrutura inicial (FERREIRA, GLAUCIUS, ANDRICOPULO, 2011).

Após o isolamento dos grupos essenciais da molécula, passa-se à etapa dos testes pré-clínicos, considerados estes o grande filtro da Pesquisa e Desenvolvimento (P\&D) de fármacos. Nessa etapa são realizados testes in vitro e in vivo com o objetivo de checar os parâmetros de segurança. Estes testes tem objetivo de identificar os efeitos tóxicos das moléculas selecionadas, no sistema orgânico, onde verifica-se a citotoxicidade e mutagenicidade, dentre outros. Também é possível dentro dos testes pré-clínicos determinar a absorção, a distribuição, o metabolismo, a excreção do novo composto, seu grau de estabilidade e pureza. A etapa pré-clínica no desenvolvimento de fármacos é de extrema importância visto que estes testes são realizados em animais, oferecendo margens de segurança para início de testes em humanos (PIERONI et al., 2009).

Após a aprovação das moléculas na etapa pré-clínica, inícia-se o estágio dos ensaios clínicos considerados os mais caros do desenvolvimento de fármacos. Os testes clínicos, em humanos, são subdivididos em 4 fases, a saber:

- Fase I: São geralmente realizados com cerca de 20-100 voluntários saudáveis, com o principal objetivo de saber se o composto é seguro em seres humanos, podendo também determinar o intervalo de doses. Propõese nesta fase estabelecer uma evolução preliminar da segurança, do perfil farmacocinético e, quando possível, um perfil farmacodinâmico (PhRMA, 2007; PIERONI et al., 2009; ANVISA, 2013; PhRMA, 2013).

- Fase II: Esta etapa é considerada o estudo terapêutico piloto onde o composto é avaliado em voluntários portadores da patologia (doentes), com cerca de 100-500 voluntários. Nesta etapa se estabelece as relações de dose-resposta, ou seja, a concentração que consegue combinar os melhores efeitos terapêuticos ao menor conjunto de reações adversas (PhRMA, 2007; PIERONI et al., 2009; ANVISA, 2013; PhRMA, 2013).

- Fase III: Esta fase é classificada como estudo terapêutico ampliado, onde o composto está prestes a se tornar um fármaco. Nesta fase é estudado um maior número maior de candidatos (cerca de 1000 a 5000 voluntários) e tem o objetivo de ampliar os estudos terapêuticos como a determinação de interação com outros fármacos e a interferência de fatores individuais como idade, sexo, raça, dentre outros. A avaliação é sempre feita de maneira 
comparativa, utilizando-se outro tratamento como referência. Com base no resultado deste teste é possível passar para a quarta fase (PhRMA, 2007; PIERONI et al., 2009; ANVISA, 2013; PhRMA, 2013).

- Fase IV: Classificada como farmacovigilância, onde o composto se torna um fármaco, e passa pelo processo de registro realizado pelas agências reguladoras. Após registrado o fármaco está pronto para a comercialização, onde ainda é monitorado com o objetivo de detectar eventos adversos pouco frequentes ou não esperados (PhRMA, 2007; PIERONI et al., 2009; ANVISA, 2013; PhRMA, 2013).

O sucesso para o desenvolvimento de fármacos exige diversos esforços, aliados à alta tecnologia e bons pesquisadores, algumas vezes também é preciso muita persistência e sorte, mas também, não se pode deixar de levar em consideração, que o desenvolvimento de um fármaco pode trazer benefícios aos pacientes portadores de doenças que aguardam novos fármacos na esperança de cura (BARREIRO \& FRAGA, 2008).

Sabe-se que quanto mais avançada for a fase de pesquisa clínica de um fármaco, maiores são os investimentos necessários, e estes investimentos podem se tornar um grande prejuízo, pois diversas falhas no desenvolvimento de uma pesquisa clínica podem ser descobertos com o avanço das fases pesquisadas. Os principais motivos de falhas de desenvolvimento de um novo fármaco são a baixa biodisponibilidade (39\%); a ausência de eficácia (29\%); a detecção efeitos tóxicos (21\%); e razões de mercado (6\%). Devido a isto, muitas indústrias farmacêuticas se desinteressaram em investir na P,D\&l de compostos inovadores, desta forma, investimentos em modificações moleculares de fármacos já disponíveis na terapêutica tem sido a opção adotada pela indústria farmacêutica como modo de facilitar a pesquisa e diminuir a possibilidade de falhas terapêuticas (CALIXTO, \& SIQUEIRA, 2008).

\subsection{Planejamento de fármacos}

\subsubsection{Modificação molecular}

A metodologia de modificação molecular de fármacos leva à identificação de novos compostos-protótipos que atuam pelo mesmo mecanismo de ação do composto de partida. A modificação molecular de compostos já estabelecidos na terapêutica é essencial na seleção de compostos candidatos com maiores probabilidades de não serem abandonados, mais adiante, nos estudos de fase clínica. Um bom exemplo de modificação molecular bem sucedida foi o desenvolvimento da ranitidina a partir da cimetidina (figura 3), no qual as 
modificações estruturais resultaram em aumento da potência e maior seletividade pelo subtipo 2 de receptores histaminérgicos, alvos terapêuticos de ambos os fármacos (BARREIRO \& FRAGA, 2008).

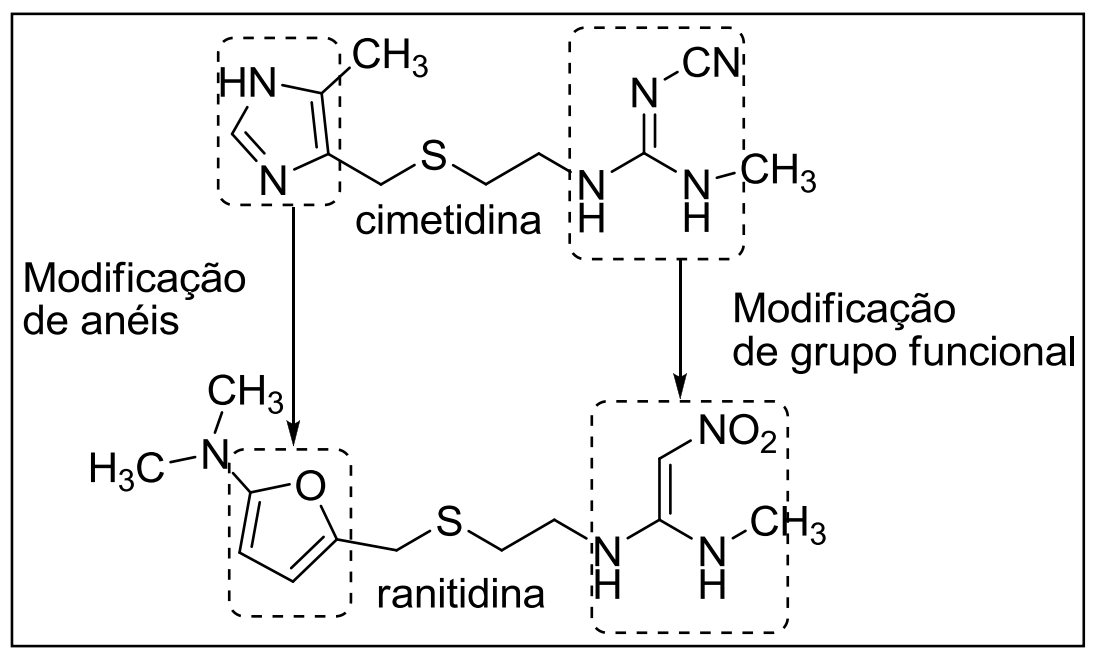

Figura 3. Ranitidina planejada por modificações moleculares da cimetidina.

No caso, a cimetidina (figura 3) teve sua eficácia otimizada por modificações moleculares subsequentes, planejadas de maneira a preservar as propriedades farmacocinéticas identificadas nos bioensaios. Uma vez otimizado, o composto-protótipo identificado na série congênere bioativa e com comprovada ausência de toxicidade, tem uma nova estrutura química, que pode ser submetida às fases de ensaios clínicos, resultante por fim, em um novo fármaco (BARREIRO, 2002).

Diversas modificações moleculares vêm sendo amplamente empregadas na descoberta de fármacos de classes terapêuticas distintas, sendo esta ferramenta muito utilizada pela indústria farmacêutica como forma de desenvolver fármacos com melhor perfil farmacológico e, principalmente, com melhor aceitação comercial. Dentre elas, a modificação molecular fundamentada no bioisosterismo tem permitido a identificação de novos derivados terapeuticamente úteis.

O termo bioisosterismo surgiu da aplicação do princípio do isosterismo, em moléculas bioativas, que defendia que átomos ou grupos de átomos com estrutura eletrônica e propriedades físico-químicas similares apresentavam o mesmo comportamento no sistema biológico. Nessa definição foram consideradas as moléculas que continham o mesmo número de átomos, a mesma disposição de número de elétrons e as mesmas características físico-químicas (KOROLKOVAS \& BURCKHALTER, 1988; BARREIRO \& FRAGA, 2008). 
O emprego do bioisosterismo como estratégia de modificação molecular para descoberta de novos fármacos permite que se antecipe uma comparável afinidade entre as duas substâncias bioisostéricas por um dado sítio receptor, consequentemente, um potencial de atividade biológica similar. Entretanto quando as substituições bioisostéricas são efetuadas em grupos funcionais considerados farmacofóricos, presentes na estrutura de um determinado fármaco ou de um composto-protótipo, as alterações físico-químicas introduzidas podem ser suficientes para modificarem drasticamente, atenuando ou abolindo, as respostas farmacológicas deste composto. Além disso, mesmo em alterações bioisostérias introduzidas em regiões moleculares não-farmacofóricas, as modificações das propriedades farmacocinéticas nos processos de biotransformação pode ser de tal ordem que venham a alterar de modo expressivo, as respostas indesejáveis do novo derivado (BARREIRO \& FRAGA, 2008).

O sucesso do emprego desta estratégia no desenvolvimento de novas substâncias farmacoterapeuticamente atraentes tem observado significativo crescimento em distintas classes terapêuticas incluindo os antimicrobianos. A descoberta de novos fármacos envolve tanto a pesquisa por entidades químicas novas, como a modificação molecular de fármacos já existentes melhorando o perfil farmacológico, ou até utilizar a estrutura química de um fármaco como molde para um novo composto químico com atividade biológica específica (BARREIRO \& FRAGA, 2005).

\subsubsection{Estudos de relações entre estrutura química e atividade biológica}

O estudo das relações estrutura-atividade (SAR, Structure-Activity Relationship) aliado à modelagem molecular de pequenas moléculas é um importante passo na otimização de protótipos já existentes e no planejamento racional de candidatos a fármacos (WERMUTH, 2008).

Considera-se que a grande maioria dos fármacos disponíveis na terapêutica sejam absorvidos passivamente, tendo que ultrapassar a bicamada lipídica que constitui o ambiente hidrofóbico das membranas biológicas. Neste sentido destaca-se a importância das propriedades físico-químicas (eletrônica, esteroequímica e lipofílica), para que o fármaco atinja concentrações plasmáticas capazes de produzir o efeito biológico que influenciam tanto na distribuição na biofase quanto na interação com a biomacromolécula alvo. O percurso de um fármaco pode ser resumido nas etapas destacadas na figura 4 (BARREIRO \& FRAGA, 2005). 


\begin{tabular}{|c|c|c|c|c|c|c|}
\hline & Fase Farmacêutica & Fármaco $\mathrm{F}$ & Fase Farmacocinética & Fármaco & Fase Farmacodinâmica & \\
\hline Dose $\rightarrow$ & $\begin{array}{c}\text { Desintegração da } \\
\text { forma farmacêutica } \\
\text { Dissolução da } \\
\text { Substância ativa }\end{array}$ & $\underset{\text { Disponibilidade }}{\stackrel{\text { para absorção }}{\longrightarrow}}$ & $\begin{array}{l}\text {-Absorção } \\
\text {-Distribuição } \\
\text {-Metabolização } \\
\text {-Excreção }\end{array}$ & 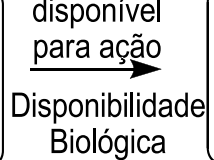 & $\begin{array}{c}\text { Interação } \\
\text { fármaco- receptor }\end{array}$ & $\rightarrow$ Efeito \\
\hline
\end{tabular}

Figura 4. Fases importantes na ação de fármacos (PEREIRA, 2007).

Os estudos de SAR podem delinear o planejamento e desenvolvimento de novos agentes terapêuticos menos tóxicos e mais seletivos. Pequenas modificações na molécula de fármacos também podem levar a um melhor perfil farmacocinético (BARREIRO, 2002; TAVARES, 2004; PATRICK, 2009). A influência da estrutura química sobre a atividade biológica envolve a compreensão de cada grupo funcional da molécula que irá interagir com seu receptor. Desta forma, a modificação molecular de grupos substituintes, afeta significativamente as propriedades físico-químicas e em consequência alteram a resposta biológica de fármacos (TAVARES, 2004).

As propriedades físico-químicas são um conjunto extenso de propriedades moleculares diretamente relacionadas às forças intermoleculares envolvidas na interação fármaco-receptor e também relacionadas às propriedades de transporte e distribuição de fármacos. Os parâmetros físico-químicos representam uma importante ferramenta para determinar as propriedades das substâncias, classificar estruturas químicas ou até mesmo observar similaridade entre elas. O desenvolvimento e estudo aprofundado destes parâmetros ou descritores físico-químicos desencadearam os estudos de relações quantitativas entre a estrutura e a atividade (QSAR, Quantitative Structure-Activity Relationships), tornando-se assim, uma das mais importantes contribuições na área da química medicinal, visto que estes estudos fundamentam o planejamento de compostos com maiores chances de se tornarem fármacos (KUBINYI, 1993; TAVARES, 2004; ARROIO, HONORIO, SILVA, 2010). Os estudos de QSAR consideram a existência da relação entre as propriedades físico-químicas de uma molécula e sua estrutura, e tentam estabelecer relações matemáticas para descrever e, em seguida, prever uma dada propriedade para um conjunto de compostos análogos, geralmente pertencentes a uma mesma família química. Este estudo é amplamente aplicado com objetivo de desenvolver fármacos com propriedades bem definidas, evitando o custo da síntese experimental de grande número de compostos (KUBINYI, 1993; HANSCH \& LEO, 1995; TAVARES, 2004).

O desenvolvimento de projetos envolvendo programas de modelagem molecular e suas aplicações na pesquisa farmacêutica constituem um campo de estudo denominado planejamento de fármacos auxiliado por computador (CADD, Computer-Aided Drug Design), 
que tem como expectativa a descoberta de moléculas promissoras (mais potentes e seletivas) considerando propriedades tridimensionais específicas. Os estudos de propriedades estéricas, eletrônicas e lipofílicas, de mecanismo de ação, das relações entre estrutura química e atividade biológica (SAR) e das interações fármaco-receptor são aspectos que podem ser explorados através da modelagem molecular (WERMUTH, 2008). Atualmente os programas de modelagem molecular permitem a representação da visualização e determinação de parâmetros geométricos e eletrônicos de uma molécula isolada, além de realizar estudos em macromoléculas (proteínas) e complexos fármacoreceptor.

Para a análise de dados, precedentes ao estudo de relação estrutura-atividade, destacam-se os métodos multivariados, frequentemente aplicados à Química, que tem por finalidade verificar a existência de similaridades entre as amostras que, por sua vez, correspondem às semelhanças na composição química. Desta forma alguns algoritmos foram desenvolvidos para elaborar gráficos que representem a maior quantidade possível das informações contidas em um conjunto de dados. Entre eles, destacam-se a análise por agrupamento hierárquico (HCA) e a análise de componentes principais (PCA). O uso desses algoritmos tem como objetivo principal aumentar a compreensão do conjunto de dados (parâmetros), examinando a presença ou a ausência de agrupamentos naturais entre as amostras. Estas análises são de fácil interpretação, pois apresentam seus resultados experimentais na forma de gráficos onde é possível verificar quais dos parâmetros analisados (variáveis) são os principais responsáveis pela formação dos grupos de amostras (CORREIA \& FERREIRA 2007).

HCA e PCA permitem a visualização gráfica de todo o conjunto de dados, mesmo quando o número de amostras e variáveis é elevado. Ambos são classificados como exploratórios ou não supervisionados, visto que nenhuma informação com relação à identidade das amostras é levada em consideração. Tanto HCA quanto PCA permitem a interpretação multivariada de conjuntos de dados grandes e complexos por meio de gráficos bi ou tridimensionais. Estes gráficos apresentam informações que expressam as interrelações que podem existir entre as variáveis (propriedades físico-químicas), facilitando a interpretação multivariada do comportamento das amostras (CORREIA \& FERREIRA 2007).

\subsubsection{Propriedades físico-químicas que influenciam a ação de fármacos}

As propriedades físico-químicas que mais influenciam nos estudos de relações estrutura-atividade são a distribuição eletrônica, a hidrofobicidade e a estereoquímica. Cada uma destas propriedades contribui aditiva e independentemente para a atividade biológica, 
sendo que estas propriedades podem ser relacionadas através de modelos matemáticos que correlacionam os parâmetros físico-químicos de uma série de compostos análogos com a atividade biológica por eles desempenhada (HANSCH \& FUJITA, 1964; KUBINYI, 1993; CRONIN \& SHULTZ, 2003; TAVARES, 2004; ARROIO, HONORIO, SILVA, 2010).

A distribuição eletrônica é a propriedade que tem influência considerável sobre a atividade do fármaco. Quando o fármaco atinge seu sítio-alvo, a distribuição de elétrons em sua estrutura ditará o tipo de interação que será formada entre o fármaco e o seu receptor (KUBINYI, 1993). Com relação aos parâmetros eletrônicos podemos citar a constante sigma, $\sigma$, de Hammet que descreve a influência de um certo grupo ou de um substituinte sobre a distribuição eletrônica da molécula, sendo muito utilizada em estudos de QSAR. Outros estudos também tiveram grande importância, porém o trabalho de Hammet nos anos 40 desencadeou um marco histórico dos estudos de QSAR (HANSCH \& FUJITA, 1964; KUBINYI, 1993; HANSCH, \& LEO, 1995).

Hammet em seu estudo inicial demonstrou que a adição de grupos substituintes ligados ao ácido benzóico na posição para ou meta influenciavam o efeito eletrônico, de maneira a contribuir ou dificultar a ionização destas moléculas. Desta forma determinou a constante $\sigma$, mais conhecida como constante de grupo representada pela seguinte equação 1. Valores positivos de $\sigma$ representam substituintes retiradores de elétrons enquanto que valores negativos são representados por substituintes doadores de elétrons (KUBINYI, 1993; HANSCH \& LEO, 1995; TAVARES, 2004).

$$
\sigma=\log \left(K_{x} / K_{0}\right)
$$

Equação 1.

- $\mathrm{K}_{\mathrm{x}}$ é a constante de ionização do ácido benzóico substituído;

- $\mathrm{K}_{0}$ é a constante de ionização do ácido benzóico não substituído;

$-\sigma$ é a constante de grupo

Com os valores de $\sigma$ estipulados para diversos substituintes, Hammet determinou uma relação linear de energia livre, conhecida como equação de Hammet (Equação 2), determinando que os derivados que apresentam grupos doadores ou retiradores de elétrons, ligados ao ácido benzoico, possuem valores de $\sigma$ negativos ou positivos, respectivamente (KUBINYI, 1993; TAVARES, 2004).

Com relação a Equação 2, coeficiente angular $\rho$ é conhecido como constante de reação e mede a sensibilidade de uma reação ao efeito eletrônico do substituinte $X$. $O$ valor de $\rho$ é positivo quando a reação é favorecida por grupos que atraem elétrons e negativo quando a reação é favorecida por grupos que doam elétrons (KUBINYI, 1993). 


$$
\log \mathrm{K}_{\mathrm{x}}=p \sigma+\log \mathrm{K}_{\mathrm{H}}
$$

Equação 2.

- $\mathrm{K}_{\mathrm{x}}$ e $\mathrm{K}_{\mathrm{H}}$ é a constante de ionização para o composto substituído e não substituído; - $p$ é o coeficente angular da equação e indica a susceptibilidade da ocorrência da reação ao efeito eletrônico exercido pelo grupo substituinte ; $-\sigma$ é a constante de grupo.

A outra propriedade físico-química de grande importância é a hidrofobicidade, sendo a propriedade mais utilizada em estudos de planejamento de novos fármacos. Sabese que a hidrofobicidade exerce forte influência nos processos de absorção, transporte, distribuição e excreção do fármaco pelo sistema biológico, além de contribuir com as interações fármaco-receptor podendo influenciar na intensidade da atividade biológica (KUBINYI, 1993; TAVARES, 2004). Os parâmetros de hidrofobicidade mais utilizados em estudos de SAR e QSAR são o coeficiente de partição $(P)$ e o parâmetro m de Hansch. $O$ coeficiente de partição $(P)$ é definido pela razão entre a concentração da substância na fase orgânica (solvente apolar) e a concentração na fase aquosa (solvente polar), em um sistema de duas fases sob condição de equilíbrio (Equação 3). O coeficiente de partição pode ser determinado por métodos calculados ou experimentais como, o Shake-flask, a Cromatografia de Camada Delgada (CCD), e a Cromatografia Líquida de Alta Eficiência (CLAE) (KUBINYI, 1979; KUBINYI, 1993; TAVARES, 2004).

$$
\mathrm{P}=\left(\mathrm{C}_{\mathrm{org}} / \mathrm{C}_{\mathrm{aq}}\right) \quad \text { Equação } 3 .
$$

- $\mathrm{P}=$ coefieciente de partição

- $\mathrm{C}_{\text {org }}=$ Concentração do composto em fase orgânica

$-\mathrm{C}_{\mathrm{aq}}=$ Concentração do composto em fase aquosa

O parâmetro $\pi$ de Hansch determina a contribuição hidrofóbica de um determinado grupo substituinte para o coeficiente de partição da molécula como um todo. Esta medida é determinada pela relação logarítmica entre o coeficiente de partição $\left(\log \mathrm{P}_{\mathrm{x}}\right)$ de um composto substituído e o coeficiente de partição ( $\left.\log \mathrm{P}_{\mathrm{H}}\right)$ de seu análogo não substituído (Equação 4). Por definição, valores positivos de $\pi$ de Hansch são encontrados para grupos substituintes com caráter mais lipofílico enquanto que valores negativos apresentam caráter mais hidrofílico (HANSCH \& FUJITA, 1964; KUBINYI, 1993; TAVARES, 2004).

$$
\pi_{X}=\log P_{X}-\log P_{H}
$$

- $\pi_{X}$ é o parâmetro que reflete a contribuição hidrofóbica do grupo substituinte, $X$;

- PX é o coeficiente de partição do composto X-substituído;

- $\mathrm{P}_{\mathrm{H}}$ o coeficiente de partição do composto não substituído. 
A estereoquímica da molécula é uma propriedade que rege a seletividade na interação fármaco-receptor de forma espacial. Compostos químicos que apresentam a mesma fórmula molecular, mas que possuem diferentes isômeros podem apresentar atividades biológicas completamente diferentes entre si. Qualquer alteração espacial de um fármaco pode conduzir à total inativação, diminuição do efeito biológico ou aparecimento de outro efeito, podendo ser este inclusive tóxico (KUBINYI, 1993; TAVARES, 2004). Desta forma, o arranjo espacial entre os grupamentos essenciais da molécula compõe aspectos fundamentais na compreensão das diferenças na interação fármaco-receptor (BARREIRO \& FRAGA, 2005).

O primeiro estudo realizado para determinar parâmetros estéricos foi definido por Taft (1952) o qual determinou a relação logarítmica entre constantes de hidrólise ácida de acetatos alfa-substituídos (TAFT, 1952). Com estudos mais aprofundados deste parâmetro, observou-se que este modelo proposto por Taft mostrou-se questionável, pois existem outros fatores que influenciam na reação de hidrólise, tornando este parâmetro inviável para estudos de planejamento de fármacos (KUBINYI, 1993, HANSCH \& LEO, 1995; TAVARES, 2004).

Outro estudo de marco histórico foi de Verloop e colaboradores, em 1976, que determinou a partir do programa computacional "Sterimol Program" parâmetros estereoquímicos de grupos substituintes a partir de ângulos de ligação padrão, raios de van der Waals e comprimentos de ligação (KUBINYI, 1993, HANSCH \& LEO, 1995). Outro estudo de grande importância a respeito da influência estereoquímica sobre as conformações adotadas pelas moléculas nos estudos de QSAR foi introduzido por Cramer (1988), que determinou por métodos computacionais, campos de interação molecular calculados em uma caixa virtual (grid) e correlacionou estes campos com os valores de atividade biológica. Esta metodologia ficou conhecida como análise comparativa de campos moleculares (CoMFA, Comparative molecular Field Analysis), que estimulou o desenvolvimento de estudos de relação estrutura-atividade em três dimensões (QSAR-3D) (CRAMER, 1988; VERMA, 2010).

\subsubsection{Escolha dos grupos substituintes}

O diagrama de Craig foi a primeira contribuição para o delineamento de séries para estudos de QSAR (KUBINYI, 1993). Craig demonstrou que a constante de hidrofobicidade $\pi$ é estatisticamente independente da constante eletrônica $\sigma$. Com base neste estudo e na necessidade de selecionar grupos de substituintes apropriados para estudos de QSAR, foi sugerido um diagrama, em duas dimensões, cujas coordenadas são descritores estruturais 
independentes (figura 5). A proposta do Diagrama de Craig é selecionar grupos substituintes apropriados para estudos de QSAR, porém esta escolha requer alguns cuidados, pois o estudo da atividade biológica em função dos dois parâmetros físico-químicos requer uma escolha adequada dos substituintes de forma a abranger os quatro quadrantes da distribuição cartesiana. Esta escolha apropriada pode minimizar o número de compostos a serem sintetizados e avaliados frente à atividade biólogica, evitando-se assim a colinearidade entre parâmetros e correlações não significativas (CRAIG, 1971; TAVARES, 2004).

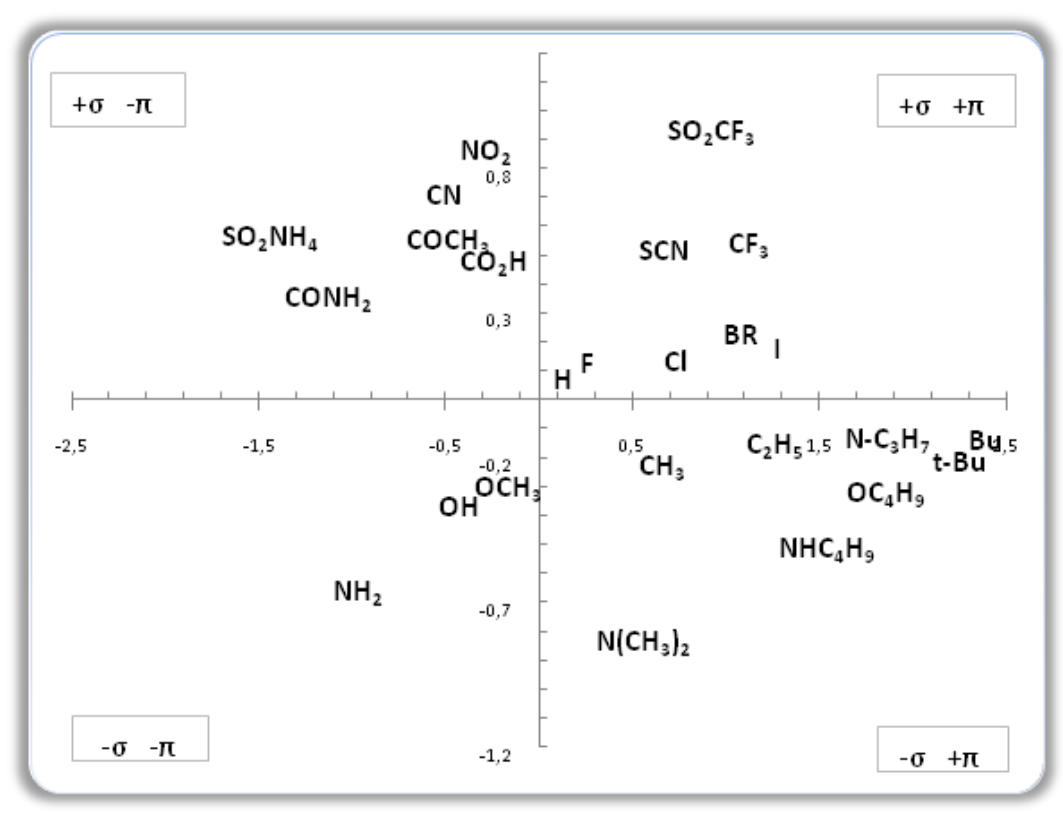

Figura 5. Diagrama de Craig

De acordo com o diagrama de Craig, substituintes devem ser selecionados em quadrantes diferentes, buscando a maior dispersão possível, sendo sugerido selecionar os grupos: $\mathrm{H}$ (na origem do diagrama), $\mathrm{Cl}$ ou $\mathrm{Br}$ (recebedores de elétrons com características hidrofóbicas), $\mathrm{NO}_{2}$ (recebedor de elétrons), $\mathrm{NH}_{2}$ (doador de elétrons com características polares), $\mathrm{N}\left(\mathrm{CH}_{3}\right)_{2}$ (doador de elétrons com característica hidrofóbica) (KUBINYI, 1993; TAVARES, 2004). 


\subsection{Composto protótipo e mecanismo de ação}

A nifuroxazida (5-nitro-2-furfurilideno 4- hidroxibenzidrazida) é um fármaco que foi utilizado na década de 70 como agente antimicrobiano no combate a infecções intestinais (figura 6), porém entrou em desuso na década seguinte com a introdução no mercado de novos fármacos mais eficazes e mais seguros no combate destas infecções (TAVARES, PENNA, AMARAL, 1997).

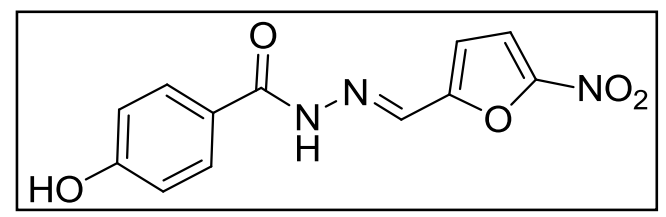

Figura 6. Nifuroxazida

A nifuroxazida apresenta duas subestruturas químicas em sua molécula que propiciam sua atividade biológica. O primeiro grupo a ser destacado é o grupo azometínico $(-\mathrm{CH}=\mathrm{N}-)$, ligado ao carbono 2 do anel heterocíclico, o qual confere uma ampla faixa de aplicação biológica e são conhecidos desde 1946 (DOMAGK, BHNISH, MIETZCH, 1946). A segunda subestrutura química importante na molécula da nifuroxazida é o grupo 5-nitrofurano. Este é o grupo farmacofórico, pertencente a classe dos nitrocompostos empregados na prática clínica desde 1944 e, entre suas aplicações, destacam-se as ações antibacteriana, antineoplásica, antiparasitária e antifúngica (PAULA, SERRANO, TAVARES, 2009; MORETH et al., 2010).

Além da nifuroxazida outros fármacos como o nifurtimox (antiparasitário), nitrofural (antibacteriano) e nitrofurantoína (antibacteriano), (figura 7), apresentam em suas moléculas tanto o grupo azometínico quanto o grupo nitrofurânico. Acredita-se que a relação entre estas duas subestruturas apresentam propriedades antimicrobianas que resulta em provável sinergismo farmacológico frente a diversos micro-organismos (FOYE, LEMKE, WILLIAMS, 1995; TAVARES, PENNA, AMARAL, 1997).

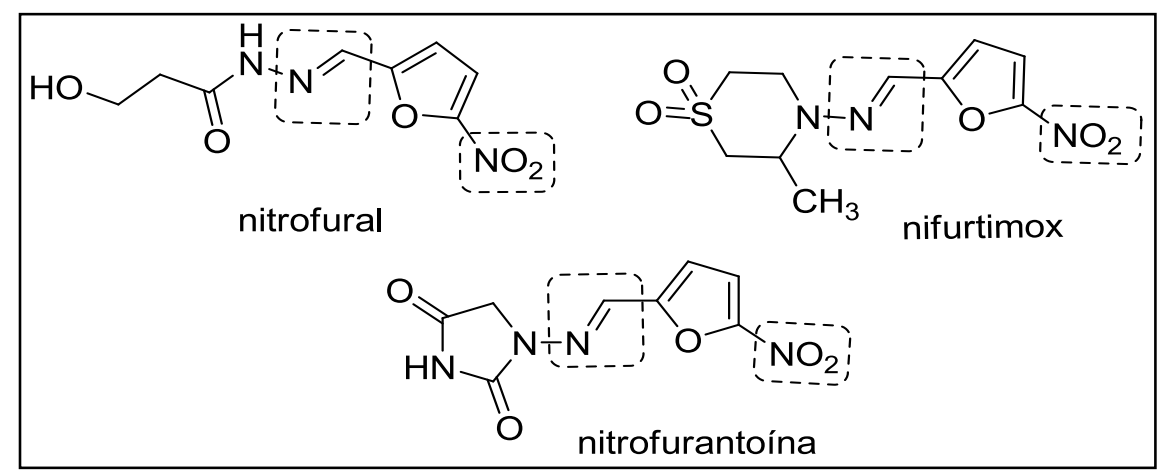

Figura 7. Fármacos nifurtimox, nitrofural e nitrofurantoína, em destaque as subestruturas responsáveis pela ação antimicrobiana. 
Os nitrocompostos, em geral, têm sido alvo de inúmeras discussões sobre sua mutagenicidade, já que a atividade biológica destes compostos parece estar relacionada à danos no DNA causados pelos produtos de biorredução do grupo nitro. Estudos realizados nos últimos anos demonstram que a ação mutagênica assim como a toxicidade destes compostos, pode variar conforme a estrutura química de cada nitrocomposto, assim como o tempo de exposição e a dose utilizada (TOCHER, 1997; AGUIERRE et al. 2005; PAULA, SERRANO, TAVARES, 2009; MORETH et al., 2010).

Algumas hipóteses têm sido publicadas referentes ao mecanismo de ação desta classe, sendo o mecanismo mais aceito atualmente, o proposto por Viodé e colaboradores, onde a ação dos nitrocompostos in vivo é decorrente da redução do grupo nitro que envolve diferentes intermediários e derivados reativos para esta classe de compostos. Esta redução do grupo nitro é subdividida em duas possíveis rotas biossintéticas, como ilustrado na figura 8, onde preliminarmente o grupo nitro se reduz e gera o grupo nitro ânion-radical $\left(\mathrm{NO}_{2}{ }^{-{ }^{-}}\right)$, catalisada pela enzima NADPH-citocromo P450 redutase (VIODÉ et al., 1999).

Em meio anaeróbio, o ânion-radical nitro e a hidroxilamina, formados na redução, são os principais metabólitos do processo de redução enzimática. Em meio aeróbio, o ânion-radical nitro, gerado no processo de redução enzimática, interage com o oxigênio molecular presente no meio, em uma etapa metabólica denominada ciclo fútil, formando o ânion-radical $\left(\mathrm{O}_{2}{ }^{--}\right)$. Este por sua vez, forma peróxido de hidrogênio $\left(\mathrm{H}_{2} \mathrm{O}_{2}\right)$, após receber um elétron e dois prótons, que podem reagir com enzimas ferrodoxinas, liberando espécies reativas como radicais hidroxila $\left(\mathrm{OH}^{-}\right)$, que são tóxicas para espécies celulares bacterianas e parasitárias (VIODÉ et al., 1999; PAULA, SERRANO, TAVARES, 2009). 


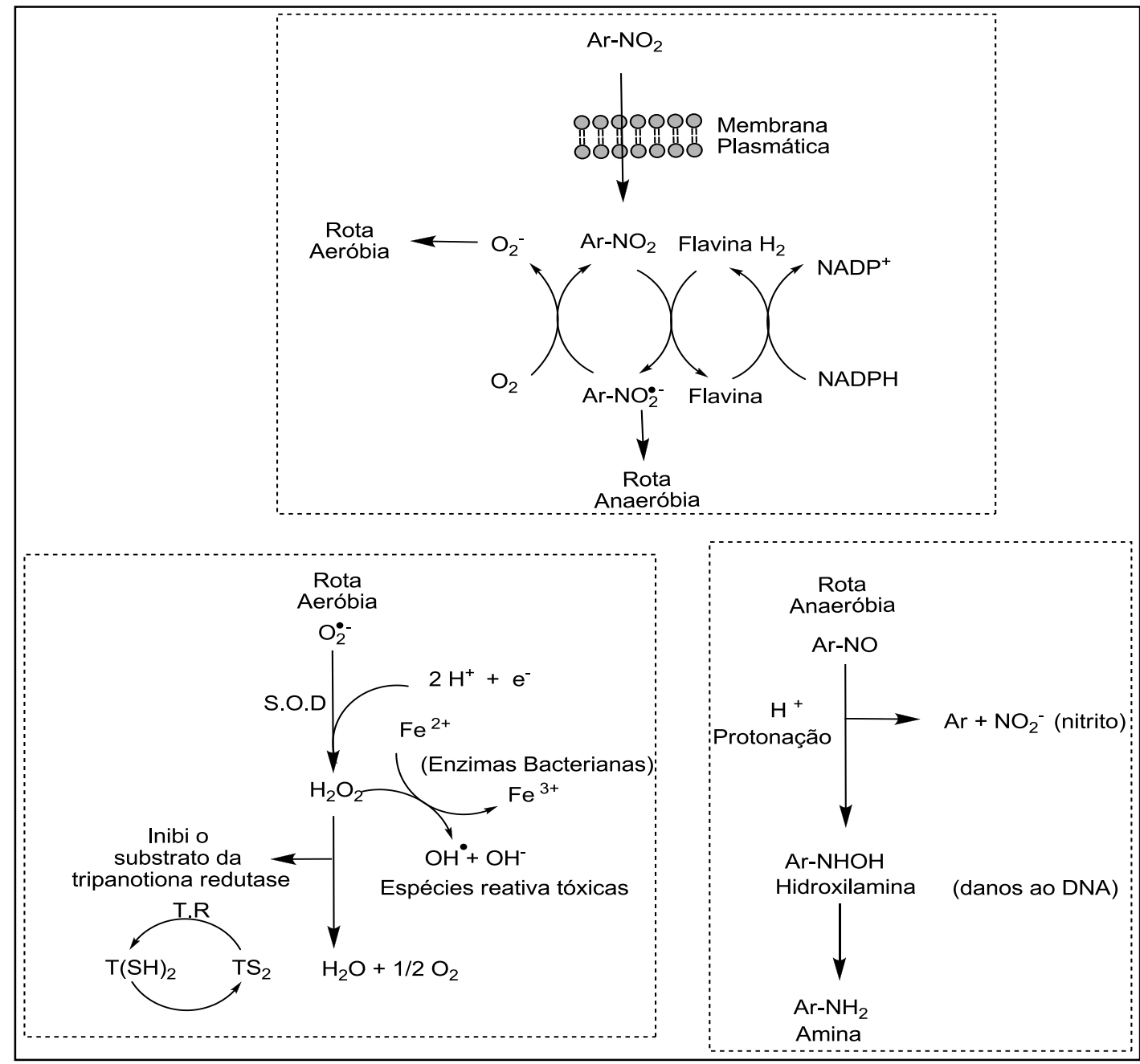

Figura 8. Processo de redução do grupo nitro via aeróbia e via anaeróbia (PAULA, SERRANO, TAVARES, 2009; VIODÉ et al., 1999).

\subsubsection{Derivados nitrotiofênicos}

Trabalhos sugerem que a troca do anel furânico pelo anel tiofênico (figura 9) no grupo farmacofórico dos compostos nitrofurânicos, podem favorecer a ação farmacológica. Trabalhos têm demonstrado, ao longo dos anos que os derivados nitrotiofênicos apresentaram excelente atividade antiparasitária frente ao Tripanosona cruzi e antibacteriana frente à Staphylococcus aureus (CERECETTO et al., 1998; ISHII et al. 2011; MASUNARI \& TAVARES, 2006 (A)). Desta forma, observa que esta variação estrutural pode trazer benefícios no combate de micro-organismos. 


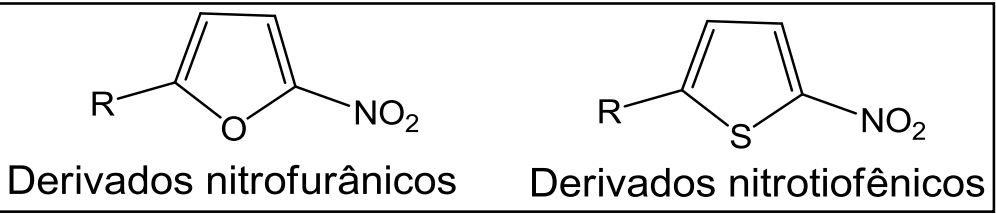

Figura 9. Diferença estrutural entre os derivados nitrocompostos.

Estudos de citotoxicidade e permeabilidade celular de derivados da nifuroxazida realizados em nosso grupo de pesquisa (FERNANDES et al., 2012), demonstraram que os derivados nitrotiofênicos (figura 9) quando comparados aos seus análogos nitrofurânicos apresentaram menor toxicidade e melhor viabilidade celular. A partir deste trabalho, torna-se plausível supor que a toxicidade dos nitrocompostos è dependente de múltiplos fatores, como sua estrutura química, tempo de exposição e dose utilizada. (SAPEL'NIKOVA et al., 2002; FERNANDES et al., 2012).

Segundo FERNANDES e colaboradores, este tipo de comportamento dos derivados tiofênicos pode ser explicado pelo maior raio atômico do átomo de enxofre em comparação com o átomo de oxigênio. Dessa forma, a maior toxicidade dos derivados furânicos poderia estar associada ao átomo de oxigênio que, devido a sua maior capacidade de doar elétrons, poderia aumentar a reatividade do grupo nitro ligado ao anel furânico (FERNANDES et al., 2012).

Observando outros estudos de derivados nitrotiofênicos frente a micro-organismos podemos destacar o trabalho de Gayral e colaboradores (GAYRAL, RIGOTHIER, GANTIER, 1981) onde foi demonstrado que derivados 5-nitrotiofênicos se mostravam mais ativos contra protozoários que os 5-nitrofurânicos e, subsequentemente, foi descrita significante atividade antiparasitária de grupos azometínicos (TEDLAOUTI \& GASQUET, 1990) e aldiminas (TEDLAOUTI et al., 1991) na série dos derivados tiofênicos. RANDO e colaboradores (2002) avaliaram a atividade de derivados nitrotiofênicos, frente à Mycobacterium tuberculosis, e identificaram como composto de maior atividade tuberculostática a 5-nitro-2-tiofilideno 4-metoxibenzidrazida, composto este semelhante aos estudados neste trabalho (RANDO, et al., 2002).

HOSSEINZADEH e colaboradores (2012) estudaram novas séries de análogos nitrotiofênicos como os derivados A e B da figura 10, os quais apresentaram excelente atividade antimicrobiana frente a Staphylococcus aureus, Staphylococcus epidermidis e Bacillus subtilis (HOSSEINZADEH, et al., 2012) . 


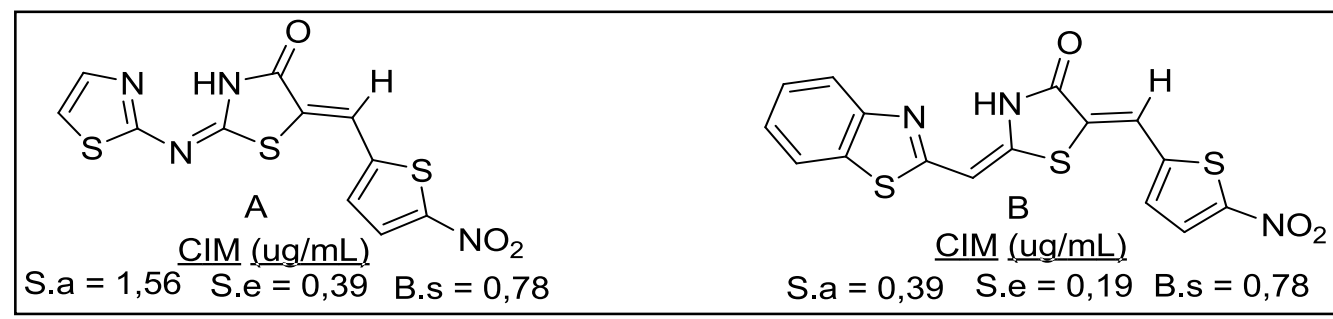

Figura 10. Novos derivados nitrotiofênicos e suas atividades antimicrobianas.

Comprovada a atividade antimicrobiana e antiprotozoária dos derivados nitrotiofênicos ao longo dos anos, aliadas ao fato de pesquisadores aprofundarem cada vez mais o entendimento do mecanismo de ação desses compostos, acredita-se que a síntese e a determinação da atividade biológica desses análogos, baseada em estudos de modificação molecular planejada, constituiem em uma alternativa extremamente viável para a seleção de fármacos que sejam ativos contra inúmeras doenças de caráter emergencial, como no caso das infecções hospitalares. 


\section{OBJETIVO}

Este trabalho tem como objetivo a modificação molecular da estrutura química da nifuroxazida (5-nitro-2-furfurilideno-4-hidroxibenzidrazida), com a finalidade de identificar análogos mais ativos frente a diferentes micro-organismos responsáveis por infecções hospitalares, envolvendo as etapas de planejamento, síntese, identificação, avaliação da atividade antimicrobiana e estudos de relações estrutura-atividade que possam auxiliar na previsão de novos análogos com perfil farmacológico otimizado, direcionando assim, para a seleção de novos candidatos a fármaco.

\section{Objetivos específicos:}

- Planejar a série azometínica e a série oxadiazolínica.

- Sintetizar e identificar os compostos planejados.

- Determinar a atividade antimicrobiana dos compostos obtidos frente às cepas selecionadas de micro-organismos causadores de infecções hospitalares.

- Realizar os estudos de relações entre as propriedades físico-químicas das estruturas planejadas com a atividade antimicrobiana aplicando a análise exploratória de dados HCA e PCA. 


\section{PLANO DE TRABALHO}

Para este trabalho foram planejados 24 compostos 5-nitrotiofilidênicos, sendo 12 derivados azometínicos (séria A) e 12 derivados oxadiaxolínicos (série B). Ambas as séries apresentam estruturas análogas à nifuroxazida, como ilustrado na figura 11, sendo a troca do anel furânico pelo anel tiofênico fundamentada no conceito clássico de bioisosterismo de anéis (BARREIRO, LIMA, 2005; BARREIRO, FRAGA, 2001). Os substituintes selecionados na posição para do anel benzênico foram selecionados por meio do diagrama de dispersão de Craig, que auxiliará em futuros estudos de relações quantitativas entre a estrutura química e atividade biológica dos compostos selecionados.

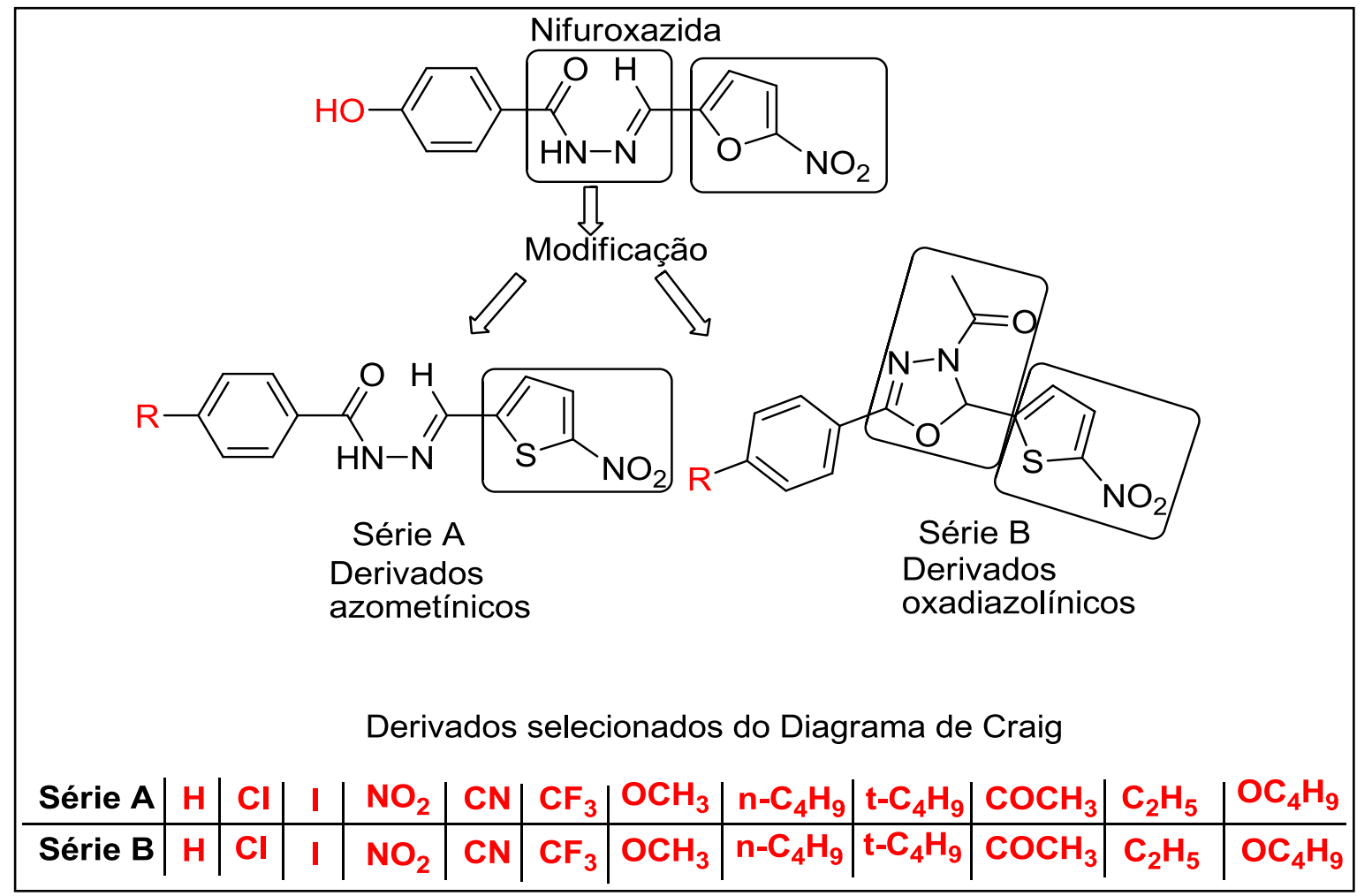

Figura 11. Estrutura química da nifuroxazida e dos derivados tiofênicos com estruturas azometínica (Série A) e oxadiazolínica (Série B). Em destaque, os locais de modificação estrutural planejados neste estudo e os substituintes selecionados.

Estudos realizados em nosso grupo (MASUNARI \& TAVARES, 2006 (A); 2006 (B); REZENDE 2002, TAVARES et al., 1999, MASUNARI, 2005), demonstraram que a substituição do anel furânico da nifuroxazida pelo anel tiofênico favoreceu significativamente a atividade antimicrobiana frente a Staphylococcus aureus. Com isso, neste trabalho procedeu-se a investigação da atividade antimicrobiana frente aos principais microorganismos causadores de infecções hospitalares, selecionando cepas de bactérias Gram positivas, Gram negativas e fungos. 
Com a conclusão da síntese e avaliação da atividade antimicrobiana procedeu-se os estudos de relação entre a estrutura química e atividade biológica, com o objetivo de determinar quais parâmetros físico-químicos poderiam auxiliar no delineamento de possíveis compostos mais promissores para o tratamento das infecções com caráter de multirresistência.

\section{MATERIAIS}

\subsection{Reagentes, solventes e meios de cultura}

- Ácidos benzóicos substituídos 98\% - Aldrich Chemical Company, Inc.;

- 5-nitro-2-tiofenocarboxaldeído 99\% - Aldrich Chemical Company, Inc.;

- Álcool etílico PA - Labsynth Produtos Químicos para Laboratório;

- Álcool metílico PA - Labsynth Produtos Químicos para Laboratório;

- Ácido sulfúrico PA - Labsynth Produtos Químicos para Laboratório;

- Ácido acético PA - Labsynth Produtos Químicos para Laboratório;

- Anidrido acético PA - Labsynth Produtos Químicos para Laboratório;

- Acetona PA - Labsynth Produtos Químicos para Laboratório;

- $\quad$ N,N - dimetilformamida PA (DMF) - Labsynth Produtos Químicos para Laboratório;

- Dimetilsulfóxido- $\mathrm{d}_{6}$ 99,5\% (DMSO- $\mathrm{d}_{6}$ - - Cambridge Isotope Laboratories, Inc.;

- Pentóxido de fósforo - Sigma - Aldrich Chemical Company, Inc.

- Caldo Müeller-Hinton ajustado por cátions (CAMHB), Merck: meio de cultura, dissolvido e esterilizado segundo especificações do rótulo;

- RPMI-1640 (meio tamponado com MOPS 0,165 mol/L, 1 L) Merck meio de cultura, dissolvido e esterilizado segundo especificações do rótulo;

- Solução fisiológica esterilizada (cloreto de sódio 0,9\%).

- Bactérias Gram positivas (S. aureus ATCC 29213, S. aureus VISA 3, E. faecalis ATCC 29212).

- Bactérias Gram negativas (E. coli ATCC 25922, E.cloacae ATCC 23355, K.pneumoniae ATCC 700603, S. marcescens ATCC 14756).

- Fungo (C. albicans ATCC 537Y)

\subsection{Equipamentos}

- Aparelho digital de ponto de fusão modelo MQAPF-301, Micro-química;

- Balança analítica digital Ohaus;

- Balança digital Marte; 
- Espectrômetro Bruker Advance DPX-300 Mhz,;

- Agitador com aquecimento modelo TE-0851 Tecnall;

- Rotaevaporador Fisaton;

- Estufa para secagem Marconi MA 033;

- Autoclave Stermax digital horizontal 60 Litros;

- Leitor de microplacas modelo EZ Read 400 Research (Vis).

\section{METODOLOGIA}

\subsection{Obtenção dos compostos planejados}

\subsubsection{Obtenção de benzidrazidas substituídas}

Dissolveu-se 0,01 mol de ácido benzóico substituído (1) em $50 \mathrm{~mL}$ de metanol anidro (1,23 mol) e $1 \mathrm{~mL}$ de ácido sulfúrico concentrado (0,02 mol), mantendo o sistema sob refluxo por aproximadamente quatro horas (figura 12). Após este período o sistema foi resfriado até temperatura ambiente e adicionou-se ao sistema $25 \mathrm{~mL}$ de solução de hidrato de hidrazina $80 \%(\mathrm{v} / \mathrm{v})$, sendo este novamente aquecido até temperatura de refluxo por aproximadamente uma hora (JORGE et al.,2011). A benzidrazida formada (2) foi posteriormente resfriada, filtrada, lavada com água destilada gelada e seca em presença de pentóxido de fósforo.

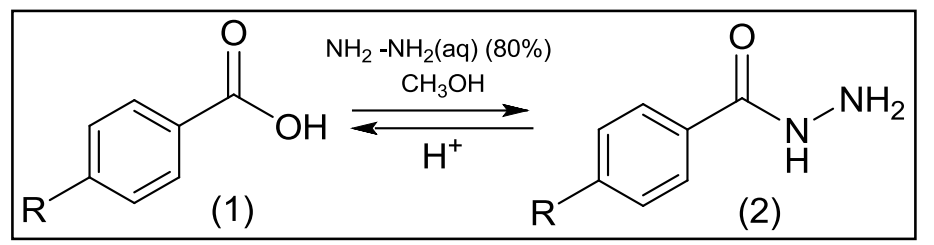

Figura 12. Formação das bezidrazidas substituídas.

\subsubsection{Obtenção dos derivados azometínicos (Série A)}

Adicionou-se, sob agitação constante, 0,01 mol de 5-nitro-2-tiofenocarboxaldeído (3) (figura 13), à mistura de água destilada, ácido sulfúrico concentrado, ácido acético glacial e metanol na proporção de 8:7:8:20, respectivamente (MASUNARI, 2005). Aqueceu-se o meio reacional até temperatura de refluxo, procedendo à adição lenta e constante de 0,01 mol da benzidrazida substituída (2). O sólido formado (4) foi filtrado, lavado com água destilada gelada e seco em presença de pentóxido de fósforo. A fim de garantir pureza aos compostos obtidos, procedeu-se a recristalização dos mesmos em sistema dimetilformamida/água. 
<smiles>[R]c1ccc(C(=O)NN)cc1</smiles>

(2)

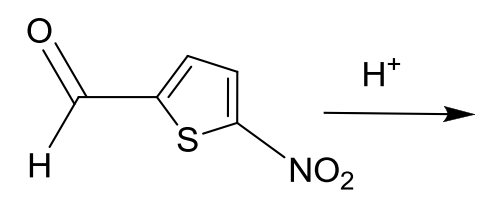

(3)<smiles>[R]c1ccc(C(=O)N/N=C/c2ccc([N+](=O)[O-])s2)cc1</smiles>

(4)

Figura 13. Obtenção de derivados tiofilidênicos azometínicos (Série A).

5.1.3 Obtenção dos derivados oxadiazolínicos (Série B)

Para obtenção dos derivados tiofilidênicos oxadiazolínicos (5) (Figura 14), procedeu-se a ciclização oxidativa dos compostos da série A (derivados tiofilidênicos azometínicos - composto 4), em presença de anidrido acético. Adicionou-se $10 \mathrm{~mL}$ de anidrido acético (pureza > 99\%) $(0,09 \mathrm{~mol})$ a 0,01 mol de 5-nitro-2-tiofilidênico benzidrazida substituída (4). Aqueceu-se o sistema até temperatura de 100 - 120 ㅇ sob agitação constante, mantendo a mistura sob atmosfera de nitrogênio gasoso por 18-24 h, sendo acompanhada por cromatografia de camada delgada (CCD) (ISHIl et al., 2011). O sistema foi resfriado e adicionou-se água destilada, na mesma proporção do volume de anidrido acético, sob agitação constante até formação de precipitado. Os derivados tiofilidênicos oxadiazolínicos (5) foram recristalizados com acetona/água, filtrados e secos em presença de pentóxido de fósforo.

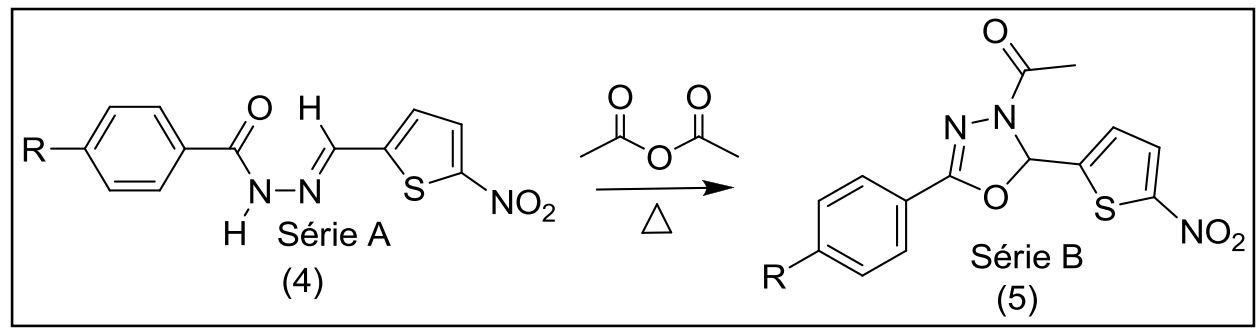

Figura 14. Obtenção de derivados tiofilidênicos oxadiazolínicos (Série B).

\subsection{Análises físico-químicas}

A estrutura química dos compostos planejados e sintetizados foram comprovadas utilizando-se análise de espectrometria de ressonância magnética nuclear de hidrogênio e de carbono (RMN ${ }^{1} \mathrm{H}$ e RMN ${ }^{13} \mathrm{C}$ ). A determinação da faixa de fusão e a análise elementar de carbono, hidrogênio e nitrogênio $(\mathrm{CHN})$ foram utilizadas como critério de pureza dos compostos obtidos.

Os espectros de RMN foram realizados em espectrômetro Bruker, modelo Advance DPX-300 Mhz, no Laboratório de Análise Instrumental/FCF/USP. Utilizou-se DMSO- $d_{6}$ como 
solvente e tetrametilsilano como padrão de referência interna. Os espectros obtidos foram analisados com auxílio do software Mestre-C (versão 5.0).

A faixa de fusão dos compostos obtidos foi determinada em lamínulas de vidro, utilizando-se aparelho digital de marca Micro-química modelo MQAPF-301 e as análises elementares foram realizadas em analisador CHN modelo Elementar Analyser $24013 \mathrm{CHN}$, Perkin-Elmer, na Central Analítica/IQ/USP.

\subsection{Ensaios Microbiológicos}

A determinação da concentração inibitória mínima (CIM) para os compostos selecionados foi realizada em duas fases. A primeira, nomeada fase I, foi determinada de forma quantitativa a atividade antimicrobiana utilizando-se o método de microdiluição sucessiva padronizada pela Clinical and Laboratory Standarts Institute (CLSI, 2007). A segunda fase, nomeada fase II, foi realizada subsequentemente, adaptada e otimizada para testes de microdiluição a partir da metodologia empregada por nosso grupo de pesquisa com objetivo de intensificar a sensibilidade do ensaio e estreitar a faixa de valores de CIM obtidos na primeira fase (TAVARES; PENNA; AMARAL, 1997; MASUNARI \& TAVARES, 2006 (A); MASUNARI \& TAVARES, 2006 (B); ISHIl et al, 2011; JORGE, 2011; JORGE et al, 2011).

\subsubsection{Preparo dos meios de cultura}

Os meios de cultura utilizados para o crescimento microbiano, caldo Mueller-Hinton com ajuste de cátions (CAMHB) (bactérias) e meio RPMI 1640 (fungo), foram preparados conforme as especificações do fabricante indicadas no rótulo do produto e conforme os padrões estipulados pelas normas da CLSI (CLSI, 2007; CLSI, 2002). A esterilização dos meios de cultura bem como os outros materiais utilizados no ensaio, foi realizada em autoclave, operando a $121^{\circ} \mathrm{C}$ por 30 minutos.

\subsubsection{Preparo do inóculo}

Preparo do inóculo das cepas bacterianas Gram positivas (S. aureus ATCC 29213, S. aureus VISA 3, E. faecalis ATCC 29212) e Gram negativas (E. coli ATCC 25922, E. cloacae ATCC 23355, K.pneumoniae ATCC 700603, S. marcescens ATCC 14756).

Para preparo do inóculo foram escolhidas cinco colônias de bactérias, com diâmetro aproximado de $1 \mathrm{~mm}$, após cultura de 24 horas em meio de cultura apropriado para seu crescimento. As colônias foram colhidas com o auxílio de swab estéril, suspensas 
em $4 \mathrm{~mL}$ de caldo Mueller-Hinton com ajuste de cátions (CAMHB) e agitada por 15 segundos em agitador tipo vórtex.

Sua densidade celular foi ajustada com espectrofotômetro UV/VIS por acréscimo de meio $C A M H B$ suficiente para obter-se transmitância equivalente à solução-padrão da escala de McFarland 0,5 em comprimento de onda de $625 \mathrm{~nm}$. Esta suspensão apresenta concentração de $1,0 \times 10^{8} \mathrm{UFC} / \mathrm{mL}$ como preconizada pela norma M100-S17 da CLSI (CLSI, 2007).

Transferiu-se 1,0 mL desta suspensão para frasco contendo 99,0 mL de solução fisiológica esterilizada, com barra magnética e pérolas de vidro esterilizados, gerando uma suspensão de concentração $1,0 \times 10^{6} \mathrm{UFC} / \mathrm{mL}$. Agitou-se por 15 minutos e transferiu 1,0 mL desta suspensão para frasco contendo $99,0 \mathrm{~mL}$ de meio CAMHB, com barra magnética e pérolas de vidro esterilizados, gerando suspensão de $1,0 \times 10^{4} \mathrm{UFC} / \mathrm{mL}$. Manteve-se esta suspensão sob agitação por 15 minutos, sendo posteriormente utilizada nos ensaios.

Preparo do inóculo de cepa de C. albicans ATCC 537Y

Para preparo do inóculo foram escolhidas cinco colônias, com diâmetro aproximado de $1 \mathrm{~mm}$, de cultura de 24 horas de Candida albicans em ágar Sabourauddextrose inclinado, que foram colhidas com uso de swab estéril e suspensas em $5 \mathrm{~mL}$ de solução salina estéril $0,85 \%$. A suspensão foi colocada em agitador de vórtex por 15 segundos e sua densidade celular ajustada com espectrofotômetro UV/VIS por acréscimo de solução salina estéril a 0,85 \% suficiente para obter-se transmitância equivalente a uma solução-padrão da escala de McFarland 0,5 em comprimento de onda de $530 \mathrm{~nm}$.

Após ajuste da turbidez, a suspensão de levedura sofreu diluição 1:50 em solução salina estéril 0,85\%, seguida de agitação por 15 minutos em frasco com agitador e pérolas de vidro. Foi realizada diluição 1:20 em meio RPMI-1640 estéril, seguida por nova agitação por 15 minutos. Esta suspensão de trabalho fornece inóculo com concentração de $1 \times 10^{3} \mathrm{a}$ $5 \times 10^{3} \mathrm{UFC} / \mathrm{mL}$ (CLSI, 2002). As microplacas foram incubadas a $35^{\circ} \mathrm{C}$ em estufa pelo período de 48 horas, como padronizados pela CLSI.

\subsubsection{Preparo das soluções de compostos a serem testados}

Para cada composto sintetizado foi preparada uma solução em dimetilsulfóxido (DMSO) e a partir desta foram realizadas diluições nos meios de cultura selecionados com o objetivo de obter soluções finais do solvente que não interferissem nas análises microbiológicas. A tabela 4 demonstra as porcentagens limites de DMSO que não interferem nas análises microbiológicas de cada micro-organismo utilizado no estudo. Assim a 
concentração final desejada de DMSO para cada micro-organismo foi ajustada, sendo esta solução final utilizada na avaliação microbiológica.

Tabela 4. Porcentagem de dimetilsulfóxido (DMSO) limitante para não inibição do crescimento dos micro-organismos utilizados nos ensaios microbiológicos.

\begin{tabular}{c|c}
\hline Micro-organismo & \% de DMSO \\
\hline ATCC 537Y C. albicans & 6 \\
ATCC 29213 S. aureus & 12,5 \\
ATCC 25922 E.coli & 12,5 \\
Visa 3 S. aureus & 12,5 \\
ATCC 23355 E.cloacae & 12,5 \\
ATCC 700603 K.pneumoniae & 12,5 \\
ATCC 29212 E. faecalis & 12,5 \\
ATCC 14756 S. marcescens & 12,5 \\
\hline
\end{tabular}

\subsubsection{Determinação da concentração inibitória mínima (CIM)}

\section{Fase I}

A atividade antimicrobiana dos compostos obtidos foi determinada utilizando o método de microdiluição seriada conforme as normas padronizadas pela Clinical and Laboratory Standarts Institute (CLSI, 2007; CLSI, 2002).

Utilizou-se microplacas de 96 poços, fundo chato, divididos em 12 colunas e 8 linhas $(\mathrm{A}-\mathrm{H})$ e reservatório de armazenamento de compostos, conforme mostra a figura 15 .

Nas colunas 1, 2 e 11, foram adicionados $100 \mu \mathrm{L}$ da solução dos compostos sintetizados (linhas A a F), $100 \mu \mathrm{L}$ do fármaco de referência, na concentração de $64 \mu \mathrm{g} / \mathrm{mL}$, na linha $\mathrm{G}$ e $100 \mu \mathrm{L}$ do controle de solvente (20\% de DMSO em meio CAMHB/RPMI) na linha $\mathrm{H}$. Após esta distribuição foi adicionado mais $100 \mu \mathrm{L}$ de meio de cultura em todas as colunas, com exceção da coluna 1 (Figura 15.a). Desta forma procedeu-se a diluição seriada iniciando na coluna 2. Cada poço foi homogeneizado, retirando $100 \mu \mathrm{L}$ e transferindo este volume para a coluna 3. Após homogeneização, $100 \mu \mathrm{L}$ foram novamente transferidos para a coluna 4, e assim sucessivamente até a coluna 10, que após homogeneização, descartou-se $100 \mu \mathrm{L}$. Adicionou-se $100 \mu \mathrm{L}$ de inóculo em todas as 
colunas, com exceção da coluna 11 (controle negativo do teste) (Figura 15.b). As microplacas foram vedadas, homogeneizadas e incubadas a $35^{\circ} \mathrm{C}$, por 18 horas (bactérias) ou 48 horas (fungo). Os ensaios foram realizados em triplicata.

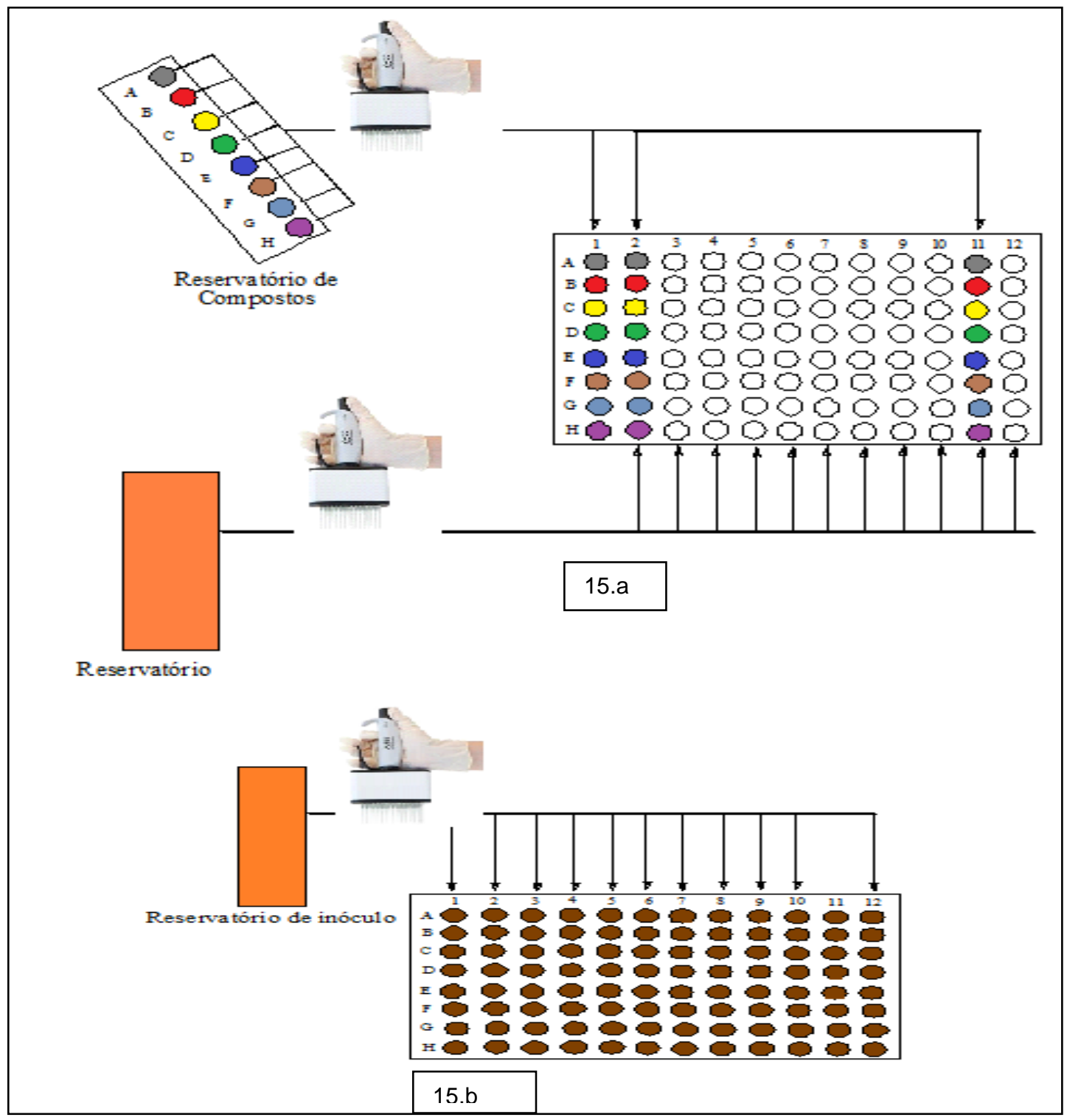

Figura 15. Procedimento de determinação da CIM. (a) Adição de meio de cultura e de soluções-mãe; (b) Adição de inóculo.

\section{Fase II}

Os ensaios da fase II foram realizados com a finalidade de estreitar-se a faixa de valores CIM obtidos na fase I (TAVARES; PENNA; AMARAL, 1997; MASUNARI \& TAVARES, 2006 (A); MASUNARI \& TAVARES, 2006 (B); ISHIl et al. 2011; JORGE et al.,2011). Preparou-se $1 \mathrm{~mL}$ de soluções-estoques dos compostos sintetizados, em 
concentrações equivalentes ao dobro do valor de MIC determinado na fase I, em meio CAMHB/RPMI contendo no máximo $10 \%$ de DMSO.

Distribuiu-se $100 \mu \mathrm{L}$ da solução-estoque nos poços da coluna 1 da microplaca (Figura 16.a) e adicionou-se $100 \mu \mathrm{L}$ de meio CAMHB/RPMI à solução-estoque inicial, desta forma diluindo-a em 10\%. Após homogeneização, $100 \mu \mathrm{L}$ desta nova solução-estoque foram distribuídos na coluna 2 da microplaca (Figura 16.b). Procedeu-se a nova diluição de 10\% da solução-estoque pela adição de $100 \mu \mathrm{L}$ de meio CAMHB/RPMI, com distribuição nos poços da coluna 3. Este procedimento foi repetido sucessivamente até a coluna 11, que recebeu adicionalmente $100 \mu \mathrm{L}$ de meio CAMHB/RPMI (controle de esterilidade). A coluna 12 recebeu $100 \mu \mathrm{L}$ de meio CAMHB/RPMI (controle de crescimento).

Todos os poços, com exceção da coluna 11, foram inoculados com $100 \mu \mathrm{L}$ de suspensão de micro-organismo. A microplaca foi vedada, homogeneizada e incubadas a 35 ${ }^{\circ} \mathrm{C}$ por 18 horas (bactérias) ou 48 horas (fungo). Todos os ensaios foram realizados em triplicata.

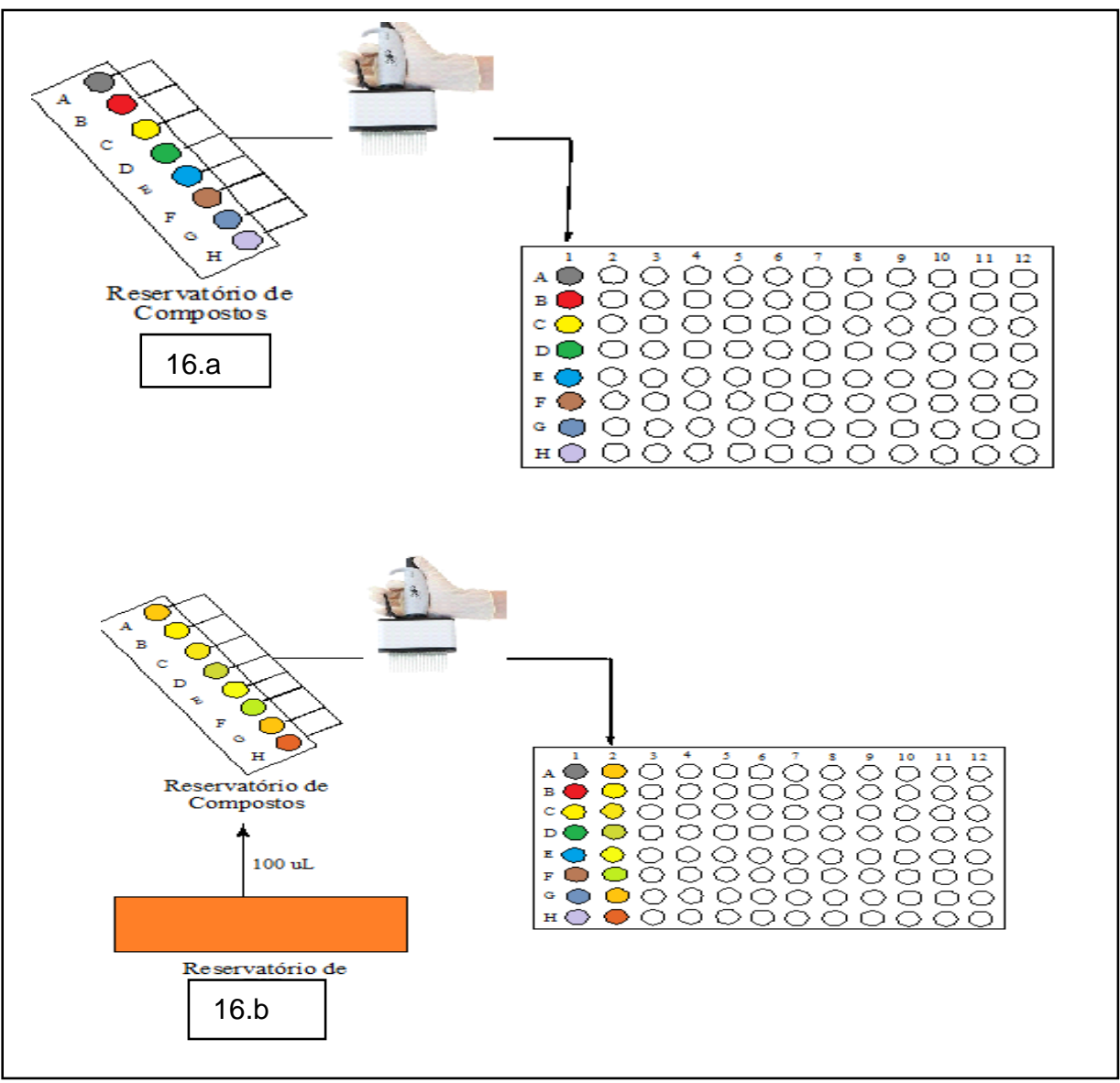

Figura 16. Procedimento geral adotado para diluição dos compostos na fase II. (a) Adição das primeiras soluções de compostos; (b) Primeira diluição dos compostos. 


\subsubsection{Tratamento dos dados obtidos}

Após o período de incubação realizou-se a leitura das absorbâncias das 3 placas incubadas, em leitor de microplacas modelo EZ Read 400 Research (Vis), e também a leitura de uma quarta placa, com a mesma concentração de compostos da triplicata, porém sem o inóculo. Esta foi considerada como o branco da leitura. Para o ensaio com bactérias foi realizada a leitura da absorbância em comprimento de onda de $625 \mathrm{~nm}$ e para o ensaio com fungo a leitura foi realizada em $530 \mathrm{~nm}$. Este procedimento foi adotado com o objetivo de determinar a concentração inibitória mínima (CIM) através da equação 5. A faixa de CIM foi determinada pela concentração no poço que apresentou inibição acima ou igual a 90 \%. Junto a esta análise foram realizadas leituras visuais com o objetivo de confirmar a leitura realizada pelo leitor de microplaca.

$[(\mathrm{A}-\mathrm{X})-\mathrm{MCP}] / \mathrm{MCP} \times 100=\mathrm{MIC}$

Equação 5.

$$
\begin{aligned}
& A=\text { branco } \\
& X=\text { triplicatas } \\
& M C P=\text { media do controle positivo } \\
& \text { MIC =inibição acima ou igual a } 90 \%
\end{aligned}
$$

Os dados obtidos de CIM foram tratados para posterior utilização do cálculo de $\mathrm{IC}_{90}$ (concentração inibitória de $90 \%$ das células bacterianas ou fúngicas) com o auxílio do programa OriginPro8.0 empregando-se o modelo de curva exponencial.

\subsection{Estudos de relações estrutura-atividade}

Os estudos da relação entre as propriedades físico-químicas dos derivados 5-nitro2-tiofilidênicos com estrutura azometínica e oxadiazolínica e avaliação da atividade biológica frente aos micro-organismos selecionados, iniciaram-se com a construção dos modelos moleculares tridimensionais dos derivados, seguido pelo cálculo de propriedades moleculares e análise exploratória de dados.

Utilizou-se, nesta etapa, computadores com o sistema operacional Windows de configuração Intel® Core $i 5^{\mathrm{TM}} 2.40 \mathrm{GHz}$, RAM 4.0 GB, NVIDIA ${ }^{\circledR}$ GeForce ${ }^{\circledR}$ GT $310 \mathrm{M} 320 \mathrm{MB}$ e outro com sistema Red Hat Enterprise Linux de configuração Intel ${ }^{\circledR}$ Core 2TM QUAD Q6600, 2,40GHz, RAM 4.0G, NVIDIA ${ }^{\circledR}$ GeForce ${ }^{\circledR}$ 9600GT 512MB. 
5.4.1 Construção das moléculas tridimensionais

O programa utilizado na construção dos modelos moleculares em 3D dos compostos das duas séries foi o Hyperchem 8.0 (Hypercube, Inc: 2008. Gainesville, FL, EUA). Como geometria de referência para os derivados da série $A$ utilizou-se a estrutura cristalografada do fármaco nifuroxazida (NF) (código LEQTAC, $R_{\text {fator }}=0,11$ ) proveniente do CSD, Cambridge Structural Database (PNIEWSKA \& JANUCHOWSKI, 1998). Referente à série $B$, foram construídos os modelos moleculares em 3D a partir da estrutura cristalografada da NF e da estrutura análoga, 2-[4-acetil-5-(bifenil-4-il)-4,5-di-idro-1,3,4oxadiazol-2-il]fenilacetato, contendo o anel oxadiazolínico $\left(R_{\text {factor }}=0,035\right)(Y E H Y E, A R I F F I N$, RAHMAN, 2010).

A otimização geométrica dos compostos não substituídos de ambas as series (série $A-\boldsymbol{H}$ e série $B-\boldsymbol{H})$ foi realizada no programa Hyperchem 8.0 em método de campo de força empírico MM+ (derivado do campo de força empírico MM2) (ALLINGER, 1977). Calcularamse as cargas atômicas parciais de ponto único para as estruturas série $\boldsymbol{A}-\boldsymbol{H}$ e série $\boldsymbol{B}-\boldsymbol{H}$ com o método de mecânica quântica, semi-empiríco Hamiltoniano AM1 (AustimModel 1) (DEWAR et al., 1985).

O programa MOLSIM 3.2 (DOHERTY, 2002; MOLSIM 3.2; The Chem21 Group, Inc: 1997, Lake Forest, IL, EUA) foi utilizado para minimizar a energia dos modelos moleculares 3D das estruturas série $\boldsymbol{A}-\boldsymbol{H}$ e série $\boldsymbol{B}-\boldsymbol{H}$ antes do desenvolvimento da simulação de dinâmica molecular. Este programa teve acesso gentilmente disponibilizado pelo laboratório LAPEN/FBF/FCF sob coordenação da Profa. Titular Elizabeth Igne Ferreira. Neste trabalho utilizaram-se os métodos de declive máximo (steepest descent) com 500 interações e o de gradientes conjugados (conjugated gradient) com 20.000 iteraçãos, com critério de convergência de $0,01 \mathrm{kcal} / \mathrm{mol}$. Constante dielétrica de 3,5 foi utilizada porque simula 0 ambiente dos sistemas biológicos, considerando que a constante dielétrica no interior de enzimas varia de 2 a 5. (ADMET/MI-QSAR, The Chem21 Group, Inc., 2001). A temperatura inicial de referência foi de $310 \mathrm{~K}\left(36,8^{\circ} \mathrm{C}\right)$, que corresponde à temperatura do ensaio biológico realizado no estudo.

O programa MOLSIM 3.2 também foi utilizado para a simulação de dinâmica molecular (DM) de $1 \mathrm{~ns}(1.000 .000$ passos, cada passo de $1 \mathrm{fs}), 310 \mathrm{~K}(36,8 \stackrel{\circ}{\mathrm{C}})$, a fim de gerar o perfil de amostragem conformacional (PAC). Arquivos trajetória foram salvos a cada 20 passos de simulação, resultando assim em 50.000 confôrmeros (PAC). Foi necessário adotar restrições de posição para alguns átomos do núcleo comum do conjunto investigado (massas fictícias 5.000 u.m.a). Selecionaram-se confôrmeros de energia mais baixa do PAC e comparou-se com o modelo molecular inicial e com o minimizado a fim de se verificar se a 
integridade estrutural foi mantida após a simulação. O critério utilizado foi o valor do desvio quadrático médio de posições atômicas (RMSD, root-mean-square deviation). Quanto menor o valor de RMSD mais semelhante são as estruturas, sendo que utilizou-se um limite de 0,1 $\AA$ para ambas as séries estudadas. Esta medida auxiliou a escolha do confôrmero de energia mais baixa para prosseguir os estudos. Os confôrmeros de energia mais baixa selecionados nesta etapa foram novamente minimizados de acordo com o mesmo protocolo mencionado para o programa MOLSIM 3.2.

Os confôrmeros de menor energia, série $\boldsymbol{A}-\boldsymbol{H}$ e série $\boldsymbol{B}-\boldsymbol{H}$ selecionados na DM serviram como modelo para construção dos análogos da série $A$ e $B$, respectivamente. Os análogos na posição 4 do anel benzênico de cada série, foram inseridos no programa Hyperchem 8.0 e para cada composto foi realizada a otimização de geometria com o método de campo de força empírico MM+, apenas para os grupos substituintes alterados na posição 4 do anel benzênico, preservando as coordenadas do restante da estrutura. Calcularam-se as cargas atômicas parciais de ponto único com o método de mecânica quântica, semi-empiríco Hamiltoniano AM1 para cada composto.

\subsubsection{Cálculo de propriedades moleculares}

Descritores ou variáveis independentes de diversas naturezas (lipofílica, eletrônica, estereoquímica, topológica) foram calculadas para os modelos construídos de cada compostos.

As cargas atômicas parciais de potencial eletrostático (ChelpG) (BRENEMAM \& WIBERG, 1990), energias de orbitais moleculares de fronteira $E_{\text {Hомо (orbital molecular }}$

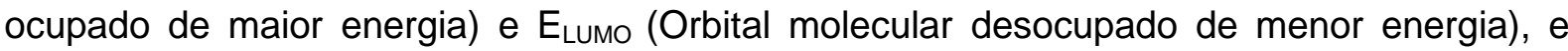
momento dipolo $(\mu$, total e nos eixos $\mathrm{x}, \mathrm{y}, \mathrm{z})$ foram calculadas pelo programa Gaussian $03 \mathrm{~W}$ (Gaussian 03W for Windows, version 6; Gaussian Inc.: 1995-2003, Pittsburgh, PA, EUA). Empregou-se os métodos ab initio Hartree-forck (MORGON \& COUTINHO, 2007) com conjunto de base $3-21 G^{*}$. Nesta mesma etapa, foram obtidos os mapas de potencial eletrostático (MPE) dos ligantes.

Descritores que expressam a lipofilicidade/hidrossolubilidade, conectividade (topológicos) e características estereoquímicas foram calculados pelo programa Marvin Beans (Marvin Beans, version 5.0.4.1; Chem Axon Ldta.: 1998-2010, Budapeste, Hungria). E o coeficiente de partição n-octanol/água calculado $C_{\log } \mathrm{P}_{\mathrm{MB}}$, foi calculado pelo método de pesos do programa, que atribui pesos iguais para os métodos de VISVANADHAN et al.,1989, KLOPMAN et al., 1994 e PHYSPROP ${ }^{\odot}$ database. 
Valores de ClogP foram obtidos também no programa Sybyl 8.0 (Sybyl 8.0 for Linux; Tripos, Inc.: 2007. St. Louis, EUA). Foram gerados os mapas de potencial lipofílico (MPL) calculados em superfície molecular de Connolly, obtida com sonda de raio de 1,4 , utilizando dois métodos disponibilizados no programa: ClogPSG-SLN (SLN, Sybyl line notation) (GHOSE et al., 1998) e ClogPSV (VISVANADHAN et al., 1989).

Os descritores referentes aos grupos substituintes que descrevem suas contribuições hidrofóbicas ( $\pi)$, eletrônicas ( $\sigma, F$ e R), estereoquímicas ( $L, B 1$ e B5) e estereoquímica/hidrofóbica (MR), foram retirados da literatura como forma de complementar o estudo (HANSCH, LEO, HOEKMAN, 1995).

A partir da obtenção das propriedades moleculares, gerou-se uma matriz de 37 colunas (variáveis independentes ou descritores ou propriedades calculadas), mais a atividade biológica linearizada $(\log 1 / C)$ de cada micro-organismo testado no estudo (variável dependente). Procedeu-se a pré-seleção das variáveis independentes mais representativas. Os dois filtros utilizados neste estudo foram o coeficiente de correlação linear de Pearson entre cada propriedade ou descritor e o valor de atividade biológica (variável dependente) e os gráficos de dispersão (scatter plots) entre atividade biológica e cada propriedade calculada (FERREIRA, 2002). A matriz final obtida foi utilizada para a análise exploratória dos dados (WERMUTH, 2008).

\subsubsection{Análise exploratória de dados: HCA e PCA}

As análises exploratórias de dados foram realizadas subsequentes à obtenção dos descritores, sendo que as matrizes de dados de propriedades moleculares geradas foram tratadas no programa Pirouette 3.11 (Pirouette 3.11, Infometrix Inc., 1990-2003,Woodinville). A matriz gerada com os dados de propriedades e de atividade biológica teve seus dados pré-processados por auto-escalamento, devido a distintas ordens de magnitude entre as variáveis independentes calculadas.

A análise de componentes principais (Principal Component Analysis, PCA) é um método de compressão de dados que se baseia na correlação entre as variáveis. Normalmente, a PCA é utilizada com o objetivo de visualizar a estrutura dos dados, encontrar similaridades entre amostras, detectar amostras anômalas (outliers) e reduzir a dimensionalidade do conjunto de dados. Neste estudo os dados foram decompostos em duas matrizes sendo uma de escores, relacionada às amostras e outra de pesos (loadings), relacionando as variáveis (FERREIRA, 2002). O principio desta análise é estabelecer relações entre as propriedades físico-químicas e a atividade biológica. 
A análise de agrupamentos hierárquicos (Hierarchical Cluster Analysis, HCA) foi apresentado sob a forma de dendogramas (FERREIRA, 2002). A HCA foi desenvolvida com método de agrupamento completo e as distâncias entre as amostras foram calculadas por meio da distância Euclidiana. As distâncias calculadas entre as amostras foram definidas em uma matriz de similaridade, cujos elementos são os chamados índices de similaridade que variam entre 0 e 1 , sendo 0 valor de 1 equivalente à máxima similaridade. $\mathrm{O}$ HCA foi realizado para amostras e para variáveis. No primeiro caso, a atividade biológica é considerada como variável dependente e obtêm-se agrupamentos por compostos. No segundo, a atividade biológica é considerada variável independente e obtém-se a distribuição dos descritores que melhor similaridade apresentam com a atividade biológica (FERREIRA, 2002; Pirouette, 2003).

O uso desses algoritmos tem como objetivo principal aumentar a compreensão do conjunto de dados, examinando a presença ou ausência de agrupamentos naturais entre as amostras. Ambos são classificados como exploratórios ou não supervisionados, visto que nenhuma informação com relação à identidade das amostras é levada em consideração (CORREIA \& FERREIRA, 2007).

\section{RESULTADOS E DISCUSSÂO}

\subsection{Síntese e identificação dos compostos}

Neste trabalho foram sintetizados doze compostos tiofilidênicos com estrutura azometínica (série A) e dez com estrutura oxadiazolínica (série B). São apresentados a seguir os resultados obtidos, abordando os dados de síntese, as etapas de obtenção das benzidrazidas e dos compostos planejados. A identificação dos compostos foi realizada através de análises de $\mathrm{RMN}{ }^{1} \mathrm{H}$ e $\mathrm{RMN}{ }^{13} \mathrm{C}$. A determinação da análise elementar de $\mathrm{CHN}$ foi utilizada como critério de pureza e a faixa de fusão foi realizada como complemento neste critério. Com a finalidade de facilitar a interpretação do grande número de dados experimentais obtidos na síntese dos análogos citados, os dados foram colocados em tabelas que serão apresentadas a seguir.

\subsubsection{Obtenção de benzidrazidas substituídas}

A primeira etapa envolveu duas reações, a esterificação (figura 17) seguida de aminólise (figura 18), sem 0 isolamento dos respectivos intermediários. Ambos os procedimentos foram baseados em dados da literatura os quais relatam que um dos fatores facilitadores da reação de amonólise é a dissolução do éster em etanol (JORGE et al. 2011; 
MORRISON \& BOYD, 1994). Verificando o mecanismo de reação (figuras 17 e 18), observase que o álcool e o ácido presentes na primeira reação podem favorecer a protonação do carbono carbonílico do éster, tornando-o mais susceptível ao ataque nucleofílico pela hidrazina e promovendo a amonólise, devido à formação da benzidrazida.

A reação de esterificação (figura 17) é caracterizada por ser reversível e, geralmente, quando o equilíbrio é atingido, permanece no meio considerável quantidade de reagentes e de produtos. Para deslocar o equilíbrio no sentido da formação dos produtos, pode-se utilizar a remoção de um dos produtos ou utilizar excesso de um dos reagentes, neste caso o metanol, por ser menos dispendioso e de fácil remoção, favorecendo a reação subsequente, a amonólise (SOLOMONS \& FRYHLE, 2004). O ácido utilizado como catalisador propicia a protonação do oxigênio carbonílico do ácido carboxílico (1) tornando o carbono carbonílico mais suscetível ao ataque nucleofílico do metanol (2). Após este ataque, o intermediário formado (3) perde um próton formando intermediário tetraédrico neutro (4). Posteriormente este intermediário sofre protonação em uma de suas hidroxilas, desencadeando a perda de uma molécula de água (5). Por fim, ocorre a perda de um próton deste intermediário (6) obtendo-se assim o benzoato de metila (7) (SOLOMONS \& FRYHLE, 2004).

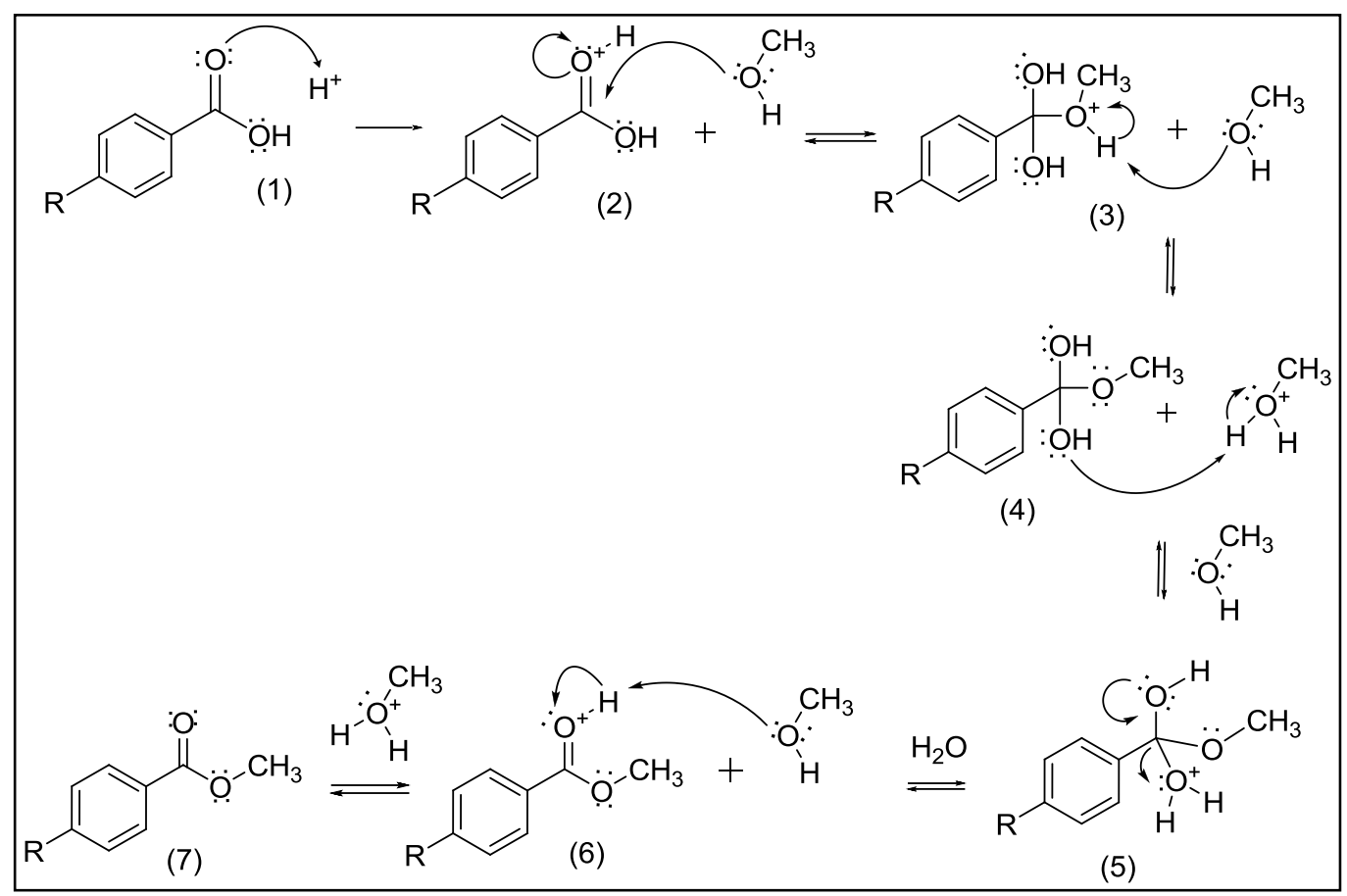

Figura 17. Mecanismo de esterificação de Fischer. 
A aminólise (figura 18) ocorre quando o carbono carbonílico do éster, deficiente em elétrons, sofre ataque nucleofílico da hidrazina (7), formando intermediário instável (8), que resulta no intermediário (9) Este é dissociado, (10), ocorrendo a eliminação de alcoxila (metanol) obtendo-se assim a benzidrazida (11) (SOLOMONS \& FRYHLE, 2004).

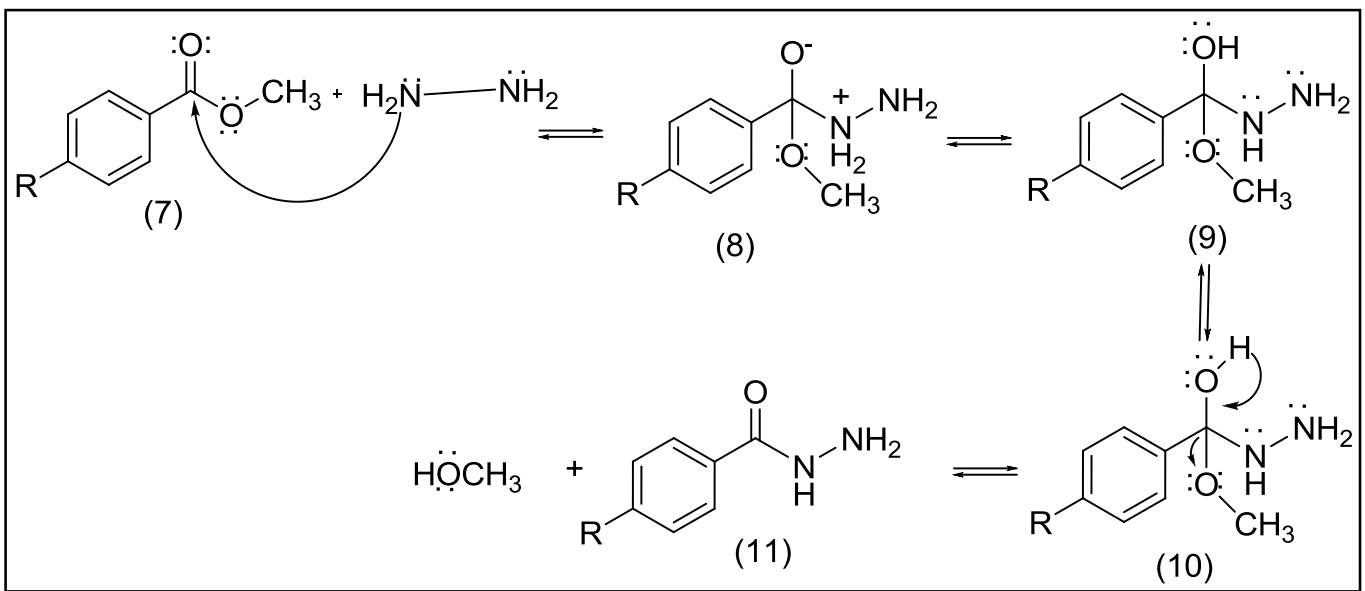

Figura 18. Mecanismo de reação de aminólise.

As benzidrazidas foram identificadas por meio da faixa de fusão determinada experimentalmente e comparada com dados da literatura. $O$ rendimento encontrado nesta etapa ficou entre 79 a 90\%. Baseado na literatura, a figura 19 ilustra a síntese da benzidrazida (3) em uma única etapa (caminho 1) a qual foi realizada no presente estudo e apresentou valores de rendimento superiores quando comparada a estudos anteriores, em que se isolava o éster (2), caminho 2 (JORGE et al., 2011). Observa-se que esta otimização sintética (caminho 1) favoreceu o rendimento obtido das benzidrazidas substituídas (-H, $\mathbf{O C H}_{3},-\mathbf{N O}_{2}$ e $-\mathbf{C F}_{3}$ ) em comparação ao caminho 2. A tabela 5 ilustra os rendimentos experimentais comparando com a literatura em ambos os caminhos.

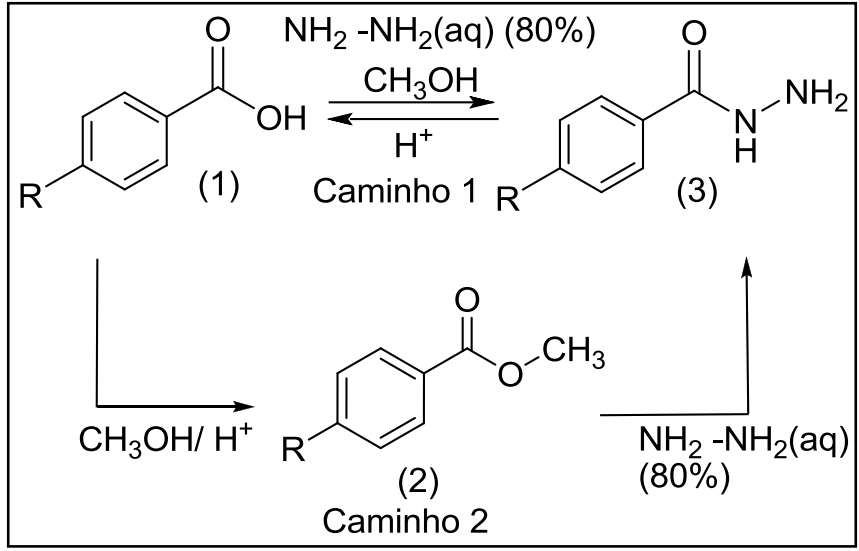

Figura 19. Ilustração dos dois possíveis caminhos sintéticos para formação das benzidrazidas substituídas. 
Tabela 5. Relação de rendimentos de benzidrazidas 4-R-substituídas obtidas com respectivos rendimentos descritos na literatura.

\begin{tabular}{|c|c|c|c|c|c|c|c|c|}
\hline \multirow{2}{*}{$\mathbf{R}$} & \multirow{2}{*}{$\begin{array}{l}\text { MM } \\
(\mathrm{g})\end{array}$} & \multirow{2}{*}{$\begin{array}{l}\text { Faixa de fusão } \\
\text { (ㄷ) exp. }\end{array}$} & \multirow{2}{*}{$\begin{array}{c}\text { Faixa de } \\
\text { fusão }\left(\stackrel{\circ}{ }{ }^{\circ}\right) \text { lit. }\end{array}$} & \multirow{2}{*}{$\begin{array}{c}\text { Rendimento } \\
\text { Experimental } \\
(\%)\end{array}$} & \multirow{2}{*}{$\begin{array}{c}\text { Rendimento } \\
\text { Literatura }^{\mathrm{a}} \\
(\%)\end{array}$} & \multicolumn{3}{|c|}{ Rendimento literatura $\mathbf{n}(\%)^{b}$} \\
\hline & & & & & & éster & benzidrazida & Global $^{c}$ \\
\hline $\mathbf{H}$ & 136,15 & $110,7-111,2$ & $110,0-113,0^{3}$ & 85 & $88^{1}$ & $89^{1}$ & $67^{1}$ & $53,9^{1}$ \\
\hline $\mathrm{n}-\mathrm{C}_{4} \mathrm{H}_{9}$ & 192,26 & $75,9-76,2$ & $74,4-76,6^{3}$ & 89 & ------ & $90^{3}$ & $82^{3}$ & $73,8^{3}$ \\
\hline $\mathrm{Cl}$ & 170,60 & $160,2-161,2$ & $162,0-164,0^{3}$ & 91 & $85^{1}$ & $96^{1}$ & $88^{1}$ & $84,0^{1}$ \\
\hline $\mathrm{CN}$ & 161,16 & $197,0-198,0$ & $197,0-198,0^{4}$ & 86 & ----- & $91^{2}$ & $70^{2}$ & $63,7^{2}$ \\
\hline $\mathrm{OCH}_{3}$ & 166,18 & $93,0-94,5$ & $90,0-93,0^{2}$ & 81 & ----- & $82^{2}$ & $55^{2}$ & $45,1^{2}$ \\
\hline $\mathrm{COCH}_{3}$ & 178,19 & $175,7-178,8$ & $179,8-181,2^{3}$ & 79 & ----- & $86^{3}$ & $73^{3}$ & $62,7^{3}$ \\
\hline t- $\mathrm{C}_{4} \mathrm{H}_{9}$ & 192,26 & $125,9-127,1$ & ------ & 78 & ------ & ----- & ----- & ------ \\
\hline $\mathrm{NO}_{2}$ & 181,15 & $218,8-220,4$ & $219,0-221,0^{2}$ & 80 & $76^{1}$ & $96^{1}$ & $51^{1}$ & $49,0^{1}$ \\
\hline $\mathbf{I}$ & 262,05 & $162,3-164,2$ & $164,1-165,2^{3}$ & 83 & $91^{4}$ & $95^{4}$ & $78^{4}$ & $74,0^{4}$ \\
\hline $\mathrm{CF}_{3}$ & 204,15 & $114,5-116,2$ & $115,0-116,0^{2}$ & 89 & $81^{1}$ & $81^{1}$ & $59^{1}$ & $48,0^{1}$ \\
\hline $\mathrm{OC}_{4} \mathrm{H}_{9}$ & 208,12 & $107,3-109,2$ & $106,7-109,6^{3}$ & 85 & ------ & $83^{3}$ & $66^{3}$ & $54,8^{3}$ \\
\hline $\mathrm{C}_{2} \mathrm{H}_{5}$ & 164,09 & $121,1-123,9$ & $122,2-124,0^{3}$ & 88 & ------ & $90^{3}$ & $75^{3}$ & $67,5^{3}$ \\
\hline
\end{tabular}

a:obtenção das benzidrazidas partindo-se do ácido benzóico - caminho 1 (Figura 19) b: benzidrazidas obtidas partindo-se do isolamento do éster - caminho 2 (Figura 19); c: $\eta \%$ global $=\eta \%$ éster $x \quad \eta \%$ benzidrazida/10 ${ }^{2} ; 1$. JORGE et al. 2011; 2 . REZENDE, 2002;

3. MASUNARI, 2005; 4. JORGE, 2011. 
6.1.2 Obtenção de derivados tiofilidênicos azometínicos

A obtenção dos compostos planejados para série A consistiu na reação de adição nucleofílica (figura 20), por meio de um composto carbonílico, o 5-nitro-2tiofenocarboxaldeído e uma amina, no caso a benzidrazida substituída (SOLOMONS \& FRYHLE, 2004).

Em decorrência da acidez elevada do meio reacional, ocorre protonação do oxigênio carbonílico do grupamento aldeídico tornando-o suscetível ao ataque nucleófilico da benzidrazida (1) (figura 20). Em seguida os intermediários (2 e 3) resultam na liberação de uma molécula de água (4). A reação se completa com a desprotonação do intermediário imina (5), obtendo-se sua forma neutra (6) correspondente a base de Schiff, compostos da série A (CAREY \& SUNDBERG, 2000).

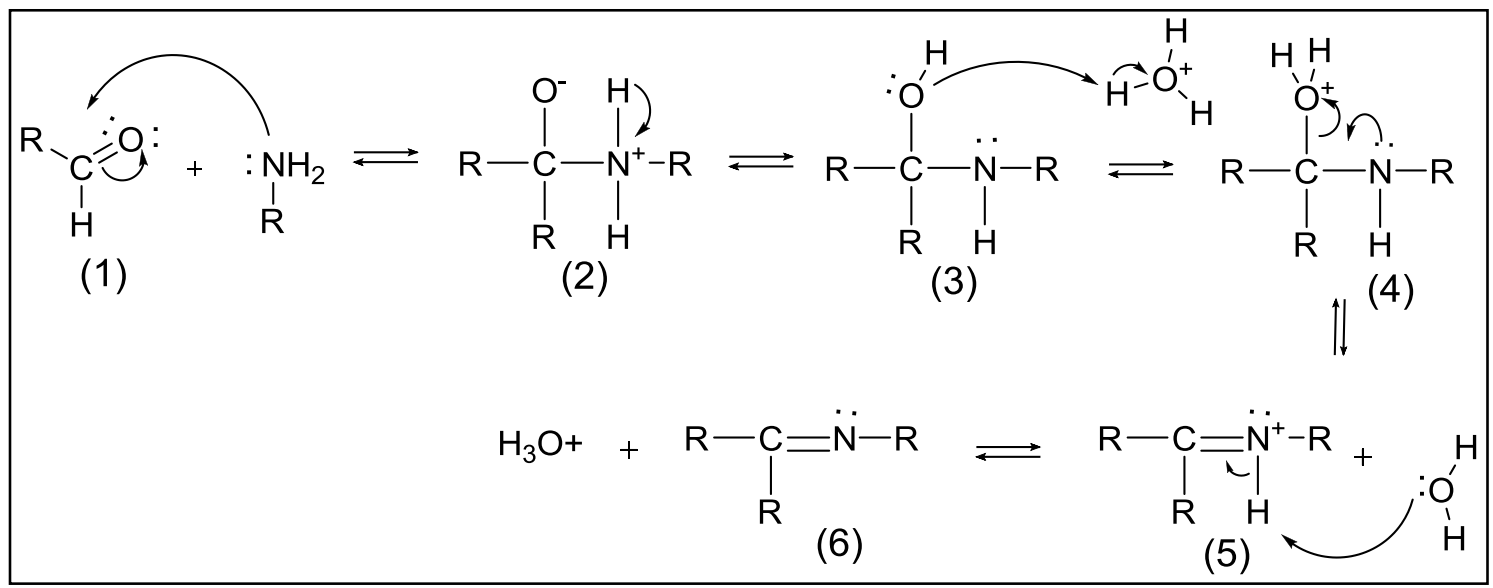

Figura 20. Mecanismo de reação de obtenção de bases de Schiff.

Os dados referentes a esta etapa sintética estão descritos na tabela 6 e 7, em comparação com os rendimentos da literatura. O rendimento médio desta etapa ficou entre 69 e $92 \%$. Também observa-se que o não isolamento do éster reflete em um ganho de rendimento real, economizando tempo, materiais e melhora no rendimento dos produtos finais (série A). O rendimento experimental global médio ficou em torno de $70 \%$ sendo considerado um ganho de $10 \%$ em comparação ao descrito na literatura que isolou o éster. Observa-se que o composto com melhor rendimento experimental foi o 5-nitro-2-tiofilideno4-clorobenzidrazida (série $\mathrm{A}-\mathrm{Cl}$ ) com rendimento global de $82 \%$. 
Tabela 6. Rendimentos parciais e totais obtidos na síntese dos derivados 5-nitro-2-tiofilideno benzidrazidas substituídas - série A.

\begin{tabular}{|c|c|c|c|c|c|c|c|c|}
\hline \multirow[b]{2}{*}{$\mathbf{R}$} & \multicolumn{3}{|c|}{ Rendimento experimental (caminho 1) $\eta(\%)^{a}$} & \multicolumn{4}{|c|}{ Rendimento literatura (caminho 2) n (\%) } & \multirow{2}{*}{$\begin{array}{l}\text { Relaçãc } \\
\text { Exp-Lit }\end{array}$} \\
\hline & benzidrazida & $\begin{array}{c}\text { base de } \\
\text { Schiff }\end{array}$ & global $^{d}$ & éster & benzidrazida & $\begin{array}{c}\text { base de } \\
\text { Schiff }\end{array}$ & global $^{e}$ & \\
\hline $\mathbf{H}$ & 85 & 86 & 73,1 & $87^{3}$ & $62^{3}$ & $93^{3}$ & 55,5 & 17,6 \\
\hline $\mathrm{n}-\mathrm{C}_{4} \mathrm{H}_{9}$ & 89 & 75 & 66,8 & $90^{3}$ & $82^{3}$ & $98^{3}$ & 72,0 & 5,2 \\
\hline $\mathbf{C l}$ & 91 & 91 & 82,8 & $98^{3}$ & $86^{3}$ & $96^{3}$ & 81,0 & 1,8 \\
\hline CN & 86 & 69 & 59,3 & $91^{2}$ & $70^{2}$ & $80^{2}$ & 51,0 & 8,3 \\
\hline $\mathrm{OCH}_{3}$ & 81 & 80 & 64,8 & $82^{2}$ & $55^{2}$ & $95^{2}$ & 43,0 & 21,8 \\
\hline $\mathrm{COCH}_{3}$ & 79 & 72 & 57,0 & $86^{3}$ & $73^{3}$ & $90^{3}$ & 56,5 & 1,5 \\
\hline t- $\mathrm{C}_{4} \mathrm{H}_{9}$ & 78 & 93 & 72,5 & ----- & ----- & ----- & ------ & ------ \\
\hline $\mathrm{NO}_{2}$ & 80 & 92 & 73,6 & $87^{2}$ & $46^{2}$ & $94^{2}$ & 38,0 & 35,6 \\
\hline I & 83 & 90 & 74,7 & $96^{3}$ & $76^{3}$ & $95^{3}$ & 70,4 & 4,3 \\
\hline $\mathrm{CF}_{3}$ & 89 & 82 & 73,0 & $89^{2}$ & $83^{2}$ & $88^{2}$ & 65,0 & 8,0 \\
\hline $\mathrm{OC}_{4} \mathrm{H}_{9}$ & 85 & 95 & 80,8 & $83^{3}$ & $66^{3}$ & $97^{3}$ & 53,1 & 27,7 \\
\hline $\mathrm{C}_{2} \mathrm{H}_{5}$ & 88 & 91 & 80,0 & $90^{3}$ & $75^{3}$ & $94^{3}$ & 63,4 & 16,7 \\
\hline
\end{tabular}

a:obtenção das benzidrazidas partindo-se do ácido benzóico - caminho 1 (Figura 19); b: benzidrazidas obtidas partindo-se do isolamento do éster - caminho 2 (Figura 19); c: (\%) global experimental (caminho 1) - global da literatura (caminho 2); d: $\eta \%$ global $=\eta \%$ benzidrazida $x \eta \%$ base de Schiff $/ 10^{2} ;$ e. $\eta \%$ global $=\eta \%$ éster $x \eta \%$ benzidrazida $x \eta \%$ base de Schiff $/ 10^{3}$;

2.REZENDE, 2002; 3.MASUNARI, 2005. 
Tabela 7. Obtenção de derivados tiofilidênicos azometínicos R-substituídos (série A): faixa de fusão e massa molar.

\begin{tabular}{|c|c|c|c|}
\hline $\mathbf{R}$ & MM (g) & $\begin{array}{l}\text { Faixa de fusão } \\
\qquad \operatorname{exp~(ㅇㅡ).~}\end{array}$ & $\begin{array}{c}\text { Faixa de fusão } \\
\text { lit }\left({ }^{\circ} \mathrm{C}\right) .\end{array}$ \\
\hline $\mathbf{H}$ & 275,28 & $242,0-244,1$ & $246,5-247,3^{3}$ \\
\hline $\mathrm{n}-\mathrm{C}_{4} \mathrm{H}_{9}$ & 331,29 & $175,0-176,0$ & $175,8-177,1^{3}$ \\
\hline $\mathrm{Cl}$ & 309,73 & $285,0-286,0$ & $288,1-290,1^{2}$ \\
\hline $\mathrm{CN}$ & 300,29 & $239,5-241,4$ & $236,0-238,0^{2}$ \\
\hline $\mathrm{OCH}_{3}$ & 305,31 & $233,7-234,8$ & $237,0-239,0^{2}$ \\
\hline $\mathrm{COCH}_{3}$ & 317,32 & $226,0-227,9$ & $227,6-229,8^{3}$ \\
\hline t- $\mathrm{C}_{4} \mathrm{H}_{9}$ & 331,39 & $272,0-273,8$ & ------ \\
\hline $\mathrm{NO}_{2}$ & 320,28 & $239,0-243,0$ & $237,0-239,0^{2}$ \\
\hline I & 401,18 & $276,1-278,9$ & $276,5-277,9^{3}$ \\
\hline $\mathrm{CF}_{3}$ & 343,28 & $200,0-203,3$ & $199,0-201,0^{2}$ \\
\hline $\mathrm{OC}_{4} \mathrm{H}_{9}$ & 347,09 & $199,5-201,2$ & $200,5-201,6^{3}$ \\
\hline $\mathrm{C}_{2} \mathrm{H}_{5}$ & 303,07 & $208,6-209,5$ & $207,2-208,5^{3}$ \\
\hline
\end{tabular}

2. REZENDE, 2002; 3. MASUNARI, 2005.

As análises de ressonância magnética nuclear (RMN ${ }^{1} \mathrm{H}$ e $\mathrm{RMN}{ }^{13} \mathrm{C}$ ) foram realizadas com o objetivo de comprovar a identidade química dos compostos planejados.

Os sinais mais comuns nas análises de $\mathrm{RMN}{ }^{1} \mathrm{H}$ dos derivados 5-nitro-2-tiofilideno benzidrazidas substituídas são observados na figura 21 . No espectro de $R M N{ }^{1} H$ do composto 5-nitro-2-tiofilideno 4-nitrobenzidrazida (série $\mathrm{A}-\mathrm{NO}_{2}$ ), observou-se 0 deslocamento dos hidrogênios 8 em 12,2 ppm e 6 em 8,6 ppm ambos na forma de um singleto. Os deslocamentos dos hidrogênios 4 e 3, aparecem na forma de dois dupletos, respectivamente em 8,1 e 7,5 ppm com acoplamentos $J=4,2 \mathrm{~Hz}$. Os hidrogênios 11/15 e 12/14 do anel benzênico apresentam deslocamento em 7,6 e 7,9 respectivamente ambos com acoplamentos de $J=8,0 \mathrm{~Hz}$. 


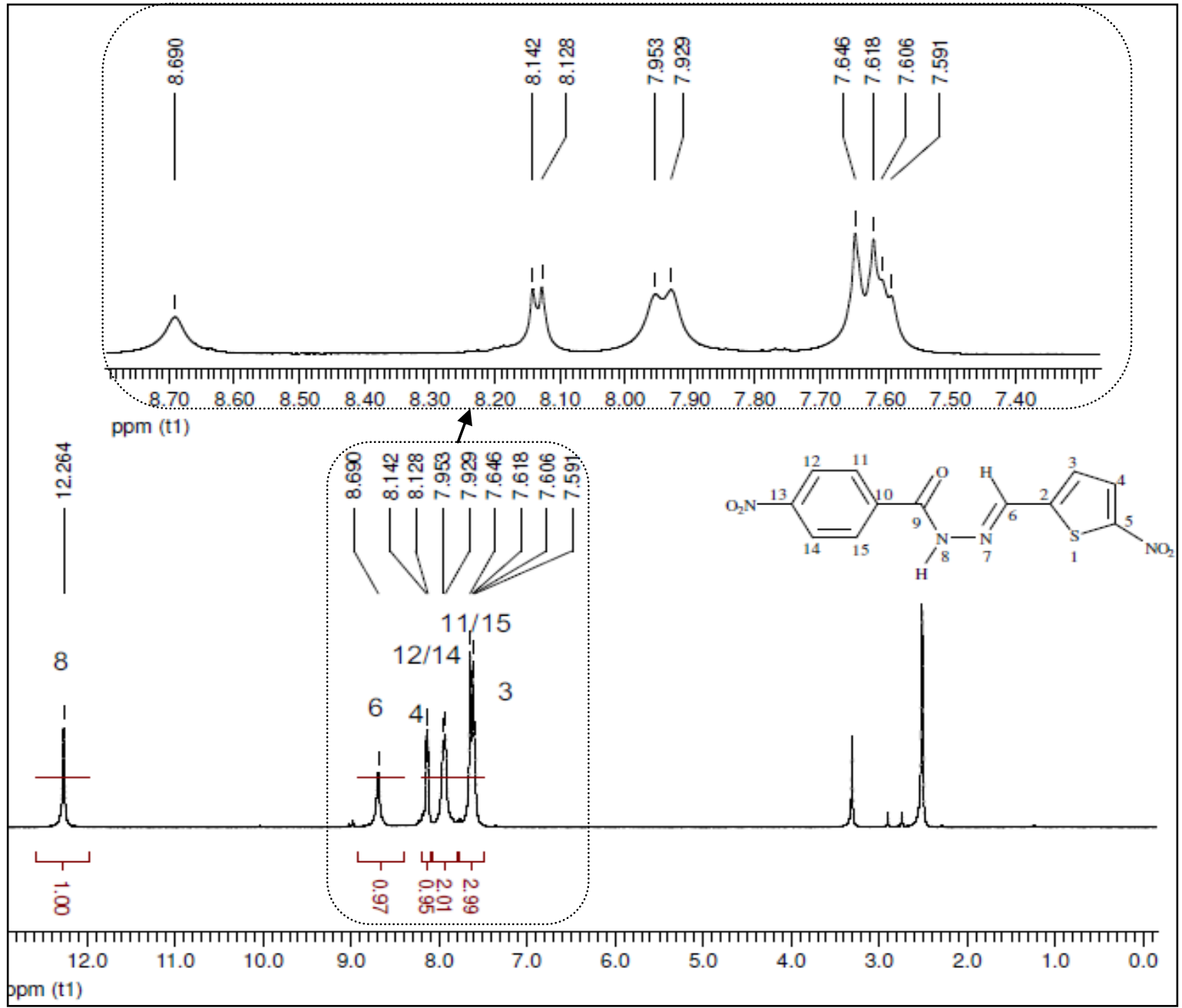

Figura 21. Espectro de $\mathrm{RMN}{ }^{1} \mathrm{H}$ do composto 5-nitro-2-tiofilideno 4-nitrobenzidrazida (série $\mathrm{A}-\mathrm{NO}_{2}$ ).

No espectro de RMN ${ }^{13} \mathrm{C}$ do mesmo composto (série A-NO $\mathrm{N}_{2}$ ) (Figura 22), observamse sinais em 161,8 ppm referente ao carbono 9 (carbonila), em 130,0 ppm referente a ao carbono 6 (azometínico), e, entre 123,6 a 142,2 observam-se os carbonos aromáticos e azometínicos. Portanto, estes dados evidenciam sucesso na obtenção do composto de interesse para o presente estudo. 


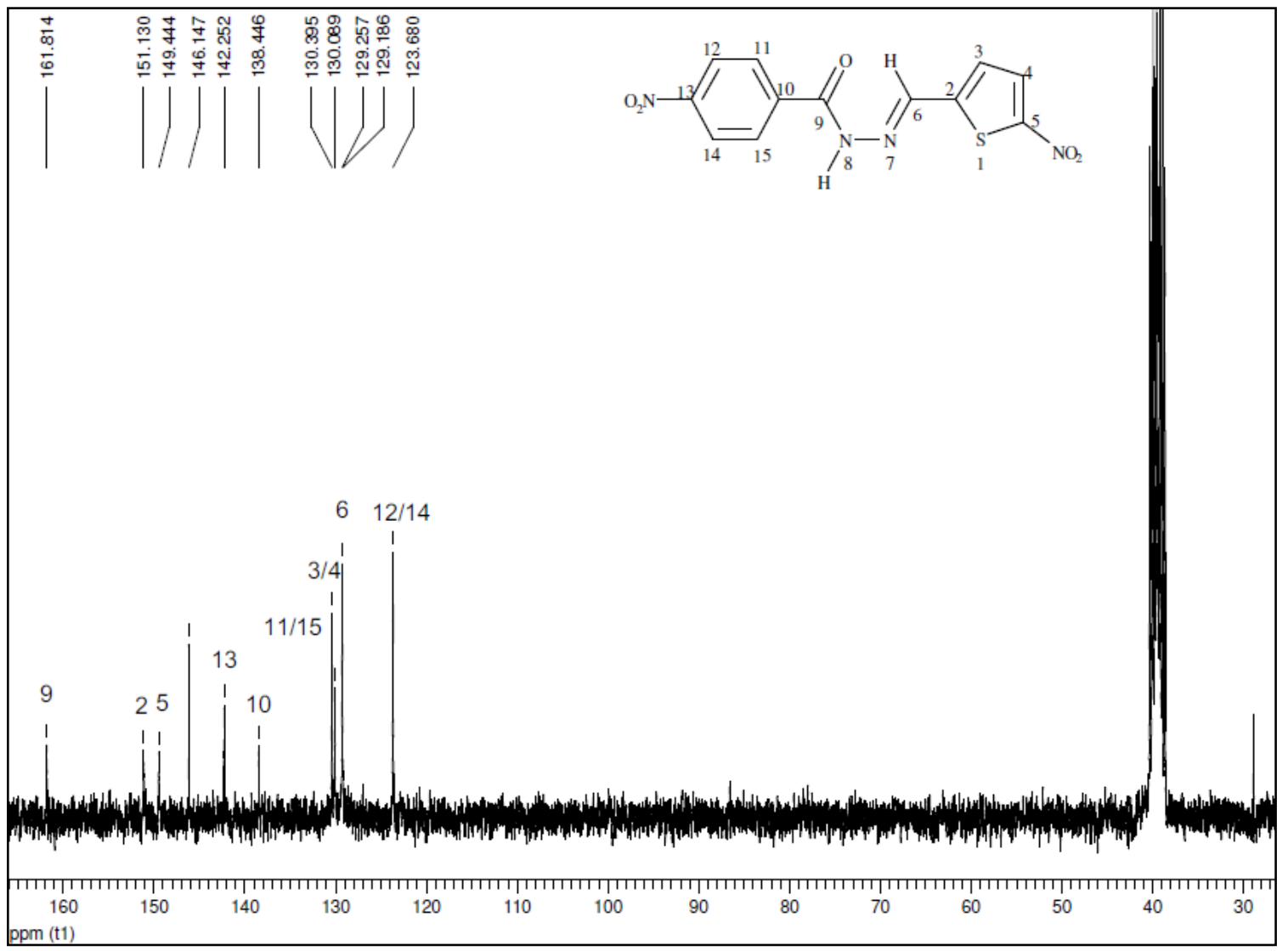

Figura 22. Espectro de $\mathrm{RMN}{ }^{13} \mathrm{C}$ do composto 5-nitro-2-tiofilideno 4-nitrobenzidrazida.

Nas tabelas 8 e 9 apresentam-se os dados referentes aos sinais obtidos da espectrometria de RMN ${ }^{1} \mathrm{H}$ e RMN ${ }^{13} \mathrm{C}$, sendo que os espectros de cada composto são apresentados no anexo 1 deste trabalho. A análise elementar (tabela 10) indica baixa variação das porcentagens obtidas experimentalmente em relação às calculadas, comprovando assim grau de pureza satisfatório. 
Tabela 8. Principais sinais de $\mathrm{RMN}{ }^{1} \mathrm{H}(\mathrm{ppm})$ em DMSO $d_{6}$ de derivados tiofilidênicos azometínicos 4-R-substituídas (série A).

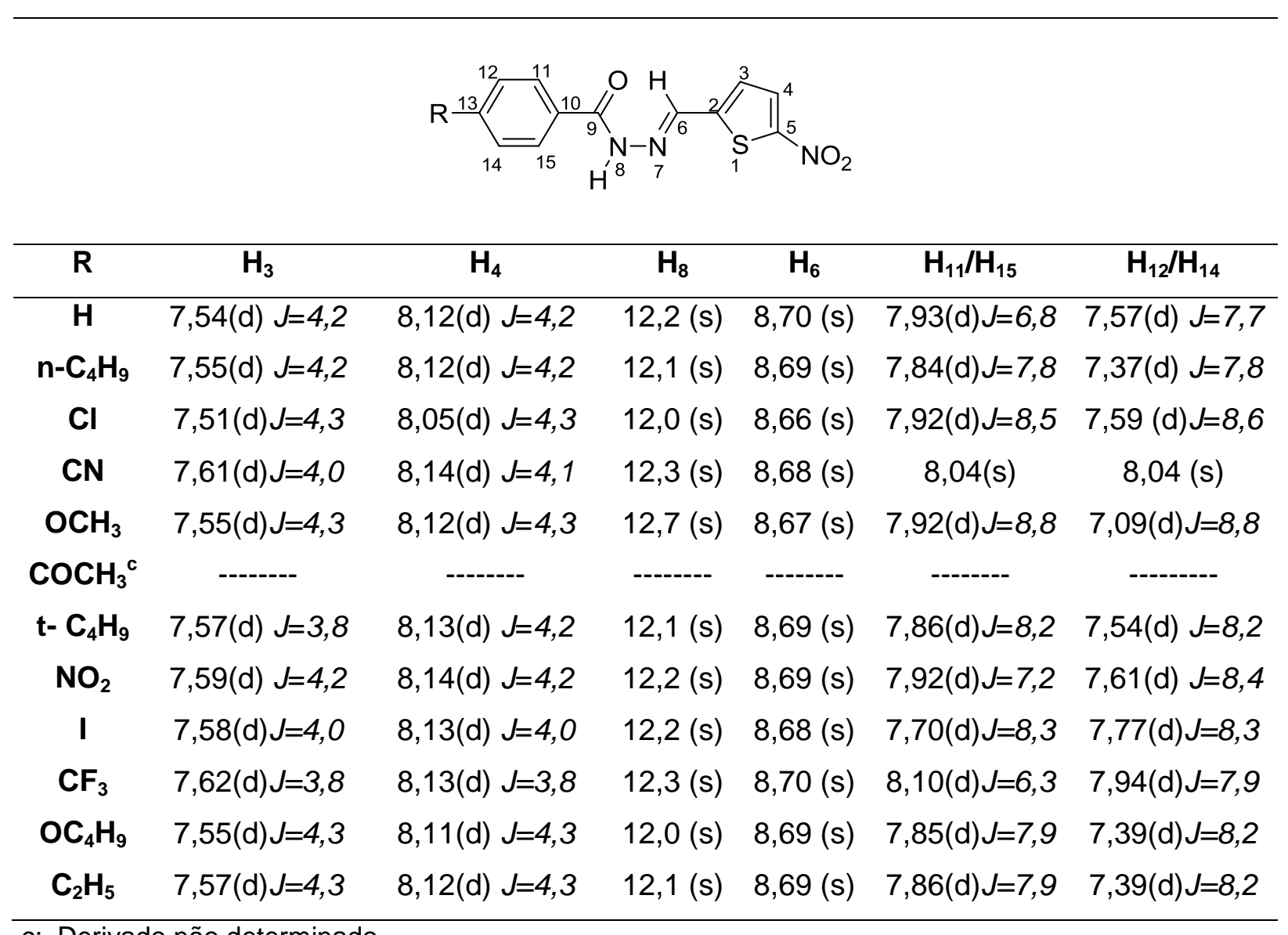


Tabela 9. Principais sinais de RMN ${ }^{13} \mathrm{C}$ (ppm) em DMSO $d_{6}$ de derivados tiofilidênicos azometínicos 4-R-substituídas (série A).

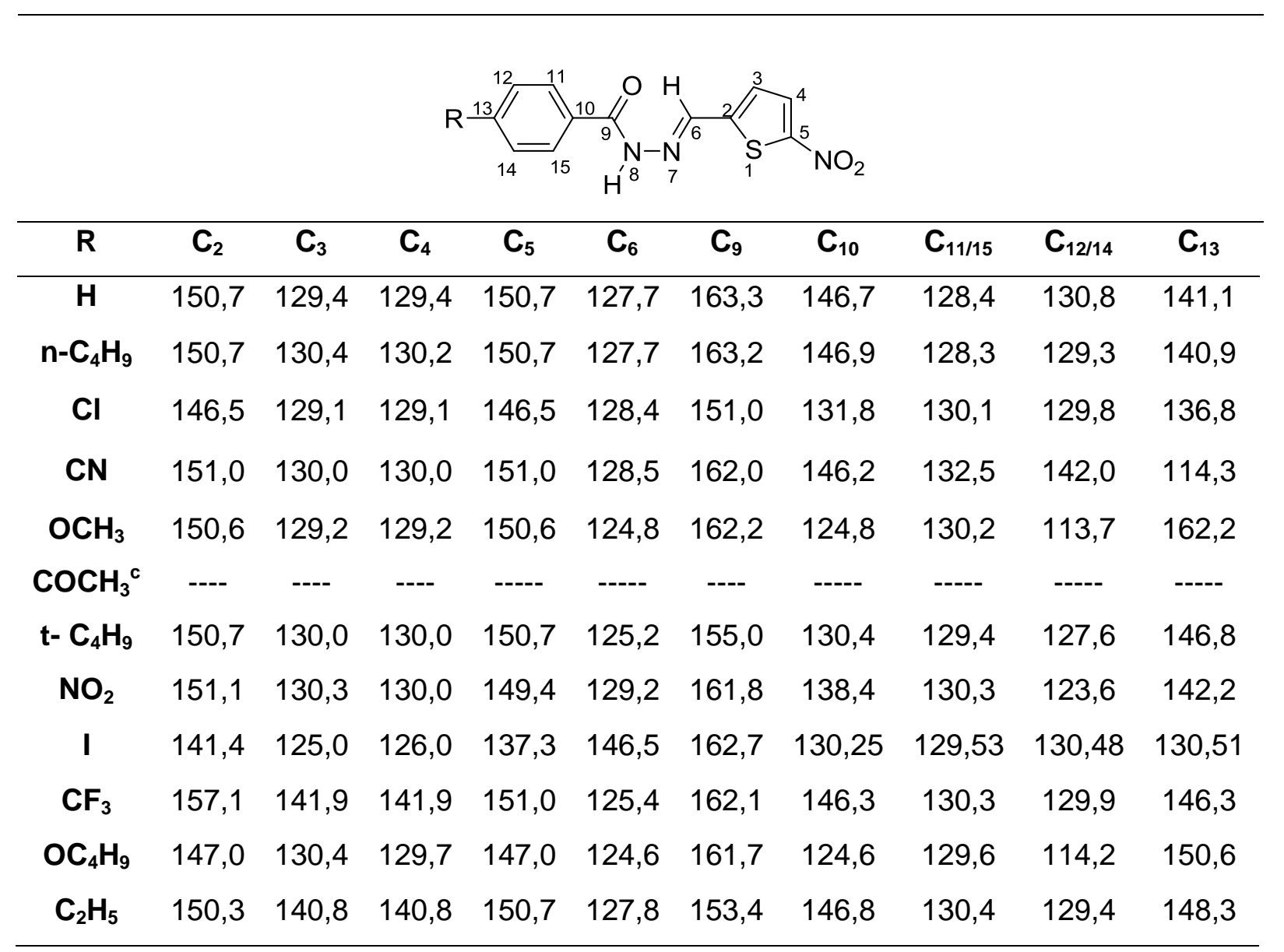

c: Derivado não determinado 
Tabela 10. Análise elementar dos derivados tiofilidênicos oxadiazolínicos 4-R-substituídas (série A).

\begin{tabular}{|c|c|c|c|c|c|c|c|c|c|c|}
\hline \multirow{2}{*}{$\mathrm{R}$} & \multirow{2}{*}{ MM (g) } & \multicolumn{3}{|c|}{$\% \mathrm{C}$} & \multicolumn{3}{|c|}{$\% \mathrm{H}$} & \multicolumn{3}{|c|}{$\% \mathrm{~N}$} \\
\hline & & Exp. & Cal. & $\Delta$ & Exp. & Cal. & $\Delta$ & Exp. & Cal. & $\Delta$ \\
\hline $\mathbf{H}$ & 275,28 & 49,31 & 49,14 & 0,17 & 3,83 & 3,78 & 0,05 & 14,32 & 14,33 & 0,01 \\
\hline $\mathrm{n}-\mathrm{C}_{4} \mathrm{H}_{9}$ & 331,29 & 58,31 & 57,99 & 0,34 & 5,16 & 5,17 & 0,01 & 12,27 & 12,07 & 0,20 \\
\hline $\mathrm{Cl}$ & 309,73 & 46,22 & 46,53 & 0,31 & 2,59 & 2,60 & 0,01 & 13,74 & 13,57 & 0,17 \\
\hline CN & 300,29 & 49,39 & 49,05 & 0,34 & 3,17 & 3,05 & 0,12 & 17,74 & 17,60 & 0,14 \\
\hline $\mathrm{OCH}_{3}$ & 305,31 & 48,59 & 48,29 & 0,30 & 3,76 & 4,05 & 0,29 & 13,63 & 13,00 & 0,63 \\
\hline $\mathrm{COCH}_{3}{ }^{\mathrm{c}}$ & 317,32 & & --- & -- & ---- & --- & --- & --- & ---- & -- \\
\hline $\mathrm{t}-\mathrm{C}_{4} \mathrm{H}_{9}$ & 331,39 & 57,81 & 57,99 & 0,08 & 5,15 & 5,17 & 0,02 & 12,65 & 12,68 & 0,03 \\
\hline $\mathrm{NO}_{2}$ & 320,28 & 42,03 & 42,60 & 0,27 & 2,83 & 2,98 & 0,15 & 15,82 & 16,56 & 0,74 \\
\hline I & 401,18 & 35,68 & 35,93 & 0,25 & 1,99 & 2,01 & 0,02 & 10,01 & 10,47 & 0,46 \\
\hline $\mathrm{CF}_{3}$ & 343,28 & 43,66 & 43,22 & 0,44 & 2,29 & 2,79 & 0,50 & 12,55 & 11,63 & 0,92 \\
\hline $\mathrm{OC}_{4} \mathrm{H}_{9}$ & 347,39 & 55,80 & 55,32 & 0,48 & 5,16 & 4,93 & 0,23 & 11,57 & 11,50 & 0,07 \\
\hline $\mathrm{C}_{2} \mathrm{H}_{5}$ & 303,34 & 51,71 & 51,76 & 0,05 & 4,77 & 4,70 & 0,07 & 13,31 & 13,08 & 0,23 \\
\hline
\end{tabular}


6.1.3 Obtenção dos derivados tiofilidênicos oxadiazolínicos

A obtenção da série $B$ dos compostos planejados constituiu-se em reação entre as bases de Schiff e anidrido acético (figura 23). Assim, baseando-se na literatura (JOULE \& MILLS, 2007), foi proposto o mecanismo de reação apresentada na figura 23, que se baseia, primeiramente, no ataque nucleofílico dos pares eletrônicos do nitrogênio imínico da base de Schiff a uma das carbonilas do anidrido acético (1), ocorrendo sua clivagem e resultando em grupo acetila e íon acetato, onde o grupo acetila se liga a amina terciária gerando carga parcial positiva resultando em um carbocátion transitório (2). O íon acetato ataca o próton da hidrazida (3), resultando, no final da reação, em ácido acético e o produto desejado. $O$ oxigênio azometínico, com carga parcial negativa, ataca o carbocátion (3) ocorrendo a ciclização oxidativa (4).

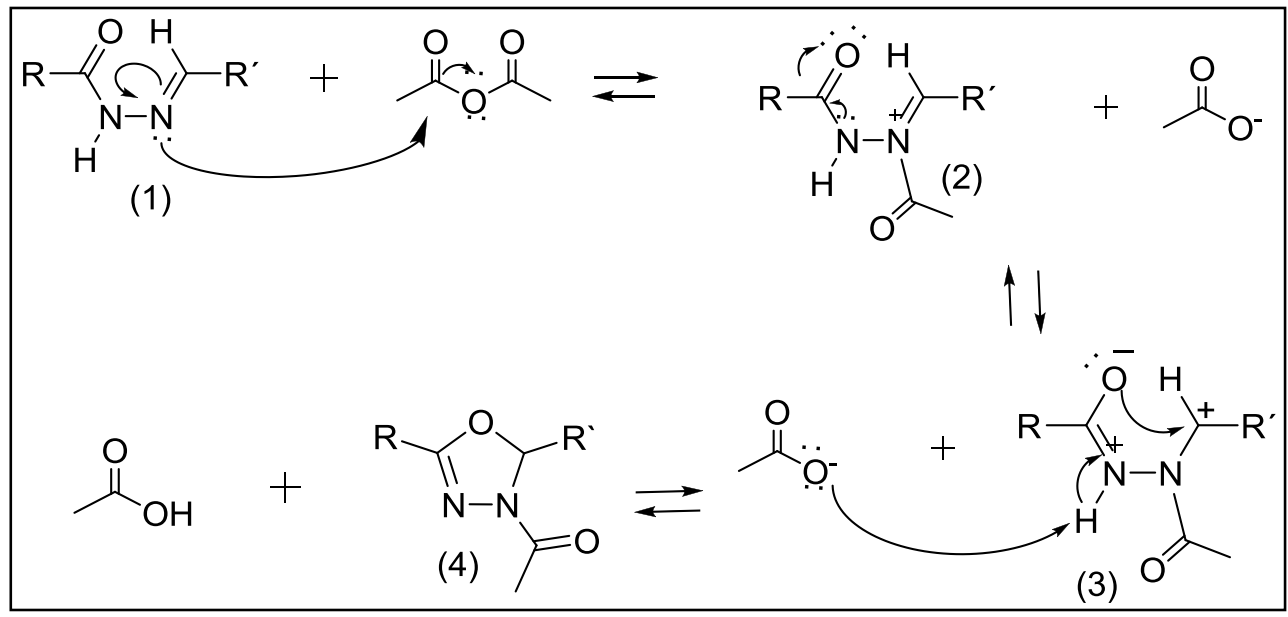

Figura 23. Mecanismo de reação para obtenção dos derivados tiofilidênicos oxadiazolínicos.

Os dados referentes a esta etapa sintética estão descritos na tabela 11, em comparação com os rendimentos da literatura, o rendimento desta etapa ficou entre 47 e 65 $\%$. Observa-se que o composto com melhor rendimento experimental foi o 2-[5-nitrotiofiliden-2-il]-3-acetil-5-[4-cloro-fenil]-2,3-diidro-1,3,4-oxadiazolinas (série $\mathrm{B}-\mathrm{Cl})$ apresentando rendimento global de 54,0\%. O rendimento experimental médio para a série B ficou em torno de $56 \%$ sendo considerado muito próximo ao da literatura que ficou em torno de 59\% (ISHII et al., 2011). Problemas como a não formação dos compostos e baixo rendimento estão sendo estudados com o objetivo de serem sanados. 
Tabela 11. Rendimentos parciais e totais das etapas de preparação dos derivados tiofilidenos oxadiazolínicos 4-R-substituídos (série B).

\begin{tabular}{|c|c|c|c|c|c|c|c|c|}
\hline \multirow{2}{*}{$\mathbf{R}$} & \multirow{2}{*}{$\begin{array}{l}\text { MM } \\
(g)\end{array}$} & \multirow{2}{*}{$\begin{array}{l}\text { Faixa de } \\
\text { fusão }\left({ }^{\circ} \mathrm{C}\right) \\
\quad \exp \end{array}$} & \multicolumn{4}{|c|}{ Rendimento experimental (caminho 1) $n(\%)^{a}$} & \multirow{2}{*}{$\begin{array}{c}\text { Faixa de } \\
\text { fusão }\left({ }^{\circ} \mathrm{C}\right) \text { lit }\end{array}$} & \multirow{2}{*}{$\begin{array}{c}\begin{array}{c}\text { Rendimento } \\
\text { literatura }\end{array} \\
\text { oxadiazol }\end{array}$} \\
\hline & & & benzidrazida & $\begin{array}{l}\text { base de } \\
\text { Schiff }\end{array}$ & oxadiazol & global $^{b}$ & & \\
\hline $\mathrm{H}$ & 317,32 & $98,1-99,2$ & 85 & 86 & 63 & 46,0 & 63 & $72^{5}$ \\
\hline $\mathrm{n}-\mathrm{C}_{4} \mathrm{H}_{9}$ & 373,43 & -------- & 89 & 75 & -------- & ------ & -------- & ------ \\
\hline Cl & 351,76 & $126,9-127,8$ & 91 & 91 & 65 & 54,0 & 65 & $70^{5}$ \\
\hline $\mathrm{CN}$ & 342,33 & $130,1-134,5$ & 86 & 69 & 52 & 31,0 & 52 & $53^{5}$ \\
\hline $\mathrm{OCH}_{3}$ & 347,35 & $112,0-113,5$ & 81 & 80 & 49 & 31,7 & 49 & $51^{5}$ \\
\hline $\mathrm{COCH}_{3}$ & 359,36 & ------ & 79 & 72 & --------- & ------- & --------- & ----- \\
\hline t- $\mathrm{C}_{4} \mathrm{H}_{9}$ & 373,43 & -------- & 78 & 93 & --------- & ------- & ------- & ------ \\
\hline $\mathrm{NO}_{2}$ & 362,32 & $189,3-190,8$ & 80 & 92 & 55 & 40,5 & 55 & $57^{5}$ \\
\hline $\mathbf{I}$ & 443,22 & $155,4-155,8$ & 83 & 90 & 54 & 40,3 & 54 & $55^{5}$ \\
\hline $\mathrm{CF}_{3}$ & 385,32 & $134,0-135,4$ & 89 & 82 & 65 & 47,5 & 65 & $59^{5}$ \\
\hline $\mathrm{OC}_{4} \mathrm{H}_{9}$ & 389,10 & $116,2-117,8$ & 85 & 95 & 49 & 39,6 & 49 & $32^{5}$ \\
\hline $\mathrm{C}_{2} \mathrm{H}_{5}$ & 345,08 & $104-1-106,2$ & 88 & 91 & 52 & 41,6 & 52 & $62^{5}$ \\
\hline
\end{tabular}

a:obtenção das benzidrazidas partindo-se do ácido benzóico - caminho 1 (Figura 19); b. $\eta \%$ global $=\eta \%$ benzidrazida $x \quad \eta \%$ base de Schiff $x \eta \%$ oxadiazol $/ 10^{3} ; 5$.ISHII et al, 2011. 
A análise de espectros $\mathrm{RMN}{ }^{1} \mathrm{H}$ permitiu constatar a formação dos compostos da série B. Na figura 24 apresenta-se o espectro de $\mathrm{RMN}{ }^{1} \mathrm{H}$ do composto (série $\mathrm{B}-\mathrm{NO}_{2}$ ), em que nota-se a presença de um singleto em aproximadamente 7,46 ppm indicando 0 hidrogênio 2, mostrando a ciclização do grupamento azometínico da base de Schiff; logo, a formação do anel 1,3,4-oxadiazolínicos. Já em 2,33ppm, há um singleto característico de metila ligada à carbonila, referente ao grupo acetil situado na posição $\mathbf{3}$ do anel oxadiazolínico indicando os hidrogênios 22. Em 8,38 e 8,09 ppm há um dupleto com constante de acoplamento $J=8,6 \mathrm{~Hz}$, referente aos prótons do anel fenílico 16/18 e 15/19. Um dupleto em 7,73 ppm e outro em 7,28 ppm, indicando os hidrogênios 8 e 7 respectivamente com constante de acoplamento $J=4,0 \mathrm{~Hz}$, referentes ao anel tiofênico.

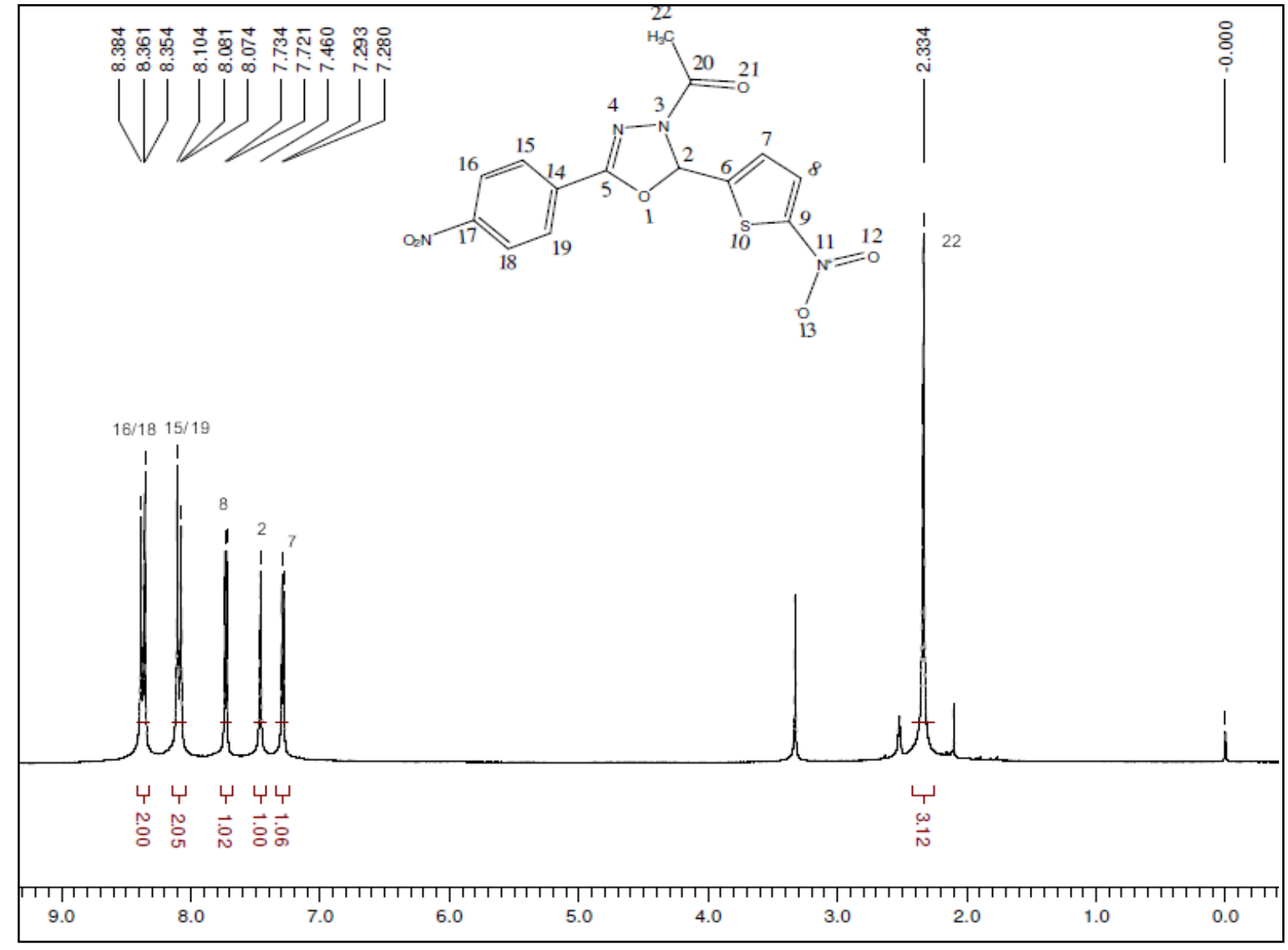

Figura 24. Espectro de $\mathrm{RMN}{ }^{1} \mathrm{H}$ do composto 2-[5-nitro-tiofiliden-2-il]-3-acetil-5-[4-nitrofenil]-2,3-diidro-1,3,4-oxadiazolinas. 
$\mathrm{Na}$ figura 25 apresenta-se o espetro de $\mathrm{RMN}{ }^{13} \mathrm{C}$ do substituinte (série $\mathrm{B}-\mathrm{NO}_{2}$ ), o qual apresenta os sinais típicos de formação dos derivados oxadiazolínicos. No espectro podemos observar os sinais de carbono carbonílico, 20, em 167,4 ppm, de radicais alquílicos (metila do grupo acetil) carbono 22 em 21,0 ppm , e em 86,5 ppm, sinal referente ao carbono assimétrico do anel oxadiazolínico, carbono 2 . Todos os espectros de RMN de ${ }^{1} \mathrm{H}$ e ${ }^{13} \mathrm{C}$ estão em conformidades com as modificações moleculares propostas e estão disponíveis no anexo 2 deste trabalho.

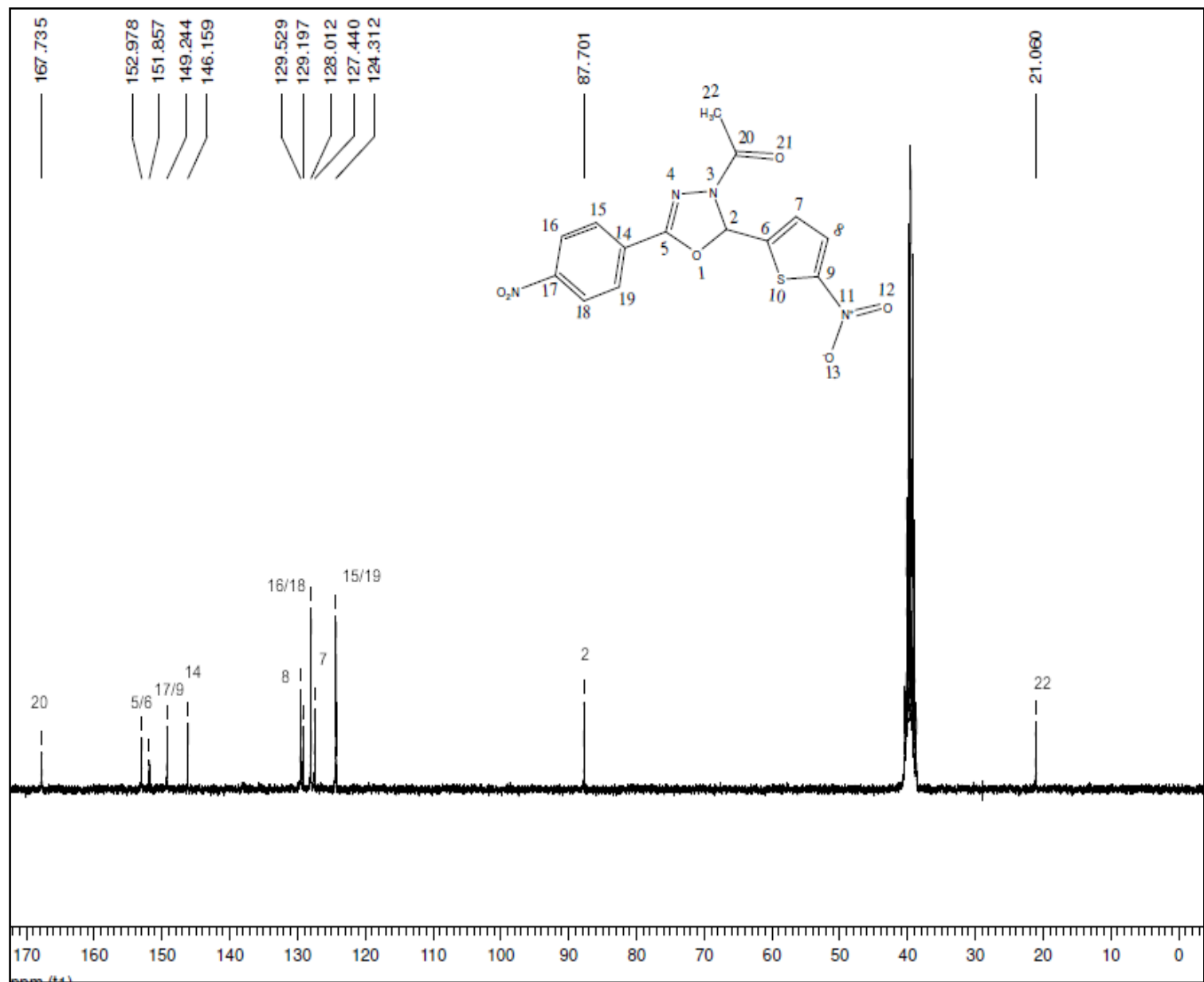

Figura 25. Espectro de RMN ${ }^{13} \mathrm{C}$ do composto 2-[5-nitro-tiofiliden-2-il]-3-acetil-5-[4-nitrofenil]-2,3-diidro-1,3,4-oxadiazolinas.

Nas tabelas 12 e 13 apresentam-se os dados referentes aos sinais obtidos da espectrometria de $\mathrm{RMN}{ }^{1} \mathrm{H}$ e $\mathrm{RMN}{ }^{13} \mathrm{C}$, sendo que os espectros de cada composto são apresentados no anexo 2 deste trabalho. A análise elementar (tabela 14) indica baixa variação das porcentagens obtidas experimentalmente em relação às calculadas, comprovando assim grau de pureza satisfatório. 
Tabela 12. Principais sinais de $\mathrm{RMN}{ }^{1} \mathrm{H}$ (ppm) em DMSO d6 de derivados tiofilidênicos oxadiazolínicos 4-R-substituídas (série B).

\begin{tabular}{|c|c|c|c|c|c|c|}
\hline & & & $R^{17} \|_{18}^{5}$ & $\underbrace{-6}_{10} \overbrace{-O_{13}^{\prime}=}^{8}=$ & & \\
\hline $\mathbf{R}$ & $\mathrm{CH}_{3-22}$ & $\mathrm{H}_{2}$ & $\mathrm{H}_{7}$ & $\mathbf{H}_{8}$ & $\mathrm{H}_{15} / \mathrm{H}_{19}$ & $\mathrm{H}_{16} / \mathrm{H}_{18}$ \\
\hline $\mathbf{H}$ & $2,30(s)$ & $7,57(\mathrm{~m})$ & $7,47(\mathrm{~d}) \mathrm{J}=4,2$ & $8,08(d) J=4,2$ & $7,55(\mathrm{~m})$ & $7,86(d) J=8,4$ \\
\hline $\mathrm{n}-\mathrm{C}_{4} \mathrm{H}_{9}{ }^{\mathrm{c}}$ & ---- & ---- & ---- & ----- & ---- & ------ \\
\hline $\mathrm{Cl}$ & $2,29(s)$ & $7,57(\mathrm{~s})$ & $7,47(d) J=4,2$ & $8,08(d) J=4,2$ & $7,88(d d) J=8,6$ & $7,61(d) J=8,7$ \\
\hline $\mathrm{CN}$ & $2,31(s)$ & $7,61(\mathrm{~s})$ & $7,49(d) J=4,2$ & $8,08(\mathrm{~d}) J=4,2$ & $8,02(s)$ & $8,02(s)$ \\
\hline $\mathrm{OCH}_{3}$ & $2,27(\mathrm{~s})$ & $7,55(\mathrm{~s})$ & $7,44(d) J=4,2$ & $8,05(d) J=4,2$ & $7,88(d) J=8,8$ & $7,11(d) J=8,8$ \\
\hline $\mathrm{COCH}_{3}{ }^{\mathrm{c}}$ & ---- & ---- & ------ & ------ & ------ & ------- \\
\hline t- $\mathrm{C}_{4} \mathrm{H}_{9}{ }^{\mathrm{c}}$ & ---- & ---- & ----- & ----- & ------- & ------- \\
\hline $\mathrm{NO}_{2}$ & 2,33(s) & $7,45(\mathrm{~s})$ & $7,27(\mathrm{~d}) \mathrm{J}=3,8$ & $7,71(\mathrm{~d}) \mathrm{J}=3,8$ & $8,38(d) J=8,9$ & $8,94(d) J=8,9$ \\
\hline $\mathbf{I}$ & $2,27(\mathrm{~s})$ & $7,56(\mathrm{~s})$ & $7,46(d) J=4,2$ & $8,07(d) J=4,2$ & $7,62(\mathrm{~d}) J=8,1$ & $7,95(d) J=8,1$ \\
\hline $\mathrm{CF}_{3}$ & 2,32(s) & $7,62(\mathrm{~s})$ & $7,52(d) J=4,2$ & 8,07 (d) $J=4,2$ & $7,94(d) J=8,5$ & 8,07 (d) $J=7,8$ \\
\hline $\mathrm{OC}_{4} \mathrm{H}_{9}$ & $2,27(s)$ & $7,53(\mathrm{~s})$ & $7,45(\mathrm{~d}) \mathrm{J}=4,2$ & $8,07(d) J=4,2$ & $7,80(d) J=8,8$ & 7,10 (d) $J=8,8$ \\
\hline $\mathrm{C}_{2} \mathrm{H}_{5}$ & $2,29(s)$ & $7,55(\mathrm{~s})$ & $7,46(d) J=4,2$ & $8,07(d) J=4,2$ & $7,80(d) J=8,2$ & $7,41(d) J=8,2$ \\
\hline
\end{tabular}

c: Derivados não determinados 
Tabela 13. Principais sinais de $\mathrm{RMN}{ }^{13} \mathrm{C}$ (ppm) em DMSO $\mathrm{d}_{6}$ de derivados tiofilidênicos oxadiazolínicos 4R-substituídas (série B).

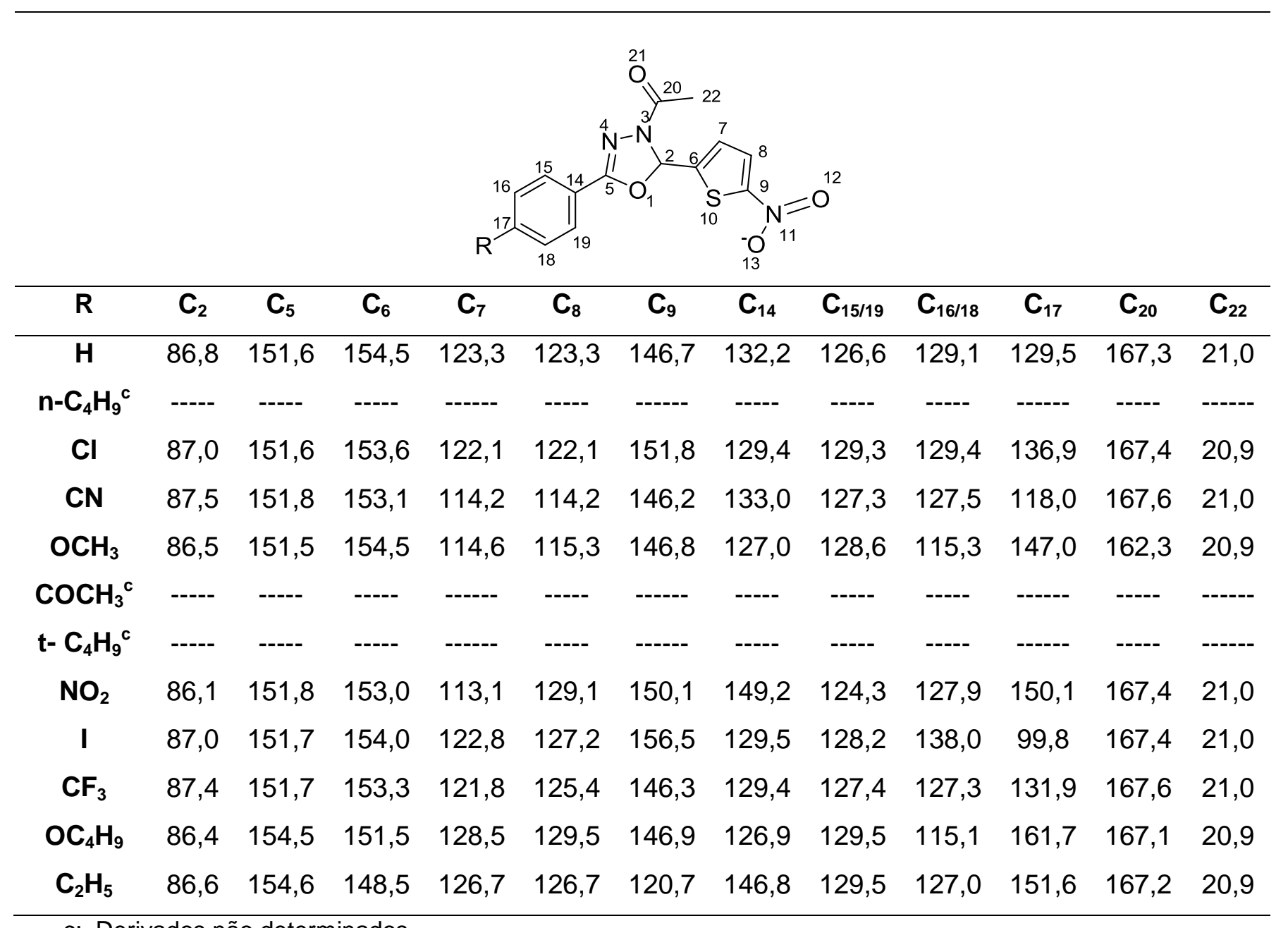


Tabela 14. Análise elementar dos derivados tiofilidênicos oxadiazolínicos 4-R-substituídas (série B).

\begin{tabular}{|c|c|c|c|c|c|c|c|c|c|c|}
\hline & & & & & & $\mathrm{NC}$ & & & & \\
\hline \multirow[b]{2}{*}{$\mathrm{R}$} & \multirow{2}{*}{ MM (g) } & \multicolumn{3}{|c|}{$\% \mathrm{C}$} & \multicolumn{3}{|c|}{$\% \mathrm{H}$} & \multicolumn{3}{|c|}{$\% \mathrm{~N}$} \\
\hline & & Exp. & Cal. & $\Delta$ & Exp. & Cal. & $\Delta$ & Exp. & Cal. & $\Delta$ \\
\hline $\mathbf{H}$ & 317,32 & 53,01 & 52,99 & 0,02 & 3,53 & 3,49 & 0,04 & 13,24 & 13,24 & 0,00 \\
\hline$n-C_{4} H_{9}{ }^{c}$ & 377,11 & ---- & ---- & ---- & ---- & ---- & ---- & ---- & --- & ---- \\
\hline $\mathrm{Cl}$ & 351,76 & 47,81 & 47,80 & 0,01 & 2,88 & 2,87 & 0,01 & 12,11 & 11,95 & 0,16 \\
\hline $\mathrm{CN}$ & 342,33 & 52,45 & 52,63 & 0,18 & 2,94 & 2,94 & 0,00 & 16,22 & 16,37 & 0,15 \\
\hline $\mathrm{OCH}_{3}$ & 347,35 & 51,80 & 57,87 & 0,07 & 3,85 & 3,77 & 0,08 & 12,05 & 12,10 & 0,05 \\
\hline $\mathrm{COCH}_{3}{ }^{\mathrm{c}}$ & 359,06 & ---- & ---- & ---- & ---- & ---- & ---- & ---- & ---- & --- \\
\hline$t-C_{4} H_{9}{ }^{c}$ & 373,11 & ---- & ---- & ---- & ---- & ---- & ---- & ---- & ---- & ---- \\
\hline $\mathrm{NO}_{2}$ & 362,32 & 46,51 & 46,41 & 0,10 & 2,73 & 2,78 & 0,05 & 15,43 & 15,46 & 0,03 \\
\hline 1 & 442,94 & 37,98 & 37,94 & 0,04 & 2,19 & 2,27 & 0,08 & 9,47 & 9,48 & 0,01 \\
\hline $\mathrm{CF}_{3}$ & 385,32 & 46,83 & 46,76 & 0,13 & 2,59 & 2,62 & 0,03 & 10,95 & 10,91 & 0,04 \\
\hline $\mathrm{OC}_{4} \mathrm{H}_{9}$ & 389,43 & 56,07 & 55,52 & 0,55 & 4,80 & 4,92 & 0,013 & 11,09 & 10,79 & 0,30 \\
\hline $\mathrm{C}_{2} \mathrm{H}_{5}$ & 345,08 & 55,74 & 55,64 & 0,09 & 4,45 & 4,38 & 0,07 & 12,10 & 12,17 & 0,08 \\
\hline
\end{tabular}




\subsubsection{Dificuldades sintéticas}

Dentre os vinte e quatro compostos planejados e propostos, três (figura 26) deles demonstraram que não foi possível a obtenção pelas rotas sintéticas propostas no trabalho.

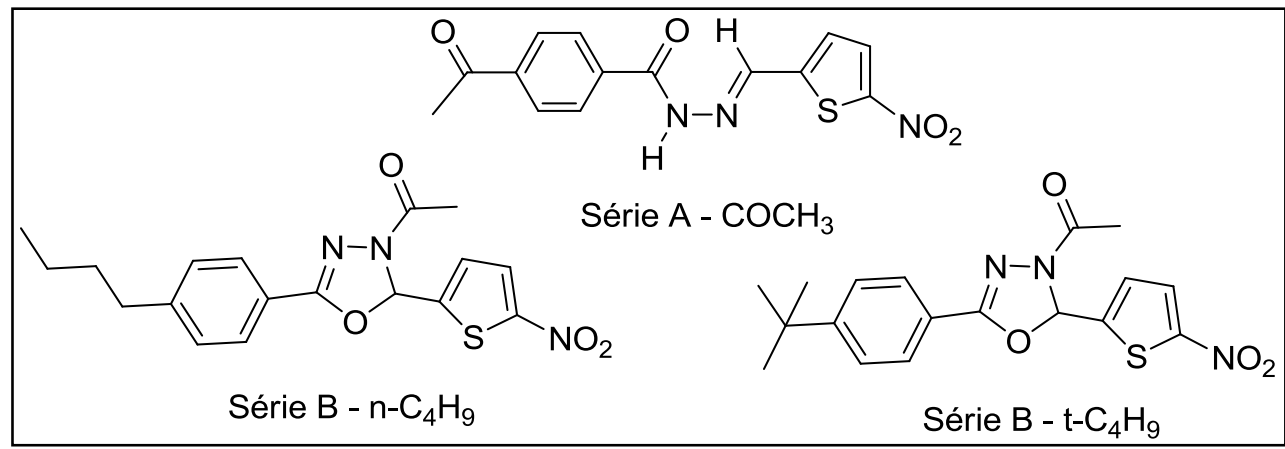

Figura 26. Derivados não obtidos pela via sintética proposta.

Primeiramente foi observada a dificuldade sintética no derivado série $\mathrm{A}-\mathrm{COCH}_{3}$. Este derivado apresentou em seu espectro de $\mathrm{RMN}{ }^{1} \mathrm{H}$, destacado na figura 27, diversos sinais que não são característicos de sua estrutura planejada, demonstrando estar impuro. Mesmo contendo impurezas, sua formação é evidenciada com os sinais em 2,64 ppm apresentando um singleto característico de metila ligada à carbonila, referente ao grupo acetil situado na posição para do anel benzênico, o sinal de deslocamento do hidrogênio da hidrazina é observado em 12,3ppm e também do hidrogênio do carbono da dupla ligação em 8,94 ppm, ambos na forma de um singleto.

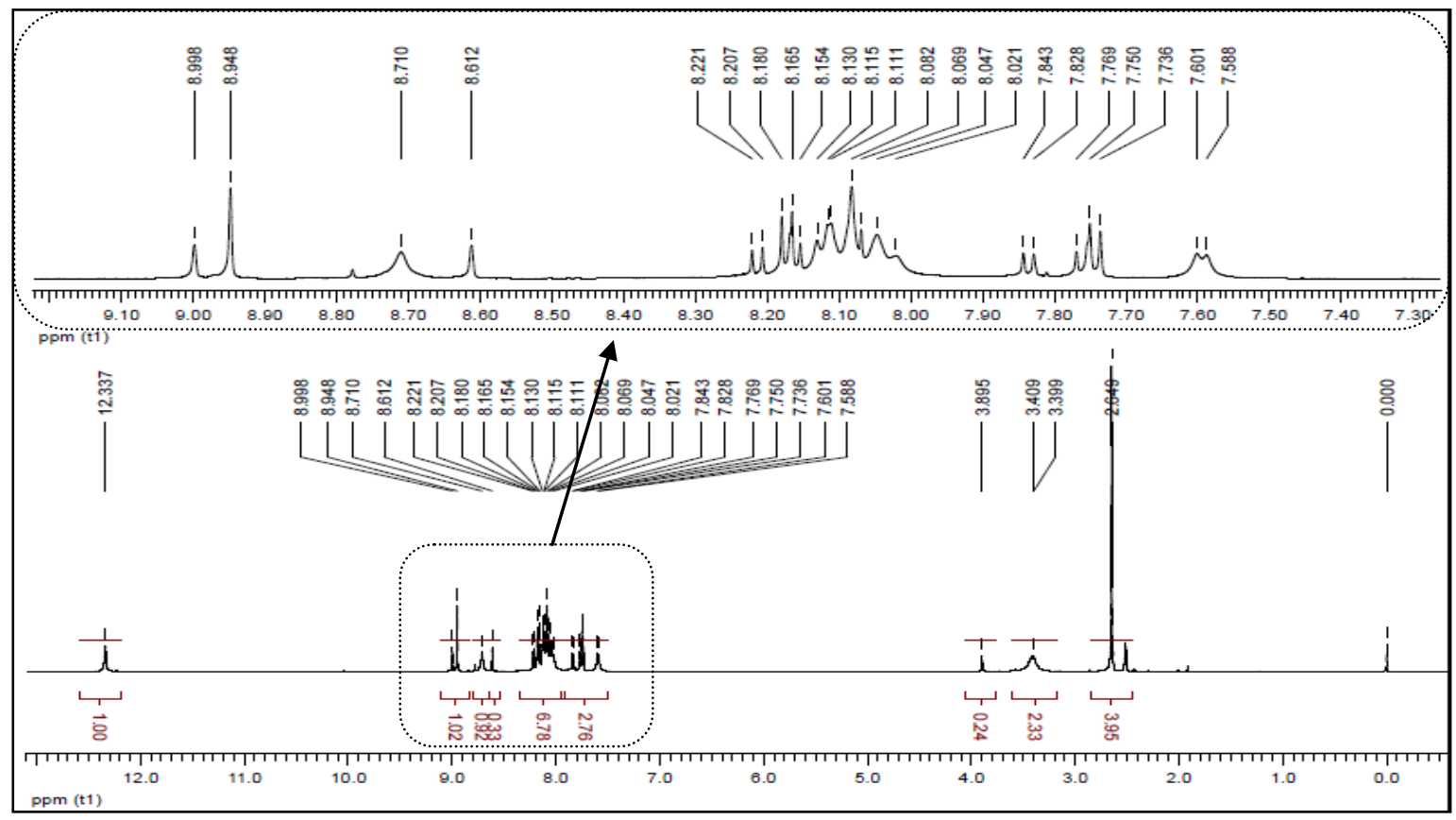

Figura 27. $\mathrm{RMN}{ }^{1} \mathrm{H}$ Realizado neste trabalho com o objetivo da tentativa de identificação do derivado - série $\mathrm{A}-\mathrm{COCH}_{3}$. 
Com a observação do $\mathrm{RMN}{ }^{1} \mathrm{H}$ do derivado série $\mathrm{A}-\mathrm{COCH}_{3}$ foi realizado tentativas de recristalização com diversos solventes, com o objetivo de purificar o composto de interesse. A recristalização não apresentou resultado satisfatório, assim uma cromatografia em coluna foi proposta com o objetivo de tentar isolar o derivado, pois em uma previa avaliação por cromatografia em camada delgada (CCD) observou que havia impurezas neste composto de interesse. Desta forma, procedeu-se a realização da purificação deste composto por coluna, porém quando isolado e avaliado por $\mathrm{RMN}^{1} \mathrm{H}$, não se observou a presença do sinal do deslocamento do hidrogênio da hidrazida e ainda observou-se sinais de impurezas, destacados na figura 28. Desta forma, até o presente momento não foi possível concluir a obtenção do composto série $\mathrm{A}-\mathrm{COCH}_{3}$. Com isto, novas tentativas sintéticas estão sendo estudadas com o objetivo de obter o composto série $\mathrm{A}-\mathrm{COCH}_{3}$.

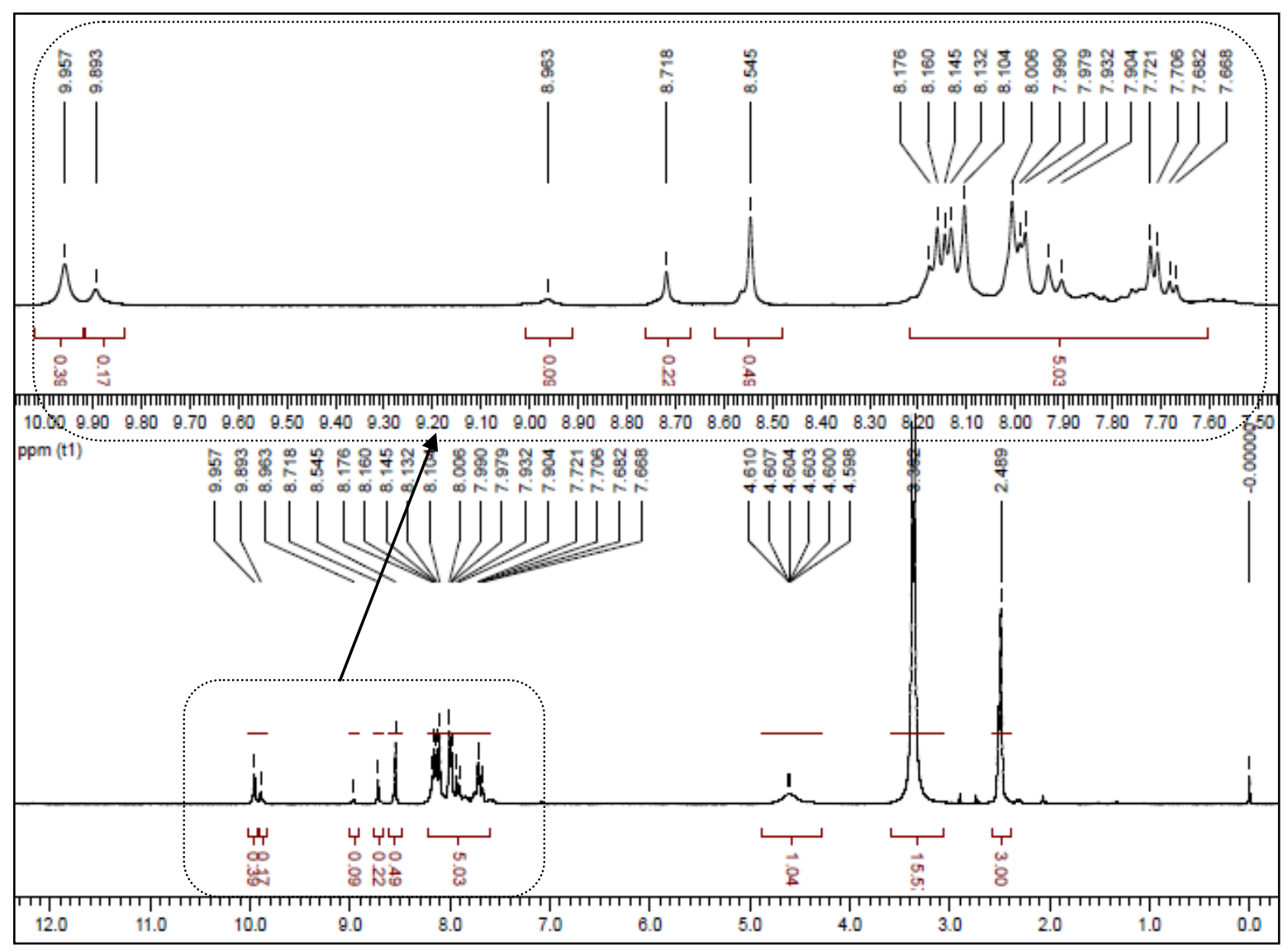

Figura 28. $\mathrm{RMN}{ }^{1} \mathrm{H}$ do derivado série $\mathrm{A}-\mathrm{COCH}_{3}$, após cromatográfica em coluna líquida.

Os outros dois derivados com dificuldades sintéticas são os, série $B-n-C_{4} \mathrm{H}_{9}$ e série $\mathrm{B}-\mathrm{t}-\mathrm{C}_{4} \mathrm{H}_{9}$. Ambos os derivados apresentam a confirmação da molécula da série $\mathrm{A}$ (Anexo 1 ), porém quando colocados em contato com anidrido acético e realizado o procedimento de síntese, com o aumento da temperatura os compostos degradam em seus respectivos ácidos benzóicos (figura 29 e 30). Esta etapa sintética foi realizada quatro vezes para a 
tentativa de obtenção do composto série $\mathrm{B}-\mathrm{n}-\mathrm{C}_{4} \mathrm{H}_{9}$ e cinco vezes para tentativa de obtenção do composto série $\mathrm{B}-\mathrm{t}-\mathrm{C}_{4} \mathrm{H}_{9}$.

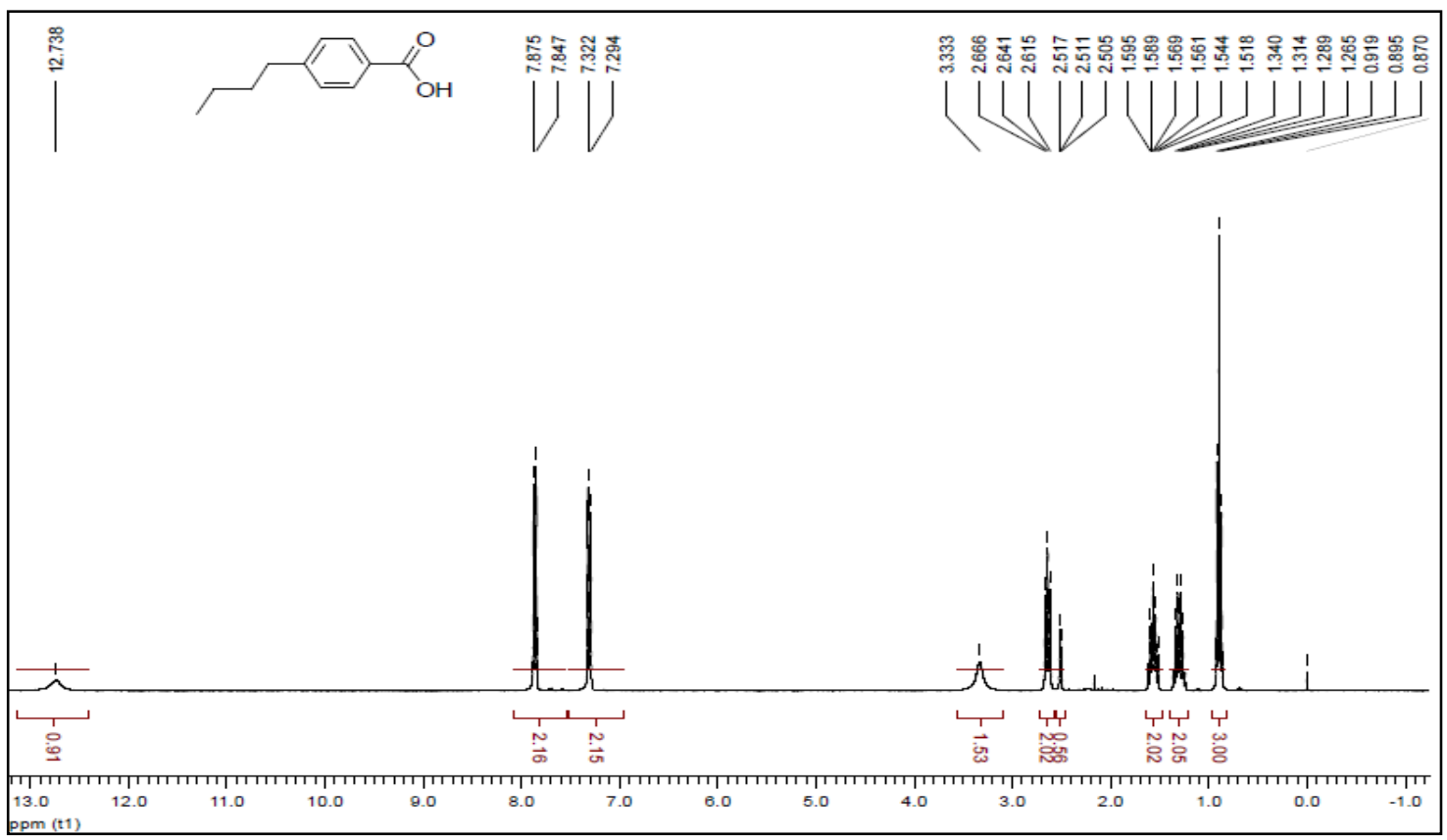

Figura 29. Confirmação do ácido 4-butilbenzoíco por $\mathrm{RMN}{ }^{1} \mathrm{H}$, após tentativa de obtenção do composto série $\mathrm{B}-\mathrm{n}-\mathrm{C}_{4} \mathrm{H}_{9}$.

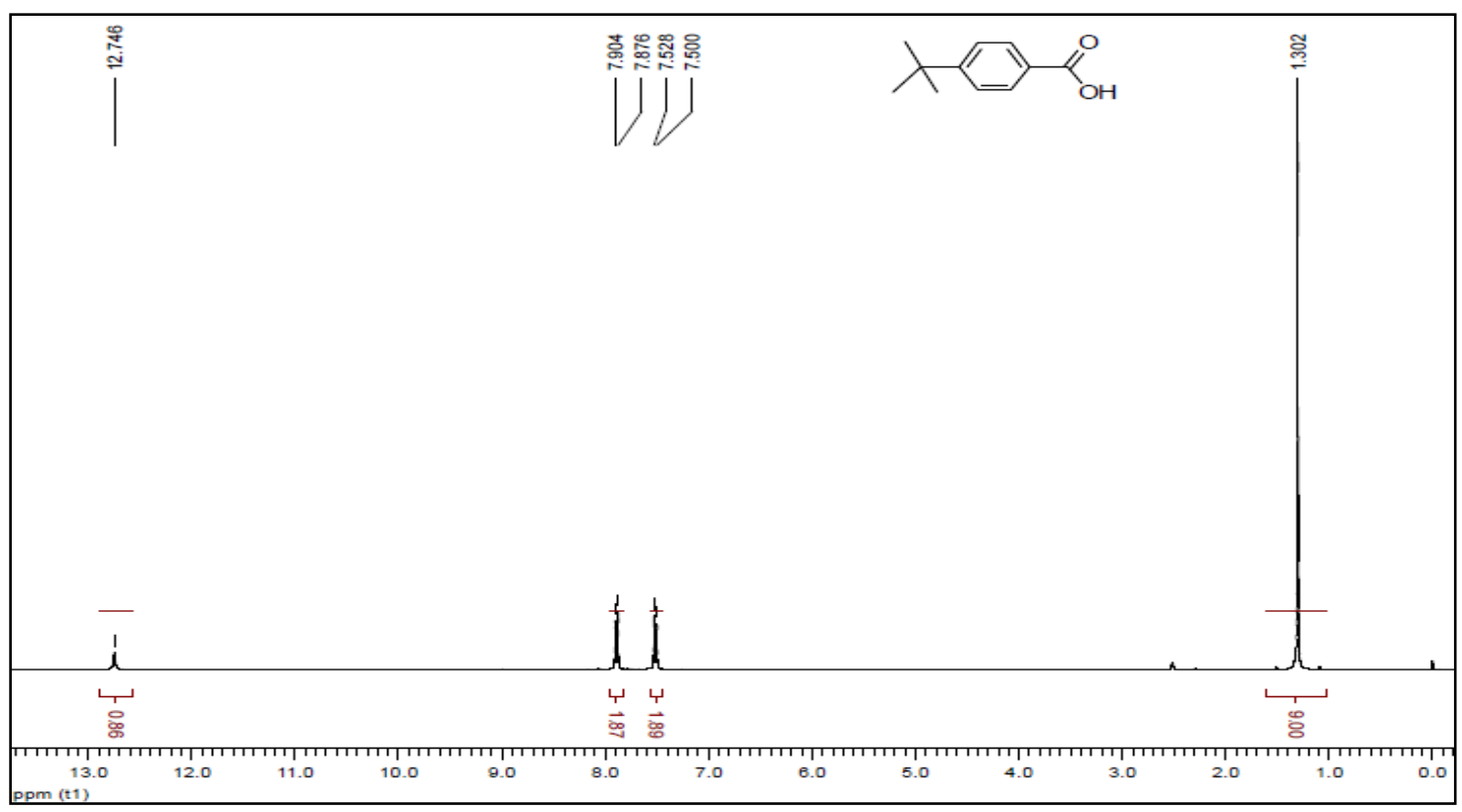

Figura 30. Confirmação do ácido 4-t-butilbenzoíco por $\mathrm{RMN}^{1} \mathrm{H}$, após tentativa de obtenção do composto série $\mathrm{B}-\mathrm{t}-\mathrm{C}_{4} \mathrm{H}_{9}$. 
Em todas as tentativas de síntese tanto do composto série $B-n-C_{4} H_{9}$ quanto do composto série $\mathrm{B}-\mathrm{t}-\mathrm{C}_{4} \mathrm{H}_{9}$, observou-se a confirmação dos seus receptivos ácidos benzóicos como destacados nas figuras 29 e 30. As temperaturas foram variadas com o objetivo de verificar se havia alguma influência na degradação dos compostos, sendo que na proposta da rota sintética, a temperatura variava de $100-120^{\circ} \mathrm{C}$. A partir da primeira síntese, onde se observou a degradação, novas sínteses foram realizadas com a diminuição da temperatura (série $\mathrm{B}-\mathrm{n}-\mathrm{C}_{4} \mathrm{H}_{9}: 100^{\circ} \mathrm{C} ; 80^{\circ} \mathrm{C} ; 70^{\circ} \mathrm{C}$; série $\mathrm{B}-\mathrm{t}-\mathrm{C}_{4} \mathrm{H}_{9}: 100^{\circ} \mathrm{C} ; 80^{\circ} \mathrm{C} ; 70^{\circ} \mathrm{C} ; 50^{\circ} \mathrm{C}$ ) e novamente não se observou a formação dos compostos de interesse.

Com as diversas tentativas de síntese do composto série $\mathrm{B}-\mathrm{n}-\mathrm{C}_{4} \mathrm{H}_{9}$ e do composto série $\mathrm{B}-\mathrm{t}-\mathrm{C}_{4} \mathrm{H}_{9}$, pode-se observar que a influência do meio ácido com a quebra do anidrido acético em ácido acético, é um dos fatores limitantes na degradação destes compostos, sendo que uma nova rota sintética deverá ser proposta para estes compostos (ALMEIDA, 2008).

\subsection{Ensaios Microbiológicos}

6.2.1 Determinação da concentração inibição mínima (CIM) frente a cepas de S. aureus ATCC 29213, S. aureus VISA 3 E. coli ATCC 25922, C. albicans ATCC 573Y, E. faecalis ATCC 29212, K. pneumoniae ATCC 700603 e E. cloacae ATCC 23355 S. marcescens ATCC 14756.

Foram determinadas as concentrações inibitórias mínimas (CIM) de vinte compostos obtidos (Série A - H, OCH $, \mathrm{Cl}, \mathrm{CN}, \mathrm{NO}_{2}, \mathrm{CF}_{3}, \mathrm{I}, n-\mathrm{C}_{4} \mathrm{H}_{9}, t-\mathrm{C}_{4} \mathrm{H}_{9}, \mathrm{OC}_{4} \mathrm{H}_{9}, \mathrm{C}_{2} \mathrm{H}_{5}$; Série $\mathrm{B}-\mathrm{H}, \mathrm{Cl}, \mathrm{CN}, \mathrm{NO}_{2}, \mathrm{CF}_{3}, \mathrm{OCH}_{3}, \mathrm{I}, \mathrm{OC}_{4} \mathrm{H}_{9}, \mathrm{C}_{2} \mathrm{H}_{5}$ ) frente a cepas de S.aureus ATCC 29213, S. aureus VISA 3 E.coli ATCC 25922, C. albicans ATCC 573Y, E. faecalis ATCC 29212, K.pneumoniae ATCC 700603 e E.cloacae ATCC 23355, S. marcescens ATCC 14756, seguindo a metodologia descrita nos itens 5.3, deste trabalho. Destacando que todos os fatores que poderiam intervir no resultado do ensaio, como a natureza do microorganismo que foi testado, a concentração do inóculo, tempo de incubação, meios de cultura utilizados no ensaio, condições ambientais e armazenamento das cepas, foram padronizados com objetivo de garantir a confiabilidade dos resultados. Também destaca-se que os compostos mostraram-se solúveis nas condições especificadas de diluição como descrito no item 5.3.3.

A técnica de microdiluição empregada na realização dos ensaios microbiológicos foi padronizada com finalidade de possibilitar a comparação dos valores de atividade obtidos frente às cepas em questão. Esta metodologia mostra-se altamente viável, pois permite quantificar pequenas variações de atividade antimicrobiana dos compostos testados, comparando este método com a metodologia empregada em estudos anteriores, que 
utilizava a macrodiluição em tubos de ensaio. Observa-se que a técnica de microdiluição economiza tempo e material, além de apresentar maior sensibilidade em determinar o valor de CIM e possibilitar a utilização da leitora de microplaca, que auxilia na obtenção de dados, tornando este método exato e facilmente reprodutível, minimizando erros experimentais que ocorrem por leitura visual e aumentando a confiabilidade dos resultados.

As faixas de CIM obtidas na fase I foram estreitadas com a realização da fase II, com o objetivo de tornar mais precisa a determinação da CIM. Cabe destacar, também que as duas fases realizadas foram feitas variando instrumentos e analistas com o objetivo de validar a metodologia, e também auxiliar na determinação da porcentagem $I_{90}$ (concentração de composto suficiente para inibir $90 \%$ da população microbiana).

Apresenta-se nas tabelas de 15 a 22 as faixas de CIM da série A (derivados tiofilidênicos azometínicos) e série $B$ (derivados tiofilidênicos oxadiazolínicos) frente às cepas de S. aureus ATCC 29213, S. aureus VISA 3, E. coli ATCC 25922, C. albicans ATCC 573Y E. faecalis ATCC 29212, K.pneumoniae ATCC 700603, E. cloacae ATCC 23355 e S. marcescens ATCC 14756. 
Tabela 15. Concentração inibitória mínima, CIM ( $\mu \mathrm{M}$ e $\mu \mathrm{g} / \mathrm{ml})$, de 5-nitro-2-tiofilideno benzidrazidas 4-R-substituídas (Série A) e dos derivados tiofilidênicos oxadiazolínicos 4-Rsubstituídas (Série B) frente à cepa de S. aureus ATCC 29213.

\begin{tabular}{|c|c|c|c|c|c|c|c|}
\hline & $\mathrm{H}$ & & & & $\begin{array}{c}y \\
-N\end{array}$ & $\mathrm{NO}_{2}$ & \\
\hline Série - A & MM (g) & $\mu M$ & $\mu \mathrm{g} / \mathrm{ml}$ & Série - B & MM (g) & $\mu M$ & $\mu \mathrm{g} / \mathrm{ml}$ \\
\hline $\mathbf{H}$ & 275,28 & $7,26-3,63$ & $2,0-1,0$ & $\mathbf{H}$ & 317,32 & $6,30-3,15$ & $2,0-1,0$ \\
\hline$n-C_{4} H_{9}$ & 331,29 & $6,03-3,01$ & $2,0-1,0$ & $\mathrm{Cl}$ & 351,76 & $5,68-2,84$ & $2,0-1,0$ \\
\hline $\mathrm{Cl}$ & 309,73 & $6,45-3,22$ & $2,0-1,0$ & $\mathrm{CN}$ & 342,33 & $5,25-2,62$ & $1,80-0,9$ \\
\hline CN & 300,29 & $3,33-1,66$ & $1,0-0,5$ & $\mathrm{OCH}_{3}$ & 347,35 & $7,20-3,60$ & $2,5-1,25$ \\
\hline $\mathrm{OCH}_{3}$ & 305,31 & $3,27-2,06$ & $1,0-0,63$ & $\mathrm{NO}_{2}$ & 362,32 & $5,51-2,75$ & $2,0-1,0$ \\
\hline$t-C_{4} H_{9}$ & 331,39 & $>96,56$ & $>32$ & I & 442,94 & $6,77-3,38$ & $3,0-1,5$ \\
\hline $\mathrm{NO}_{2}$ & 320,28 & $12,07-6,03$ & $4,0-2,0$ & $\mathrm{CF}_{3}$ & 385,32 & $7,79-3,89$ & $3,0-1,5$ \\
\hline I & 401,18 & $>79,76$ & $>32$ & $\mathrm{OC}_{4} \mathrm{H}_{9}$ & 389,43 & $10,2-5,1$ & $4,0-2,0$ \\
\hline $\mathrm{CF}_{3}$ & 343,28 & $5,82-2,91$ & $2,0-1,0$ & $\mathrm{C}_{2} \mathrm{H}_{5}$ & 345,08 & $4,34-2,17$ & $1,5-0,75$ \\
\hline $\mathrm{OC}_{4} \mathrm{H}_{9}$ & 347,39 & $92,20-45,10$ & $32-16$ & Cloranfenicol & 323,13 & $6,18-3,09$ & $2,0-1,0$ \\
\hline $\mathrm{C}_{2} \mathrm{H}_{5}$ & 303,34 & $26,37-13,18$ & $8,0-4,0$ & Vancomicina & $1.449,3$ & $1,38-0,69$ & $2,0-1,0$ \\
\hline
\end{tabular}


Tabela 16. Concentração inibitória mínima, CIM $(\mu \mathrm{M}$ e $\mu \mathrm{g} / \mathrm{ml})$, de 5-nitro-2-tiofilideno benzidrazidas 4-R-substituídas (Série A) e dos derivados tiofilidênicos oxadiazolínicos 4-R-substituídas (Série B) frente à cepa de $S$. aureus VISA 3.

\begin{tabular}{cccc|cccc}
\hline & & & & \\
\end{tabular}


Tabela 17. Concentração inibitória mínima, CIM ( $\mu \mathrm{M}$ e $\mu \mathrm{g} / \mathrm{ml})$, de 5-nitro-2-tiofilideno benzidrazidas 4-R-substituídas (Série A) e dos derivados tiofilidênicos oxadiazolínicos 4-R-substituídas (Série B) frente à cepa de $C$. albicans ATCC 573Y.

\begin{tabular}{cccc|cccc}
\hline & & & & & & \\
\hline
\end{tabular}


Tabela 18. Concentração inibitória mínima, CIM ( $\mu \mathrm{M}$ e $\mu \mathrm{g} / \mathrm{ml})$, de 5-nitro-2-tiofilideno benzidrazidas 4-R-substituídas (Série A) e dos derivados tiofilidênicos oxadiazolínicos 4-R-substituídas (Série B) frente à cepa de E. faecalis ATCC 29212.

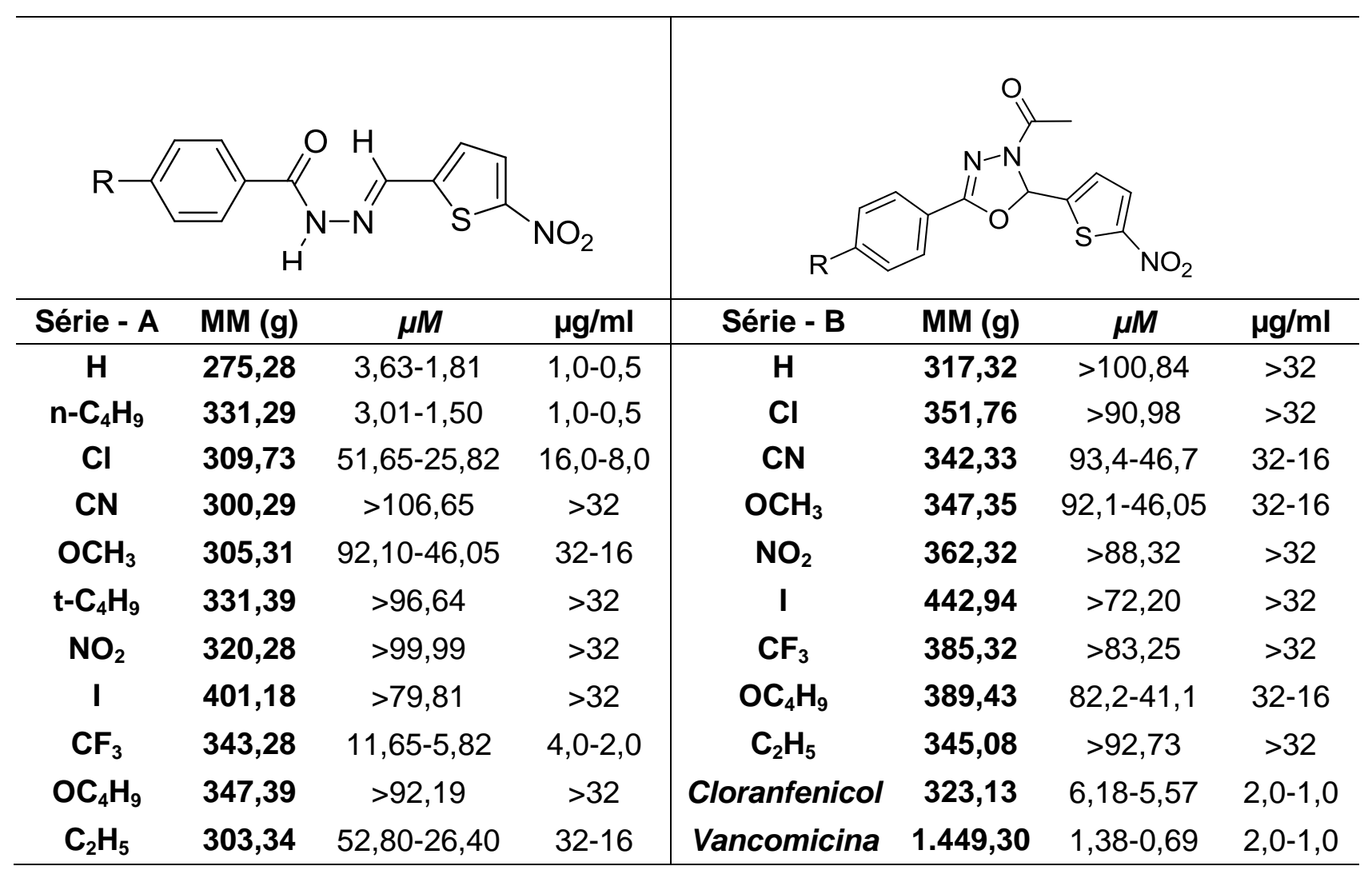


Tabela 19. Concentração inibitória mínima, CIM $(\mu \mathrm{M}$ e $\mu \mathrm{g} / \mathrm{ml})$, de 5-nitro-2-tiofilideno benzidrazidas 4-R-substituídas (Série A) e dos derivados tiofilidênicos oxadiazolínicos 4-Rsubstituídas (Série B) frente à cepa de K. pneumoniae ATCC 700603.

\begin{tabular}{|c|c|c|c|c|c|c|c|}
\hline Série - A & MM (g) & $\mu M$ & $\mu \mathrm{g} / \mathrm{ml}$ & Série - B & MM (g) & $\mu M$ & $\mu \mathrm{g} / \mathrm{ml}$ \\
\hline $\mathbf{H}$ & 275,28 & $>116,25$ & $>32$ & $\mathrm{H}$ & 317,32 & $>100,84$ & $>32$ \\
\hline$n-C_{4} H_{9}$ & 331,29 & $>96,592$ & $>32$ & $\mathrm{Cl}$ & 351,76 & $>90,971$ & $>32$ \\
\hline $\mathrm{Cl}$ & 309,73 & $>103,32$ & $>32$ & $\mathrm{CN}$ & 342,33 & $93,4-46,7$ & $32-16$ \\
\hline CN & 300,29 & $>106,56$ & $>32$ & $\mathrm{OCH}_{3}$ & 347,35 & $>92,126$ & $>32$ \\
\hline $\mathrm{OCH}_{3}$ & 305,31 & $>104,81$ & $>32$ & $\mathrm{NO}_{2}$ & 362,32 & $>88,32$ & $>32$ \\
\hline $\mathrm{t}-\mathrm{C}_{4} \mathrm{H}_{9}$ & 331,39 & $>96,563$ & $>32$ & I & 442,94 & $>72,20$ & $>32$ \\
\hline $\mathrm{NO}_{2}$ & 320,28 & $>99,913$ & $>32$ & $\mathrm{CF}_{3}$ & 385,32 & $>83,05$ & $>32$ \\
\hline I & 401,18 & $>79,765$ & $>32$ & $\mathrm{OC}_{4} \mathrm{H}_{9}$ & 389,43 & $>82,24$ & $>32$ \\
\hline $\mathrm{CF}_{3}$ & 343,28 & $>93,218$ & $>32$ & $\mathrm{C}_{2} \mathrm{H}_{5}$ & 345,08 & $>92,73$ & $>32$ \\
\hline $\mathrm{OC}_{4} \mathrm{H}_{9}$ & 347,39 & $>92,195$ & $>32$ & Levofloxacino & 361,36 & $<1,38$ & $<0,5$ \\
\hline $\mathrm{C}_{2} \mathrm{H}_{5}$ & 303,34 & $>105,59$ & $>32$ & Cloranfenicol & 323,13 & $99-49$ & $32-16$ \\
\hline
\end{tabular}


Tabela 20. Concentração inibitória mínima, CIM $(\mu \mathrm{M}$ e $\mu \mathrm{g} / \mathrm{ml})$, de 5-nitro-2-tiofilideno benzidrazidas 4-R-substituídas (Série A) e dos derivados tiofilidênicos oxadiazolínicos 4-Rsubstituídas (Série B) frente à cepa de E. cloacae ATCC 23355.

\begin{tabular}{cccc|cccc}
\hline & & & & & \\
\end{tabular}


Tabela 21. Concentração inibitória mínima, CIM $(\mu \mathrm{M}$ e $\mu \mathrm{g} / \mathrm{ml})$, de 5-nitro-2-tiofilideno benzidrazidas 4-R-substituídas (Série A) e dos derivados tiofilidênicos oxadiazolínicos 4-R-substituídas (Série B) frente à cepa de E. coli ATCC 25922.

\begin{tabular}{cccc|cccc}
\hline & & & & \\
\end{tabular}


Tabela 22. Concentração inibitória mínima, CIM $(\mu \mathrm{M}$ e $\mu \mathrm{g} / \mathrm{ml})$, de 5-nitro-2-tiofilideno benzidrazidas 4-R-substituídas (Série A) e dos derivados tiofilidênicos oxadiazolínicos 4-R-substituídas (Série B) frente à cepa de S. marcescens ATCC 14756.

\begin{tabular}{|c|c|c|c|c|c|c|c|}
\hline & $\mathrm{H}^{\prime}$ & & $\mathrm{VO}_{2}$ & & & $\mathrm{NO}_{2}$ & \\
\hline Série - A & MM (g) & $\mu M$ & $\mu \mathrm{g} / \mathrm{ml}$ & Série - B & MM (g) & $\mu M$ & $\mu \mathrm{g} / \mathrm{ml}$ \\
\hline $\mathbf{H}$ & 275,28 & $>116,25$ & $>32$ & $\mathbf{H}$ & 317,32 & $>100,84$ & $>32$ \\
\hline $\mathrm{n}-\mathrm{C}_{4} \mathrm{H}_{9}$ & 331,29 & $>96,59$ & $>32$ & $\mathrm{Cl}$ & 351,76 & $>90,97$ & $>32$ \\
\hline $\mathrm{Cl}$ & 309,73 & $>103,32$ & $>32$ & $\mathrm{CN}$ & 342,33 & $93,47-46,7$ & $32-16$ \\
\hline $\mathrm{CN}$ & 300,29 & $>106,56$ & $>32$ & $\mathrm{OCH}_{3}$ & 347,35 & $>46,00$ & $>32$ \\
\hline $\mathrm{OCH}_{3}$ & 305,31 & $>104,81$ & $>32$ & $\mathrm{NO}_{2}$ & 362,32 & $>88,32$ & $>32$ \\
\hline $\mathrm{t}-\mathrm{C}_{4} \mathrm{H}_{9}$ & 331,39 & $>96,56$ & $>32$ & I & 442,94 & $>72,20$ & $>32$ \\
\hline $\mathrm{NO}_{2}$ & 320,28 & $>99,91$ & $>32$ & $\mathrm{CF}_{3}$ & 385,32 & $>83,05$ & $>32$ \\
\hline $\mathbf{I}$ & 401,18 & $>79,76$ & $>32$ & $\mathrm{OC}_{4} \mathrm{H}_{9}$ & 389,43 & $>82,24$ & $>32$ \\
\hline $\mathrm{CF}_{3}$ & 343,28 & $>93,21$ & $>32$ & $\mathrm{C}_{2} \mathrm{H}_{5}$ & 345,08 & $>92,73$ & $>32$ \\
\hline $\mathrm{OC}_{4} \mathrm{H}_{9}$ & 347,39 & $>92,19$ & $>32$ & Ampicilina & 349,41 & $91,6-45,8$ & $32-16$ \\
\hline $\mathrm{C}_{2} \mathrm{H}_{5}$ & 303,34 & $>105,59$ & $>32$ & Cloranfenicol & 323,13 & $12,30-6,20$ & $4,0-2,0$ \\
\hline
\end{tabular}


Entre os compostos sintetizados e testados frente à cepa ATCC 29213 de $S$. aureus, destaca-se os compostos da série A, 5-nitro-2-tiofilideno 4-cianobenzidrazida (série A-CN) e 5-nitro-2-tiofilideno 4-metoxibenzidrazida (série $\mathbf{A}-\mathbf{O C H}_{3}$ ) como os mais ativos ( $\mathrm{CIM}$ $=3,33 \mu M ; 3,27 \mu M)$, até mesmo em comparação aos fármacos, vancomicina e cloranfenicol, utilizados como referência para o teste de sensibilidade. Enquanto que os compostos 5-nitro-2-tiofilideno 4-terc-butilbenzidrazida (série $\mathrm{A}-\mathbf{t}-\mathbf{C}_{4} \mathbf{H}_{9}$ ), 5-nitro-2-tiofilideno 4-iodobenzidrazida (série $A-I$ ) e 5-nitro-2-tiofilideno 4-butoxibenzidrazida (série $A-\mathbf{O C}_{4} \mathbf{H}_{9}$ ) apresentaram a menor atividade ( $\mathrm{CIM}=\geq 90,0 \mu \mathrm{M}$ para os três derivados). Referente a cepa VISA 3 de $S$. aureus observa-se uma certa coerência de resultados em comparação a cepa ATCC 29213, onde poucos compostos variaram para a série A em questão.

Alguns compostos da série $A$ também apresentaram atividade promissora frente à bactéria E. faecalis ATCC 29212, onde observa-se que os compostos 5-nitro-2-tiofilideno 4benzidrazida (série A-H) e 5-nitro-2-tiofilideno 4-butilbenzidrazida (série A-n- $\mathbf{C}_{4} \mathbf{H}_{9}$ ) apresentaram excelente atividade antimicrobiana ( $\mathrm{CIM}=3,63 \mu \mathrm{M} ; 3,01 \mu \mathrm{M})$.

Frente à cepa Candida albicans ATCC 573Y, observou-se que os derivados da série A não apresentaram atividade biológica considerável de avaliação promissora para possíveis fármacos no combate a fungos ( $\mathrm{CIM}=\geq 26,0 \mu \mathrm{M}$ para todos os derivados).

Referente às cepas de bactérias Gram negativas (E. coli ATCC 25922, S. marcescens ATCC 14756, E.cloacae ATCC 23355 e K.pneumoniae ATCC 700603) constatou-se que dentre os compostos da série $A$, nenhum derivado apresentou atividade biológica considerável.

No caso da série $B$, observa-se que os compostos de maior atividade frente à cepa ATCC 29213 de $S$. aureus foram os 2-[5-nitro-tiofiliden-2-il]-3-acetil-5-[4-ciano-fenil]-2,3diidro-1,3,4-oxadiazolinas (série B-CN) e o 2-[5-nitro-tiofiliden-2-il]-3-acetil-5-[4-etil-fenil]-2,3diidro-1,3,4-oxadiazolinas (série $\left.\mathrm{B}_{-} \mathrm{C}_{2} \mathrm{H}_{5}\right)(\mathrm{CIM}=5,25 ; 4,34 \mu \mathrm{M})$. Enquanto que os compostos de menor atividade foram o 2-[5-nitro-tiofiliden-2-il]-3-acetil-5-[4-butoxi-fenil]-2,3diidro-1,3,4-oxadiazolinas (série $\quad \mathrm{B}_{-}-\mathrm{OC}_{4} \mathrm{H}_{9}$ ) e 0 2-[5-nitro-tiofiliden-2-il]-3-acetil-5-[4trifluormetil-fenil]-2,3-diidro-1,3,4-oxadiazolinas (série ${\left.\mathrm{B}-\mathrm{CF}_{3}\right)}_{\text {) }}(\mathrm{CIM}=10,2 \mu M ; 7,79 \mu M)$. Referente a cepa VISA3 observa-se a mesma tendência de atividade biológica, com algumas exceções como no caso do derivado 2-[5-nitro-tiofiliden-2-il]-3-acetil-5-[4-nitro-fenil]2,3-diidro-1,3,4-oxadiazolinas (série $\mathrm{B}-\mathrm{NO}_{2}$ ) que apresentou melhor atividade antimicrobiana frente a esta cepa $(\mathrm{CIM}=3,66 \mu M)$.

Levando em consideração a série B frente à cepa C. albicans ATCC 573Y, observou-se excelente atividade antimicrobiana do derivado 2-[5-nitro-tiofiliden-2-il]-3-acetil5-[4-ciano-fenil]-2,3-diidro-1,3,4-oxadiazolinas (série B-CN) apresentando CIM = 5,84 $\mu \mathrm{M}$ e 
o derivado de menor atividade foi o 2-[5-nitro-tiofiliden-2-il]-3-acetil-5-[4-butoxi-fenil]-2,3diidro-1,3,4-oxadiazolinas (série $\mathrm{B}-\mathrm{OC}_{4} \mathrm{H}_{9}$ ) apresentando $\mathrm{CIM}=41,0 \mu \mathrm{M}$.

Referente às cepas de bactérias Gram negativas (E. coli ATCC 25922, S. marcescens ATCC 14756, E.cloacae ATCC 23355 e K.pneumoniae ATCC 700603) constatou-se que dentre os compostos da série $B$, nenhum derivado apresentou atividade biológica considerável. Também observa-se que a série $B$ não apresentou atividade biológica promissora frente a bacteria $E$. faecalis.

Estudos anteriores de nosso grupo de pesquisa avaliaram os compostos da série $A$ frente a outras cepas de $S$. aureus (ATCC 25923 e resistente à meticilina - MRSA) e alguns compostos da série B já foram avaliados frente às cepas de Candida albicans ATCC 573Y, e frente à cepa de $S$. aureus com resistência intermediária a vancomicina - VISA3. Levando em consideração estas avaliações anteriores, podemos fazer comparações de atividade biológica dos derivados frente aos micro-organismos anteriormente testados (REZENDE, 2002; MASUNARI, 2005; ISHII et al, 2011; SONEHARA, 2009). A CIM da cepa de $S$. aureus ATCC 29213, utilizada neste trabalho, apresentou certa incompatibilidade em comparação à literatura, porém diversos fatores influenciaram na diferença dos resultados, como: o meio de cultura utilizado na literatura (caldo TSB - Tryptic Soy Broth), sendo que neste trabalho foi utilizado meio caldo Mueller-Hinton padronizado pela CLSI, as leituras das microplacas que foram realizadas com o auxílio de um leitor de microplaca; além de diferenças no tempo de incubação, quantidade de inóculo e características morfológicas dos micro-organismos testados.

A mudança dos fatores citados interferiu na análise de alguns compostos testados no presente estudo, observando uma grande variação entre alguns derivados, como por exemplo, o derivado série $\mathrm{A}-\mathbf{n}-\mathbf{C}_{4} \mathbf{H}_{\mathbf{9}}$, que apresentou boa atividade biológica experimental $(\mathrm{CIM}=6,03 \mu M)$ frente a cepa de $S$. aureus ATCC 29213, mas não apresentou atividade biológica frente às cepas de $S$. aureus ATCC 25923 e $S$. aureus-MRSA realizado por Masunari 2005 ( $\mathrm{CIM}=37,12 \mu \mathrm{M} ; 76,67 \mu \mathrm{M})$. Acredita-se que isto esteja relacionado à precipitação do composto junto no de cultura TSB utilizado nos estudos da literatura, este fato ainda esta sendo avaliado com o objetivo de compreender qual a relação do composto com o meio de cultura TSB (REZENDE, 2002; MASUNARI, 2005).

Referente à série $\mathrm{B}$, observou-se nos resultados experimentais pouca variação quando comparados à literatura, isto pelo fato da avaliação da literatura ter sido realizada nos mesmos moldes da avaliação experimental, porém a única diferença frente avaliação antimicrobiana dos derivados série $B$ frente às cepas de $S$. aureus - MRSA e $S$. aureus VISA3 foi o meio de cultura TSB e as leituras realizadas visualmente, diferentemente do 
realizado experimentalmente neste trabalho. Observa-se que o derivado série B-CN apresentou no estudo da literatura ( $S$. aureus - MRSA e S. aureus - VISA3; CIM = 3,65 $\mu M$ para ambas as cepas) atividade biológica compatível com os estudos experimentais frente a cepa S. aureus ATCC 29213 ( CIM = 5,25 $\mu M)$ e VISA 3 (CIM = 6,57 $\mu M)$ (ISHII et al, 2011). Levando em consideração a cepa $C$. albicans ATCC 573Y, em comparação aos estudos do grupo de pesquisa, também se observou pouca variação frente aos derivados série $B$, porém a única diferença frente avaliação antimicrobiana da cepa de C.albicans, realizada experimentalmente, foi a sua leitura realizada por leitor de microplaca, e não por leitura visual como realizado na literatura (ISHII et al, 2011; SONEHARA, 2009).

\subsubsection{Determinação da concentração inibitória de $90 \%\left(\mathrm{IC}_{90}\right)$ das células bacterianas e fúngicas}

Após a coleta dos dados na leitora de microplaca, os ensaios de CIM foram tratados calculando-se o desvio padrão da triplicata para posterior utilização no cálculo da $\mathrm{IC}_{90}$ e do coeficiente de correlação $\left(r^{2}\right)$, com auxílio do programa OriginPro (versão 8.0), empregandose o modelo não-linear exponencial de dose-resposta. Destaca-se que foi determinado apenas a IC 90 dos micro-organismos S. aureus ATCC 29213, C. albicans ATCC 573Y e E. faecalis ATCC 29212, pois estes apresentaram atividade biológica considerável para análise exploratória (HCA e PCA) e modelagem molecular. Destaca-se que para a cepa de $S$. aureus VISA3 não foi realizado o mesmo procedimento pelo fato desta apresentar resultados muito próximos da cepa de $S$. aures ATCC 29213.

Com o objetivo de determinar a reprodutibilidade e a validade dos valores de $\mathrm{IC}_{90}$, subsequente à realização da $\mathrm{CIM}$ da fase $\mathrm{I}$, determinou-se os valores de $\mathrm{IC}_{90}$, e a partir dos valores obtidos, realizou-se os ensaios da fase II, que foram utilizados para comparação dos resultados. Foi observado compatibilidade entre os resultados calculados e experimentais. $O$ exemplo adotado a seguir, tabela 23 e figura 31 , ilustra a determinação da $I_{90}$.

Para a construção da curva exponencial foram atribuídos 5 ou mais pontos, sendo que curvas com 5 pontos representam a exclusão de um ponto para obter melhor ajuste da curva. Já, curvas contendo mais de seis pontos representam que, para determinar o $\mathrm{IC}_{90}$, foi necessário realizar o ensaio em concentrações maiores ou menores, dependendo da atividade encontrada para o composto ou fármaco. As porcentagens de CIM apresentadas na tabela 23, se referem aos dados calculados após as leituras de absorbância realizadas no ensaio microbiológico e obtidos empregando-se o esquema apresentado no item 5.3.5, equação 5 . 
Tabela 23. Concentração Inibitória Mínima (CIM) em diferentes concentrações do composto série $\mathrm{A}-\mathrm{NO}_{2}$, frente a $S$. aureus ATCC 29213 realizado na fase $\mathrm{I}$.

\begin{tabular}{ccc}
\hline$[\boldsymbol{\mu M}]$ & $\begin{array}{c}\boldsymbol{C I M} \\
(\mathbf{\%} / \mathbf{1 0 0})\end{array}$ & $\boldsymbol{D P}$ \\
\hline 96,59 & 0,96 & 0,00 \\
48,29 & 0,97 & 0,00 \\
24,14 & 0,99 & 0,01 \\
12,07 & 0,99 & 0,01 \\
6,03 & 0,88 & 0,01 \\
3,01 & 0,58 & 0,02 \\
1,50 & 0,33 & 0,01 \\
\hline
\end{tabular}

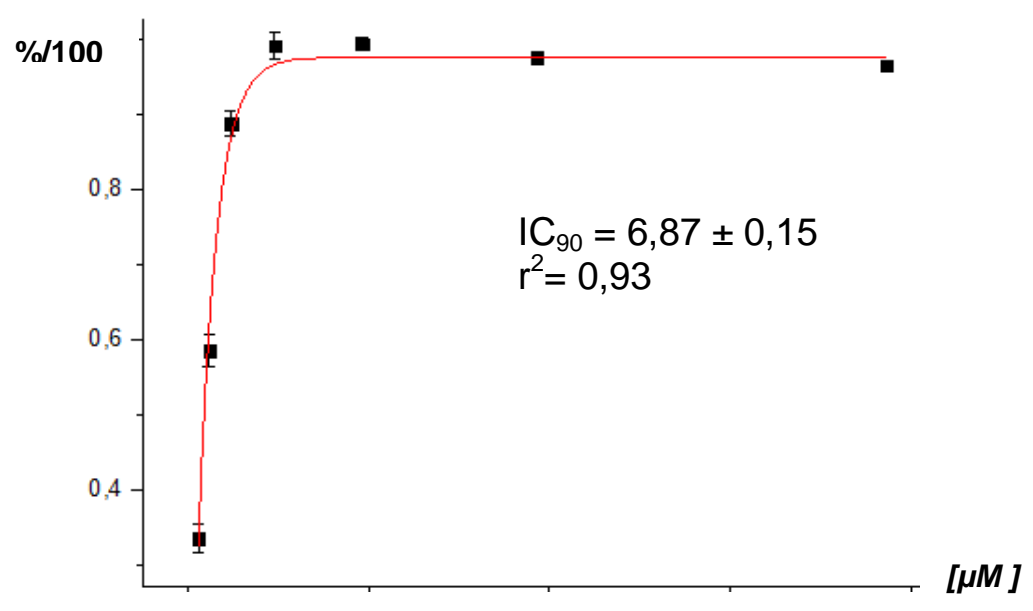

Figura 31. Curva exponencial da inibição de crescimento em diferentes concentrações do composto série $\mathrm{A}-\mathrm{NO}_{2}$, frente a $S$. aureus ATCC 29213 realizado na fase I.

As tabelas 24 e 25 apresentam os resultados de $I_{90}$ e do coeficiente de correlação $\left(r^{2}\right)$ calculados para cada série de compostos frente aos micro-organismos selecionados no trabalho. Na mesma tabela, observa-se que nomes dos compostos foram codificados para melhor entendimento e inserção nos programas computacionais. Ressalta-se que os microorganismos que não apresentaram atividade biológica promissora não tiveram suas $I_{90}$ determinadas, pois seus resultados não contribuiriam para os estudos de relação estruturaatividade. 
Tabela 24. IC $\mathrm{I}_{90}$ dos compostos da série A.

\begin{tabular}{|c|c|c|c|c|c|c|c|c|c|c|c|c|c|}
\hline \multirow{2}{*}{ Série A } & \multicolumn{5}{|c|}{ S.aureus ATCC 29213} & \multicolumn{4}{|c|}{ C. albicans ATCC 573Y } & \multicolumn{4}{|c|}{ E. faecalis ATCC 29212} \\
\hline & Código & $\begin{array}{l}I_{C_{90}} \\
(\mu M)\end{array}$ & DP & $r^{2}$ & $\begin{array}{c}\text { Fase II } \\
(\mu M)\end{array}$ & $\begin{array}{l}I_{\mathbf{C}_{90}} \\
(\mu \mathrm{M})\end{array}$ & DP & $r^{2}$ & $\begin{array}{c}\text { Fase II } \\
(\mu M)\end{array}$ & $\begin{array}{l}\mathrm{IC}_{90} \\
(\mu M)\end{array}$ & DP & $r^{2}$ & $\begin{array}{c}\text { Fase II } \\
(\mu M)\end{array}$ \\
\hline $\mathrm{H}$ & A-I & 4,59 & 0,11 & 0,92 & $4,7-4,2$ & 57,99 & 0,16 & 0,93 & $--^{----^{*}}$ & 3,6 & 0,01 & 0,88 & $3,6-3,2$ \\
\hline $\mathrm{n}-\mathrm{C}_{4} \mathrm{H}_{9}$ & $A-I I$ & 4,39 & 0,06 & 0,96 & $4,9-4,4$ & nd & nd & nd & nd & 3 & 0,01 & 0,99 & $3,0-2,7$ \\
\hline $\mathrm{Cl}$ & A-III & 5,84 & 0,03 & 0,99 & $6,3-5,7$ & nd & nd & nd & nd & 51,29 & 0,46 & 0,95 & $-----{ }^{*}$ \\
\hline $\mathrm{CN}$ & A-IV & 1,99 & 0,01 & 0,99 & $1,9-1,7$ & 49,29 & 3,52 & 0,95 & $-----^{*}$ & nd & nd & nd & nd \\
\hline $\mathrm{OCH}_{3}$ & $A-V$ & 2,84 & 0,31 & 0,99 & $3,2-2,0$ & 51,36 & 0,59 & 0,99 & $-----{ }^{*}$ & 69,17 & 5,5 & 0,95 & $-----^{*}$ \\
\hline $\mathrm{t}-\mathrm{C}_{4} \mathrm{H}_{9}$ & A-VI & nd & nd & nd & nd & nd & nd & nd & nd & nd & nd & nd & nd \\
\hline $\mathrm{NO}_{2}$ & A-VII & 6,87 & 0,15 & 0,93 & $7,0-6,3$ & 49,48 & 4,35 & 0,85 & $----^{*}$ & nd & nd & nd & nd \\
\hline I & A-VIII & nd & nd & nd & nd & nd & nd & nd & nd & nd & nd & nd & nd \\
\hline $\mathrm{CF}_{3}$ & $A-I X$ & 4,88 & 0,05 & 0,94 & $5,3-4,7$ & 46,4 & 1,47 & 0,88 & ------* & 9,41 & 0,14 & 0,99 & $9,4-8,4$ \\
\hline $\mathrm{OC}_{4} \mathrm{H}_{9}$ & $A-X$ & 90,51 & 0,56 & 0,95 & ------* & nd & nd & nd & nd & nd & nd & nd & nd \\
\hline $\mathrm{C}_{2} \mathrm{H}_{5}$ & $A-X I$ & 20,85 & 0,3 & 0,99 & -----** & nd & nd & nd & nd & 51,23 & 0,28 & 0,99 & ------* \\
\hline
\end{tabular}


Tabela 25. $\mathrm{IC}_{90}$ dos compostos da série B.

\begin{tabular}{|c|c|c|c|c|c|c|c|c|c|c|c|c|c|}
\hline \multirow{2}{*}{ Série B } & \multicolumn{5}{|c|}{ S. aureus ATCC 29213} & \multicolumn{4}{|c|}{ C. albicans ATCC $573 \mathrm{Y}$} & \multicolumn{4}{|c|}{ E. faecalis ATCC 29212} \\
\hline & Código & $\begin{array}{l}I_{90} \\
(\mu M)\end{array}$ & DP & $r^{2}$ & $\begin{array}{c}\text { Fase II } \\
(\mu M)\end{array}$ & $\begin{array}{l}I_{90} C_{90} \\
(\mu M)\end{array}$ & DP & $r^{2}$ & $\begin{array}{c}\text { Fase II } \\
(\mu M)\end{array}$ & $\begin{array}{l}I^{I C_{90}} \\
(\mu M)\end{array}$ & DP & $r^{2}$ & $\begin{array}{c}\text { Fase II } \\
(\mu M)\end{array}$ \\
\hline $\mathrm{H}$ & B-I & 5,63 & 0,11 & 0,99 & $5,6-5,1$ & 7,2 & 0,03 & 0,77 & $7,4-6,7$ & nd & nd & nd & nd \\
\hline $\mathrm{Cl}$ & B-III & 5,24 & 0,06 & 0,8 & $5,4-4,8$ & 10,28 & 0,35 & 0,99 & $11,3-10,2$ & nd & nd & nd & nd \\
\hline $\mathrm{CN}$ & B-IV & 5,14 & 0,28 & 0,98 & $5,3-4,7$ & 4,74 & 0,45 & 0,99 & $4,8-4,3$ & 91,2 & 0,08 & 0,99 & ------* \\
\hline $\mathrm{OCH}_{3}$ & B-V & 5,35 & 0,03 & 0,82 & $6,4-5,8$ & 22,85 & 0,56 & 0,99 & ------* & 69,17 & 5,5 & 0,95 & ------* \\
\hline $\mathrm{NO}_{2}$ & B-VII & 3,85 & 0,21 & 0,86 & $4,0-3,6$ & 21,63 & 0,21 & 0,98 & $-----^{*}$ & nd & nd & nd & nd \\
\hline 1 & B-VIII & 6,35 & 0,13 & 0,99 & $7,4-6,6$ & 15,58 & 1,43 & 0,93 & $-----^{\star}$ & nd & nd & nd & nd \\
\hline $\mathrm{CF}_{3}$ & B-IX & 6,77 & 0,21 & 0,98 & $7,6-6,2$ & 7,37 & 0 & 0,91 & $8,4-7,5$ & nd & nd & nd & nd \\
\hline $\mathrm{OC}_{4} \mathrm{H}_{9}$ & $B-X$ & 6,99 & 0,92 & 0,92 & $7,4-6,7$ & 40,88 & 0,34 & 0,96 & ------* & 71,23 & 1,82 & 0,94 & ------* \\
\hline $\mathrm{C}_{2} \mathrm{H}_{5}$ & B-XI & 3,97 & 0,01 & 0,99 & $4,2-3,8$ & 9,26 & 0 & 0,99 & $9,3-8,4$ & nd & nd & nd & nd \\
\hline
\end{tabular}




\subsection{Estudos de relações estrutura-atividade}

O estudo de relações estrutura-atividade dos micro-organismos foi dividido em três etapas: (1) construção dos modelos moleculares 3D dos derivados azometínicos (Série A) e derivados oxadiazolínicos (Série B), (2) cálculos das propriedades moleculares e (3) análise exploratória dos dados.

\subsubsection{Construção dos modelos moleculares 3D}

Para a construção da série A utilizou-se como molde a estrutura cristalografada do composto protótipo (nifuroxazida). Para a série $B$ realizou-se a união de fragmentos da molécula da nifuroxazida cristalografada com o composto 2-[4-acetil-5-(bifenil-4-il)-4,5-diidro-1,3,4-oxadiazol-2-il]fenil acetato, análogo aos compostos da série- $B$, sendo este composto também cristalografado (PNIEWSKA \& JANUCHOWSKI, 1998; YEHYE, ARIFFIN, RAHMAN, 2010). A figura 32 ilustra a construção dos modelos moleculares baseada nas coordenadas cartesianas $(x, y, z)$ das estruturas cristalografadas.

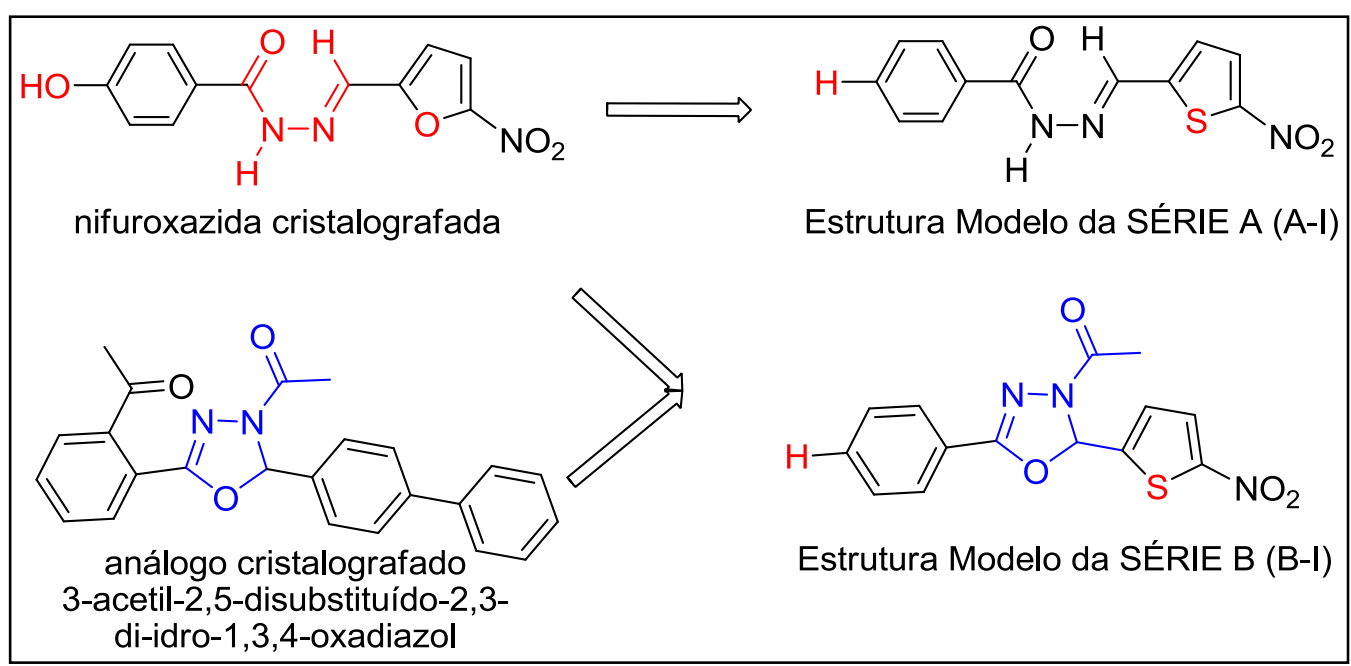

Figura 32. Representação da construção dos modelos moleculares 3D (A-I e B-I) a partir das coordenadas cartesianas das estruturas cristalografadas.

[Nota : Em vermelho porções da estrutura do composto-protótipo nifuroxazida (NF) modificadas para obtenção dos composto modelos $B-I$ e A-I. No composto cristalografado 2-[4-acetil-5-(bifenil-4-il)-4,5-di-idro-1,3,4- oxadiazol-2-il]fenil acetato, em azul está a porção da estrutura utilizada na construção do composto $B-$-I. A NF foi considerada como estrutura modelo para série $A$ sendo modificada apenas a hidroxila e o oxigênio.] 
Com a construção dos modelos moleculares iniciou-se simulações de dinâmica molecular (DM) dos compostos que permitem investigar a evolução temporal das configurações de cada molécula de interesse obtendo-se o perfil de amostragem conformacional (PAC).Obtiveram-se 50.000 confôrmeros e destes foram selecionados confôrmeros de energia mais baixa para cada série. Os confôrmeros de menor energia foram investigados quanto à manutenção de integridade estrutural em relação à estrutura inicial da simulação de DM (output da minimização), utilizando como critério os valores de RMSD, calculados no programa Hyperchem 8.0.

O critério adotado para a avaliação da integridade estrutural foi o valor de desvio quadrático médio de posições atômicas (RMSD, root-mean square deviation) calculados no programa Hyperchem 8.0. Quanto menor o valor de RMSD, menor a distância em $\AA$ (ångström) entre as posições atômicas dos confôrmeros que estão sendo comparados, indicando a manutenção de integridade estrutural (BABER et. al., 2009). Tanto para o composto A-I quanto para o composto B-I, o valor de RMSD encontrado para o confôrmero de menor energia, selecionado da DM e a estrutura minimizada, foi de 0,07 $\AA$. A figura 33 ilustra os átomos do composto $A-I$ selecionados no cálculo de sobreposição para a escolha do confôrmero de mais baixa energia da DM em comparação a estrutura inicial minimizada. Para derivado B-I proviniente da minimização, todos os átomos da molécula foram selecionados para determinar o RMSD.

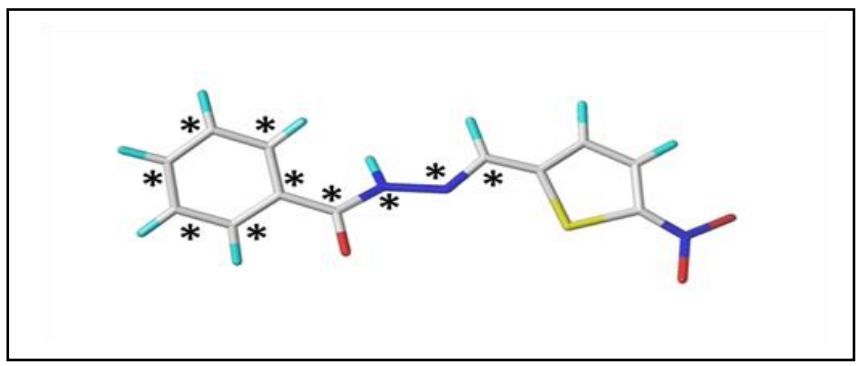

Figura 33. Modelo molecular 3D do composto A-I. ( $\left.{ }^{*}\right)$ átomos utilizados na sobreposição e cálculo dos valores de RMSD.

Um gráfico dos confôrmeros em relação às energias totais foi construído. A energia total corresponde à somatória das contribuições de energias intramoleculares de deformação axial ( $\left.E_{\text {Stretch }}\right)$, deformação angular ( $\left.E_{\text {Bend }}\right)$, deformação torsional ( $\left.E_{\text {Tors }}\right)$, interações do tipo 1-4 $\left(E_{1-4}\right)$, interações de van der Waals $\left(E_{v d W}\right)$, interações de energia eletrostática $\left(E_{C h a r g e}\right)$. As contribuições de energia intramolecular de ligação de hidrogênio e de solvatação não foram consideradas. Os gráficos obtidos e o confôrmero escolhido para 
cada série estão ilustrados no anexo 3: "Representação gráfica dos confôrmeros e suas energias totais da simulação de dinâmica molecular".

O confôrmero selecionado na simulação da DM do composto A-I foi o de número $777.440 \mathrm{com}$ energia potencial total de $14,92 \mathrm{kcal} / \mathrm{mol}$ e o confôrmero do composto B-I selecionado foi o de número $484.680 \mathrm{com}$ energia potencial total de 55,21 kcal/mol. As contribuições de energia intramolecular de solvatação $\left(E_{\text {solv }}\right)$ e de ligação de hidrogênio ( $E_{\text {lig }}$ H) foram consideradas no cálculo da energia potencial total. Na tabela 26 encontram-se os valores das contribuições de energia resultantes da simulação de DM para o confôrmero de energia mais baixa selecionado da região de equilíbrio do PAC dos compostos A-I e B-I.

Tabela 26. Valores dos parâmetros termodinâmicos obtidos para osconfôrmeros de energia mais baixa selecionados do PAC do composto A-I e do composto B-I.

\begin{tabular}{cccccccccc}
\hline Confôrmero & $\mathbf{E}_{\text {STRETCH }}$ & $\mathbf{E}_{\text {BEND }}$ & $\mathbf{E}_{\text {TORS }}$ & $\mathbf{E}_{1-4}$ & $\mathbf{E}_{\text {VDW }}$ & $\mathbf{E}_{\text {CHARGE }}$ & $\mathbf{E}_{\text {solv }}$ & $\mathbf{E}_{\text {lig H }}$ & $\mathbf{E}_{\text {TOT }}$ \\
\hline A-I & 5,07 & 20,77 & $-0,94$ & $-9,18$ & $-0,3$ & $-0,5$ & $-8,60$ & 1,01 & 7,33 \\
B-I & 25,83 & 68,54 & 2,93 & $-83,2$ & $-1,7$ & 42,82 & $-6,14$ & 0,0 & 49,07
\end{tabular}

Energias em $\mathrm{kcal} / \mathrm{mol}$. $\mathrm{E}_{\text {Stretch }}$ (contribuição de energia de deformação axial), $\mathrm{E}_{\text {Bend }}$ (contribuição de energia de deformação angular), $\mathrm{E}_{\text {TORS }}$ (contribuição de energia de deformação torsional), $\mathrm{E}_{1-4}$ (contribuição de energia de interações do tipo 1-4), $E_{\text {vdw }}$ (contribuição de energia de van der Waals), $E_{\text {CHARGE }}$ (contribuição de energia eletrostática), $E_{\text {solv }}$ (contribuição de energia de solvatação), $\mathrm{E}_{\text {lig H }}$ (contribuição de energia de ligação H), $\mathrm{E}_{\text {TOT }}$ (energia potencial total).

Uma vez selecionado o confôrmero das duas séries $A$ e $B$, a etapa subsequente à DM foi a minimização de energia no programa MOLSIM 3.2. A partir da estrutura minimizada dos compostos A-I e B-I foram construídas as moléculas dos compostos de ambas as séries selecionadas do estudo em questão. Apenas para os grupos substituintes alterados na posição 4 do anel benzênico procedeu-se a otimização de geometria em campo de força empírico MM+ e método AM1, sem quaisquer restrições, seguida pelos cálculo de cargas atômicas parciais de ponto único (programa Hyperchem 8.0).

\subsubsection{Cálculos das propriedades moleculares}

A etapa subsequente ao do estudo de modelagem molecular foi o cálculo de carga de ponto único realizado com método ab initio Hartree-Fock (MORGON \& COUTINHO, 2007) e conjunto de base $3-21 G^{*}$. O algoritmo CHELPG foi utilizado para calcular o potencial eletrostático das moléculas (BRENEMAN \& WIBERG, 1990). Este método tem o objetivo de avaliar cargas atômicas pontuais que representam de maneira satisfatória 0 potencial eletrostático molecular em um conjunto de pontos pré-definidos ao redor da molécula (GUADAGNINI, BRUNS, SOUZA, 1996). O conhecimento do potencial eletrostático mostra-se necessário em estudos que envolvem interações moleculares e 
reações químicas, uma vez que o contato inicial entre duas moléculas surge a partir de forças de interação eletrostáticas de longo alcance (HOLTJE, 1996).

Os mapas de potencial eletrostáticos (MPEs) calculados em superfície molecular de Connolly foram visualizados para os compostos que apresentaram maior e menor atividade frente a $S$. aureus, E. faecalis e C. albicans. A interpretação destes mapas é feito por meio de esquema de cores, neste caso, em uma faixa de $-0,08$ (vermelho intenso; regiões de maior distribuição de densidade eletrônica) a 0,08 (azul intenso; regiões de menor distribuição de densidade eletrônica). Os MPEs estão ilustrados na figura 34 e 35.

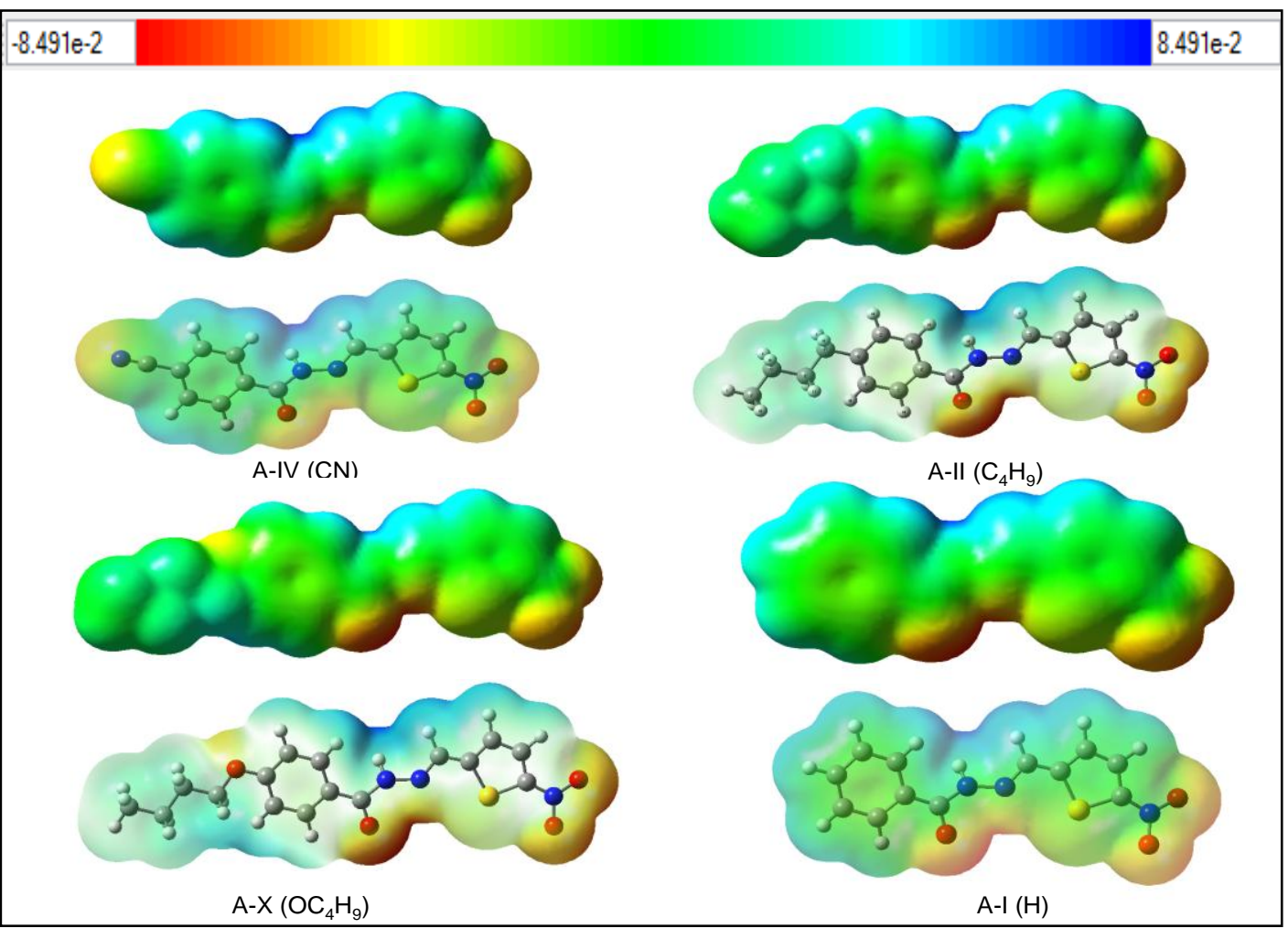

Figura 34. Mapas de potencial eletrostático (MPEs), dos compostos A-IV, A-I, AII e A-X, utilizando GaussView 3.0.

[Para as figuras 34 e 35: Coloração vermelha indica regiões de maior distribuição de densidade eletrônica $(-0,08)$ e coloração azul denota regiões de menor distribuição de densidade eletrônica $(0,08)$; as moléculas são exibidas no modelo esfera (átomos de carbono em cinza, oxigênios em vermelho, nitrogênios em azul, enxofre em amarelo e os átomos de hidrogênio são apresentados em branco)].

Analisando a série $A$ observa-se que as regiões da carbonila e dos oxigênios do grupo nitro são ricos em elétrons (coloração vermelha nas superfícies moleculares). Com a inclusão de átomo recebedor de elétrons no anel benzênico como, por exemplo, o derivado A-IV (CN), observaram-se mudanças de deslocamento de densidade eletrônica no anel benzênico, observando uma coloração em azul atribuída as características do grupo substituinte, diferente dos derivados A-I, A-X e A-II. Nota-se também, que a porção da 
carbonila apresenta uma densidade eletrônica menor para o A-IV em comparação com o restante dos compostos.

Considerando a série $B$, figura 35 , observar-se diferenças nos mapas de potencial eletrostático no grupo analisado, pois com inclusão do grupo recebedor de elétrons (B-IV), a carbonila do grupo acetil localizado acima do anel oxadiazolínico, sofre variação da densidade eletrônica em comparação aos derivados B-I e B-X.

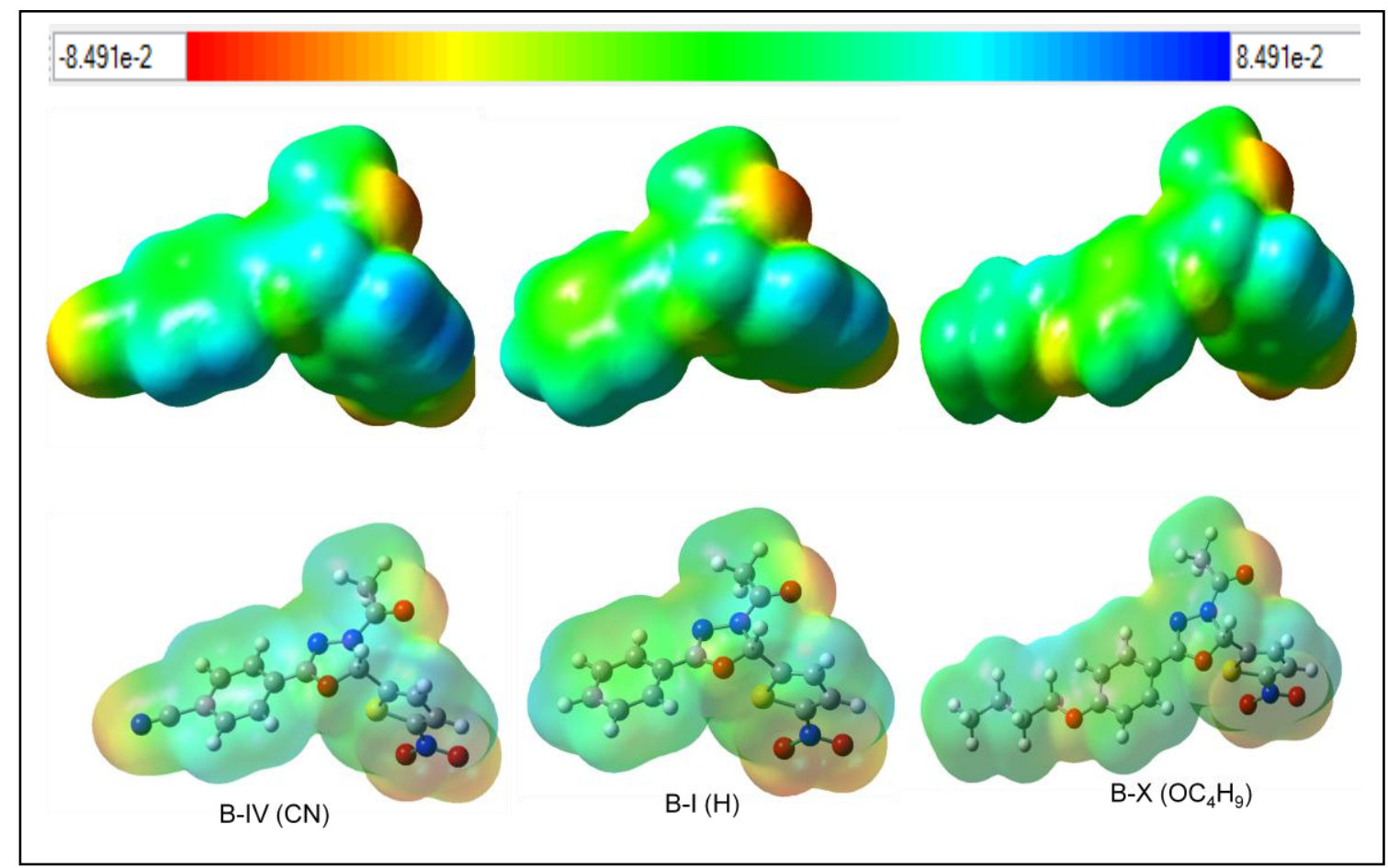

Figura 35. MPEs, dos compostos B-IV, B-I e B-X, utilizando GaussView 3.0.

A partir desta observação foram analisadas as cargas do potencial eletrostático (CHELPG) dos átomos de carbono na região para do anel benzênico (C 11-1), do átomo de oxigênio carbonílico da série $A$ e do oxigênio do anel oxadiazolínico para a série $B(O$ 1-14), do átomo de enxofre do anel tiofênico (S 2-10) e do átomo de carbono do anel tiofênico ligado ao grupo nitro (C 19-11). Estas posições foram avaliadas com o objetivo de identificar quais regiões apresentam cargas importantes que possam influenciar na atividade biológica dos compostos frente aos micro-organismos avaliados. A tabela 27 ilustra os compostos com suas respectivas numerações e as cargas (CHELPG) de cada região analisada. Os valores de carga CHELPG dos demais compostos apresentam-se no anexo 4. 
Tabela 27. Valores de CHELPG dos compostos A-I, A-IV, A-X, A-II, B-I, B-IV e B-X.

\begin{tabular}{ccccc} 
Composto & $\mathrm{O} 1-14$ & $\mathrm{~S} 2-10$ & $\mathrm{C} 11-1$ & $\mathrm{C} 19-11$ \\
\hline $\mathrm{A}-\mathrm{I}$ & $-0,55$ & $-0,03$ & $-0,02$ & 0,04 \\
$\mathrm{~A}-\mathrm{IV}$ & $-0,54$ & $-0,02$ & 0,02 & 0,06 \\
$\mathrm{~A}-\mathrm{II}$ & $-0,56$ & $-0,02$ & 0,31 & 0,04 \\
$\mathrm{~A}-\mathrm{X}$ & $-0,57$ & $-0,03$ & 0,63 & 0,05 \\
$\mathrm{~B}-\mathrm{I}$ & $-0,59$ & 0,15 & $-0,08$ & $-0,08$ \\
$\mathrm{~B}-\mathrm{IV}$ & $-0,59$ & 0,15 & $-0,03$ & $-0,07$ \\
$\mathrm{~B}-\mathrm{X}$ & $-0,61$ & 0,15 & 0,59 & $-0,08$
\end{tabular}

[Nota : O 1-14: carga do potencial eletrostático do átomo de oxigênio carbonílico para série $A$ e do oxigênio do anel oxadiazolínico para série $B$, calculados por ChelpG; S 2-10: carga do potencial eletrostático do átomo de oxigênio do anel tiofênico para as séries A e B,calculados por ChelpG; C 11-1: carga do potencial eletrostático do átomo de carbono do anel benzênico realizando ligação com substituintes na posição 4 para as séries A e B, calculados por ChelpG; C 19-11: carga do potencial eletrostático do átomo de carbono do anel tiofênico ligado ao grupo nitro para as séries A e B, calculados por ChelpG]

Os valores de carga CHELPG para os sete compostos exemplificados demonstram que não ocorreu uma grande variação entre os valores calculados de CHELPG para o oxigênio carbonilico da série A e do oxigênio do anel oxadiazolínico para série B (O 1-14), até mesmo em comparação entre as séries em questão. Para os átomos de enxofre (S 2-10) observa-se diferenciação entre as séries $A$ e $B$, e para os átomos de carbono da região para do anel benzênico, (C 11-1) observa-se valores positivos para os derivados doadores de elétrons ( $A-I I, A-X$ e B-X). Avaliando o átomo de carbono do anel tiofênico ligado ao grupo nitro (C 19-11) observam-se diferenças em que a série $A$ apresenta valores positivos para todos os compostos, e a série $B$, valores negativos também para todos os seus compostos. Nos estudos seguintes observou-se que estes descritores demonstraram influência na atividade frente aos micro-organismos $E$. faecalis e $C$. albicans.

As energias dos orbitais de fronteira de HOMO e LUMO também foram investigadas com o objetivo de melhor entendimento da contribuição eletrônica para atividade biológica. Estas propriedades fornecem informações sobre o caráter elétron-doador e/ou elétronaceitador de um composto e, consequentemente, sobre a possibilidade de formação de complexo de transferência de carga (ARROIO, HONORIO, SILVA, 2010). A energia do 
HOMO ( $\left.E_{\text {Hомо }}\right)$ está relacionada com o potencial de ionização e mede o caráter elétrondoador de um composto, ou seja, sua suscetibilidade de sofrer ataque por eletrófilos, enquanto que a energia do LUMO ( $E_{\text {LUMO }}$ ) está relacionada com a afinidade química e mede o caráter elétron-aceitador de um composto. Assim, quanto maior a energia do HOMO, maior a capacidade elétron-doadora e, quanto menor a energia do LUMO menor será a resistência para aceitar elétrons. Quanto maior a diferença entre $E_{\text {HOMO }}$ e $E_{\text {LUMO }}$ (gap) maior é a estabilidade química da molécula e menor sua reatividade em reações químicas (ARROIO, HONORIO, SILVA, 2010). As figuras 36 e 37 ilustram os derivados e seus mapas de distribuição de orbitais moleculares HOMO e LUMO calculados pelo programa GaussView 3.0.

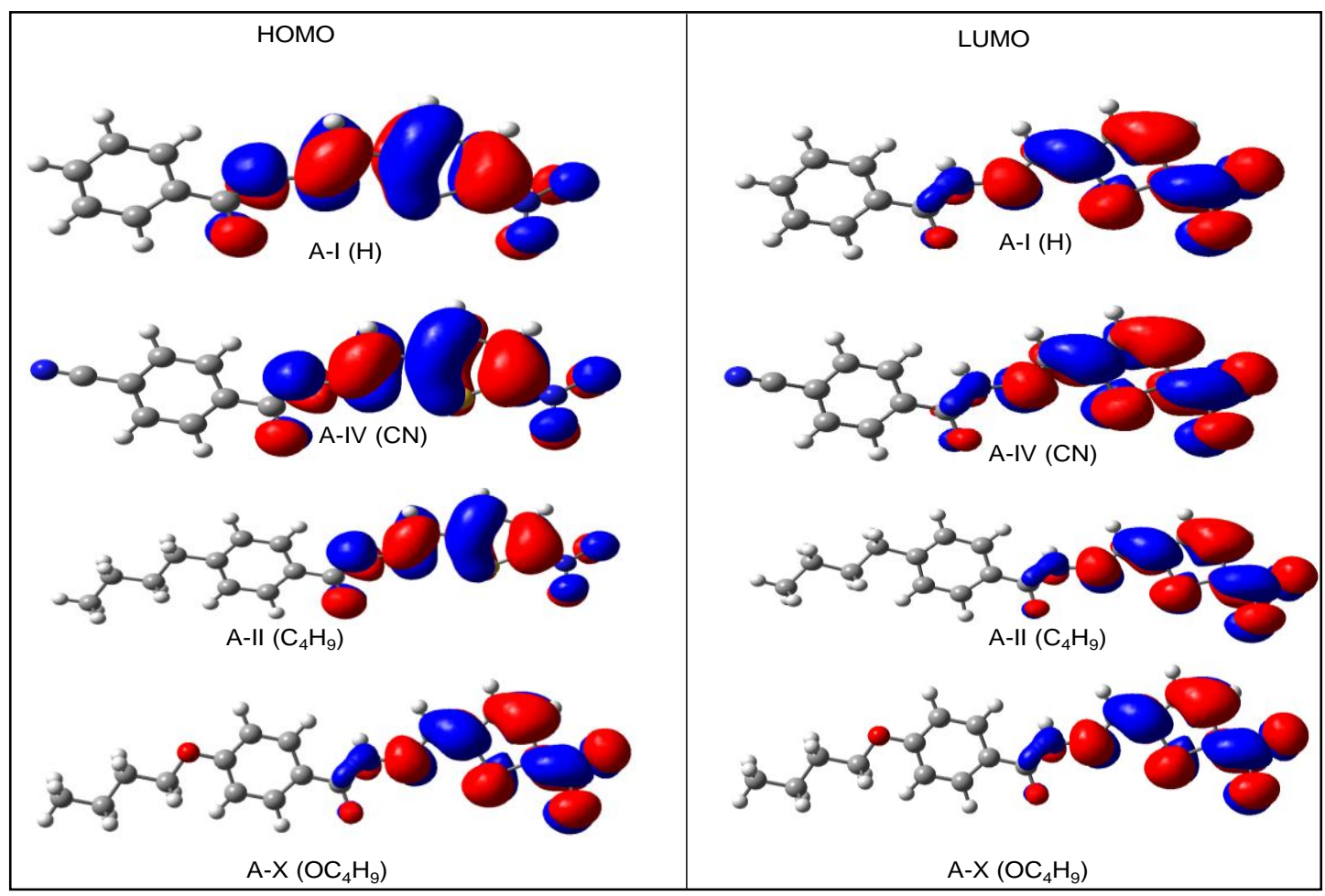

Figura 36. Mapas de distribuição de orbitais moleculares de HOMO e LUMO calculados com o método HF/3-21G* para os compostos derivados tiofênicos de estrutura azometínica (série A).

[Para as figuras 36 e 37: a isossuperfície calculada foi de $0,02 \mathrm{eV}$. As moléculas são exibidas em modelo tubo bola (átomos de carbono em cinza, oxigênios em vermelho, nitrogênios em azul, enxofre em amarelo e os átomos de hidrogênio são apresentados em branco).] 


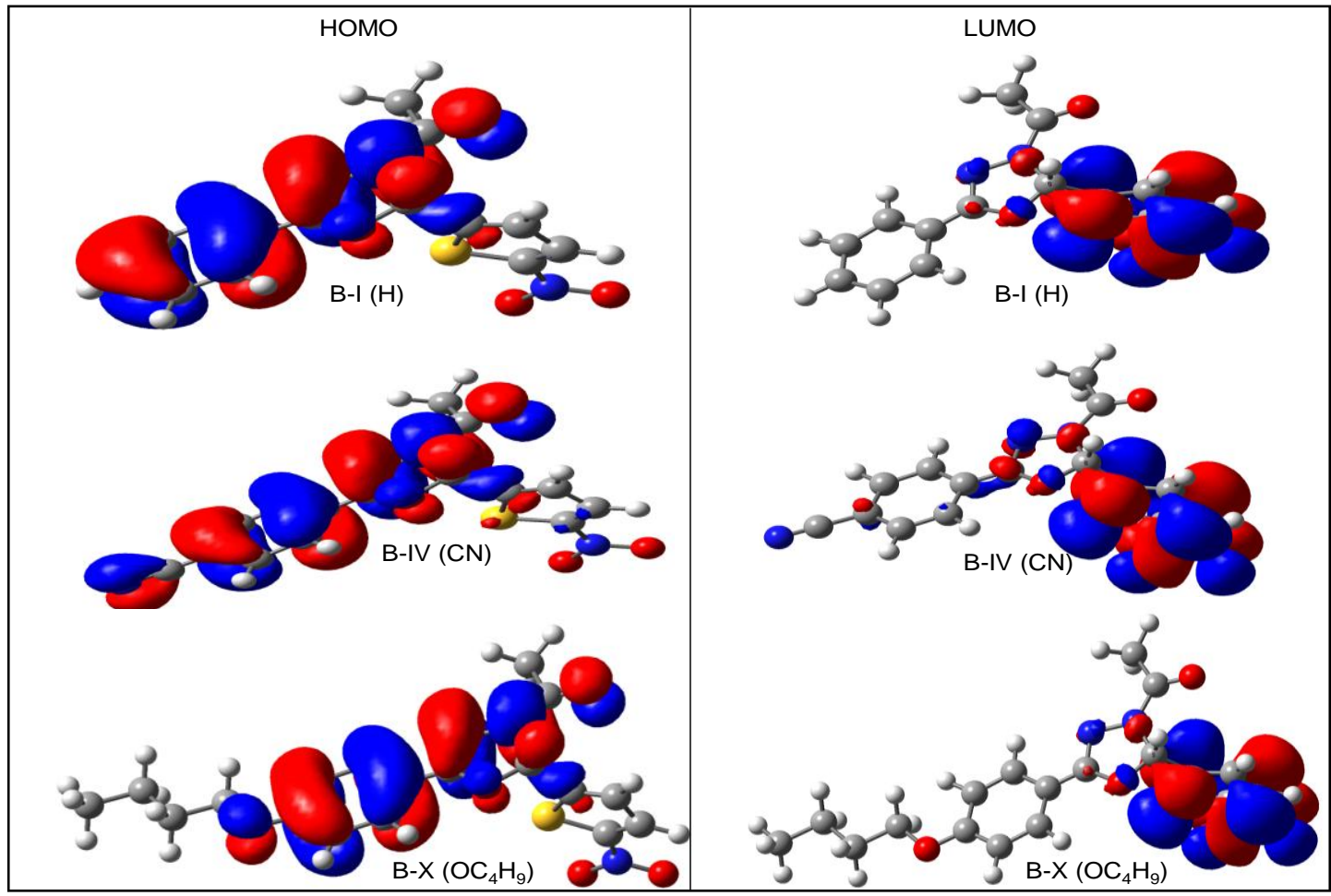

Figura 37. Mapas de distribuição de orbitais moleculares de HOMO e LUMO calculados com o método $\mathrm{HF} / 3-21 \mathrm{G}^{*}$ para os compostos derivados tiofênicos de estrutura oxadiazolínica (série B).

Comparando os mapas de distribuição de orbitais moleculares de HOMO e LUMO (figura 36 e 37), é possível visualizar nos mapas da série A (figura 36) que tanto $E_{\text {Hомо }}$ quanto $E_{\text {LUMO }}$ concentram-se na região da carbonila até o sistema nitrotiofênico. Para os compostos da série B (figura 37) observam-se diferenças, em HOMO. Grupos doadores de elétrons encontram-se na região do anel oxadiazolínico até o anel benzênico e parte de seus substituintes, com exeção do composto B-IV (figura 37 ) em que $E_{\text {Hомо }}$ encontra-se distribuído em algumas partes do anel tiofênico. Comportamento inverso é observado em LUMO, onde também é possível visualizar a presença de $E_{\text {LUMO }}$ distribuído em algumas partes do anel benzênico do composto B-IV.

Estudos anteriores de nosso grupo de pesquisa têm demonstrado que a propriedade eletrônica $E_{\text {LUMO }}$, em conjunto com o momento dipolo $(\boldsymbol{\mu})$, tabela 29, apresentam-se relevantes no entendimento das relações entre a estrutura química e a atividade biológica dos compostos que contém o grupo nitro frente a parasitas e bactérias, uma vez que esta propriedade está diretamente relacionada à capacidade da molécula de receber um elétron para que ocorra a redução do grupo nitro (JORGE, 2011; PALACEBERL, 2012). 
Estudos de modelagem molecular também foram realizados para explorar as propriedades hidrofóbicas dos compostos, a partir de seus mapas de potencial lipofílico e cálculo de valores de coeficiente de partição $(C \log P)$, por diferentes métodos. A figura 38 e 39 ilustram os mapas calculados em superfície molecular de Connoly e valores de ClogP para os compostos que apresentaram maior e menor atividade antimicrobiana frente a $S$. aureus, E. faecalis e $C$. albicans. Os mapas resultantes foram analisados de acordo com o esquema de cores, que varia em uma faixa de marrom (0,10; região mais lipofílica) a azul (0,05; região mais hidrofílica). O esquema de cores mostra-se de fácil interpretação onde azul é associado com a água e marrom como o óleo. Nota-se que a variação da hidrofobicidade não é muito pronunciada comparando-se as duas séries. Observa-se, também, que na região do anel benzênico, onde ocorre à substituição molecular, há uma região bastante lipofílica (coloração marrom), sendo esta uma característica do grupo substituinte.

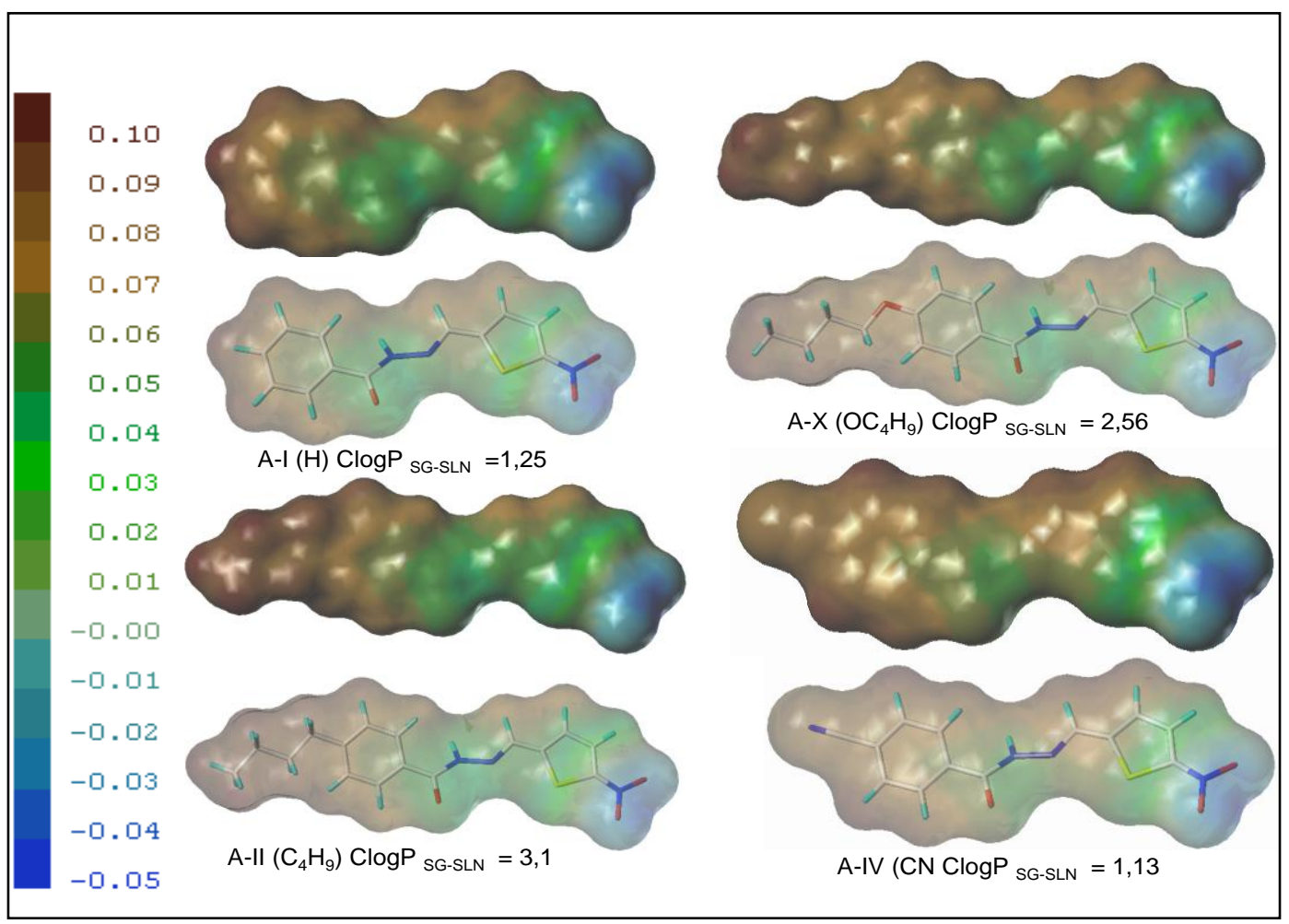

Figura 38. Mapas de potencial lipofílico (MLPs), dos compostos A-I, A-X, A-II, A-IV.

[Para as figuras 38 e 39: coloração marrom indica regiões hidrofóbicas $(0,10)$ e coloração azul denota áreas hidrofílicas $(-0,05)$; as moléculas são exibidas no modelo tubo (átomos de carbono em cinza, oxigênios em vermelho, nitrogênios em azul, enxofre em amarelo e os átomos de hidrogênio são apresentados em verde). ClogP sG-SLN calculado pelo método GHOSE et al., 1998 - SLN, Sybyl line notation.] 


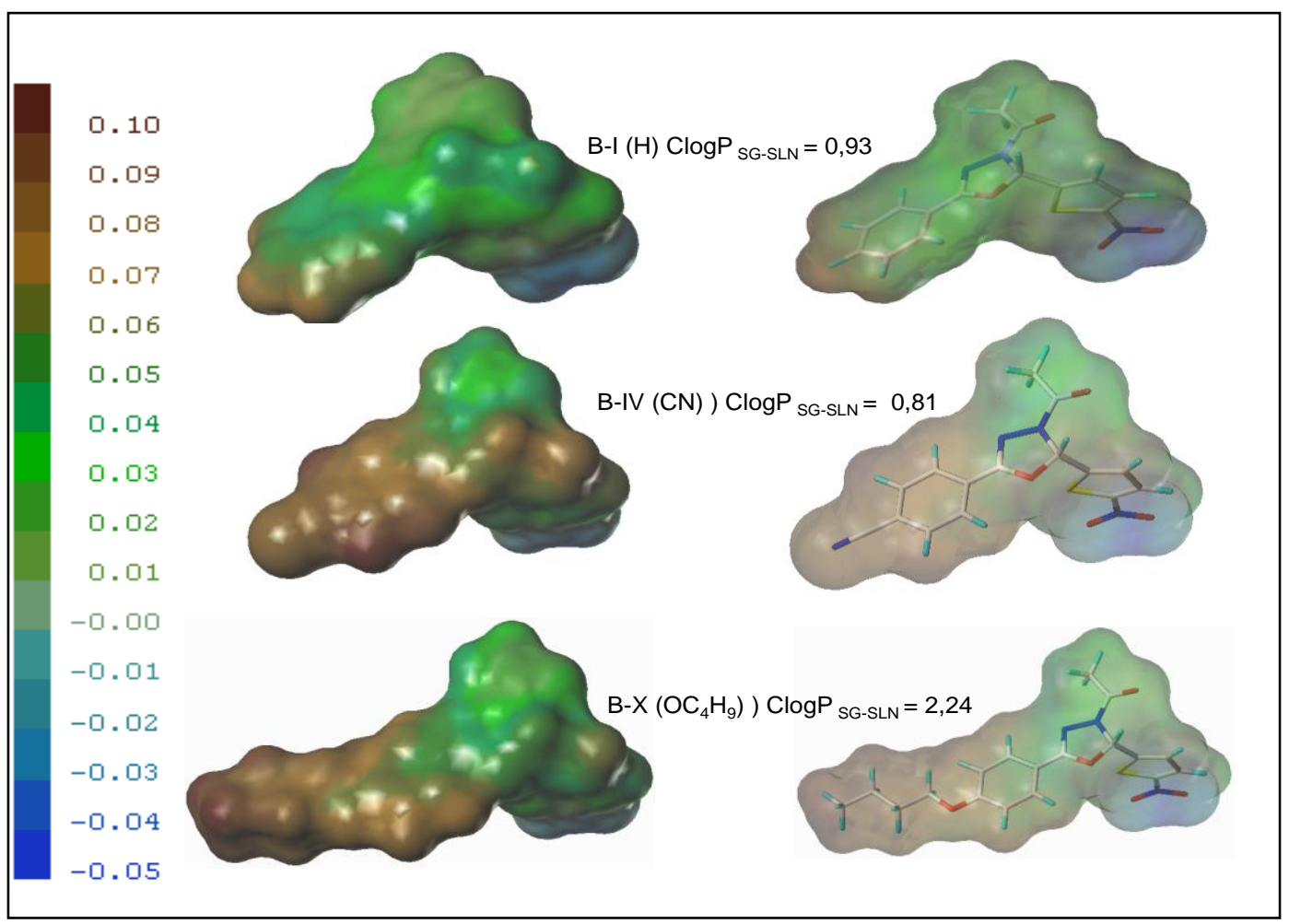

Figura 39. Mapas de potencial lipofílico (MLPs), dos compostos B-I, B-X, e B-IV.

Este estudo teve como objetivo comparar as características lipo-hidrofílicas entre as séries, considerando os valores de ClogP obtidos por diferentes métodos. Observa-se na tabela 28 que os valores de $C_{\log } \mathrm{P}_{\mathrm{SV}}$ e $\mathrm{Clog} \mathrm{P}_{\mathrm{MB}}$ indicam que a série $\mathrm{B}$ é um pouco mais lipofílica que a série $A$, dado esperado pela característica das estruturas, enquanto que os dados do ClogP sG-SLN, indica o inverso. Porém, as diferenças em valores de ClogP $\mathrm{P}_{\text {SG-SLN }}$ entre as duas séries não são significativas. A Tabela 28 mostra os valores dos três descritores calculados para todos os compostos. 
Tabela 28. Valores dos coeficientes de partição calculados por diferentes metodologias.

\begin{tabular}{|c|c|c|c|c|c|c|c|c|c|}
\hline $\begin{array}{c}\text { Série } \\
\mathrm{A}\end{array}$ & Código & $\begin{array}{c}C \log P \\
M B\end{array}$ & $\begin{array}{l}\text { ClogP } \\
\text { SG-SLN }\end{array}$ & $\begin{array}{c}C \log P \\
\text { sV }\end{array}$ & $\begin{array}{c}\text { Série } \\
\mathrm{B}\end{array}$ & Código & $\begin{array}{c}C \log P \\
M B\end{array}$ & $\begin{array}{l}\text { ClogP } \\
\text { SG-SLN }\end{array}$ & $\begin{array}{c}C \log \mathrm{P} \\
\text { sV }\end{array}$ \\
\hline $\mathrm{H}$ & $A-I$ & 2,98 & 1,25 & 3,54 & $\mathrm{H}$ & B-I & 3,29 & 0,93 & 3,77 \\
\hline $\begin{array}{c}\mathrm{n}- \\
\mathrm{C}_{4} \mathrm{H}_{9}\end{array}$ & A-II & 4,83 & 3,1 & 5,2 & $\mathrm{Cl}$ & B-III & 3,89 & 1,6 & 4,29 \\
\hline $\mathrm{Cl}$ & A-III & 3,59 & 1,91 & 4,06 & $\mathrm{CN}$ & B-IV & 3,14 & 0,81 & 3,81 \\
\hline $\mathrm{CN}$ & A-IV & 2,84 & 1,13 & 3,58 & $\mathrm{OCH}_{3}$ & B-V & 3,13 & 0,92 & 3,52 \\
\hline $\mathrm{OCH}_{3}$ & $A-V$ & 2,82 & 1,23 & 3,29 & $\mathrm{NO}_{2}$ & B-VII & 3,23 & $-1,31$ & 3,72 \\
\hline $\mathrm{t}-\mathrm{C}_{4} \mathrm{H}_{9}$ & $A-V I$ & 4,53 & 2,65 & 5,17 & I & B-VIII & 4,22 & 1,51 & 5,03 \\
\hline $\mathrm{NO}_{2}$ & A-VII & 2,92 & -1 & 3,5 & $\mathrm{CF}_{3}$ & B-IX & 4,17 & 1,87 & 4,65 \\
\hline I & A-VIII & 3,91 & 1,83 & 4,8 & $\mathrm{OC}_{4} \mathrm{H}_{9}$ & $B-X$ & 4,45 & 2,24 & 4,72 \\
\hline $\mathrm{CF}_{3}$ & $A-I X$ & 3,86 & 2,19 & 4,43 & $\mathrm{C}_{2} \mathrm{H}_{5}$ & B-XI & 4,25 & 1,87 & 4,63 \\
\hline $\mathrm{OC}_{4} \mathrm{H}_{9}$ & $A-X$ & 4,15 & 2,56 & 4,5 & & & & & \\
\hline $\mathrm{C}_{2} \mathrm{H}_{5}$ & $A-X I$ & 3,94 & 2,19 & 4,41 & & & & & \\
\hline
\end{tabular}

[Nota: Clog $_{\mathrm{MB}}$ : coeficiente de partição calculado pelo método de pesos do programa, considerado pesos iguais para os métodos de VISVANADHAN et al ., 1989, KLOPMAN et al., 1993 e PHYSPROP( database ; ClogP SG-SLN : coeficiente de partição calculado pelo método GHOSE et al., 1998 - SLN ; ClogP SV: coeficiente de partição calculado pelo método VISVANADHAN et al. , 1989].

Por fim, as propriedades estereoquímicas e topológicas foram calculadas no programa Marvin Beans e a matriz de descritores independentes foi complementada com as constantes e parâmetros referentes a grupos substituintes obtidos da literatura. Os valores dos descritores das séries completas dos compostos estão listados no anexo 4. A tabela 29 lista os descritores utilizados no estudo das duas séries. 
Tabela 29. Descritores calculados e obtidos da literatura para os compostos investigados.

\begin{tabular}{|c|c|c|c|c|}
\hline Código & Descritor & Propriedades & Descrições & Programa \\
\hline $\mathrm{x} 1$ & $\mu$ & eletrônica & momento de dipolo & \multirow{11}{*}{$\begin{array}{l}\text { GAUSSIAN } \\
\text { 03W }\end{array}$} \\
\hline$x 2$ & O 1-14 & eletrônica & $\begin{array}{c}\text { carga do potencial eletrostático do átomo de oxigênio carbonílico } \\
\text { para série A e do oxigênio do anel oxadiazolínico para série B, } \\
\text { calculados por ChelpG }\end{array}$ & \\
\hline$x 3$ & S 2-10 & eletrônica & $\begin{array}{c}\text { carga do potencial eletrostático do átomo de oxigênio do anel } \\
\text { tiofênico para as séries A e B,calculados por ChelpG } \\
\text { carga do potencial eletrostático do átomo de nitrogênio de ligação }\end{array}$ & \\
\hline$x 4$ & N 6-15 & eletrônica & $\begin{array}{c}\mathrm{N}=\mathrm{C} \text { na porção azometínica para série } \mathrm{A} \text { e no anel oxadiazolínico } \\
\text { para série } \mathrm{B} \text {, calculados por ChelpG } \\
\text { carga do potencial eletrostático do átomo de nitrogênio de ligacão }\end{array}$ & \\
\hline$x 5$ & N 5-16 & eletrônica & $\begin{array}{c}\mathrm{N}-\mathrm{H} \text { na porção amídica para série } \mathrm{A} \text { e no anel oxadiazolínico para } \\
\text { série } \mathrm{B} \text {, calculados por ChelpG }\end{array}$ & \\
\hline$x 6$ & N 7-20 & eletrônica & $\begin{array}{c}\text { carga do potencial eletrostático do átomo de nitrogênio do grupo } \\
\text { nitro ligado ao anel tiofênico para as séries A e B, calculados por } \\
\text { ChelpG }\end{array}$ & \\
\hline$x 7$ & C 11-1 & eletrônica & $\begin{array}{c}\text { carga do potencial eletrostático do átomo de carbono do anel } \\
\text { benzênico realizando ligação com substituintes na posição } 4 \text { para } \\
\text { as séries A e B, calculados por ChelpG }\end{array}$ & \\
\hline$x 8$ & C $19-11$ & eletrônica & $\begin{array}{c}\text { carga do potencial eletrostático do átomo de carbono do anel } \\
\text { tiofênico ligado ao grupo nitro para as séries A e B, calculados por } \\
\text { ChelpG }\end{array}$ & \\
\hline$x 9$ & $\mathrm{E}_{\text {Hомо }}$ & eletrônica & energia do orbital de fronteira $\mathrm{HOMO}$ & \\
\hline $\mathrm{x} 10$ & $\mathrm{E}_{\text {LUMO }}$ & eletrônica & energia do orbital de fronteira LUMO & \\
\hline $\mathrm{x} 11$ & GAP & eletrônica & diferença entre E HOMO e E LUMO & \\
\hline $\mathrm{x} 12$ & Platt & topológica & $\begin{array}{l}\text { índice que descreve a soma dos graus de contorno da superfície } \\
\text { molecular }\end{array}$ & \multirow{16}{*}{$\begin{array}{l}\text { MARVIN } \\
\text { BEANS }\end{array}$} \\
\hline $\mathrm{x} 13$ & Randic & topológica & $\begin{array}{l}\text { índice que descreve a soma harmônica das médias geométricas } \\
\text { dos graus dos vértices }\end{array}$ & \\
\hline $\mathrm{x} 14$ & Balaban & topológica & $\begin{array}{c}\text { índice que descreve a média da somatória da distância de } \\
\text { conectividade da molécula }\end{array}$ & \\
\hline x15 & Harary & topológica & $\begin{array}{l}\text { índice que descreve a metade da somatória da diagonal externa, } \\
\text { distância matricial recíproca, dos elementos da molécula }\end{array}$ & \\
\hline $\mathrm{x} 16$ & $\begin{array}{l}\text { Hyper } \\
\text { wiener }\end{array}$ & topológica & descreve uma variação do índice de Wiener & \\
\hline $\mathrm{x} 17$ & Szeged & topológica & $\begin{array}{c}\text { estende o índice de Wiener para gráficos cíclicos pela contagem do } \\
\text { número de átomos em ambos os lados de cada ligação (considera } \\
\text { aqueles átomos que estão mais perto de um ladoda ligação do que } \\
\text { do outro) }\end{array}$ & \\
\hline$x 18$ & Wiener & topológica & $\begin{array}{l}\text { índice que descreve a distância atômica topológica média (metade } \\
\text { da soma de todas as distâncias atômicas) na molécula }\end{array}$ & \\
\hline$x 19$ & Dreiding & estereoquímica & $\begin{array}{c}\text { energia relacionada com a estabilidade da conformação da } \\
\text { molécula. }\end{array}$ & \\
\hline$x 20$ & VW & estereoquímica & volume de van der Waals & \\
\hline $\mathrm{x} 21$ & ASA & estereoquímica & $\begin{array}{c}\text { superfície acessível a solvente, calculada usando o raio do } \\
\text { solvente (1,4 A para a molécula de água) }\end{array}$ & \\
\hline$x 22$ & ASA+ & estereoquímica & $\begin{array}{c}\text { superfície acessível a solvente de todos os átomos com carga } \\
\text { parcial positiva }\end{array}$ & \\
\hline$x 23$ & ASA- & estereoquímica & $\begin{array}{c}\text { superfície acessível a solvente de todos os átomos com carga } \\
\text { parcial negativa }\end{array}$ & \\
\hline$x 24$ & ASA_H & estereoquímica & superfície acessível a solvente de todos os átomos hidrofóbicos & \\
\hline$x 25$ & ASA_P & estereoquímica & superfície acessível a solvente de todos os átomos hidrofílicos & \\
\hline$x 26$ & PSA & estereoquímica & $\begin{array}{l}\text { área de superfície polar } \\
\text { coeficiente de partição calculado pelo método de pesos do }\end{array}$ & \\
\hline $\mathrm{x} 27$ & $C \log \mathrm{P}_{\mathrm{MB}}$ & hidrofóbica & $\begin{array}{l}\text { programa, considerado pesos iguais para os métodos de } \\
\text { VISVANADHAN et al ., 1989, KLOPMAN et al. , } 1993 \text { e } \\
\text { PHYSPROPC database }\end{array}$ & \\
\hline$x 28$ & $\pi$ & hidrofóbica & constante $\pi$ de Hansch & \multirow{8}{*}{$\begin{array}{l}\text { HANSCH, } \\
\text { LEO, } \\
\text { HOEKMAN } \\
1995\end{array}$} \\
\hline x29 & $\sigma$ & eletrônica & constante $\sigma$ de Hammet & \\
\hline x30 & $\mathrm{F}$ & eletrônica & constante de efeito indutivo de Swain e Lupton & \\
\hline x31 & $\mathrm{R}$ & eletrônica & constante de efeito de ressonância de Swain e Lupton & \\
\hline x32 & $\mathrm{L}$ & estereoquímica & & \\
\hline$x 33$ & B1 & estereoquímica & parâmetros de STERIMOL (VERLOOP, 1987) & \\
\hline x34 & B5 & estereoquímica & & \\
\hline$\times 35$ & MR & $\begin{array}{l}\text { estereoquímica/ } \\
\text { hidrofóbica }\end{array}$ & refratividade molar & \\
\hline$x 36$ & $\begin{array}{l}\text { ClogP } \\
\text { SG-SLN }\end{array}$ & hidrofóbica & $\begin{array}{l}\text { coeficiente de partição calculado pelo método GHOSE et al., } 1998 \text { - } \\
\text { SLN }\end{array}$ & \multirow{2}{*}{ SYBYL 8.0} \\
\hline$x 37$ & & hidrofóbica & $\begin{array}{l}\text { coeficiente de partição calculado pelo método VISVANADHAN et } \\
\text { al. , } 1989\end{array}$ & \\
\hline
\end{tabular}


Após o cálculo das propriedades físico-químicas (descritores) as variáveis dependentes (atividade biológica $\mathrm{IC}_{90}$ ) foram transformadas em potência ( $\log 1 / \mathrm{C}$ ), conforme demonstra a tabela 30 .

Tabela 30. Atividade antimicrobiana representada em potência $(\log 1 / C)$.

\begin{tabular}{|c|c|c|c|c|c|c|c|}
\hline Código & $\begin{array}{c}\text { S. } \\
\text { aureus }\end{array}$ & $\begin{array}{c}C . \\
\text { albicans }\end{array}$ & $\begin{array}{c}E . \\
\text { faecalis }\end{array}$ & Código & $\begin{array}{c}S . \\
\text { aureus }\end{array}$ & $\begin{array}{c}C . \\
\text { albicans }\end{array}$ & $\begin{array}{c}E . \\
\text { faecalis }\end{array}$ \\
\hline & $\log 1 / C^{a}$ & $\log 1 / C^{a}$ & $\log 1 / C^{a}$ & & $\log 1 / C^{a}$ & $\log 1 / C^{a}$ & $\log 1 / C^{a}$ \\
\hline A-I & 5,33 & 4,23 & 5,44 & B-I & 5,24 & 5,14 & nd \\
\hline A-II & 5,35 & nd & 5,52 & B-III & 5,28 & 4,98 & nd \\
\hline A-III & 5,23 & nd & 4,28 & B-IV & 5,28 & 5,32 & 4,04 \\
\hline A-IV & 5,70 & 4,30 & nd & B-V & 5,27 & 4,64 & 4,16 \\
\hline A-V & 5,54 & 4,28 & 4,16 & B-VII & 5,41 & 4,66 & nd \\
\hline A-VII & 5,16 & 4,30 & nd & B-VIII & 5,19 & 4,80 & nd \\
\hline A-IX & 5,31 & 4,33 & 5,02 & B-IX & 5,16 & 5,13 & nd \\
\hline$A-X$ & 4,04 & nd & nd & $B-X$ & 5,15 & 4,38 & 4,14 \\
\hline A-XI & 4,68 & nd & 4,29 & B-XI & 5,40 & 5,03 & nd \\
\hline
\end{tabular}

$\mathrm{a}=$ conversão do valor de $\mathrm{IC}_{90}$ em potência (concentração $\mathrm{C}$ em $\mathrm{M}$ ).

$\mathrm{nd}=$ não determinado (compostos que não foram possíveis de determinar $\mathrm{IC}_{90}$ )

Para a avaliação dos dados quanto à atividade antimicrobiana, representada em potência, foram elaborados, três gráficos (figura 40) a fim de se verificar a distribuição dos valores da atividade biológica dos compostos. Os derivados série $A$ estão em azul e os derivados série $\mathrm{B}$ em amarelo.

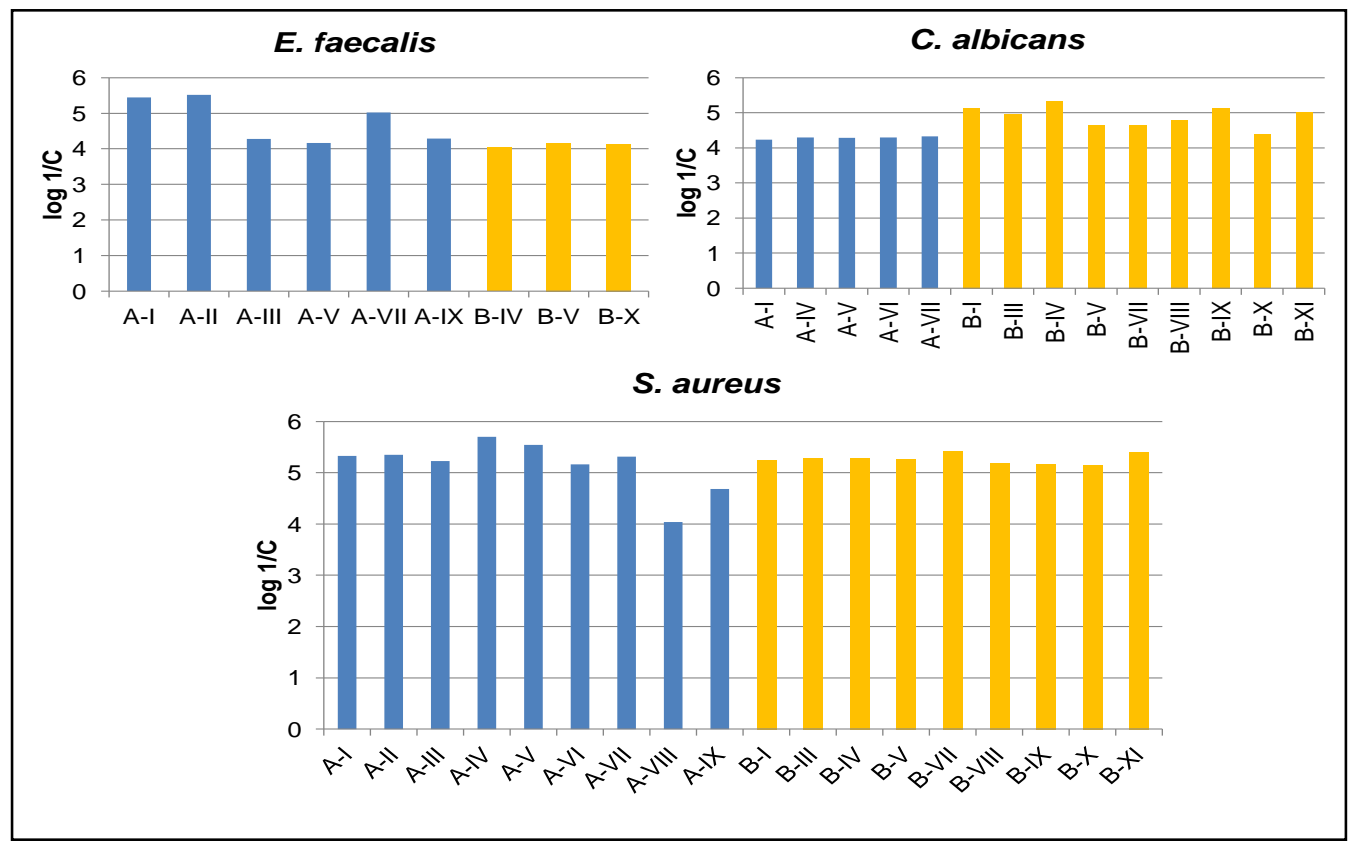

Figura 40. Valores de $\mathrm{IC}_{90}$ em potência $(\log 1 / \mathrm{C})$ dos compostos série $A$ e $B$ frente aos micro-organismos selecionados para os estudos subsequentes. 
Para a pré-seleção dos descritores moleculares foram utilizados dois filtros sendo eles o coeficiente linear de Pearson, com valor de corte em 0,3 , e os gráficos de dispersão (scatter plot) para avaliação de cada propriedade em relação a atividade biológica. Na figura 41 estão indicados exemplos, sendo que o primeiro indica ser um bom descritor pelo fato de apresentar uma boa dispersão e um coeficiente de correlação de Pearson alto $(R=0,54)$. 0 segundo não apresenta boa dispersão e um coeficiente de correlação de Pearson baixo $(R=0,12)$, sendo um descritor excluído nesta pré-seleção.
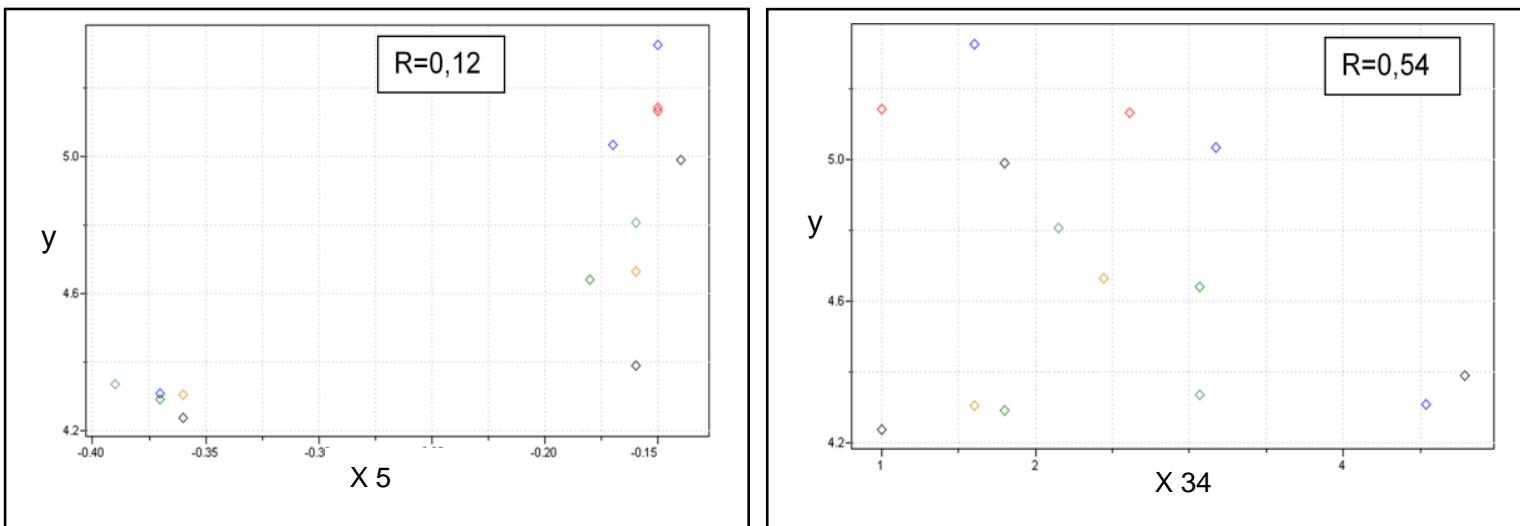

Figura 41. Exemplos de gráficos de dispersão das variáveis $x 34, x 5$ em relação à atividade frente a $C$. albicans (y) e seus coeficientes de correlação de Pearson (R).

Para a análise exploratória de $S$. aureus foram selecionados 9 descritores, assim como para as análises de C. albicans e E. faecalis, foram selecionados 11 e 12 descritores respectivamente.

\subsection{Análise exploratória dos dados}

A análise exploratória de dados foi realizada no programa Pirouette 3.11 (Infometrix, Ltda., 2003). Esta análise consiste na extração de informações dos resultados de um experimento que envolve a análise de grande número de variáveis. Muitas vezes, um pequeno número destas variáveis contém as informações mais relevantes, enquanto que a maioria das variáveis adiciona pouco ou nada à interpretação dos resultados (FERREIRA, 2002).

A Matriz de cada análise gerada neste estudo teve seus dados tratados por autoescalamento, o qual implica em subtrair de cada elemento de uma coluna da matriz de dados o valor médio da respectiva coluna e dividir o resultado pelo desvio padrão da mesma, conforme a equação 6 (MOITA NETO \& MOITA, 1998). 


$$
X i j=(X i j-\overline{X j}) / s_{j}
$$

Equação 6.

Em que: $X i j$ é o valor do descritor $j$ para o composto $i ; X j$ é a média dos valores para o descritor $j$ e $s_{j}$ é o desvio padrão dos valores para o descritor $j$.

A técnica de agrupamento hierárquico, HCA (Hierarchical Analysis ou Cluster Analysis) tem a finalidade de interligar as amostras por meio de dendogramas, onde as amostras com semelhanças entre si são agrupadas no mesmo cluster de similaridade. Os resultados desta análise são de natureza qualitativa com o objetivo de auxiliar no estudo de correlação entre variáveis. O método matemático mais utilizado é agrupar os pares de pontos que estão mais próximos, usando a distância euclidiana, equação 7 (MONTANARI, 2011, FERREIRA, 2002).

$$
d_{a b}=\left[\sum_{i}^{m}\left(x_{a j}-x_{b j}\right)^{M}\right]^{1 / M}
$$

Em que: $d_{a b}$ é a distância entre dois vetores de amostras, $a$ e $b$ são as amostras, $m$ é o número total de variáveis, $M$ é a ordem da distância, sendo $M=2$ para distância Euclidiana, $j$ é o descritor.

Os valores de distância entre pares de amostras são transformados em uma matriz de similaridade $S$ cujos elementos correspondem aos índices de similaridade, representado na equação 8 (FERREIRA, 2002).

$$
S_{k l}=1-\left(d_{k l} / d_{\max }\right)
$$

Equação 8.

Em que: $S_{k l}$ é o índice de similaridade entre duas amostras $k$ e $l, d_{k l}$ é a distância entre duas amostras, $d_{\max }$ é a maior distância no conjunto de dados.

A análise de componentes principais, PCA (Principal Component Analysis) é um método de compressão de dados com base na correlação entre variáveis. Variáveis que apresentam grande redundância entre si são colineares e a alta colinearidade é uma forte indicação de que é possível encontrar-se novas bases que melhor representem as informações presentes nos dados que aquela definida pelas medidas (MOITA NETO, MOITA, 1998; FERREIRA, 2002). Seu objetivo básico é agrupar as variáveis correlacionadas, substituindo os descritores originais por um novo conjunto chamado de componentes principais (PCs), na qual os dados são projetados. 
O novo conjunto de eixos gerado origina as PCs, as quais agrupam descritores de informações correlacionadas. Assim, foi determinado o número de PCs que explica a maior parte dos dados, sendo estas PCs não correlacionadas e ortogonais entre si (MONTANARI, 2011, FERREIRA, 2002). A equação 9 representa a obtenção das PCs.

$$
X=T L^{T}=T_{A} L_{A}{ }^{T}+E \quad \text { Equação } 9 .
$$

Em que: $X$ é a matriz dos dados auto-escalados, $T$ é a matriz de escores e $L$ é a matriz de pesos (loadings), E é a matriz de resíduos e $A$ é o número de componentes principais significativas.

Os pesos variam entre -1 e 1, desta maneira altos pesos significam que a PC gerada e a variável original são aproximadamente lineares. Na geração das matrizes $L$ e $T$ calcula-se também a porcentagem da variância explicada, a qual representa a quantidade de informação contida em cada PC (MONTANARI, 2011, FERREIRA, 2002).

Com o objetivo de diagnosticar possíveis amostras atípicas (outliers), foi avaliado o gráfico da distância residual das amostras em relação à distância de Mahalanobis. A distância Mahalanobis é uma medida de distância baseada nas correlações entre variáveis e é invariante à escala, ou seja, não depende da escala das medições. Neste caso, corresponde à distância calculada a partir do número de k fatores (PCs) (Pirouette, 2003), representada na equação 10 .

$$
M D_{i}=\left(t_{i}-t\right)^{T} S_{k}^{-1}\left(t_{i}-t\right)
$$

Em que: $S$ é a matriz de pontuações de covariância e $t$ é o vetor de escores médio.

A distância Mahalanobis é normalmente distribuída, e um valor crítico (MDcrit) pode ser determinado a partir de uma distribuição qui-quadrado com k graus de liberdade. Se uma amostra excede MDcrit, significa que a amostra pode ser uma amostra crítica (PALACE-BERL, 2012).

As análises exploratórias de dados foram divididas por micro-organimos com 0 objetivo de facilitar o entendimento entre as análises de HCA e PCA. 


\subsubsection{Análise exploratória dos dados obtidos para $S$. aureus}

O dendograma de amostras analisadas frente ao micro-organismo $S$. aureus (figura 42), utilizou um cursor de similaridade 0,61 (linha pontilhada), os compostos foram agrupados em 4 categorias. Boa parte dos compostos de alta e média atividade biológica apresentam-se no grupo 1, sendo subdividido em 1' e 1". Os derivados do subgrupo 1" apresentam características estereoquímicas ( $\mathrm{A}-\mathrm{IV}, \mathrm{A}-\mathrm{V}, \mathrm{A}-\mathrm{XI}, \mathrm{B}-\mathrm{IV}, \mathrm{B}-\mathrm{V}, \mathrm{B}-\mathrm{XI}$ ) muito similares e também apresentam o composto com melhor atividade antimicrobiana frente $S$. aureus (A-IV). Observando o descritor estereoquímico x26 (PSA) pode-se concluir que este apresenta valores entre $115,52 \AA^{2}$ a $139,75 \AA^{2}$ para grupo 1 (ver tabela anexo 4).

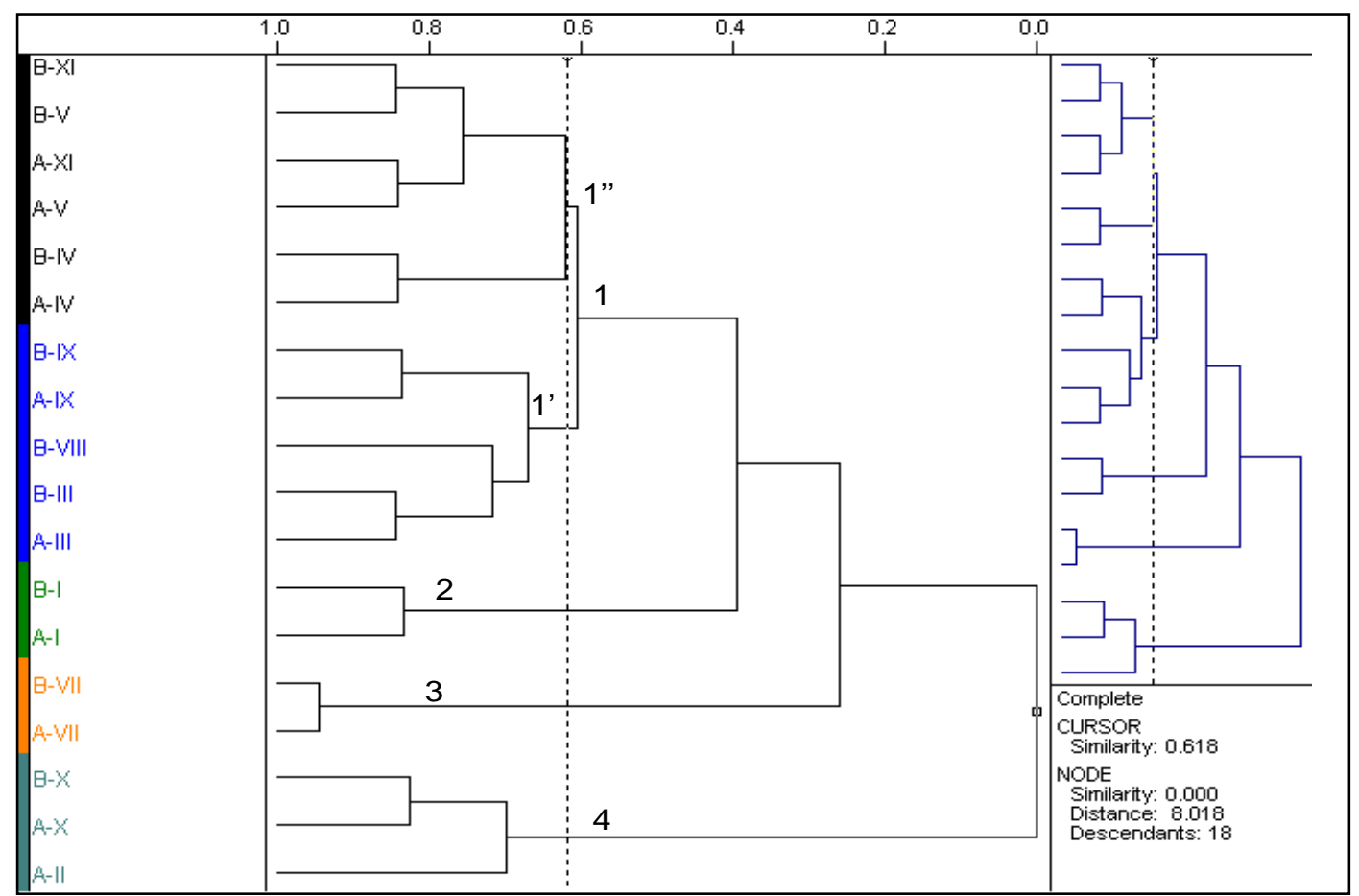

Figura 42. Dendograma dos compostos série A e B estudados frente a $S$. aureus.

A figura 43 representa a similaridade da atividade biológica de $S$. aureus com os descritores selecionados no estudo, a variável dependente $\mathrm{y}$, demonstrou grau de similaridade de 0,31 com o descritor esterioquímico x26 (PSA, área de superfície polar) demonstrando-se como importante descritor para atividade biológica contra $S$. aureus. As propriedades foram divididas em 2 grupos: o grupo 1 (similaridade 0,28 ) representa as variáveis estereoquímcas ( $x 26, x 33$ ); no grupo 2 (similaridade 0,25 ) o subgrupo 2' representam as variáveis hidrofóbica $(x 36)$ e eletrônica $(x 10)$, no subgrupo 2" é representado por uma variável topológica $(x 16)$ e quatro variáveis estereoquímicas (x35, x34, x21, x32) (ver tabela 31). 
Os resultados da análise de componentes principais (tabela 31) frente ao microorganismo $S$. aureus, mostram que a primeira componente principal (PC1 ou factor 1) descreve 53,18 \% da informação de entrada. A segunda componente principal (PC2 ou factor 2) descreve 25,42 \% desta informação. Quanto aos pesos (loadings) dos descritores nas componentes principais, verifica-se que os descritores estereoquímicos (ASA, L, B5 e $\mathrm{MR})$ tem maior peso na PC1 $(0,43)$, e novamente o descritor estereoquímico PSA, apresentando maior peso em PC2 $(0,62)$. Este descritor segundo literatura indica que compostos com áreas de superfície polar (PSA) menor ou igual a $140 \AA^{2}$ apresentam melhor biodisponibilidade oral, como observado para boa parte dos compostos avaliados neste estudo (CLARK \& PICKETT, 2000).

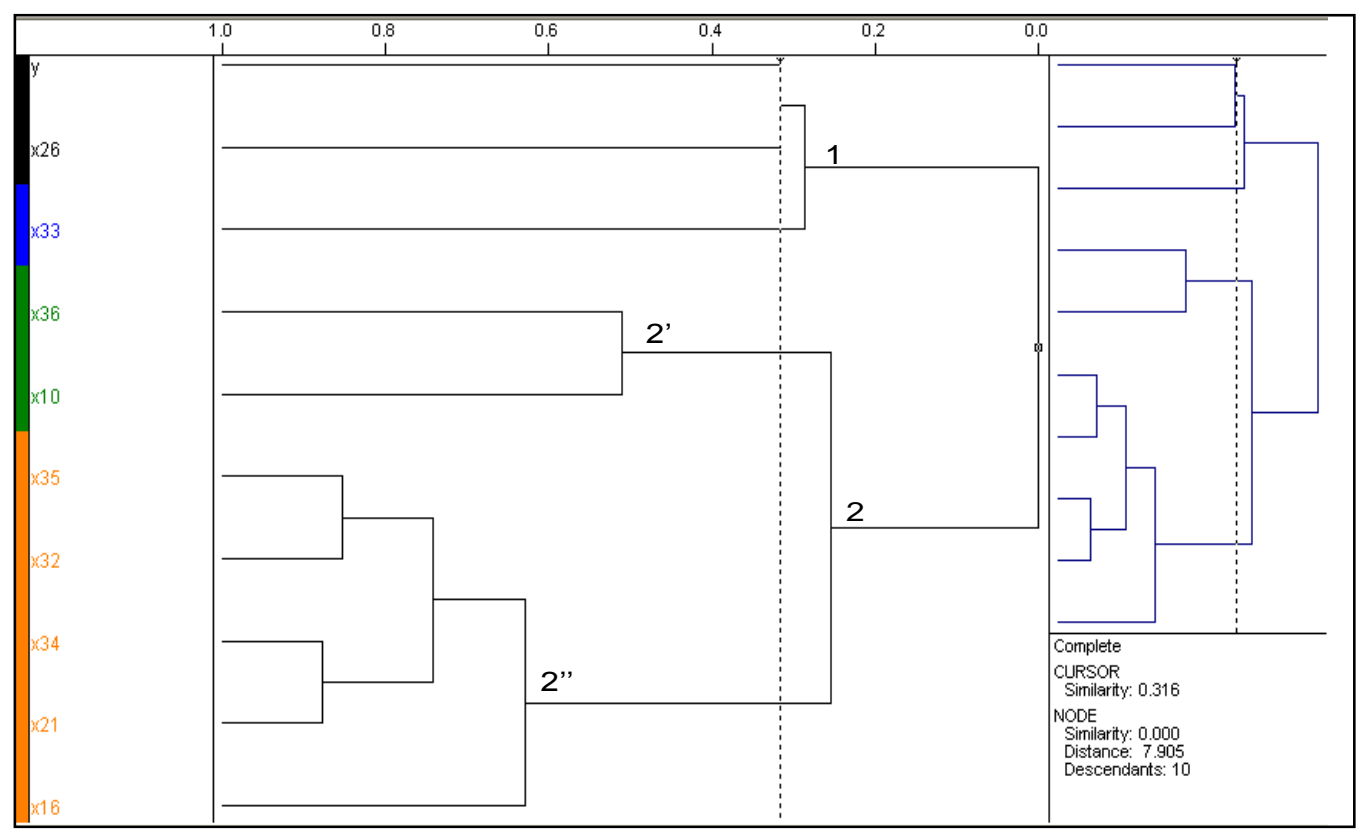

Figura 43. Dendograma dos descritores estudados frente a $S$. aureus. 
Tabela 31. Análise de PCA quanto a contribuição das PCs e valores dos pesos dos descritores frente a $S$. aureus.

\begin{tabular}{|c|c|c|c|c|c|c|c|}
\hline \multicolumn{4}{|c|}{ Seleção das componentes principais } & \multicolumn{4}{|c|}{ Pesos (loadings) } \\
\hline & Variância & Porcentagem & Cumulativo & \multicolumn{2}{|c|}{ Descritores } & $P C 1$ & PC2 \\
\hline PC1 & 81,37 & 53,18 & 53,18 & $\mathrm{x} 10$ & \multirow{2}{*}{$\begin{array}{l}E_{\text {Lumo }} \\
\text { Hyper } \\
\text { wiener }\end{array}$} & 0,09 & $-0,54$ \\
\hline PC2 & 38,90 & 25,42 & 78,62 & $\mathrm{x} 16$ & & 0,39 & 0,19 \\
\hline PC3 & 17,35 & 11,33 & 89,95 & $x 21$ & ASA & 0,43 & 0,12 \\
\hline PC4 & 7,31 & 4,77 & 94,72 & $x 26$ & PSA & $-0,07$ & 0,62 \\
\hline PC5 & 4,88 & 3,19 & 97,92 & x32 & $\mathrm{L}$ & 0,43 & 0,07 \\
\hline PC6 & 2,31 & 1,51 & 99,43 & x33 & B1 & $-0,00$ & 0,09 \\
\hline \multirow[t]{3}{*}{ PC7 } & 0,76 & 0,49 & 99,93 & x34 & B5 & 0,43 & 0,08 \\
\hline & & & & x35 & MR & 0,43 & 0,06 \\
\hline & & & & x36 & $\begin{array}{c}C \log P \text { SG- } \\
\text { SLN }\end{array}$ & 0,26 & $-0,48$ \\
\hline
\end{tabular}

[E $\mathrm{E}_{\text {Lumo }}$ : energia do orbital de fronteira LUMO; Hyper wiener : descreve uma variação do índice de Wiener; ASA : superfície acessível a solvente, calculada usando o raio do solvente $(1,4 \AA$ para a molécula de água) ; PSA : área de superfície polar; L, B1 e B5: parâmetros de STERIMOL (VERLOOP, 1987) ; MR : refratividade molar; ClogP SG-SLN : coeficiente de partição calculado pelo método GHOSE et al., 1998 - SLN.]

No gráfico de correlação entre as PCs (figura 44) observa-se a divisão de grupos com características similares como no caso da região A em concordância com o grupo 1 (figura 42) da análise de HCA, onde se observa o derivado de melhor atividade biológica (AIV) e características estereoquímicas similares ao restante dos derivados na mesma região. Nas regiões circuladas $B, C$ e $D$ observam os compostos de média e baixa atividade biológica que também apresentam coerência com a análise de HCA (grupos 2, 3 e 4).

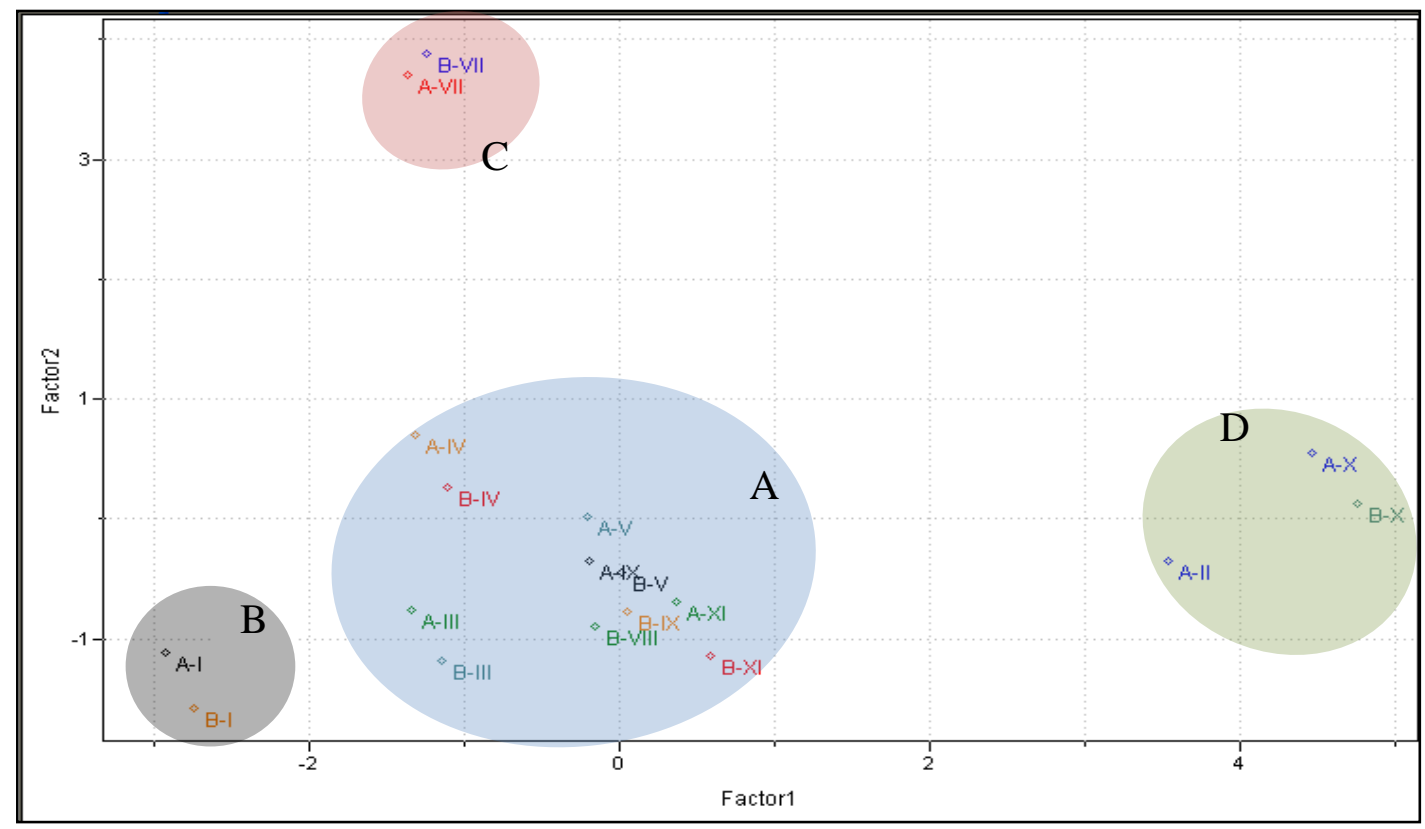

Figura 44. Escores entre PC1 e PC2, grupo dos compostos avaliados frente a $S$. aureus. 
O gráfico de amostra residual versus distância de Mahalanobis foi avaliado para diagnosticar possíveis amostras de outliers (figura 45). Observa-se pelo gráfico que não houve amostras atípicas (outliers) para a avaliação considerando a análise de $S$. aureus.

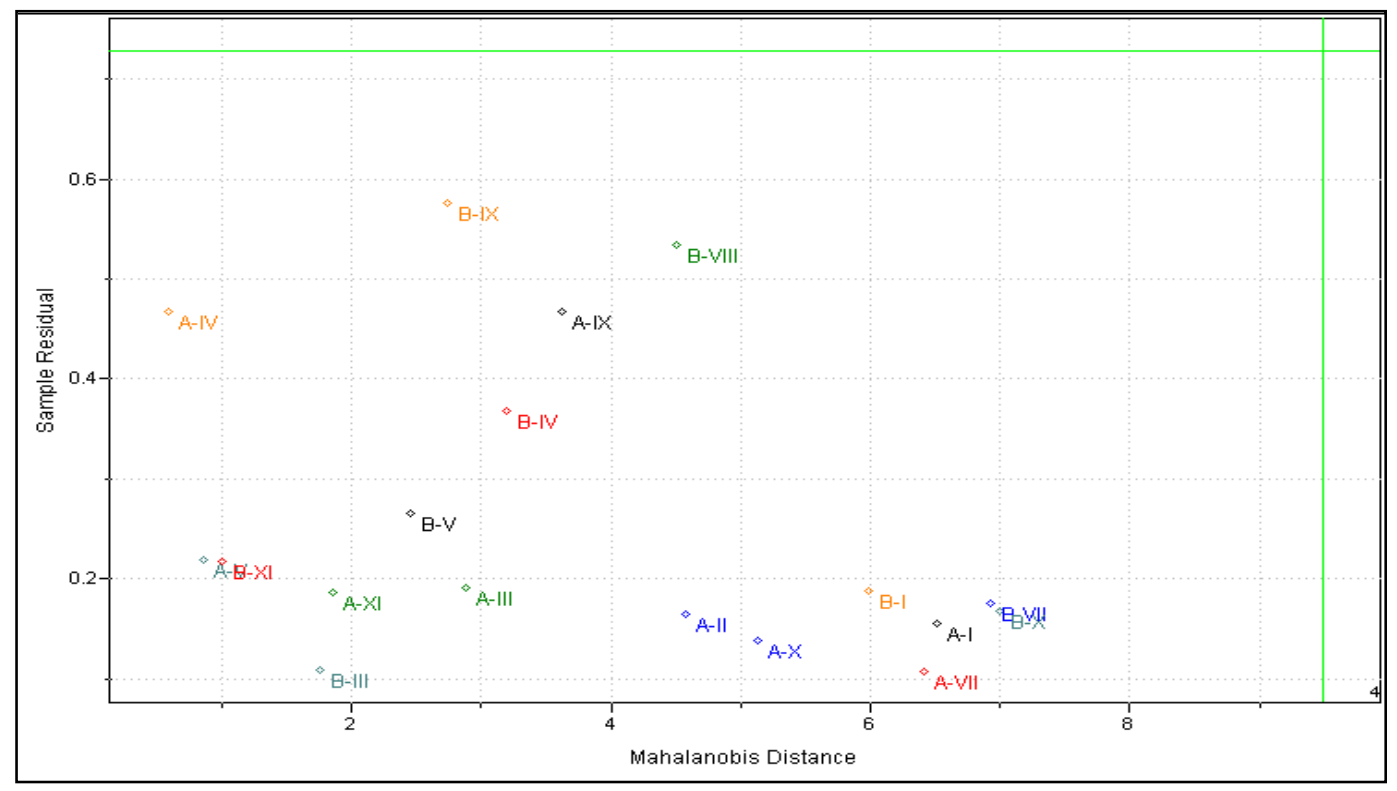

Figura 45. Distância residual das amostras em relação à distância de Mahalanobis para o micro-organimo $S$. aureus.

\subsubsection{Análise exploratória dos dados obtidos para C. albicans}

No dendograma de amostras estudadas frente a $C$. albicans (figura 46) utilizou-se como referência um cursor de similaridade de 0,52 (linha pontilhada), sendo agrupado em 3 categorias. Observa-se que os compostos com melhor atividade biológica, derivados oxadiaxolínicos (série B), agruparam-se nos grupos 1 e 2 (similaridade 0,30) e os compostos de menor atividade biológica, derivados azometínicos, agruparam-se no grupo 3. O grupo 1 (similaridade 0,48 ) apresenta os compostos com atividade biológica intermediária. No grupo 2 apresenta-se o derivado com melhor atividade biológica (B-IV), apresentando, junto aos outros derivados (B-VII, B-V, B-I e B-III), características topológicas (Balaban) muito similares (ver tabela anexo 4).

O descritor que apresenta maior similaridade com a atividade biológica referente à C.albicans, encontra-se no grupo 1, (figura 47) com similaridade de 0,42, e está relacionada com a topologia da molécula, sendo o x14, índice topológico de Balaban. 0 grupo 2, que também apresenta bom grau de similaridade, está dividido pelos descritores x37 e x27 (lipofilicidade), x20 e x19 (estereoquímica) e x12 e x15 (topológico) e os 
descritores que não apresentam similaridade com a atividade biológica estão representados no grupo 3, sendo eles, x8, x6, x2 e x7 (caráter eletrônico).

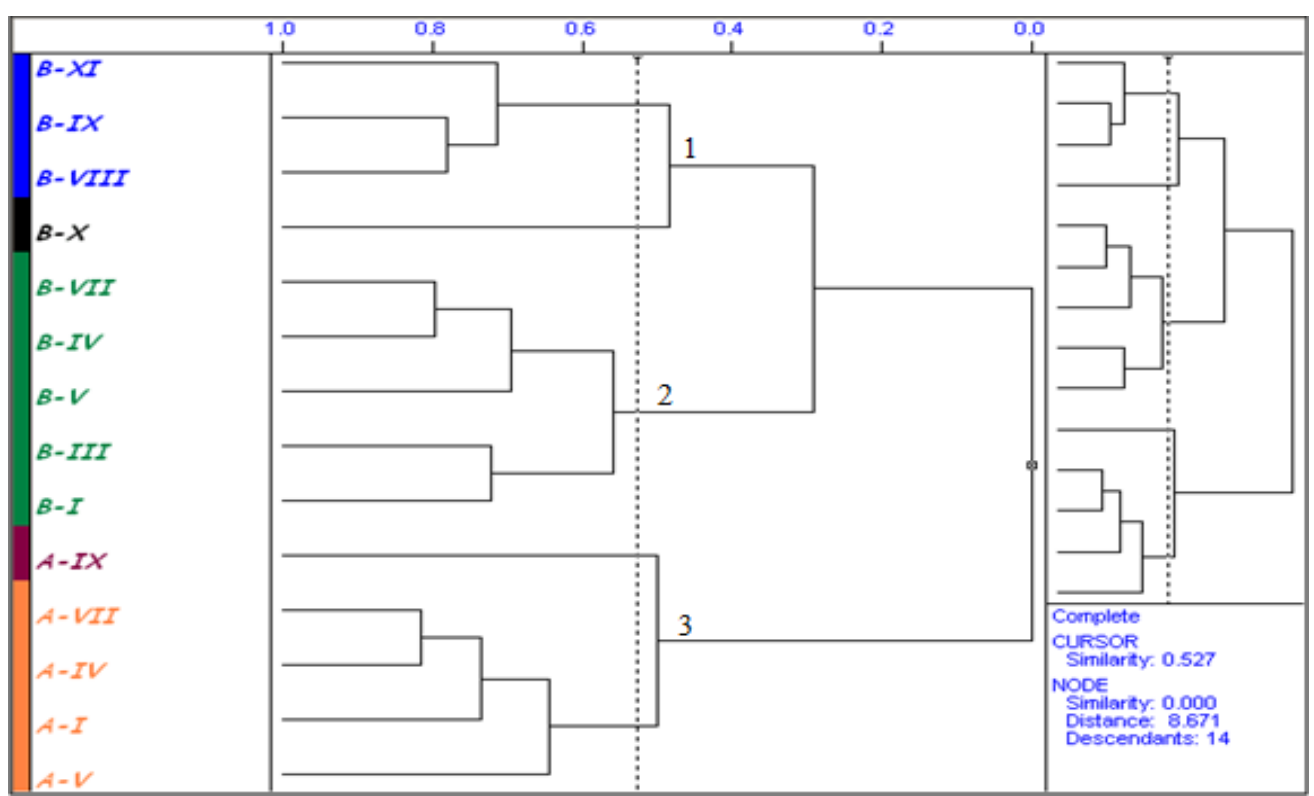

Figura 46. Dendograma dos compostos série $A$ e $B$ estudados frente a $C$. albicans.

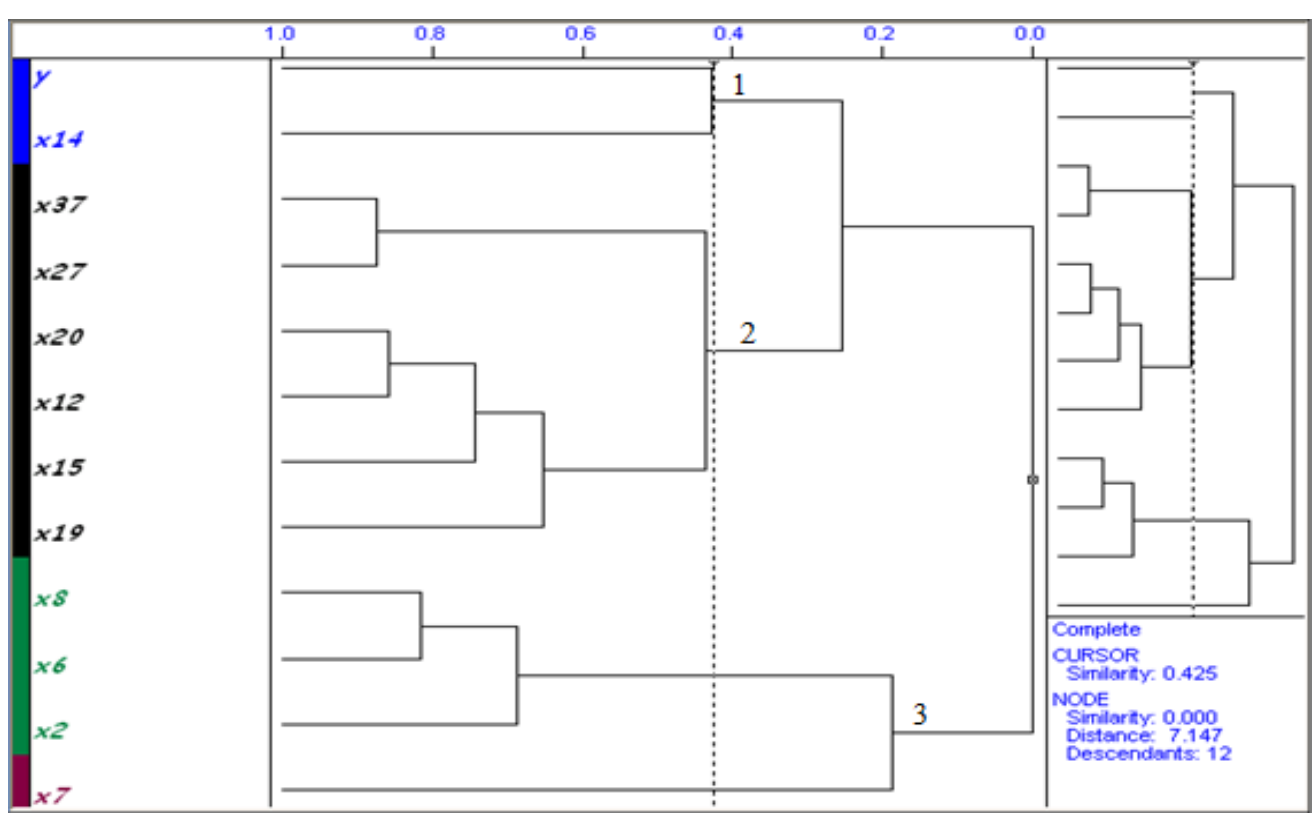

Figura 47. Dendograma dos descritores estudados frente a $C$. albicans.

Referente as análises de PCA frente a $C$. albicans pode-se observar na tabela 32 , que a PC2 (factor 2) descreve 19,25\% das informações de entrada, enquanto a PC1 (factor 1) descreve $62,03 \%$ e divide os compostos da série $A$ e $B$ ao traçar uma reta perpendicular em seu eixo O (figura 48), ou seja, separa os compostos mais ativos série $B$, dos compostos 
menos ativos série A. Referente aos pesos (loadings) das PCs observa-se na tabela 31, que a PC1 apresenta maior peso com os descritores topológicos (Platt, Harary), estereoquímicos (Dreiding, VW) e eletrônicos (O 1-14, N 7-20, C 19-11), com exceção dos descritores lipofílicos ( $\mathrm{Clog}_{\mathrm{MB}}$, ClogP sv) e dos descritores C 11-1 (eletrônico) e Balaban (topológico) que apresentam maior peso $(0,54)$ na PC2. Estudos de QSAR dos compostos benzamidínicos substituídos frente ao fungo Cryptococcus neofarmans, demonstram que a topologia da molécula (índice de Balaban) é um fator importante para a atividade biológica frente a fungos (Almeida et al., 2010). Segundo Almeida e colaboradores, quanto menor o parâmetro topológico de Balaban maior será a potência frente ao fungo C. neofarmans. Comparando as séries $A$ e $B$, confirmou-se essa colocação, pois se observou que a série $A$ apresentou uma média do parâmetro topológico de Balaban maior $(1,51)$ em comparação à série $B(1,48)$ apresentando esta atividade biológica promissora.

Tabela 32. Resultados obtidos da análise de PCA quanto a contribuição das PCs e valores dos pesos dos descritores frente a $C$. albicans.

\begin{tabular}{cccc|cccc}
\hline \multicolumn{3}{c|}{ Seleção das componentes principais } & \multicolumn{4}{c}{ Pesos (loadings) } \\
\hline & Variância & Porcentagem & Cumulativo & Descritores & PC1 & PC2 \\
\hline PC1 & 88,70 & 62,03 & 62,03 & $x 2$ & O 1-14 & $-0,33$ & 0,18 \\
PC2 & 27,54 & 19,25 & 81,30 & $x 6$ & N $7-20$ & $-0,34$ & 0,00 \\
PC3 & 13,35 & 9,33 & 90,63 & $x 7$ & C 11-1 & 0,05 & $-0,56$ \\
PC4 & 6,50 & 4,54 & 95,15 & $x 8$ & C 19-11 & $-0,34$ & 0,03 \\
PC5 & 3,80 & 2,66 & 97,83 & $x 12$ & Platt & 0,35 & $-0,11$ \\
PC6 & 1,74 & 1,21 & 99,57 & $x 14$ & Balaban & 0,01 & 0,54 \\
PC7 & 0,75 & 0,52 & 99,57 & $x 15$ & Harary & 0,35 & 0,00 \\
PC8 & 0,42 & 0,30 & 99,87 & $x 19$ & Dreiding & 0,34 & $-0,13$ \\
& & & & $x 20$ & VW & 0,35 & $-0,07$ \\
& & & & $x 27$ & Clog $\mathrm{P}_{\mathrm{MB}}$ & 0,28 & 0,36 \\
& & & & $x 37$ & ClogP & 0,25 & 0,42 \\
\hline
\end{tabular}

[Nota: O 1-14: carga do potencial eletrostático do átomo de oxigênio carbonílico para série $\mathrm{A} e$ do oxigênio do anel oxadiazolínico para série B, calculados por CHELPG; N 7-20: carga do potencial eletrostático do átomo de nitrogênio do grupo nitro ligado ao anel tiofênico para as séries $A$ e $B$, calculados por CHELPG; C 11-1: carga do potencial eletrostático do átomo de carbono do anel benzênico realizando ligação com substituintes na posição 4 para as séries $A$ e B, calculados por CHELPG; C 19-11: carga do potencial eletrostático do átomo de carbono do anel tiofênico ligado ao grupo nitro para as séries A e B, calculados por CHELPG; Platt : índice que descreve a soma dos graus de contorno da superfície molecular; Balaban : índice que descreve a média da somatória da distância de conectividade da molécula ; Harary: índice que descreve a metade da somatória da diagonal externa, distância matricial recíproca, dos elementos da molécula; Dreiding : energia relacionada com a estabilidade da conformação da molécula; VW : volume de van der Waals ; $\mathrm{Clog}_{\mathrm{MB}}$ : coeficiente de partição calculado pelo método de pesos do programa, considerado pesos iguais para os métodos de VISVANADHAN et al ., 1989, KLOPMAN et al., 1993 e PHYSPROP ${ }^{\odot}$ database; L e B5: parâmetros de STERIMOL (VERLOOP, 1987); ClogP $\mathrm{P}_{\text {Sv: }}$ coeficiente de partição calculado pelo método VISVANADHAN et al. , 1989]. 
A figura 48 demonstra concordância com a análise de HCA (figura 46), onde o agrupamento dos compostos da região A apresentam coerência com o dendograma da figura 46 (grupo 2 análise de HCA), o mesmo observa-se para a região B em coerência com o grupo 1 (figura 46), na região esquerda do gráfico observa-se os derivados série A que apresentaram baixa atividade antimicrobiana igualmente com o grupo 3 do dendograma da análise de HCA.

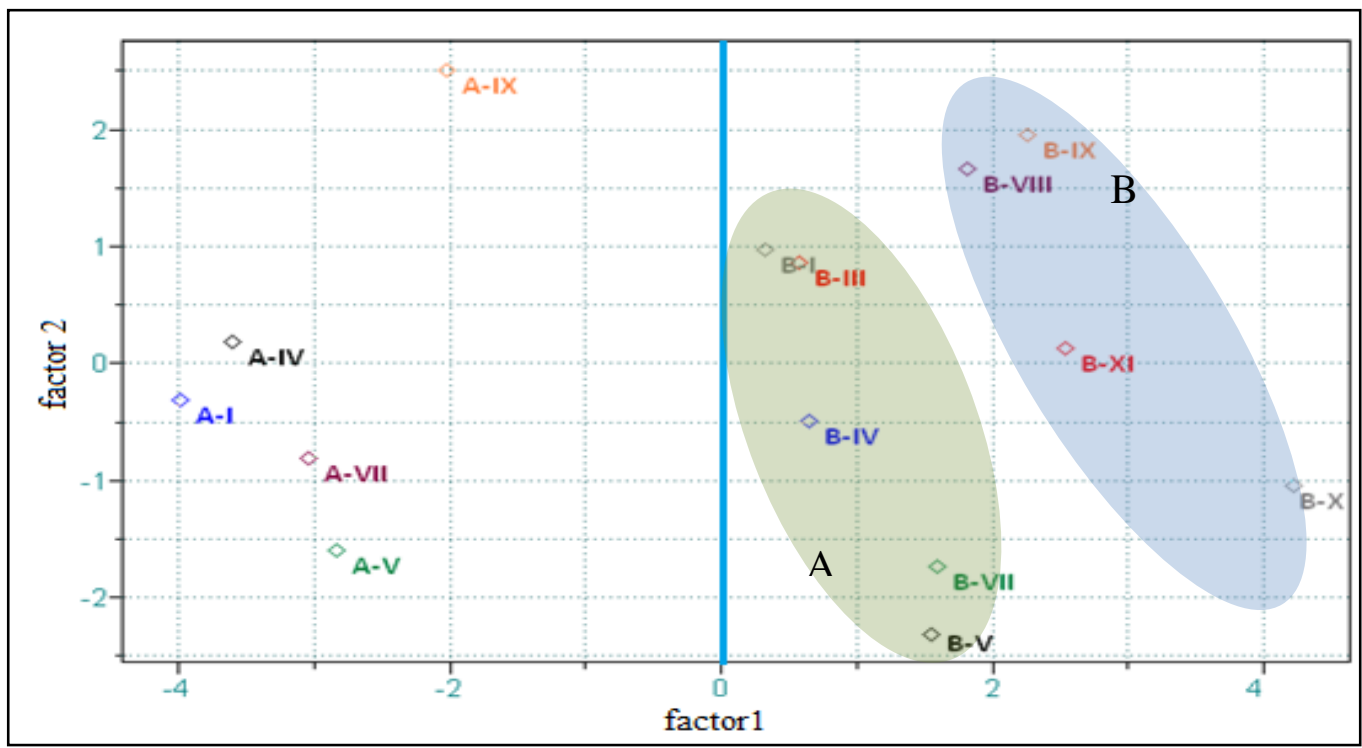

Figura 48. Escores entre PC1 e PC2, grupo dos compostos avaliados frente a C. albicans.

O gráfico de amostra residual versus distância de Mahalanobis também foi avaliado para diagnosticar possíveis amostras de outliers (figura 49). Observa-se pelo gráfico que não houve amostras atípicas (outliers) para a avaliação do micro-organismo C.albicans.

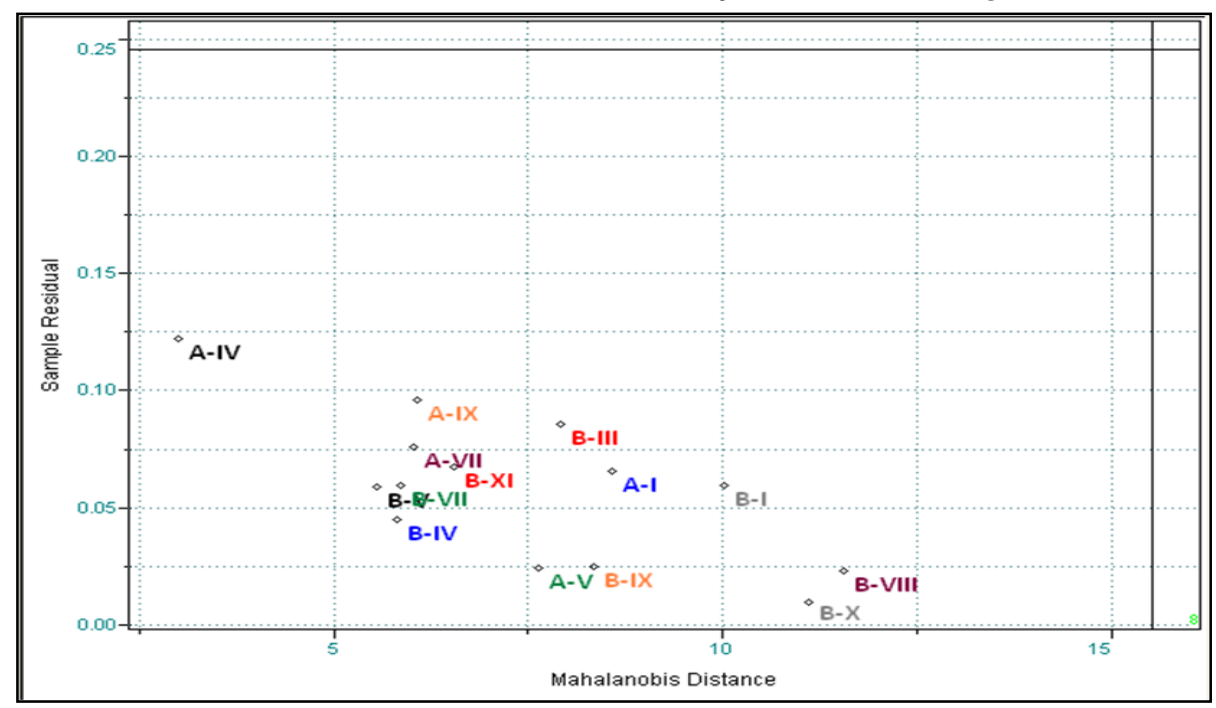

Figura 49. Distância residual das amostras em relação à distância de Mahalanobis para a análise de C.albicans. 


\subsubsection{Análise exploratória de dados obtidos para E. faecalis}

No dendograma de amostras de $E$. faecalis (figura 50 ) foi utilizado como referência um cursor de similaridade 0,61 (linha pontilhada) sendo os compostos agrupados em 4 categorias. No grupo 1 (similaridade 0,33 ) observa-se o agrupamento dos derivados oxadiazolínicos considerando os compostos de menor atividade biológica. No grupo 2 (similaridade 0,27 ) observa-se os compostos que apresentaram maior atividade biológica, observando-se relação de equilíbrio entre o caráter de lipofilicidade e efeito eletrônico. Em 2' observa-se os derivados A-II e A-XI ambos derivados azometínicos que apresentam características de alta lipofilicidade e caráter eletrônico muito similar (momento dipolo e cargas CHELPG) em comparação com os derivados de menor atividade biológica, o que pode ser um fator limitante para a atividade biológica. No subgrupo 2" observa-se os derivados A-IX e A-III com caráter eletrônico e lipofílico também muito similares. Para os derivados A-I e A-V, localizados em 2"' no dendograma, pode-se observar caráter hidro/lipofílico muito parecido (similaridade 0,82 ), sendo que estes compostos apresentam características mais hidrofílicas dentro do grupo de compostos analisados.

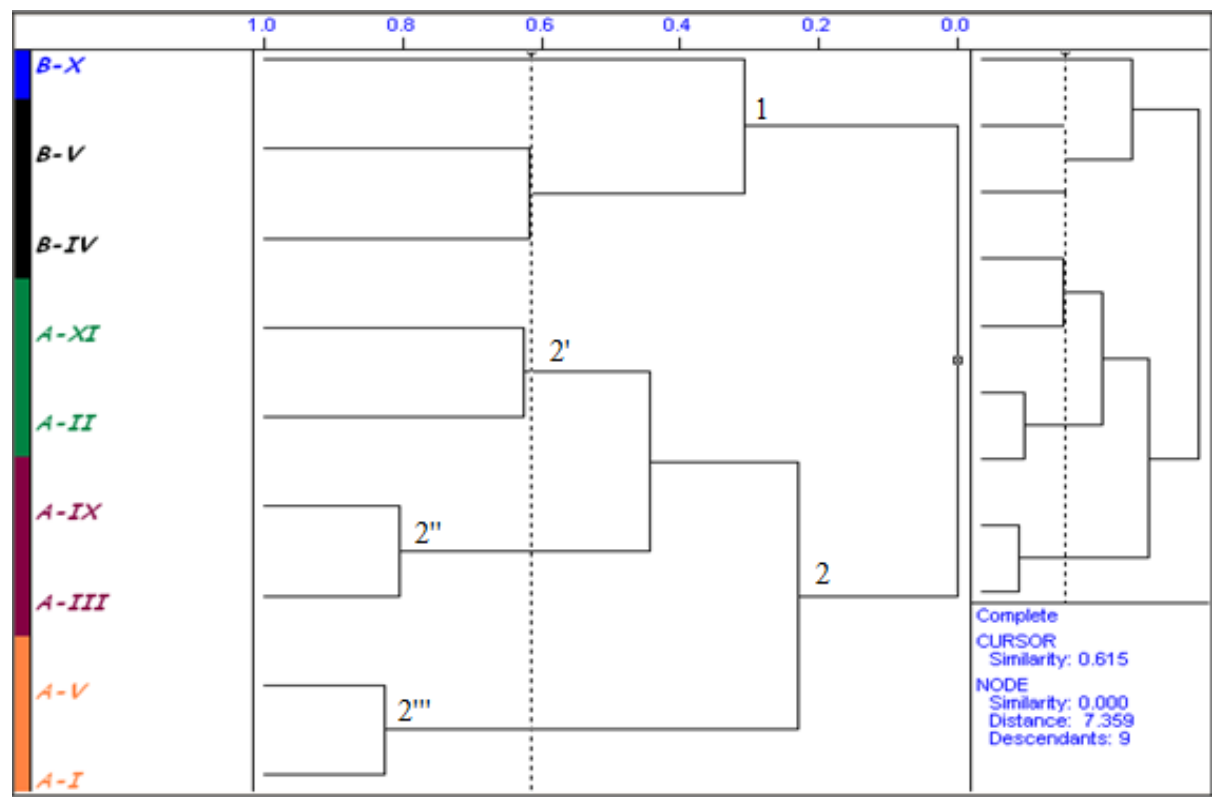

Figura 50. Dendograma dos compostos série A e B estudados frente a E. faecalis.

O descritor que melhor representa a atividade biológica frente a E. faecalis, foi o $x 1$ ( $\mu$, momento dipolo) descritor eletrônico que mede a carga deslocalizada quando átomos de eletronegatividade diferentes são interligados (figura 51), localizado no subgrupo 1', apresenta similaridade de 0,54 com a atividade biológica. O subgrupo 1" é formado pelos descritores hidrofóbicos $\left(C \log \mathrm{P}_{S V}, C \log \mathrm{P}_{\mathrm{MB}}, C \log \mathrm{P}_{\mathrm{SG}-\mathrm{SLN}}\right.$ e $\left.\pi\right)$, enquanto o subgrupo 1'” é 
formado pelas propriedades eletrônica (O 1-14), descritor de carga de potencial eletrostático (CHELPG) e estereoquímica (ASA-) superfície acessível a solvente de todos os átomos com carga parcial negativa. As propriedades que menor relacionam a atividade biológica estão destacadas no grupo 2 e se dividem em propriedades estereoquímicas (VW, Dreiding) e eletrônicas (S 2-10, $\mathrm{E}_{\text {Hомо }}$ e $\mathrm{E}_{\text {LUMO }}$ ).

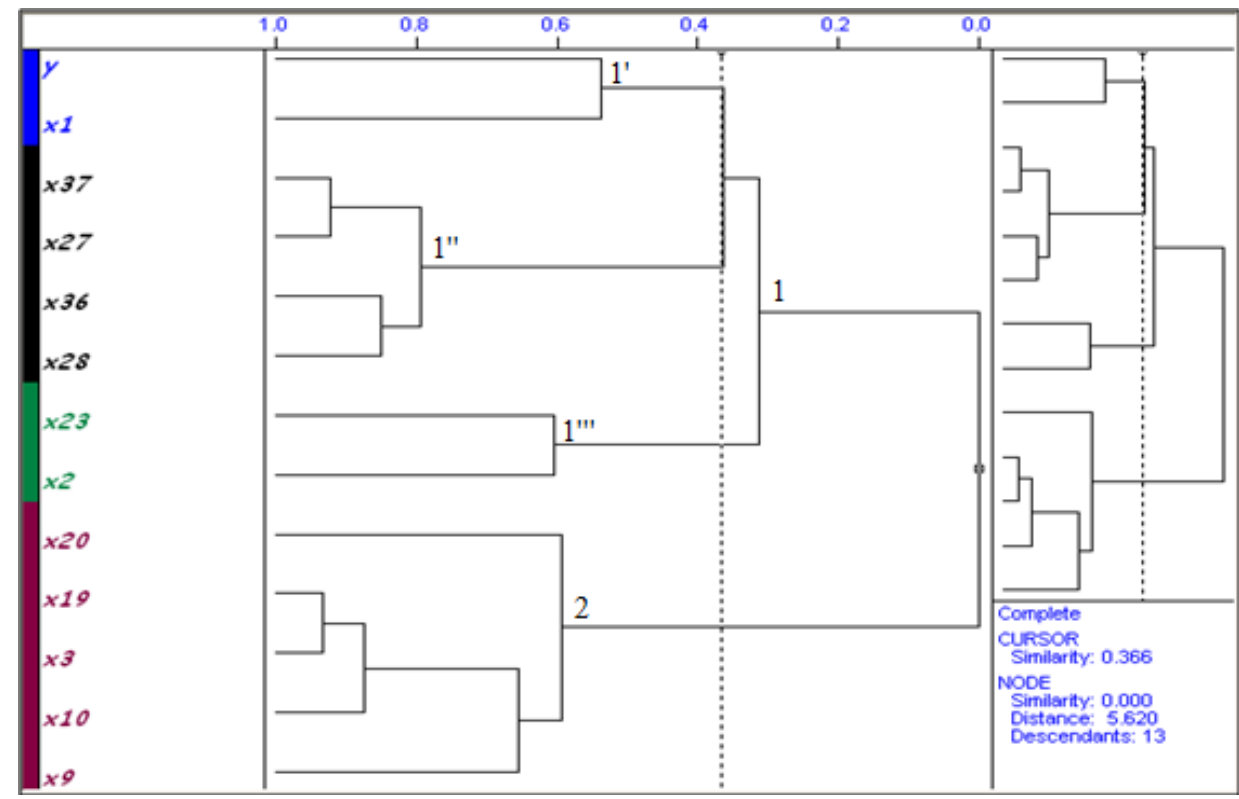

Figura 51. Dendograma dos descritores estudados frente a E. faecalis.

A análise de PCs mostra que a segunda componente principal (factor 2) descreve $35,81 \%$ da informação de entrada, conforme mostra a tabela 33. A PC1 (factor 1) descreve $52,77 \%$ e divide os compostos de séria $A$ e série $B$ ao traçar uma reta perpendicular em seu eixo 0. Comparando a análise de PCA com a de HCA, observa-se concordância nos resultados, a começar pela distinção dos derivados de ambas as séries, onde é observado no grupo 1 do dendograma da figura 50, coerência com a região D da figura 52 (derivados de menor atividade biológica). Levando em consideração os derivados de melhor atividade biológica, na análise de PCA observam-se os compostos da região $A, B$ e $C$ em concordância com os subgrupos de dendogramas 2', 2" e 2"' da figura 50 . Observando os pesos (loadings) de cada descritor na tabela 33, conclui-se que os descritores que apresentam maior peso $(0,38)$ sobre a PC1 (factor 1$)$ são os de caráter eletrônicos $(0$ 1-14, S 2-10, $\mathrm{E}_{\text {lumo }}$ ), enquanto que na PC2 (factor 2) os de caráter lipofílico (Clog $\mathrm{P}_{\mathrm{MB}}, \pi, \mathrm{Clog} \mathrm{P}$ SGSLN, ClogP sv) que apresentam pesos que variaram entre 0,46 a 0,40. O composto mais ativo (A-II) entre as duas séries apresentou alta hidrofobicidade, valor de ClogP elevado, e momento dipolo elevado, indicando que o equilíbrio hidrófilo/lipófilo tem papel importante para a atividade biológica de E. faecalis. 


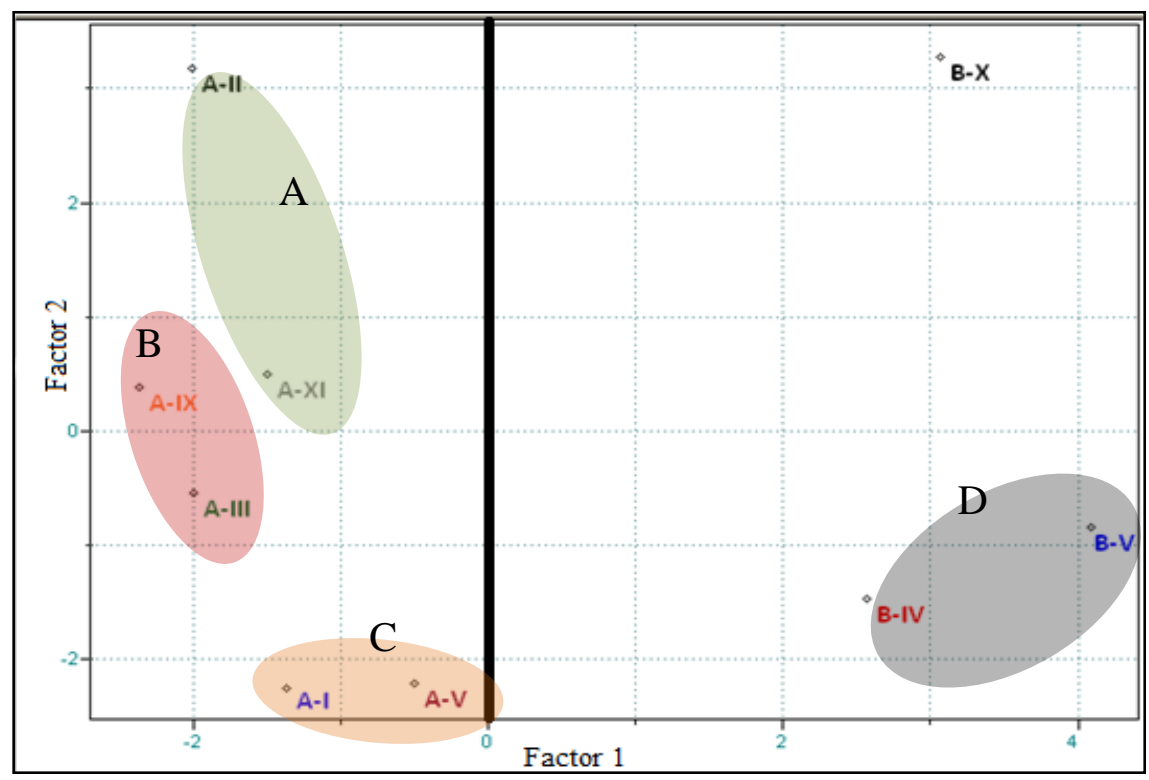

Figura 52. Escores entre PC1 e PC2, grupo dos compostos avaliados frente a E. faecalis.

Tabela 33. Resultados obtidos da análise de PCA quanto a contribuição das PCs e valores dos pesos dos descritores frente a $E$. faecalis.

\begin{tabular}{|c|c|c|c|c|c|c|c|}
\hline \multicolumn{4}{|c|}{ Seleção das componentes principais } & \multicolumn{4}{|c|}{ Pesos (loadings) } \\
\hline & Variância & Porcentagem & Cumulativo & \multicolumn{2}{|c|}{ Descritores } & $P C 1$ & $P C 2$ \\
\hline PC1 & 50.65 & 52.77 & 52.77 & $\mathrm{x} 1$ & $u$ & $-0,31$ & 0.03 \\
\hline PC2 & 34.38 & 35.81 & 88.58 & $x 2$ & O $1-14$ & $-0,38$ & -0.06 \\
\hline PC3 & 8.46 & 8.82 & 97,40 & $x 3$ & S 2-10 & 0.38 & 0.07 \\
\hline PC4 & 1.78 & 1.85 & 99.25 & $x 9$ & $\mathrm{E}_{\text {номо }}$ & 0.33 & 0.16 \\
\hline PC5 & 0,52 & 0,54 & 99,80 & $\mathrm{x} 10$ & $\mathrm{E}_{\text {LUMO }}$ & 0,38 & 0,09 \\
\hline \multirow[t]{7}{*}{ PC6 } & 0,14 & 0,15 & 99,96 & x19 & Dreiding & 0,38 & 0,07 \\
\hline & & & & $x 20$ & VW & 0,23 & 0,37 \\
\hline & & & & $x 23$ & ASA- & $-0,25$ & 0,11 \\
\hline & & & & $x 27$ & $C \log P_{M B}$ & $-0,08$ & 0,46 \\
\hline & & & & $x 28$ & $\pi$ & $-0,11$ & 0,45 \\
\hline & & & & x36 & ClogP sG- & $-0,21$ & 0,40 \\
\hline & & & & x37 & $\mathrm{Clog}_{\mathrm{P}}$ & $-0,10$ & 0,45 \\
\hline
\end{tabular}

[ $\mu$ : momento de dipolo; $O$ 1-14: carga do potencial eletrostático do átomo de oxigênio carbonílico para série $A$ e do oxigênio do anel oxadiazolínico para série $B$, calculados por CHELPG; S 2-10: carga do potencial eletrostático do átomo de oxigênio do anel tiofênico para as séries $A$ e $B$,calculados por CHELPG; $E_{\text {HOMO }}$ : energia do orbital de fronteira HOMO; $E_{L U M O}$ : energia do orbital de fronteira LUMO; Dreiding : energia relacionada com a estabilidade da conformação da molécula; VW: volume de van der Waals; ASA-: superfície acessível a solvente de todos os átomos com carga parcial negativa; $C_{\log } \mathrm{P}_{\mathrm{MB}}$ : coeficiente de partição calculado pelo método de pesos do programa, considerado pesos iguais para os métodos de VISVANADHAN et al ., 1989, KLOPMAN et al. , 1993 e PHYSPROP ${ }^{\circledR}$ database; $\pi$ : constante $\pi$ de Hansch; ClogP sG-SLN : coeficiente de partição calculado pelo método GHOSE et al., 1998 - SLN; ClogP $P_{S V}$ : coeficiente de partição calculado pelo método VISVANADHAN et al. , 1989]. 
O gráfico de amostra residual versus distância de Mahalanobis também foi avaliado para diagnosticar possíveis amostras de outliers (figura 53). Observa-se pelo gráfico que não houve amostras atípicas (outliers) para E. faecalis.

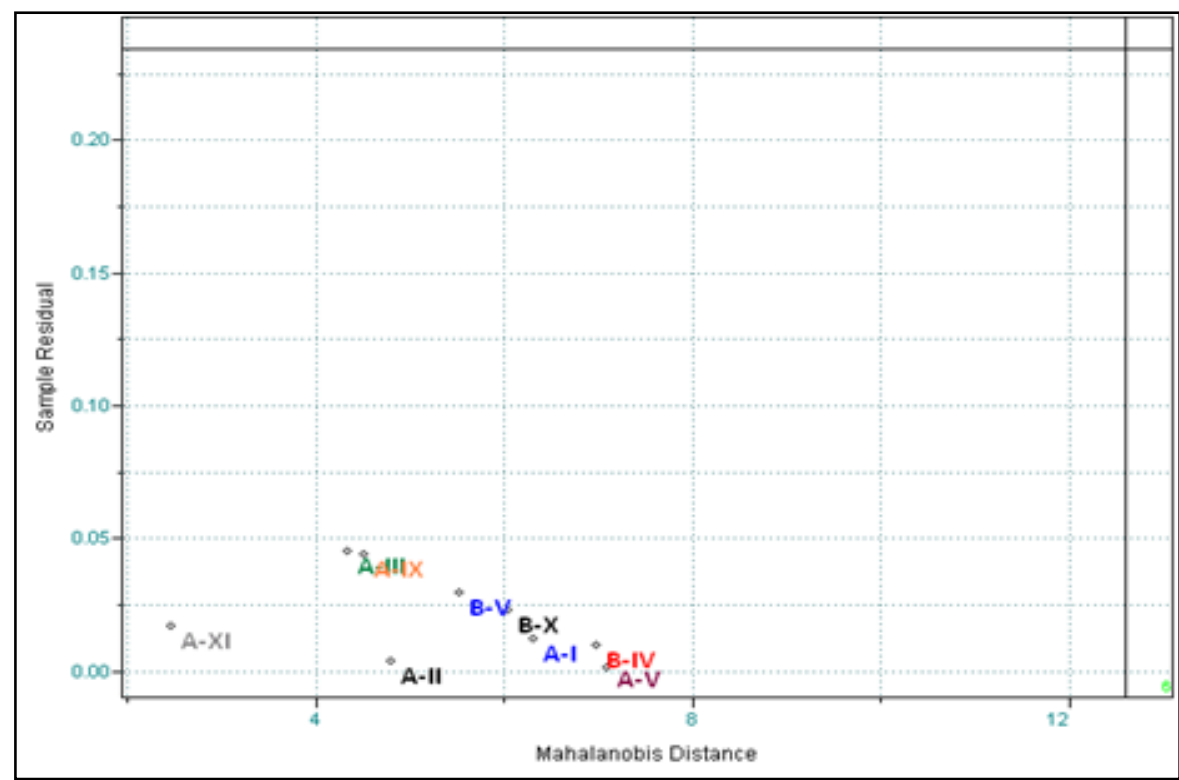

Figura 53. Distância residual das amostras em relação à distância de Mahalanobis para o micro-organismo E. faecalis.

Considerando os resultados da análise exploratória, verifica-se que além da hidrofobicidade presente nos três estudos de análises exploratórias, verificou-se também que para a atividade biológica dos compostos frente a $E$. faecalis, a contribuição da propriedade eletrônica, representada pelo momento dipolo $(\mu)$ e cargas do potencial eletrostático (CHELPG), foi de extrema importância. Para a atividade biológica dos compostos frente a $C$. albicans os descritores topológicos (Balaban e Harary) representaram grande contribuição. No caso da atividade antimicrobiana dos compostos frente a S.aureus observa-se que a melhor contribuição foi da propriedade estereoquímica, representada pelo descritor PSA (área de superfície polar).

Em estudos anteriores de comparação dos compostos da séria A (azometínicos) e série $B$ (oxadiazolínicos), observa-se que estes compostos se diferenciam estruturalmente em sua flexibilidade e na presença de regiões que possibilitam interações por ligações de hidrogênio (SONEHARA, 2009). Os compostos oxadiazolínicos apresentam estrutura mais rígida, com presença de grupo acetila, que representa possibilidade de interações por ligação de hidrogênio na região da carbonila e hidrofóbica através do grupo metila, confirmada pelos mapas de distribuição de propriedades lipofílicas e eletrônicas obtidos pelo programa Sybyl 8.0 e GaussView 3.0 (SONEHARA, 2009). Com esta teoria pode-se concluir 
que os derivados oxadiazolínicos possuem conformação mais favorável para atividade antimicrobiana de C. albicans em comparação aos derivados azometínicos, esta mesma observação aplica-se aos estudos de docking com a enzima CYP51 responsável pela síntese de ergosterol em membrana da célula de fungos (SONEHARA, 2009).

\section{CONCLUSÕES}

Foram sintetizados 20 compostos, sendo 11 derivados tiofilidênicos azometínicos (série A) e 9 derivados tiofilidênicos oxadiazolínicos (série B). Os 20 compostos obtidos foram identificados por análise espectrométrica de $\mathrm{RMN}{ }^{1} \mathrm{H}$ e de $\mathrm{RMN}{ }^{13} \mathrm{C}$. As análises de faixa de fusão e elementar ( $\mathrm{CHN}$ ) comprovaram a de pureza dos compostos obtidos. A obtenção de benzidrazidas em etapa sintética única mostrou-se compatível com a descrição na literatura e reprodutível para os novos compostos obtidos. Dificuldades sintéticas foram observadas para os derivados série $A-\mathbf{C O C H}_{3}$, série $\mathrm{B}-\mathbf{t}-\mathbf{C}_{4} \mathbf{H}_{9}$ e série $\mathrm{B}-\mathbf{n}-\mathbf{C}_{4} \mathbf{H}_{9}$, demonstrando que uma nova rota sintética deverá ser proposta para a obtenção destes compostos.

Entre os compostos testados frente às cepas de S. aureus (ATCC 29213 e VISA3), observa-se que fatores da análise biológica interferiram nos resultados, quando comparados aos descritos na literatura. Levando em consideração a metodologia e os meios de cultura utilizados na análise experimental deste trabalho, comparativamente aos da literatura, podese observar que a aplicação do método de microdiluição mostrou-se de rápida execução e mais econômico em tempo e material empregado.

Os compostos que apresentaram melhor atividade biológica frente à cepa ATCC 29213 e VISA3 foram o série A-CN (A-IV), que apresentou $\mathrm{CIM}=3,33$ - 1,66 $\mu \mathrm{M}$, e série A$\mathrm{OCH}_{3}(\mathrm{~A}-\mathrm{V})$, que apresentou $\mathrm{CIM}=3,27-1,63 \mu \mathrm{M}$, para ambas as cepas, mostrando-se mais ativo que os fármacos utilizados como padrão .

Para E. faecalis observou-se resultados promissores para os compostos série A- $\mathbf{n}$ $\mathbf{C}_{4} \mathbf{H}_{9}(\mathbf{A}-\mathrm{II})(\mathrm{CIM}=3,01-1,50 \mu M)$ e série $\mathrm{A}-\mathbf{H}(\mathbf{A}-\mathrm{I})(\mathrm{CIM}=3,63-1,81 \mu M)$ que apresentaram boa atividade antimicrobiana.

Dentre os compostos testados frente a E. coli, K. pneumoniae, E. cloacae e S. marcescens, nenhuma das duas séries apresentou atividade biológica considerável, cabendo supor que estes compostos não apresentam atividade antimicrobiana para bactérias Gram negativas.

Referente à $C$. albicans os derivados da série $B$ apresentaram considerável atividade antimicrobiana, onde o composto de maior atividade foi o composto série B-CN (B- 
IV), apresentando $\mathrm{CIM}=5,84-2,92 \mu M$, indicando ser promissor candidato a estudos mais aprofundados.

Concluiu-se que a determinação da concentração inibitória de $90 \% \quad\left(\mathrm{IC}_{90}\right)$ apresentou resultados compatíveis com ambas as fases de análise microbiológica realizadas no estudo e foi essencial estudo de relações estrutura-atividade, para a inserção destes dados nos programas computacionais que auxiliaram tanto na construção dos modelos moleculares quanto, nos estudos de análise exploratória de dados.

Os estudos de modelagem molecular realizados pelos mapas de potencial eletrostáticos (MEPs), demonstraram pouca variação de densidade eletrônica em relação aos substituintes na posição 4 para as séries A e B. Para os mapas de distribuição molecular de HOMO e LUMO pode-se observar diferenças em relação ao composto série BCN (B-IV) onde observa-se que as energias de HOMO e LUMO estão distribuídas por quase toda a molécula. Quanto às propriedades hidrofóficas pode-se comparar as características lipo-hidrofílicas entre a séria $A$ e série $B$ e seus substituintes.

Considerando os dados obtidos, a análise de relações estrutura-atividade indica que a atividade antimicrobiana para os oito micro-organismos estudados está relacionada ao equilíbrio lipofílico/hidrofílico sendo que características como o efeito eletrônico (atividade antibacteriana de E. faecalis), topológico (antifúngica de $C$. albicans) e estereoquímica (atividade antibacteriana de $S$. aureus) contribuem para o melhor entendimento da atividade antimicrobiana desempenhada pelos compostos analisados.

\section{PERSPECTIVAS}

Os resultados obtidos neste trabalho mostraram-se promissores, tanto pela atividade antimicrobiana de alguns compostos, quanto no sentido de abrir possibilidades de estudos mais aprofundados em relação à busca e entendimento de características físicoquímicas que mais influenciam a resposta biológica analisada.

O presente estudo demonstra indicações interessantes sobre as propriedades físico-químicas dos compostos azometínicos e oxadiazolínicos estudados. Assim, para etapas futuras, propõe-se:

-Síntese dos compostos da série $A-\mathbf{C O C H}_{3}$, da série $B-\mathbf{n}-\mathbf{C}_{4} \mathbf{H}_{9}$, e da série $B-t-\mathbf{C}_{4} \mathbf{H}_{9}$, explorando novas rotas sintéticas e avaliação biológica destes compostos frente a micro-organismos;

- Ampliação da série de compostos visando a possibilidade de aplicação de estudos quantitativos de relações estrututra-atividade, como a Análise de Hansch, na 
expectativa de melhor conhecer as propriedades físicoquímicas que mais influencias a atividade biológia analisada.

- Propor estudos de identificação de possíveis alvos biológicos (Enzimas e Proteínas) para os compostos azometínicos e oxadiazolínicos analisados neste estudo. 


\section{REFERÊNCIAS BIBLIOGRÁFICAS}

ADMET/MI-QSAR, Version 1.0 User's Guide; The Chem21 Group, Inc., 200. Chicago, 2001.

AGENCIA NACIONAL DE VIGILÂNCIA SANITÁRIA (ANVISA, 2011). RESOLUÇÃO - RDC № 20, DE 5 DE MAIO DE 2011.

AGENCIA NACIONAL DE VIGILÂNCIA SANITÁRIA (ANVISA, 2012). Serviços da Saúde. Disponível em http://www.anvisa.gov.br/servicosaude/controle/rede rm/index.htm. Acesso 13 de junho de 2012.

AGENCIA NACIONAL DE VIGILÂNCIA SANITÁRIA (ANVISA, 2013). Pesquisa Clínica. Considerações e definições para Pesquisa Clínica. Disponível em http://www.anvisa.gov.br/medicamentos/pesquisa/def.htm acesso 10 de agosto de 2013.

AGUIERRE. G. et al. Benzo[1,2,-c]1,2,5-oxadiazole N-oxide derivates as potential antitrypanosomal drugs. Part 3: Substituents-clustering methodology in the search for new active compounds. Bioorganic Medicinal Chemistry. v.13, p 6324-6335, 2005.

ALEKSHUN, N.M. AND LEVY, S.B. Molecular Mechanisms of Antibacterial Multidrug Resistance. Cell. v.128, p. 1037-1050, 2007.

ALLINGER, N.L. Conformational analysis. 130. MM2. A hydrocarbon force field utilizing V1 and V2 torsional terms. Journal of the American Chemical Society. v. 99, p.8127 - 8134, 1977.

ALMEIDA, L.V. (2008). Síntese e determinação da atividade antimicrobiana de 2-[5-nitrotiofen-2-il]-3-acetil-5-[4-fenil-substituído]-2,3-diidro-1,3,4-oxadiazol frente à cepa ATCC 25923 de Staphylococcus aureus. Dissertação de mestrado, Faculdade de Ciências Farmacêuticas, Universidade de São Paulo, São Paulo.

ARIAS C.A, MURRAY B.E. The rise of the Enterococcus: beyond vancomycin resistance. Nature Reviews Microbiology. v.10, p. 266-278, 2012.

ARROIO, A; HONORIO, M.; SILVA,B. F. Propriedades químico-quânticas empregadas em estudos das relações estrutura-atividade. Química. Nova. v.33, p.694-699, 2010.

ALMEIDA, Vera L. de et al. Estudos de relações estrutura-atividade quantitativas (QSAR) de bis-benzamidinas com atividade antifúngica. Química Nova. v.33, pp. 1482-1489, 2010.

BABER, J.C., THOMPSON, D.C., CROSS, J.B., HUMBLET, C. GARD: A Generally Applicable Replacement for RMSD. Journal of Chemical Information and Modeling . v. 49, p. 1889 1900, 2009. 
BARREIRO, E. J. Estratégia de simplificação molecular no planejamento racional de fármacos: a descoberta de novo agente cardioativo. Química Nova. v.25, p. 1172-1180, 2002.

BARREIRO, E. J., FRAGA, C.A.M. A questão da inovação em fármacos no Brasil: proposta de criação do programa nacional de fármacos (Pronfar). Química Nova., v.28,p. S56-S63, 2005.

BARREIRO, E.J., FRAGA, C.A.M. Química medicinal: As bases moleculares da ação dos fármacos. Artmed, $2^{\circ}$ Ed. Porto Alegre. p.536, 2008.

BOUCHER, H. W. et al. Bad Bugs, No Drugs: No ESKAPE! An Update from the Infectious Diseases Society of America. Clinical Infectious Diseases. v. 48, p. 1-12, 2009.

BRENEMAN,C.M., WIBERG,K.B. Determining atom-centered monopoles from molecular electrostatic potencials. The need for high sampling density in formamide conformational analysis. Journal of Computational Chemistry . v. 11, p. 361-373, 1990.

BRITO, M. A., CORDEIRO, B. C. Necessidade de novos antibióticos. Jornal Brasileiro de Patologia e Medicina Laboratorial. v. 48, p. 247-249, 2012.

CALIXTO, J. B., SIQUEIRA JR. J. M. Desenvolvimento de Medicamentos no Brasil: Desafios. Gazeta Médica da Bahia. v.78, p. 98-106, 2008.

CAREY, F.A., SUNDBERG, R. J. Advanced Organic Chemistry. 4.ed. New York: Plenum Press, 2000.

CERECETTO, H., et al. Synthesis and ati-trypanosomal activity of novel 5-nitro-2furaldehyde and 5-nitrothiophene-2-carboxaldehyde semicarbazone derivates. Farmaco. Lausanne, v. 53, p.89-94, 1998.

CLARK D. E. AND PICKETT S. P. Computational methods for the prediction of 'druglikeness'. Drug Discovery Today. V. 5, p. 326-336, 2000.

CLINICAL AND LABORATORY STANDARS INSTITUTE (CLSI). Performance Standards for Antimicrobial Susceptibility Testing; Seventeenth Infromational Supplement. Clinical and Laboratory Standards Institute, M100-S17, 2007.

CLINICAL AND LABORATORY STANDARS INSTITUTE (CLSI). Reference Method for Broth Dilution Antifungal Susceptibility Testing of Yeasts; Approved Standard-Second Edition. Clinical and Laboratory Standards Institute, M27-A2, 2002.

COLOMBO, A. L., GUIMARÃES, T., Epidemiology of hematogenous infections due to Candida spp. Revista da Sociedade Brasileira de Medicina Tropical, v.36, p. 599-607, 2003. 
CONLY, John. Antimicrobial resistance in Canada. Canadian Medical Association Journal, v. 167, n. 8, p. 885-891, 2002.

CORREA, L., Restrição do uso de antimicrobianos no ambiente hospitalar. Einstein: Educação Continuada em Saúde. v. 5, p. 48-52, 2007.

CORREIA, P. R. M., FERREIRA, M. M. C. Reconhecimento de padrões por métodos não supervisionados: explorando procedimentos quimiométricos para tratamento de dados analíticos. Química Nova. v. 30, p 481-497, 2007.

CDC (Centers for Disease Control and Prevention). Antibiotic resistance threats in the United States, 2013. Disponivel em http://www.cdc.gov/drugresistance/threat-report-2013/.

CRAIG, P.N. Interdependence between physical parameters and selection of substituent groups for correlation studies. Journal of the American Chemical Society. v. 14, p. 680684, 1971.

CRAMER, III, R.D., PATERSON, D.E. BUNCE, J.D. Comparative Molecular Field Analysis (CoMFA). 1. Effect of Shape on Binding of Steroids to Carrier Proteins. Journal American Chemical Society. v.110, p.5959-5967. 1988.

CRONIN, M. T. D., SCHULTZ, T. W. Pitfalls in QSAR. Journal of Molecular Structure (Theo Chem). v. 622, p. 39-51, 2003.

DEWAR, M.J.S.E., ZOEBISCH, G., HEALY, E.F., STEWART, J.J.P. AM1: A new general purpose quantum mechanical molecular model. Journal of the American Chemical Society. v. 107, p. $3902-3909,1985$.

DIENSTMANN $\mathrm{R}$, et al., Avaliação fenotípica da enzima Klebsiella pneumoniae carbapenemase (KPC) em Enterobacteriaceae de ambiente hospitalar. Jornal Brasileiro Patologia Medicina Laboratorial. v. 46, p. 23-27, 2010.

DOHERTY, D. MOLSIM: Molecular Mechanics and Dynamics Simulation Software, version 3.2 - User's Guide. The Chem21 Group Inc., 1780 Wilson Dr., Lake Forest, IL, 60045, EUA, 2002.

DOMAGK, G., BHNISH, R., MIETZCH, F. Uber eine neue, gegen Tuberkelbazillen in vitro wirksame Verbindungsklasse, Naturwissenscheften. Vol. 33, p. 315-319, 1946.

DREWS, J. Intent and coincidence in pharmaceutical discovery. The impact of biotechnology. Progress in Drug Research. v.45, p.934-939, 1995.

EAGYE, K.J, et al . In vitro activity and pharmacodynamics of commonly used antibiotics against adult systemic isolates of Escherichia coli and Pseudomonas aeruginosa at Forty US Hospitals. Clinical Therapeutics. v. 31, p. 2678-2688, 2009. 
ESPINEL-INGROFF, A. Mechanisms of resistance to antifungal agents: Yeasts and filamentous fungi. Revista Iberoamericana de Micología. v. 25, p.101-106, 2008.

Federação Nacional dos Farmacêuticos (FENAFAR). Disponível em http://www.fenafar.org.br/portal/medicamentos/62-medicaments/884-combate-a-resistenciamicrobiana.html Acesso 13 de março de 2013.

FERNANDES, M. B., et al. Caco-2 cells cytotoxicity of nifuroxazide derivatives with potential activity against Methicillin-resistant Staphylococcus aureus (MRSA). Toxicology in Vitro, v. 26, p. 535-540, 2012.

FERREIRA, M.M.C. Multivariate QSAR. Journal of the Brazilian Chemical Society. v.13, p.742-753, 2002.

FERREIRA, R. S; GLAUCIUS, O; ANDRICOPULO, A. D. Integração das técnicas de triagem virtual e triagem biológica automatizada em alta escala: oportunidades e desafios em P\&D de fármacos. Química Nova, v.34, p. 1770-1778, 2011.

FONTANA R.T. As Micobactérias de Crescimento Rápido e a infecção hospitalar: um problema de saúde pública. Revista Brasileira de Enfermagem. v.61, p. 371-376, 2008.

FONTANA, C., et al. Emergence of KPC-producing Klebsiella pneumoniae in Italy. BioMed Central. v. 40, p.1-5, 2010.

FOYE, W.O., LEMKE, T.L.,WILLIAMS, D.A. Principles of medicinal chimestry. 4ed. Baltimores: Williams e Wilkins, 1995, 995p.

GUADAGNINI, P.H., BRUNS, R.E., SOUZA, A.A. Cargas atômicas em moléculas. Química Nova. v. 19, p. 148-155, 1996.

GALES, A.C. et al. Avaliação da atividade in vitro dos novos antimicrobianos da classe das fluoroquinolonas, cefalosporinas e carbapenens contra 569 amostras clínicas de bactérias gram-negativas. Revista Associação Medica Brasil. v.43, p. 137-144, 1997.

Gaussian 03W (Gaussian 03W for Windows, version 6; Gaussian Inc.: 1995-2003, Pittsburgh, PA, EUA. Disponível em: <http:// www.gaussian.com> . Acesso em: 08 abril 2013.

GAYRAL, P., RIGOTHIER, M.C., GANTIER, J.C. Comparaison des activités antiparasitaires de deux séreis d'aldimines dês nitro-5-furane et thiophene. European Journal of Medicinal Chemistry . v.16, p.151-155, 1981.

GHOSE, A.K., VISWANADHAN, V.N., WENDOLOSKI, J.J. Prediction of Hydrophobic (Lipophilic) Properties of Small Organic Molecules Using Fragmental Methods: An Analysis of ALOGP and CLOGP Methods. The Journal of Physical Chemistry. v. 102, p. 37623772, 1998. 
GILBERT. D. N. et al. Infectious Diseases Society of America: The 10 X'20 Initiative: Pursuing a Global Commitment to Develop 10 New Antibacterial Drugs by 2020. Clinical Infectious Diseases. v.50, p. 1081-1083, 2010.

GORDON, R.; LOWY, F.D. Pathogenesis of Methicililn-Resistant Staphylococcus aureus Infection. Clinical Infectious Diseases. v.46 p. 350-359, 2008.

HALEY, R.W., et al. The efficacy of infection surveillance and control programs in preventing nosocomial infections in US hospitals. American Journal of Epidemiology. v.121, p. 182-205, 1985.

HANSCH, C., LEO, A. Exploring QSAR: fundamental and applications in chemistry and biology. Washington: American Chemical Society, 1995. 580p.

HANSCH, C., LEO, A., HOEKMAN, D. Exploring QSAR: hydrophobic, electronic, and steric constants. Washington: American Chemical Society, 1995. 368p.

HANSCH, C.; FUJITA, T. A method for the correlation of biological activity and chemical structure.; Journal of the American Chemical Society. v.86, p.1616, 1964.

HOLTJE, H.D. Molecular modeling: basic principles and applications. New York: $\boldsymbol{V C H}, 1996$.

HOSSEINZADEH, N., et al. 5-Nitro-heteroarylidene analogs of 2-thiazolylimino-4thiazolidinones as a novel series of antibacterial agents. Journal Medicinal Chemistry Research. v. 21 p.1-10, 2012.

Infectious Diseases Society of America (IDSA). Combating Antimicrobial Resistance: Policy Recommendations to Save Lives. IDSA PUBLIC POLICY. Clinical Infectious Diseases. v.52, p. 397-428, 2011.

ISHII, M., et al. Synthesis, molecular modeling and preliminary biological evaluation of a set of 3-acetyl-2,5-disubstituted-2,3-dihydro-1,3,4-oxadiazole as potential antibacterial, anti-T. cruzi and antifungal agents. Bioorganic \& Medicinal Chemistry, v. 19, p. 6292-6301, 2011.

JORGE, S.D. et al. Novel benzofuroxan derivatives against multidrug-resistant Staphylococcus aureus strains: design using Topliss decision tree, synthesis and biological assay. Bioorganic \& Medicinal Chemistry, v. 19, p. 5031-5038, 2011.

JORGE. S.D. (2011). Planejamento, desenvolvimento e estudos de QSAR de derivados benzofuroxânicos com atividade frente a Staphylococcus aureus e Trupanosoma cruzi. Tese de Doutorado, Faculdade de Ciências Farmacêuticas, Universidade de São Paulo, São Paulo.

JOULE, J.A., MILLS, K. Heterocycles Chemistry, 4 ed. Berlin: Blackwell Science. 2007. 
KOLLEF, M. Smart Approaches for Reducing Nosocomial Infections in the ICU. Chest. v. 134, p.447-56, 2008.

KOROLKOVAS, A.; BURCKHALTER, J. H.; Química Farmacêutica, Guanabara Koogan: Rio de Janeiro, 1988, 792p.

KUBINYI, H. Lipophihcity and drug activity. Progress in Drug Research, Basel, v.23, p.97198, 1979.

KUBINYI, H., QSAR: Hansch Analysis and Related Approaches, 1 ed., VHC, Weinheim, Germa. p. 1-75, 1993.

LEUNG, E. et al. World Health Day Antimicrobial Resistance Technical Working Group et al. The WHO policy package to combat antimicrobial resistance. Bulletin of the World Health Organization . v.89, p. 390-39, 2011.

LIÑARES, J. The VISA/GISA problem: therapeutic implications. Clinical Microbiology and Infection. v.7, p.8-15, 2001.

MARRA A.R, et al. Nosocomial bloodstream infections in brazilian hospitals: bnalysis of 2,563 bases from a prospective nationwide surveillance study. Journal of Clinical Microbiology. v. 49, p.1866-1871, 2011.

MARVIN BEANS (MarvinBeans, version 5.0.4.1; ChemAxon Ldt.: 1998-2010, Budapeste, Hungria. Disponível em: <http://www.chemaxon.com> . Acesso em: 02 Fev. 2013.

MASUNARI, A. (2005). Planejamento, desenvolvimento e estudos de QSAR-2D e QSAR3D de derivados 5-nitro-2-tiofilidênicos com atividade frente a Staphylococcus aureus multirresistente (CEB-Clone Endêmico Brasileiro). Tese de Doutorado, Faculdade de Ciências Farmacêuticas, Universidade de São Paulo, São Paulo.

MASUNARI, A., TAVARES, L. C. Aplicação de estudos de QSAR-2D em derivados 5-nitro2-tiofilidênicos com atividade antimicrobiana frente a Staphylococcus aureus multiresistente (MRSA) Revista Brasileira de Ciências Farmacêuticas vol. 42, p. 203-213, 2006 (B).

MASUNARI, A., TAVARES, L. C. Síntese e determinação da atividade antimicrobiana de derivados 5-nitro-2-tiofilidênicos frente a Staphylococcus aureus multi-resistente. Revista Brasileira de Ciências Farmacêuticas. v.42, p. 461-471, 2006 (A).

MENDES, R. E., et al. Metalo-b-lactamases. Jornal Brasileiro de Patologia e Medicina Laboratorial. v. 42, p. 103-113, 2006.

MENEZES, F.G. et al .Evolução da farmacoterapia de antibióticos em pacientes com infecção hospitalar. Saúde Coletiva, v.4, p. 84-88, 2007. 
MICHAEL R. M. AND ANDREW E.S. Antimicrobial resistance in hospitals: How concerned should we be? Canadian Medical Association or its licensors. v.180, p 408-415, 2009. MOITA NETO, J.M., MOITA, G.C. Uma introdução à análise exploratória de dados multivariados. Química Nova. v.21, p. 467-469, 1998.

MOLSIM 3.2 MOLSIM 3.2; The Chem21 Group, Inc: 1997, Lake Forest, IL, EUA. Disponível em: <http://www.infometrix.com/software/softdesc.html> . Acesso em: 08 abril 2013.

MONTANARI, C.A. Química Medicinal: métodos e fundamentos em planejamento de fármacos. 1 ed. São Paulo: Edusp, 2011. 712 p.

MORETH. M. et al. Nitroimidazóis-uma promissoa classe de substâncias para o tratamento da tuberculose. Revista Virtual de Química. v.2, p.105-117, 2010.

MORGON, N.H., COUTINHO, K. Métodos de Química Teórica e Modelagem Molecular. 1 ed. São Paulo: Editora Livraria da Física, 2007. 539 p.

MORRISON, R., BOYD, R. Química orgânica. 11.ed., Lisboa: Fundação Caloust Gulbenkian, 1994.

OLIVEIRA R., MARUYAMA S.A.T. Controle de infecção hospitalar: histórico e papel do estado. Revista Eletrônica Enfermagem. v. 10. p. 775-783, 2008.

PALACE-BERL, F.(2012) Planejamento, síntese e avaliação da atividade anti- $T$. cruzi de derivados furfurilidênicos com estruturas azometínica e oxadiazolínica. 236p. Dissertação de Mestrado, Faculdade de Ciências Farmacêuticas, Universidade de São Paulo, São Paulo.

PATRICK, G. L. An Introduction to Medicinal Chemistry. $2^{\circ}$ ed. Oxford, New York, 2009, $752 p$.

PAULA, F. R., SERRANO, S. H. P., TAVARES, L.C. Aspectos mecanísticos da bioatividade e toxicidade de nitrocompostos. Química Nova, v.32, p. 1013-1020, 2009.

PELEG, A.Y., HOOPER, D. C. Hospital-Acquired Infections Due to Gram-Negative Bacteria. New England Journal of Medicine. v.362, p.1804-1803, 2010.

PEREIRA, D. G., Importância do metabolismo no planejamento de fármacos. Química Nova, V.30, p. 171-177, 2007.

PHARMACEUTICAL RESEARCH AND MANUFACTURERS OF AMERICA (PhRMA, 2007). Drug Discovery and Development. Pharmaceutical Research and Manufacturers of America. Disponível em: <http://www.phrma.org/sites/default/files/159/rd brochure 022307.pdf> Washington, DC. February 2007. Acesso em março de 2013. 
PHARMACEUTICAL RESEARCH AND MANUFACTURERS OF AMERICA (PhRMA, 2013). Research and Development Drug Discovery. Disponivel em < http://www.phrma.org/research-development> Washington, DC. Acesso em março de 2013.

PIERONI, J.P. et al., Terceirização da P\&D de Medicamentos: Panorama do Setor de Testes Pré-Clínicos no Brasil. BNDES Setorial, n. 29, p. 131-158, 2009.

PIROUETTE 3.11, Infometrix Inc., 1990-2003, Woodinville.

PNIEWSKA, B., JANUCHOWSKI, M. Structural Investigations of Nifuroxazide, $p$ - HydroxyN'-(5-nitrofurfurylidene)benzhydrazide. Polish Journal of Chemistry. v.72, p. 2629-2634, 1998.

QUEENAN, A. M., BUSH, K. Carbapenemases: the versatile beta-lactamases. Clinical and Microbiology Review. v. 20, p. 440-58, Jul 2007.

RANDO, D. G. et al. Potential Tuberculostatic Agents. Topliss application on benzoic acid [(5-nitro-thiophen-2-yl)-methylene]-hydrazide series. Bioorganic \& Medicinal Chemistry, v. 10, p. $557-560,2002$.

RATTI, R. P., SOUSA, C. P. Staplylococccus aureus metilicina resistente (MRSA) e infecções nosocomiais. Revista de Ciências Farmacêuticas Básica e Aplicada. v.20 p.916, 2009.

REZENDE, P.(2002) Relações quantitativas estrutura-atividade de derivados 5-nitro-2tiofilidênicos: planejamento, síntese e determinação da atividade antimicrobiana frente a cepas de Staphylococcus aureus. Dissertação de Mestrado, Faculdade de Ciências Farmacêuticas, Universidade de São Paulo, São Paulo.

RUBINSTEIN E., et al. Linezolid (PNU-100766) versus vancomycin in the treatment of hospitalized patients with nosocomial pneumonia: A randomized, double-blind, multicenter study. Clinical Infectious Diseases, v.32, p. 402-412, 2001.

SAPEL'NIKOVA, S. V.; KUZ'MINA, N. V.; MAISTRENKO, V. N.; KUDASHEVA, F. K., Preconcentration and Voltammetric Determination of Nitro Compounds on Carbon- Paste Electrodes, Journal of Analytical Chemistry ., Moscow, v. 57, p. 532-537, 2002.

SAXENA, S., GOMBER, C. Surmounting antimicrobial resistance in the millennium superbug: Staphylococcus aureus. Central European Journal of Medicine. v.5, p.12 - 29, 2010.

SCOTT, G. Antibiotic resistance. Medicine. v. 37, p.551-556, 2009.

SILVEIRA, G. P. et al. Estratégias utilizadas no combate a resistência bacteriana. Química Nova. v.29, p.844-855, 2006. 
SOARES, V. M.. Emergência de Klebsiella pneumoniae produtora de carbapenemase (KPC) em um hospital terciário. Jornal. Brasileiro Patoologia Medica Laoratorial. v. 48, p. 251 253, 2012.

SOLOMONS, G., FRYHLE, C. Organic Chemistry. 7 ed. New York: John Wiley \& Sons, 2004.

SONEHARA, I. Y. (2009). Estudos de identificação de possíveis alvos para nitro-compostos azometínicos ou oxadiazolínicos com atividade antifúngica e anti-T. cruzi. Tese de Doutorado, Faculdade de Ciencias Farmaceuticas, Universidade de São Paulo, São Paulo.

SOUZA. L.B.G., FIGUEIREDO B.B. Prevalência de Infecções Nosocomiais Provocadas por Staphylococcus aureus Resistente à Meticilina (M.R.S.A.), no Hospital Universitário Regional de Maringá. Revista Brasileira de Análises Clínicas. v.40, p.31-34, 2008.

SYBYL 8.0 (Sybyl 8.0 for Linux; Tripos, Inc.: 2007. St. Louis, EUA).

TAFT, ROBERT W. JR. Polar and Steric Substituent Constants for Aliphatic and o-Benzoate Groups from Rates of Esterification and Hidrolysis of Esters. Journal of the American Chemical Society. v. 74, p. 3120-3128, 1952.

TAMURA, N.K., et al . Fatores de virulência de Candida spp isoladas de cateteres venosos e mãos de servidores hospitalares. Revista da Sociedade Brasileira de Medicina Tropical. v. 40 p. $91-93,2007$.

TAVARES, L. C. QSAR: A ABORDAGEM DE HANSCH. Química Nova. v.27, p. 631-639, 2004.

TAVARES. L.C., PENNA, T.C.V., AMARAL, A.T. Synthesis and biological activity of nifuroxazide and analogs I. Bollettino chimico farmaceutico. v.136, p. 244-249, 1997.

TEDLAOUTI, F., GASQUET, M. Evolution of the antimalarial activity of new compounds against Plasmodium falciparum in vitro, and Plasmodium berghei in vivo. Journal de pharmacie de Belgique . v.45, p.306-310, 1990.

TEDLAOUTI, F., et al. Synthesis and study of antiprotozoal activity of some 5-nitrothiophene aldimines. Farmaco., France, v.46, p.1195-1201, 1991.

TOCHER, J. H. Reductive activation of nitroheterocyclic compounds; General Pharmacology. v. 28, p.485, 1997.

VERMA, J., KHEDKAR,V,M., COUTINHO, E.C. 3D-QSAR in Drug Design - A Review. Current Topics in Medicinal Chemistry, v. 10, p. 95-115, 2010.

VIODÉ, C., et al. Enzymatic reduction studies of nitroheterocycles. Biochemical Pharmacology. vol. 5, p. 549-557, 1999. 
VISWANADHAN, V.N., GHOSE, A.K., REYANKAR, G.R., ROBINS, R.K. Atomic Physicochemical Parameters for Three Dimensional Structure Directed Quantitative Structure-Activity Relationships. 4. Additional Parameters for Hydrophobic and Dispersive Interactions and Their Application for an Automated Superposition of Certain Naturally Occurring Nucleoside Antibiotics. Journal of chemical information and computer sciences. v. 29, p. 163-172, 1989.

WERMUTH, C.G. The Practice of Medicinal Chemistry. 3 ed. Oxford: Elsevier, 2008. 942 p.

WISPLINGHOFF H., et al. Nosocomial bloodstream infections in US hospitals: Analysis of 24,179 cases from a prospective nationwide surveillance study. Clinical Infectious Diseases. v.39, p. 309-317, 2004.

WORLD HEALTH ORGANIZATION (WHO). Antimicrobial resistance. Fact sheet №194. February 2011. Disponível em: http://www.who.int/mediacentre/factsheets/fs194/en/ acesso em 10/03/2013.

YEHYE, W.A., ARIFFIN, A., RAHMAN, N.A., Ng, S. W. 2-[4-Acetyl-5-(biphenyl-4- yl)-4,5dihydro-1,3,4-oxadiazol-2-yl]phenyl acetate. Acta Crystallographica, Sect. E, v.66, p. 878 886, 2010. 
Anexo 1. Espectros de $R M N^{1} H$ e $R M N^{13} \mathrm{C}$ dos derivados tiofilidênicos azometínicos.

RMN ${ }^{1} \mathrm{H}: \boldsymbol{N}^{\prime}$-(5-nitrotiofen-2- il)metileno benzidrazida
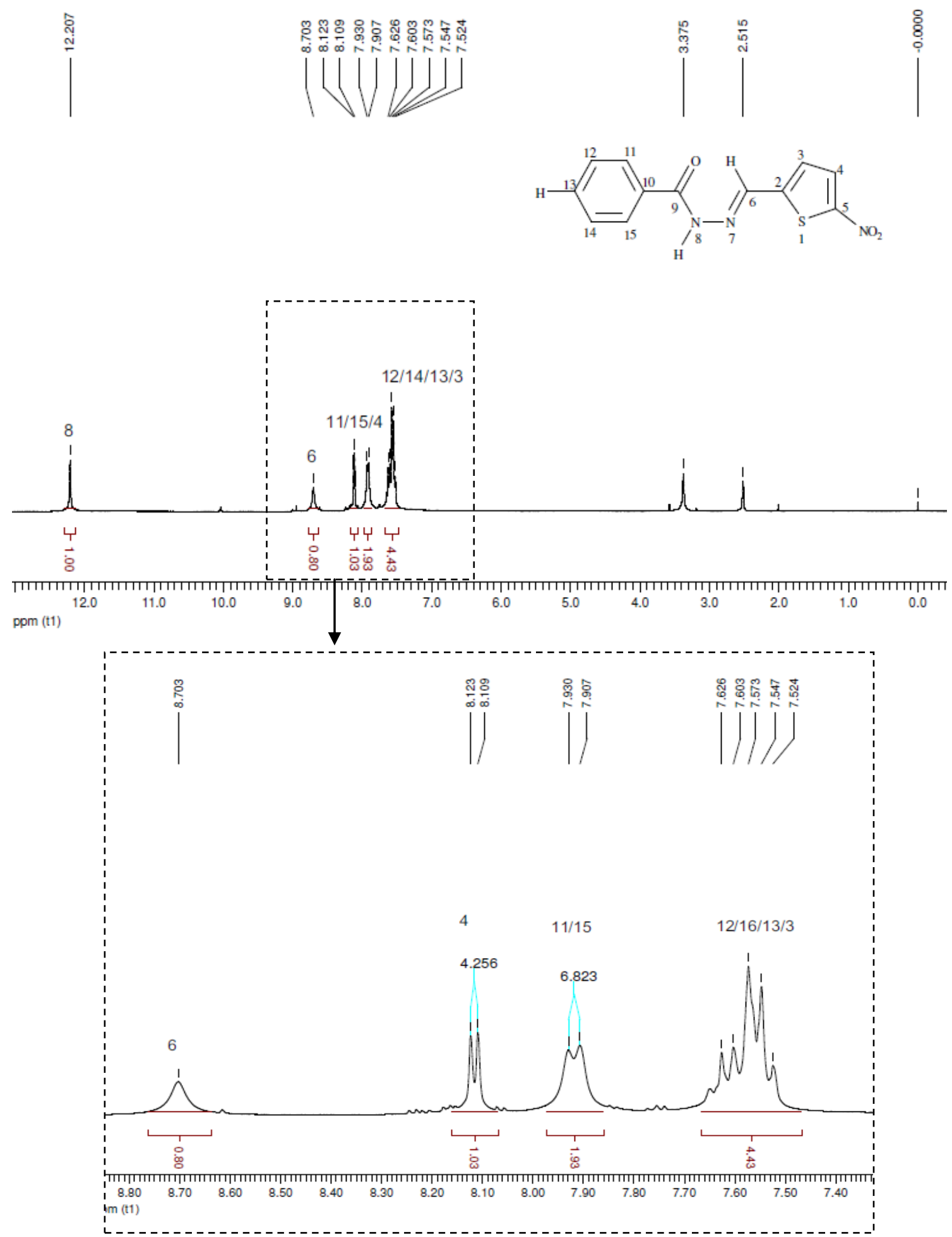
RMN ${ }^{13} \mathrm{C}: \boldsymbol{N}^{\prime}$-(5-nitrotiofen-2- il)metileno benzidrazida
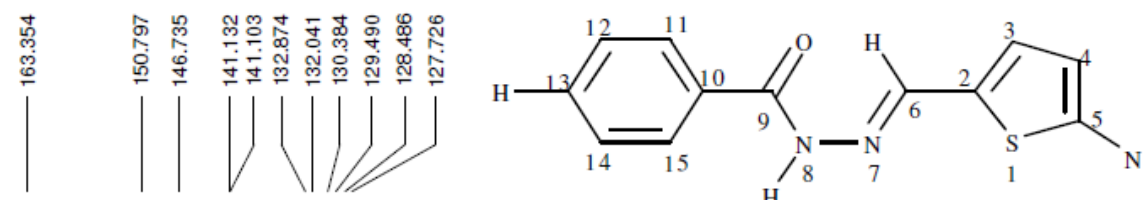
$\mathrm{H}$

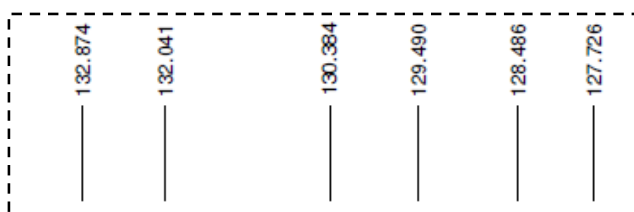

$12 / 14$

$11 / 15$

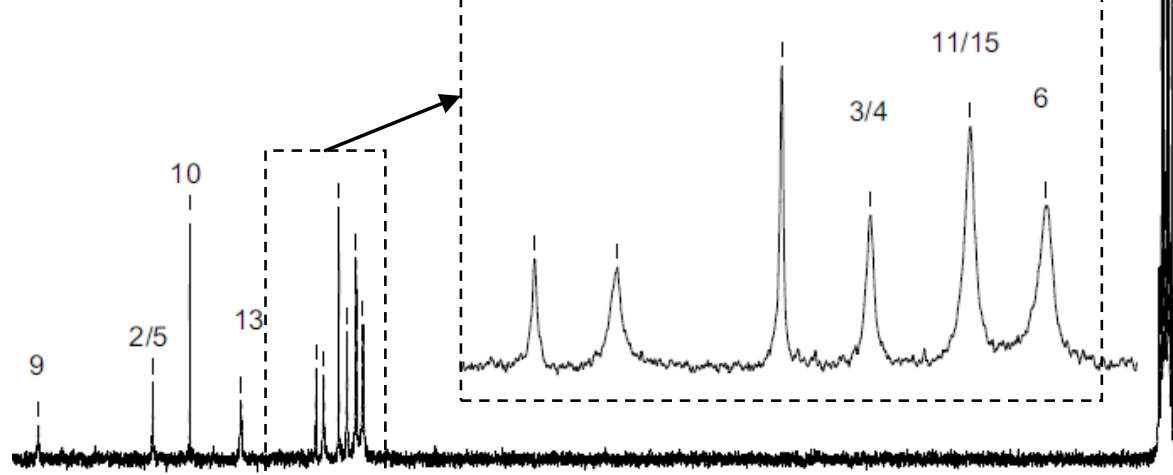

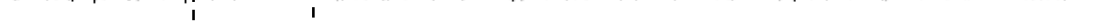

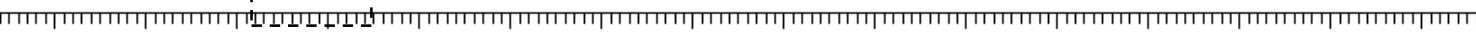

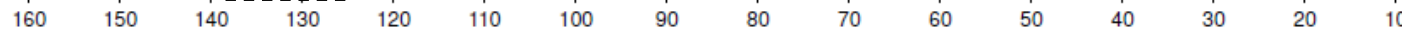


RMN ${ }^{1} \mathrm{H}$ : 4-butil-[N'-(5-nitrotiofen-2- il)metileno]benzidrazida
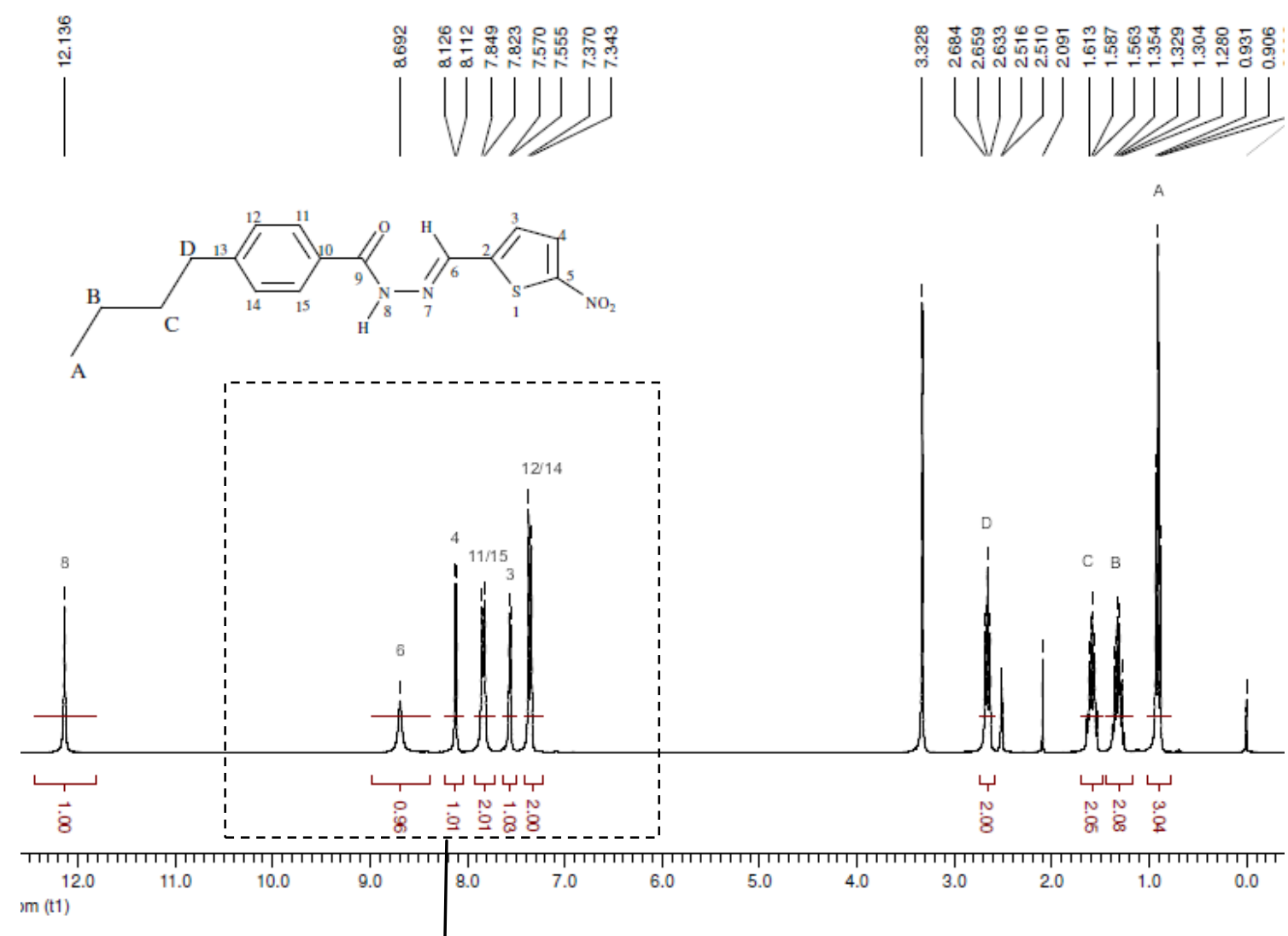

m (t1)

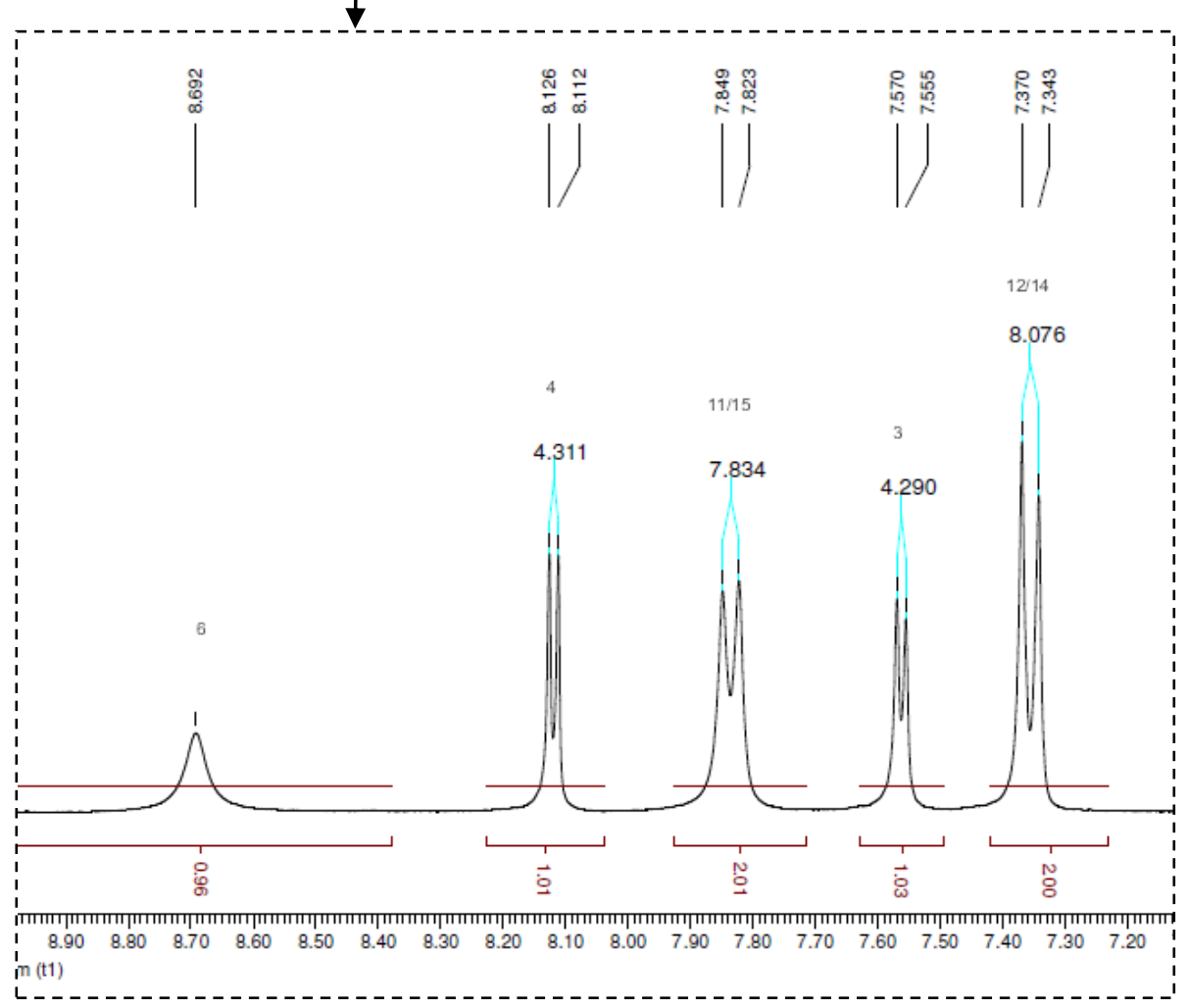


RMN ${ }^{13} \mathrm{C}:$ 4-butil-[N'-(5-nitrotiofen-2- il)metileno]benzidrazida

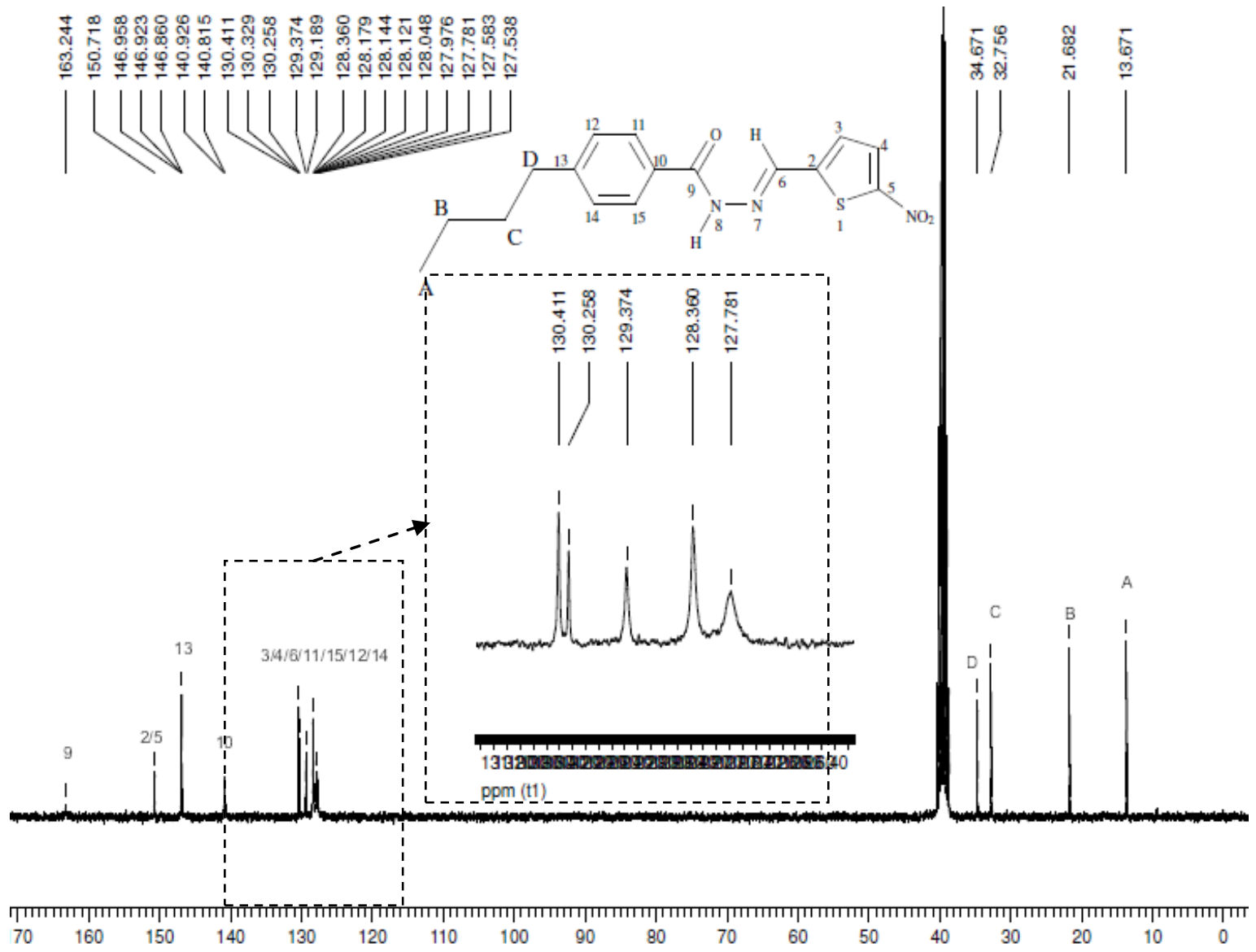


RMN ${ }^{1} \mathrm{H}$ : 4-cloro-[N'-(5-nitrotiofen-2- il)metileno]benzidrazida
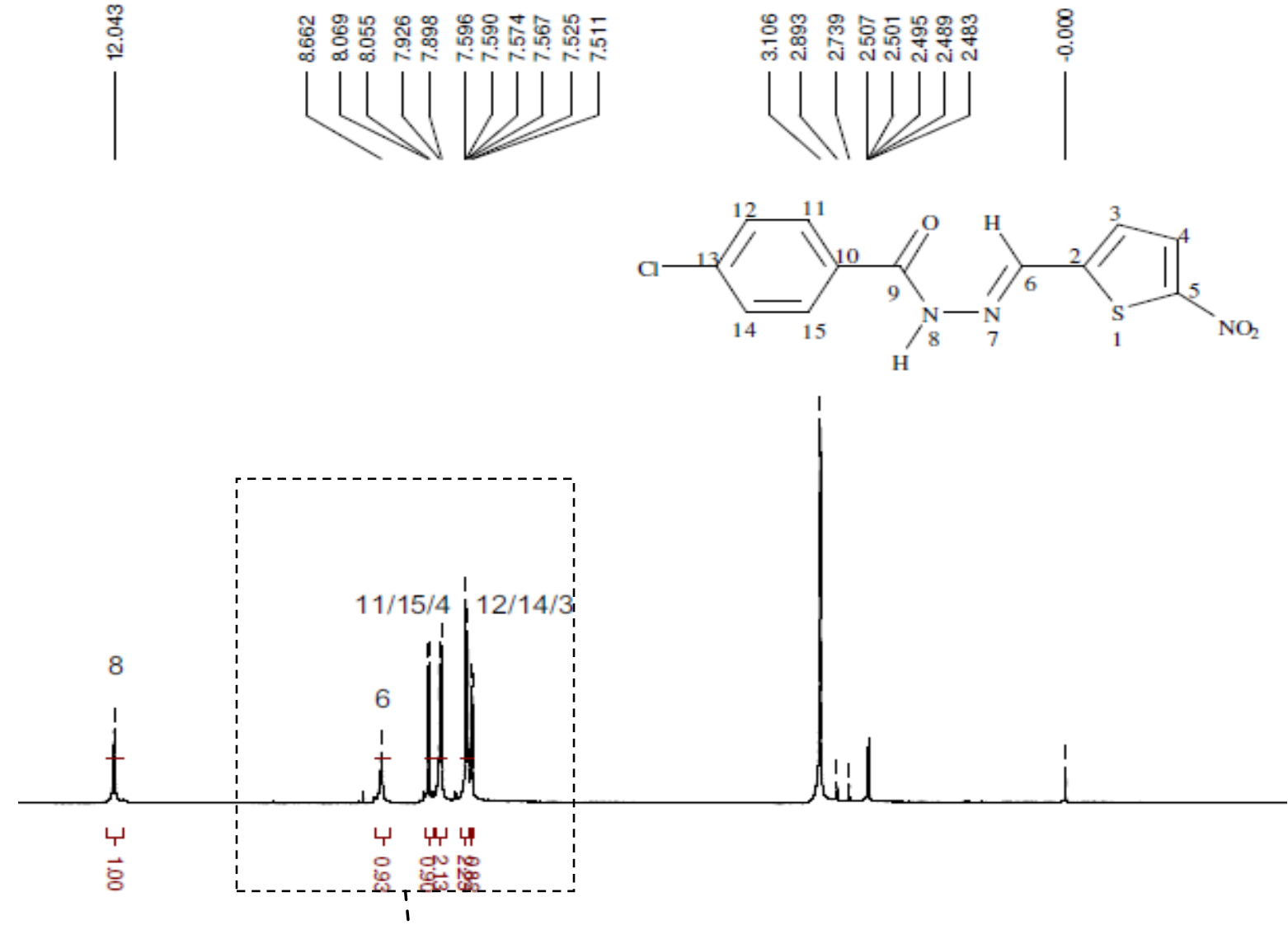

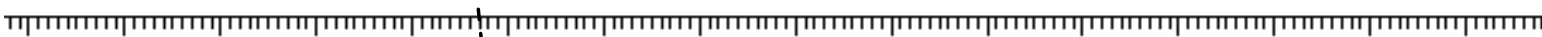

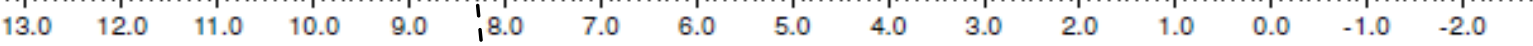
용 눙

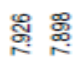

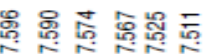
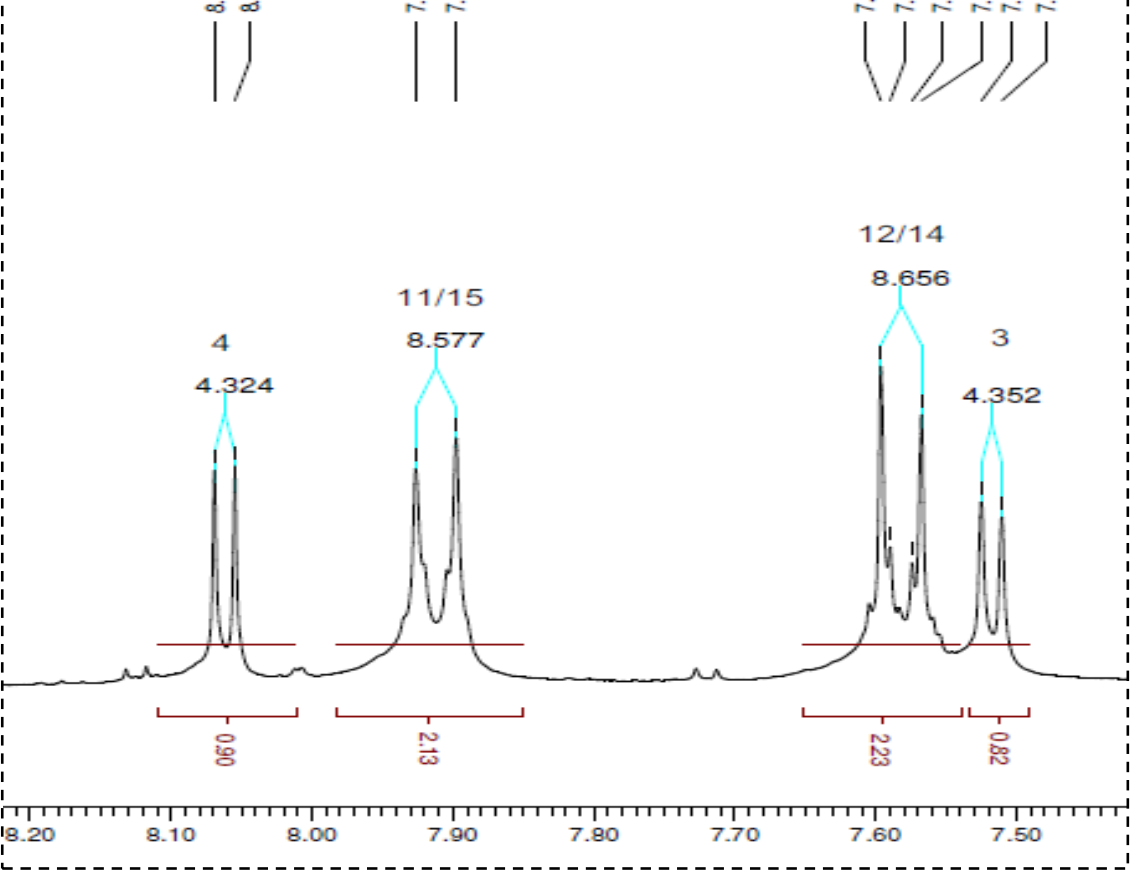
RMN ${ }^{13} \mathrm{C}:$ 4-cloro-[ $N^{\prime}-(5$-nitrotiofen-2- il)metileno]benzidrazida
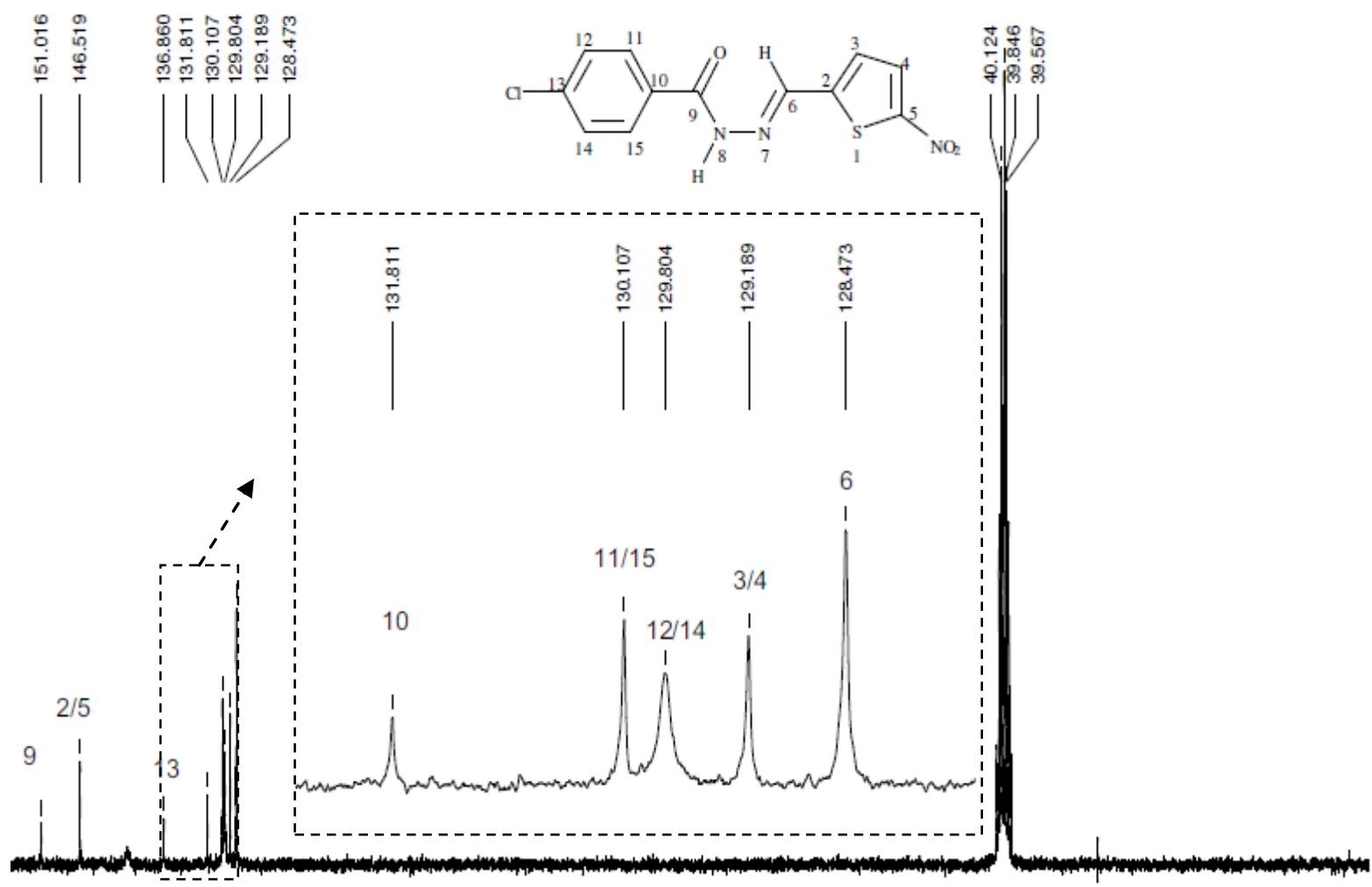

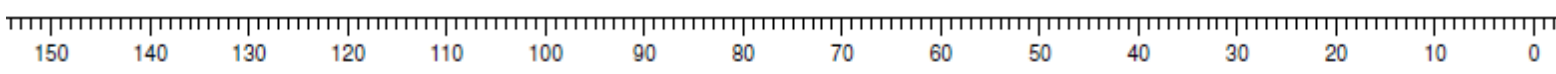
$\mathrm{ppm}(\mathrm{t} 1)$ 
RMN ${ }^{1} \mathrm{H}$ : 4-ciano-[N'-(5-nitrotiofen-2- il)metileno]benzidrazida
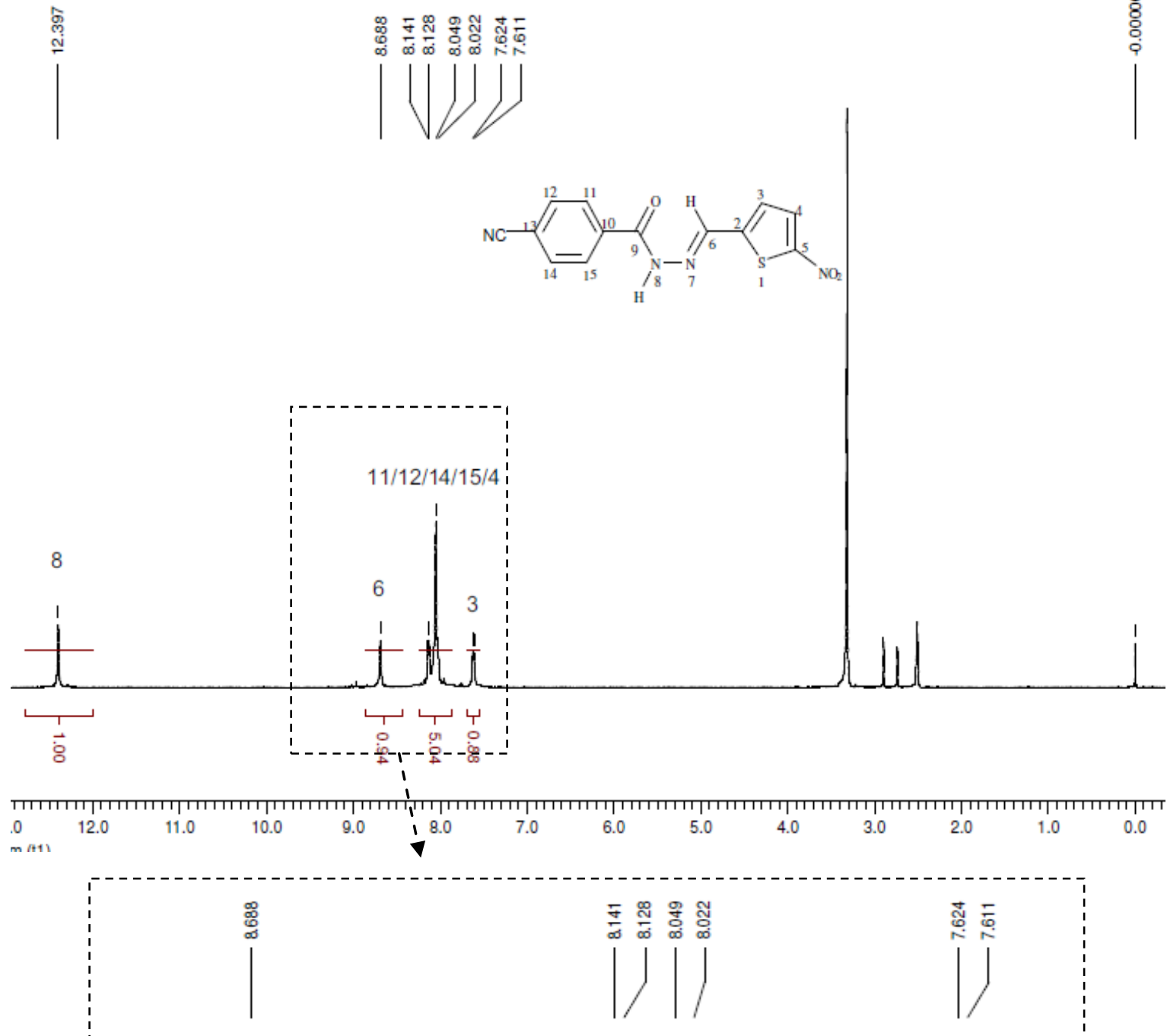

$11 / 12 / 14 / 15$

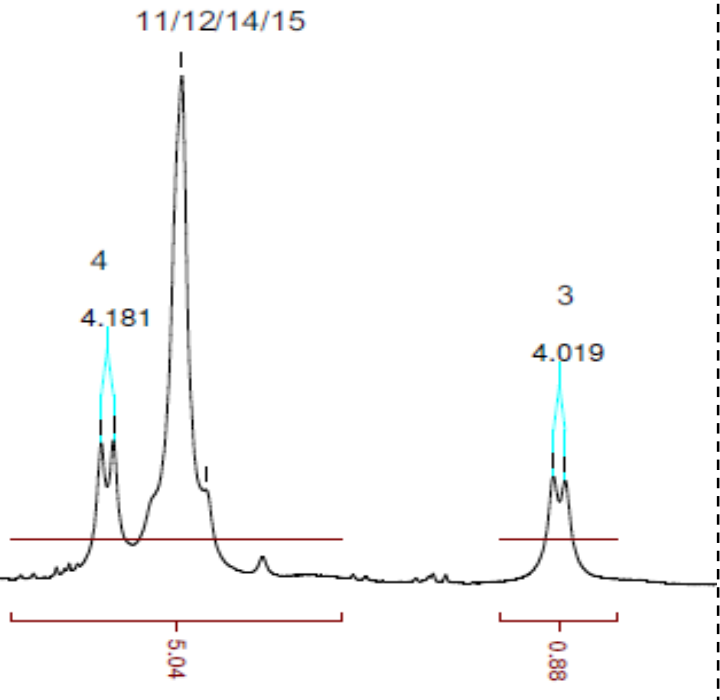

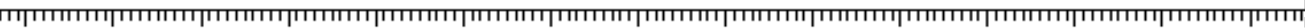
\begin{tabular}{lllllllllllllll}
\hline 8.90 & 8.80 & 8.70 & 8.60 & 8.50 & 8.40 & 8.30 & 8.20 & 8.10 & 8.00 & 7.90 & 7.80 & 7.70 & 7.60 & 7.50 \\
\hline
\end{tabular} 
RMN ${ }^{13} \mathrm{C}:$ 4-ciano-[N'-(5-nitrotiofen-2- il)metileno]benzidrazida
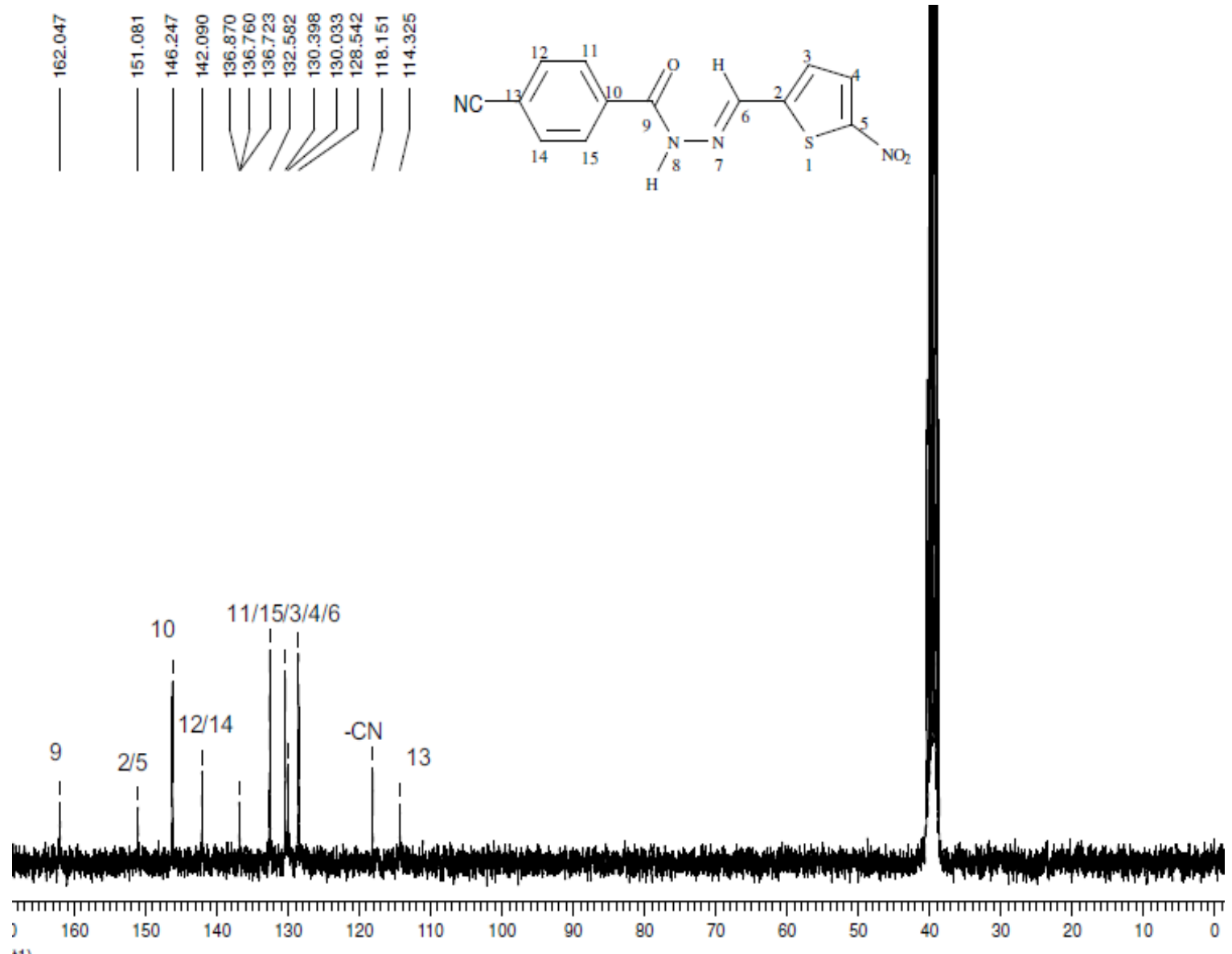

t1) 
RMN ${ }^{1} \mathrm{H}$ : 4-trifluormetil-[N'-(5-nitrotiofen-2- il)metileno]benzidrazida
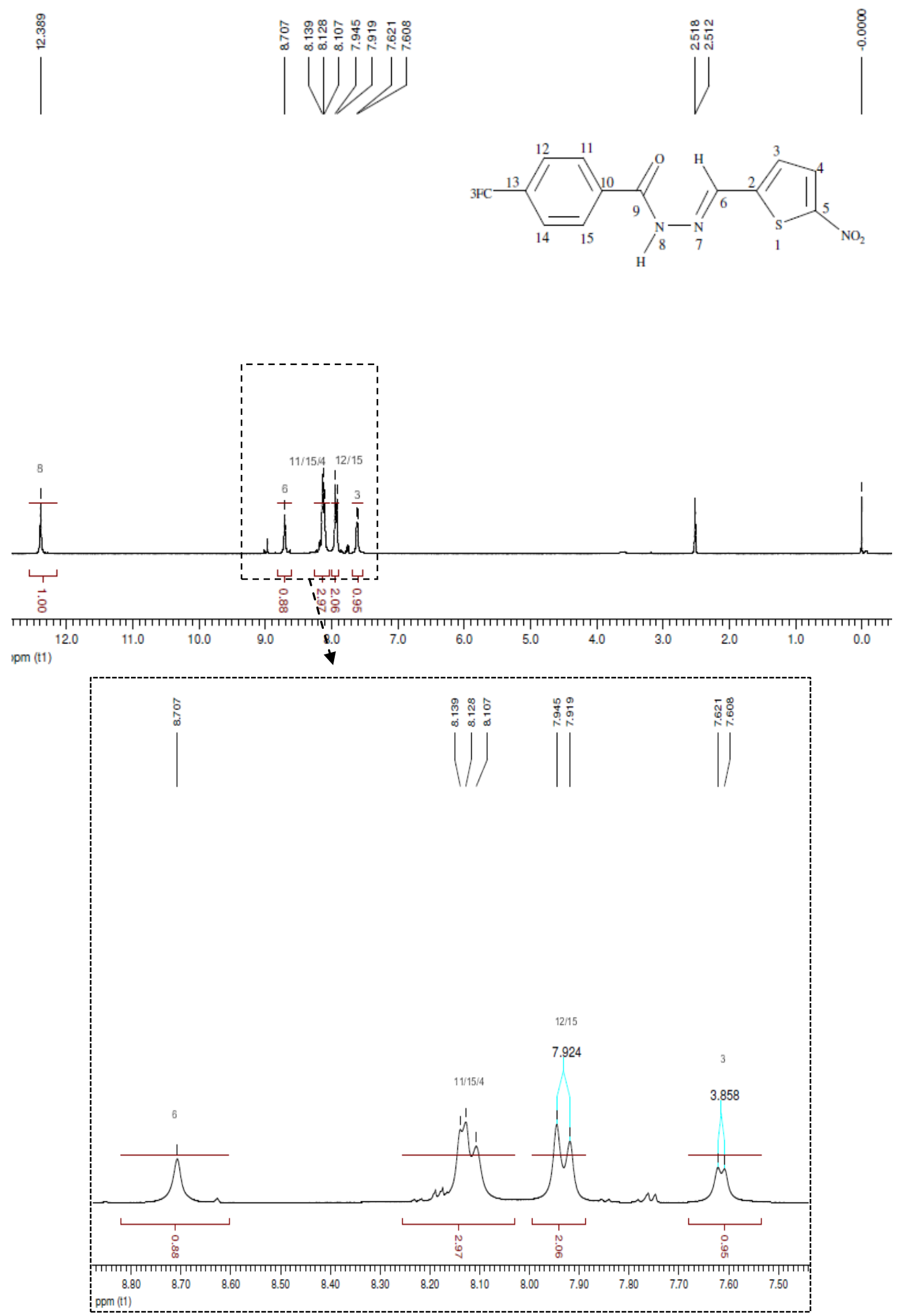
RMN ${ }^{13} \mathrm{C}$ : 4-trifluormetil-[ $N^{\prime}$-(5-nitrotiofen-2- il)metileno]benzidrazida
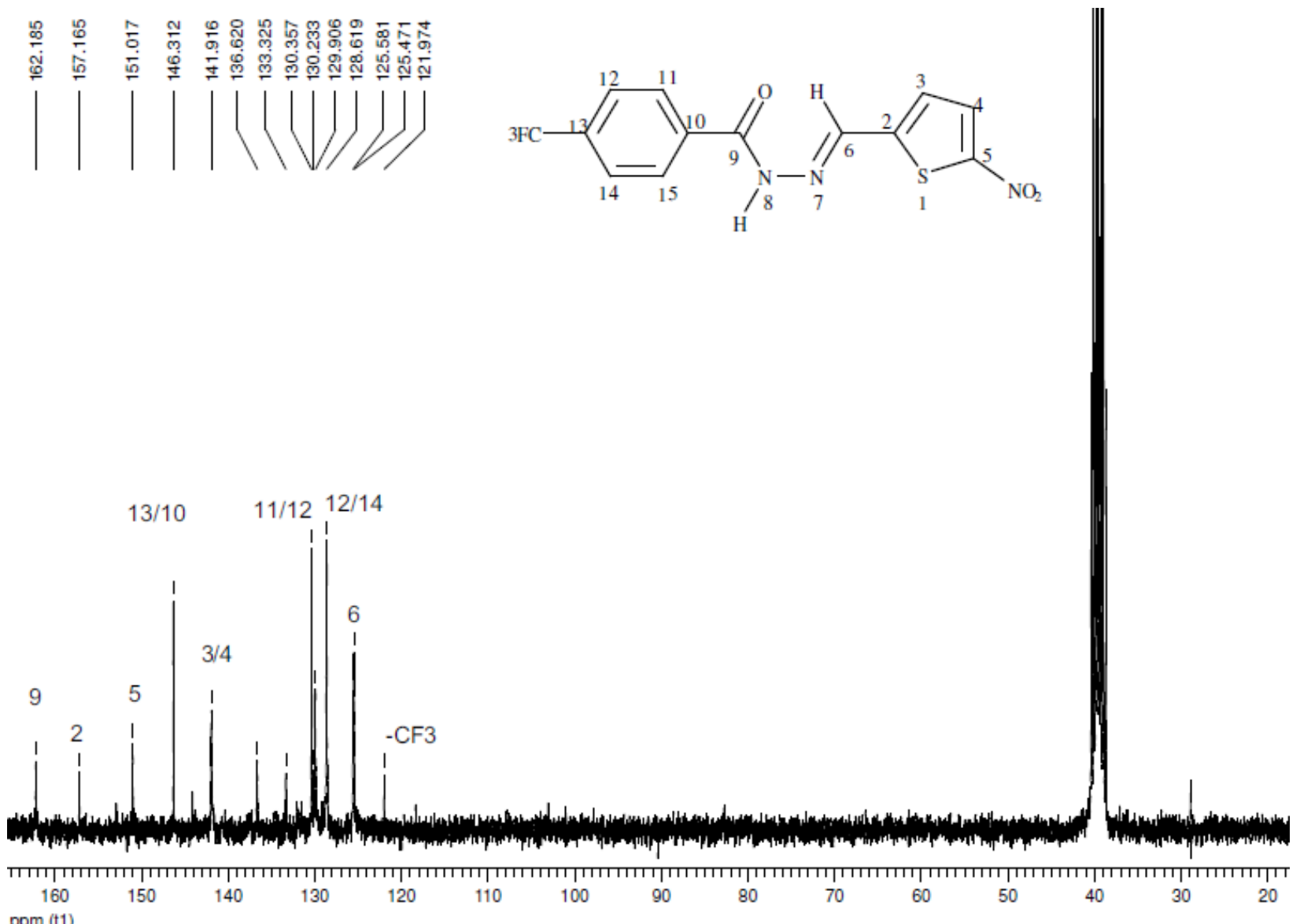
RMN ${ }^{1} \mathrm{H}:$ 4-metoxi-[N'-(5-nitrotiofen-2- il)metileno]benzidrazida

今.

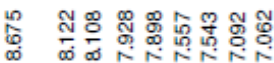

$1111 j 1$

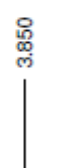

\begin{tabular}{l}
8 \\
8 \\
\hdashline \\
0 \\
0
\end{tabular}

I
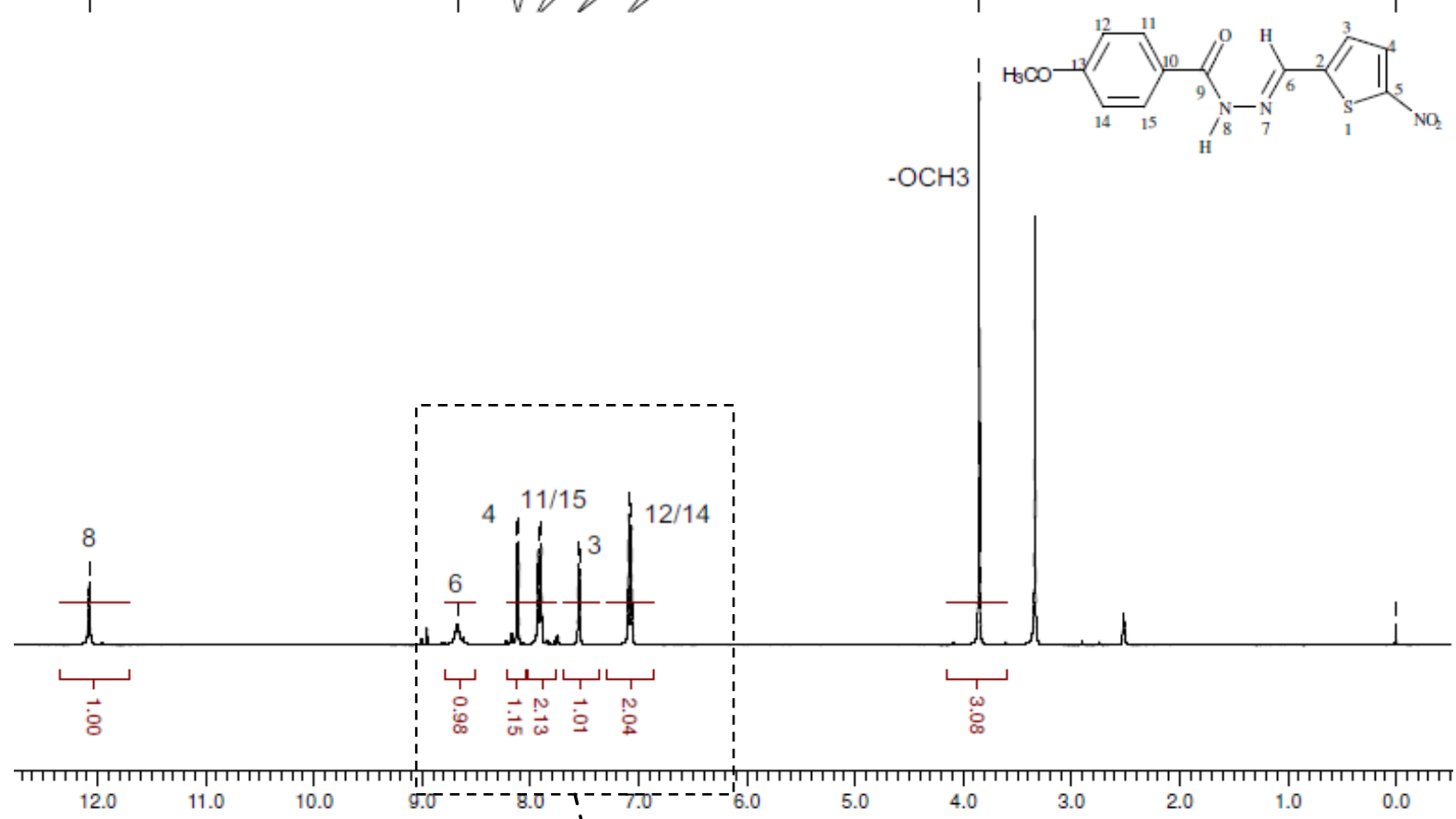
$\mathrm{pm}(\mathrm{t} 1)$
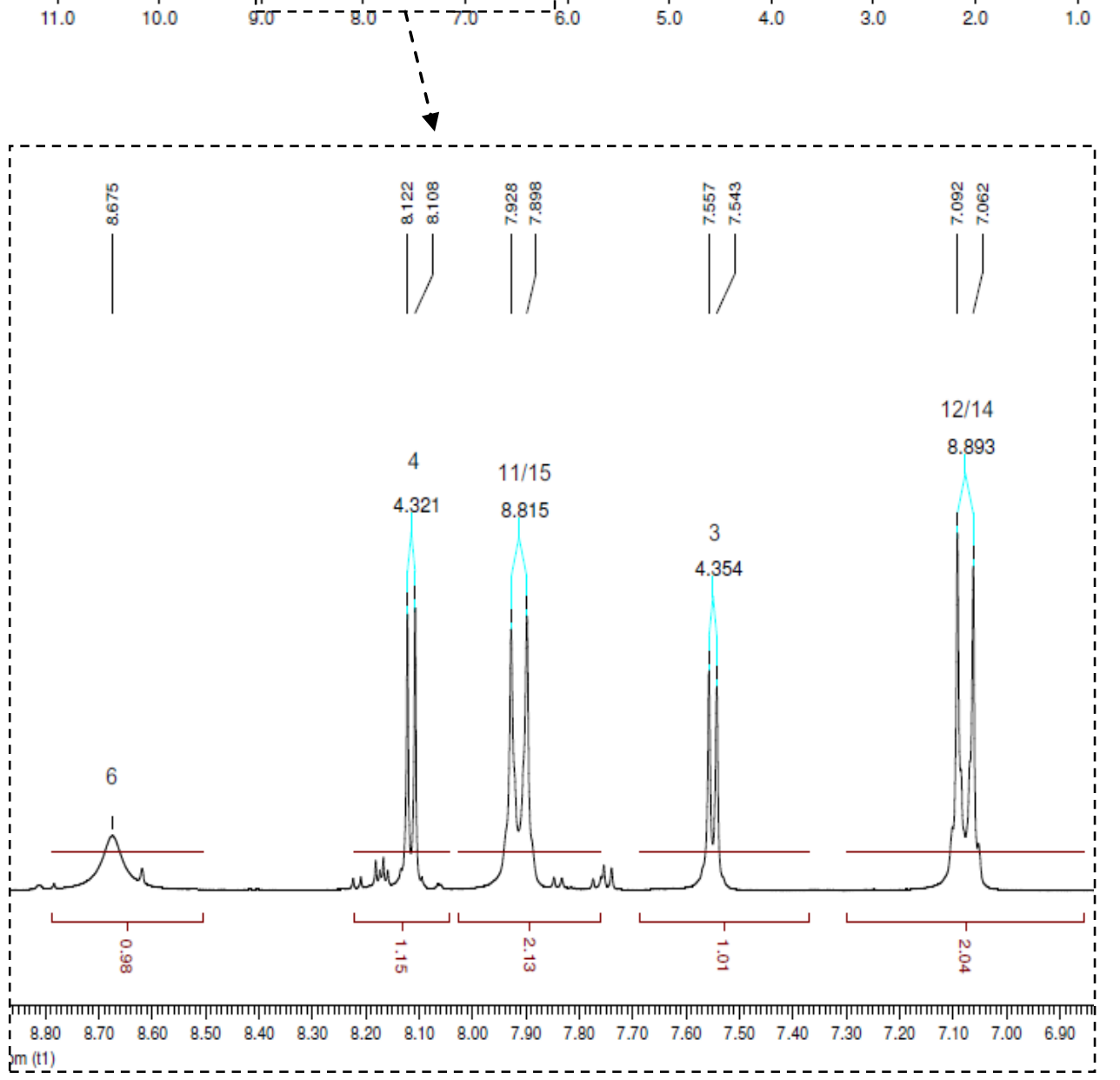
$\mathrm{RMN}{ }^{13} \mathrm{C}:$ 4-metoxi-[N'-(5-nitrotiofen-2- il)metileno]benzidrazida

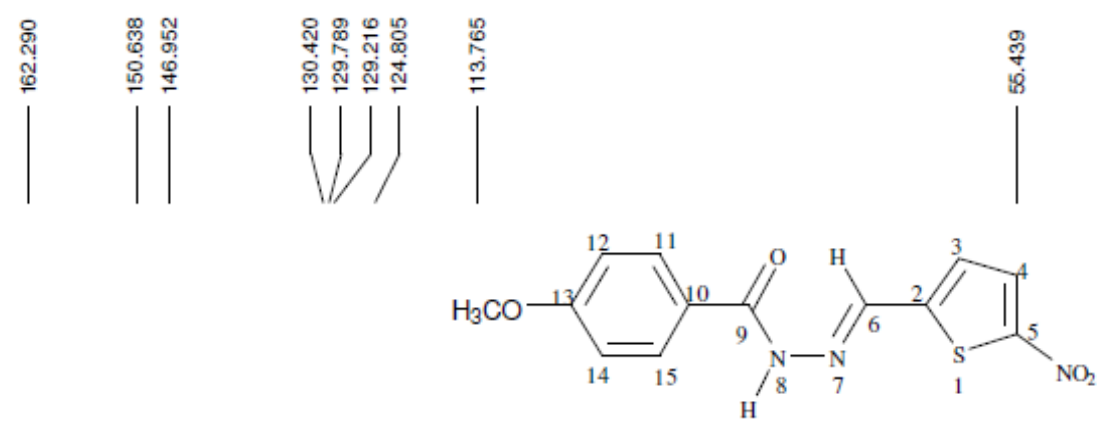

$\mathrm{OCH} 3$

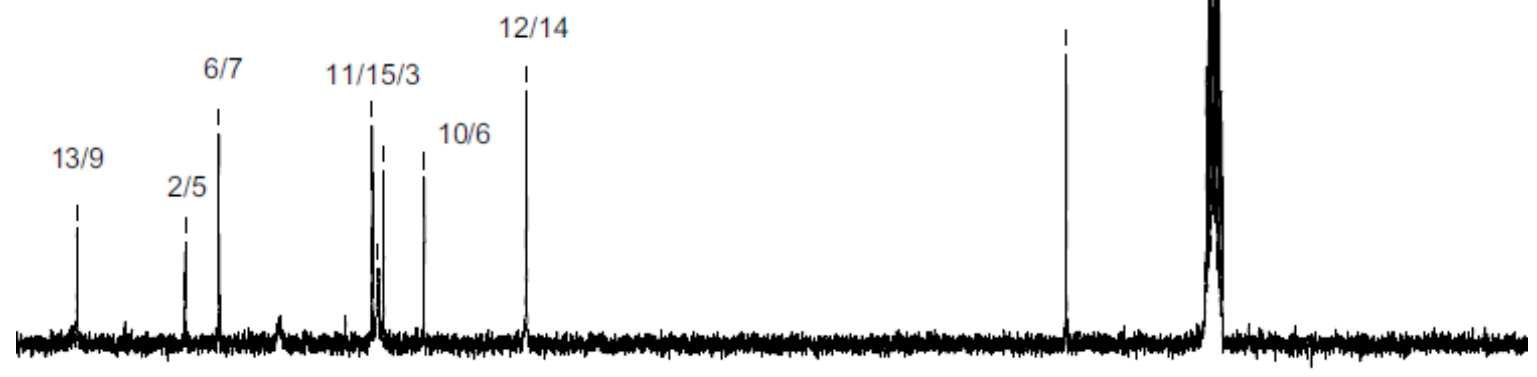

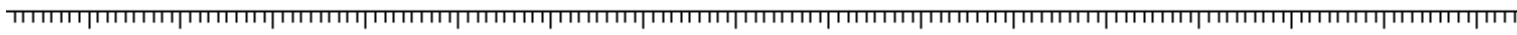
$\begin{array}{ccccccccccccccccc}160 & 150 & 140 & 130 & 120 & 110 & 100 & 90 & 80 & 70 & 60 & 50 & 40 & 30 & 20 & 10 \\ \mathrm{pm}(\mathrm{t} 1) & & & & & & & & & & \end{array}$ 
RMN ${ }^{1} \mathrm{H}$ : 4-nitro-[ $N^{\prime}$-(5-nitrotiofen-2- il)metileno]benzidrazida
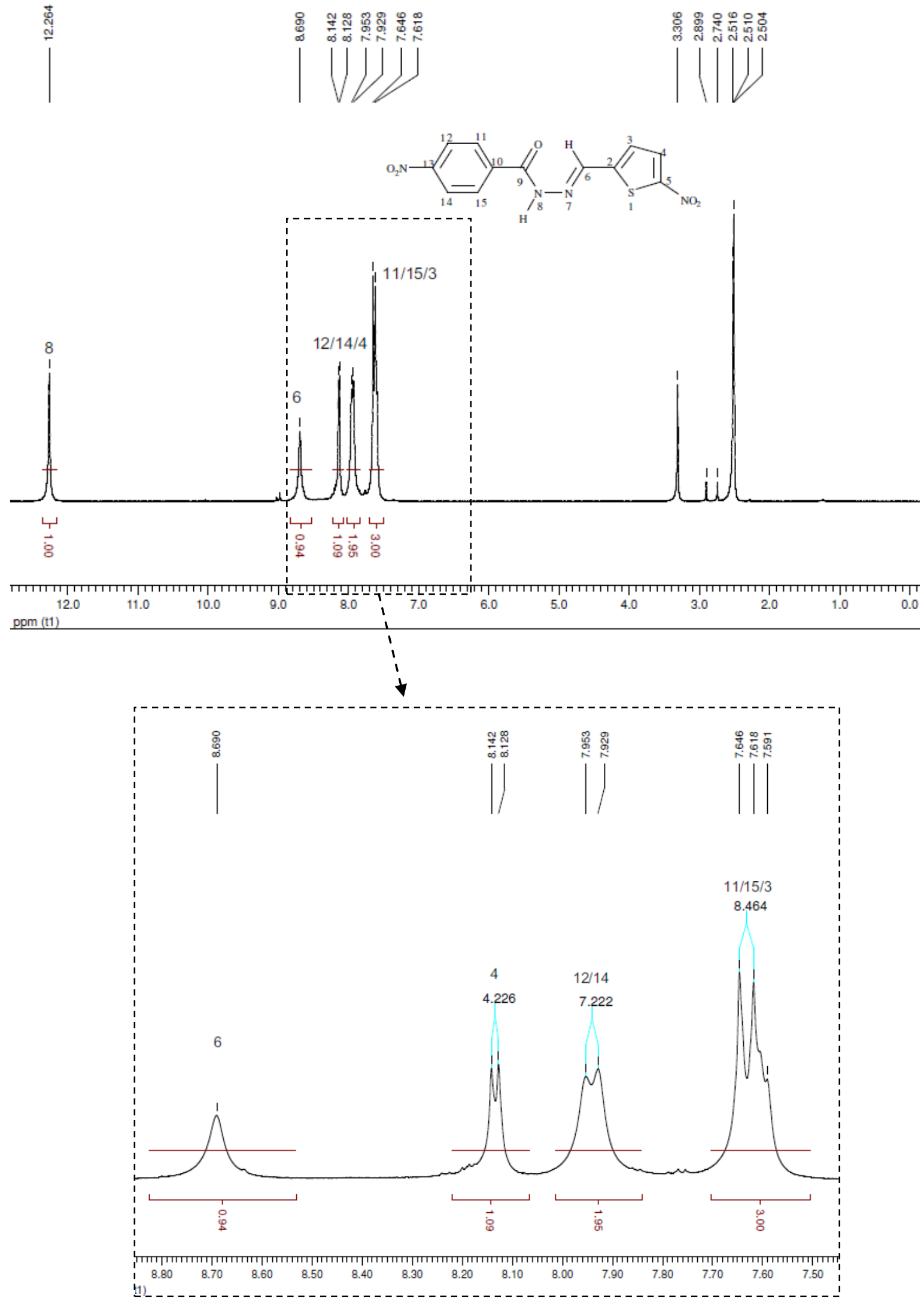


\section{RMN ${ }^{13} \mathrm{C}:$ 4-nitro-[ $N^{\prime}$-(5-nitrotiofen-2- il)metileno]benzidrazida}
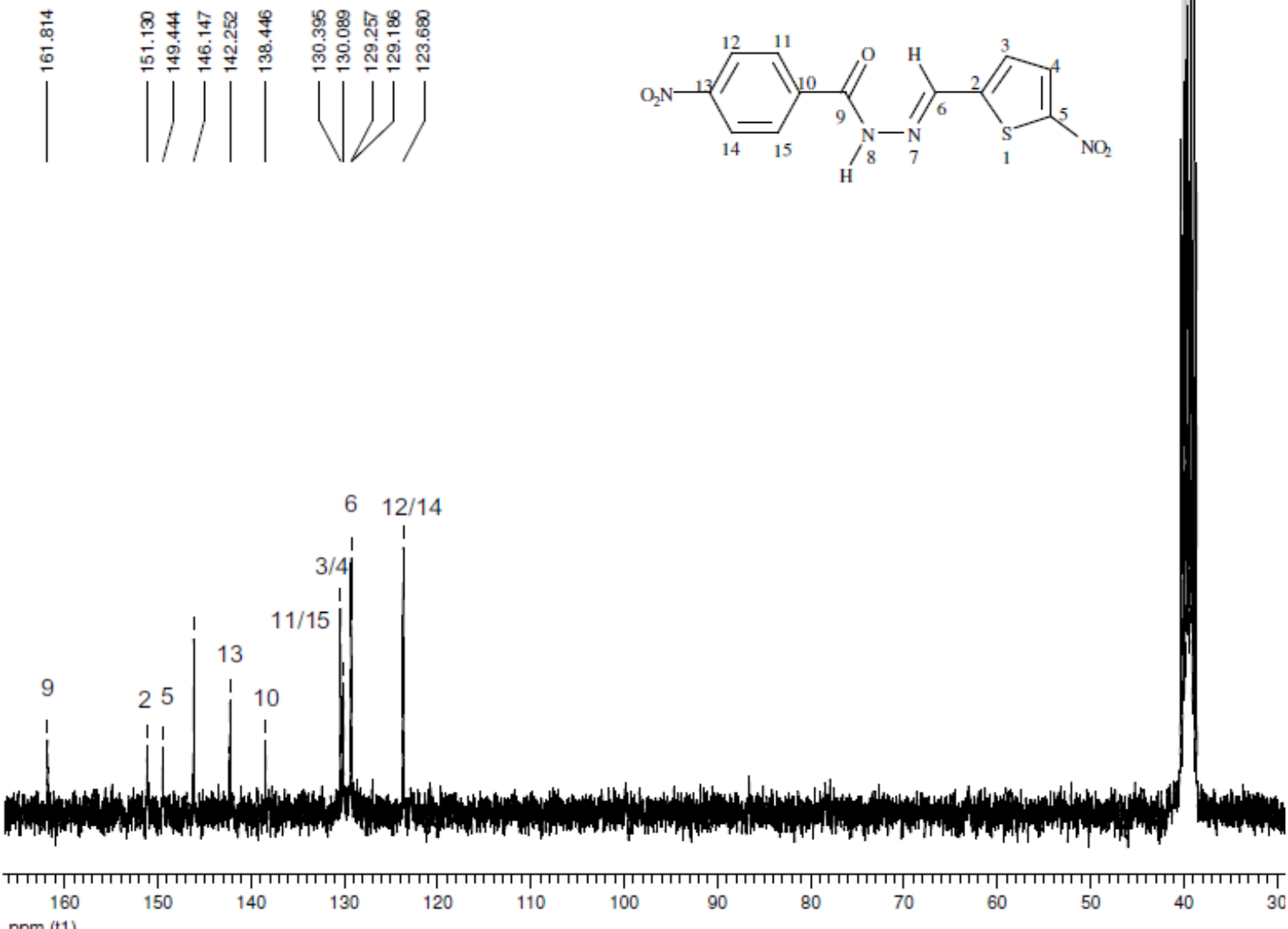
RMN ${ }^{1} \mathrm{H}$ : 4-tercbutil-[N'-(5-nitrotiofen-2- il)metileno]benzidrazida
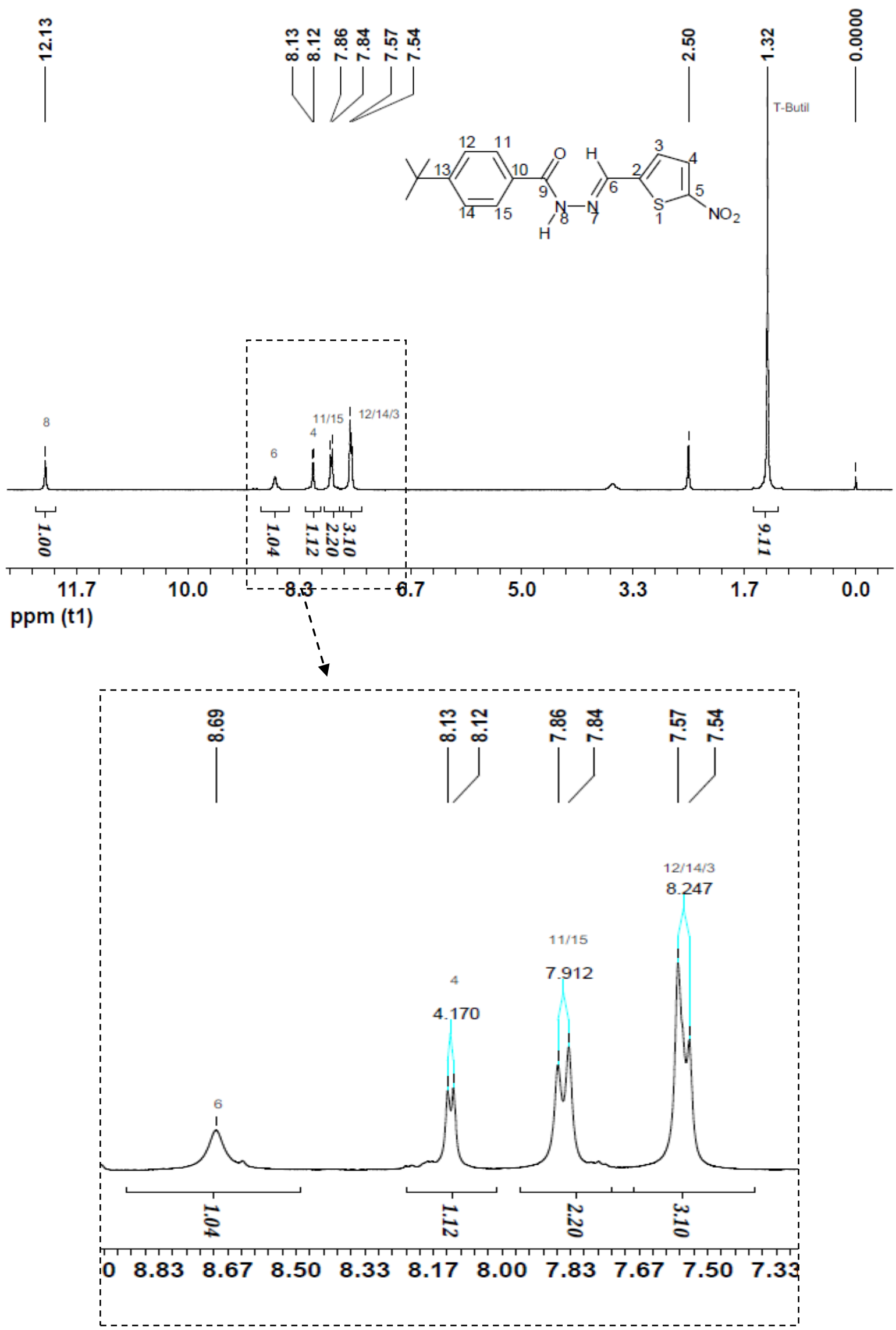

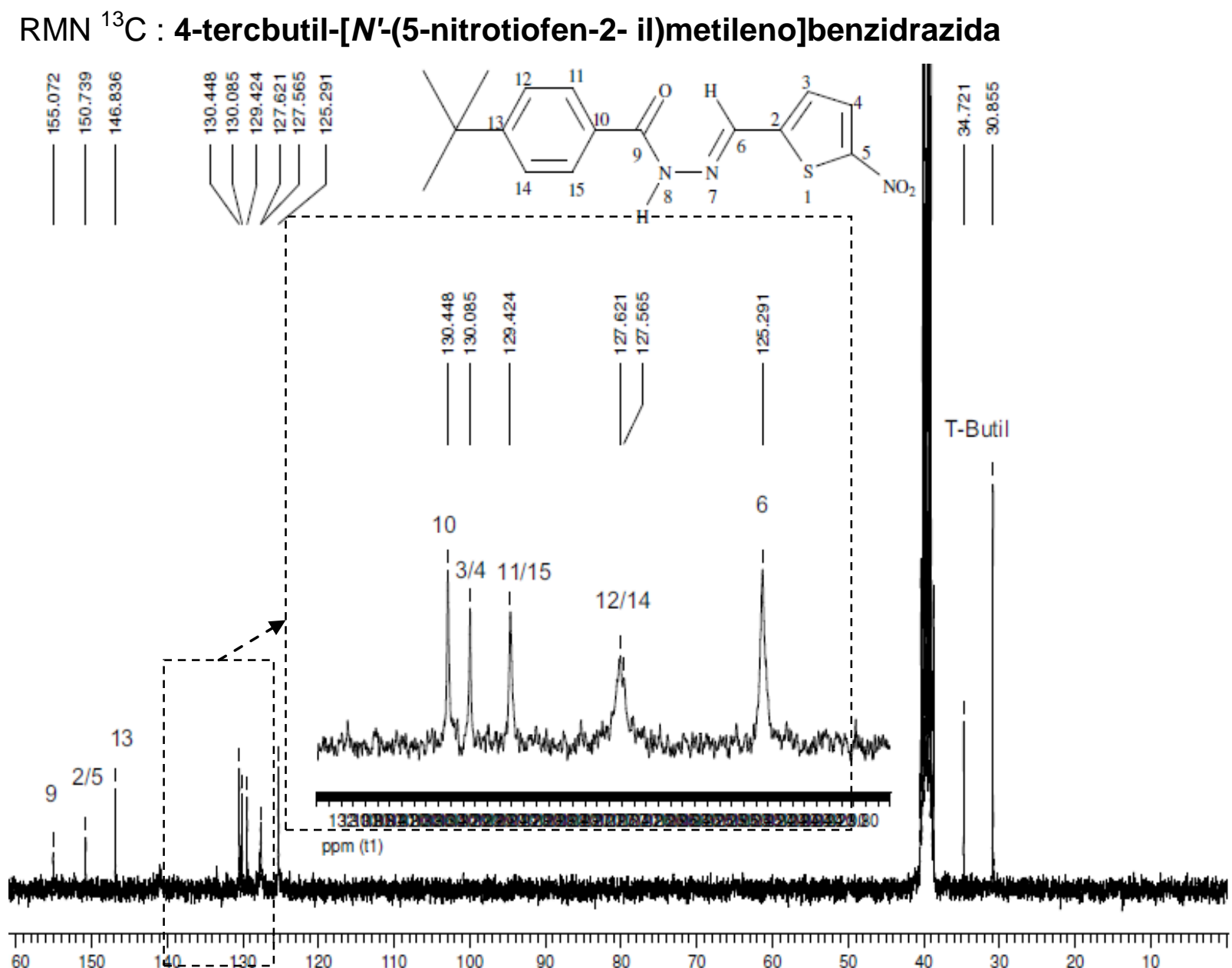

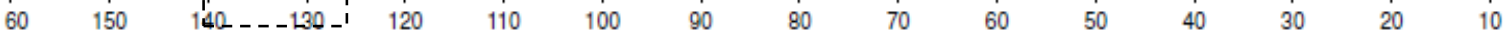
$\mathrm{pm}(\mathrm{t} 1)$ 
RMN ${ }^{1} \mathrm{H}$ : 4-iodo-[N'-(5-nitrotiofen-2- il)metileno]benzidrazida
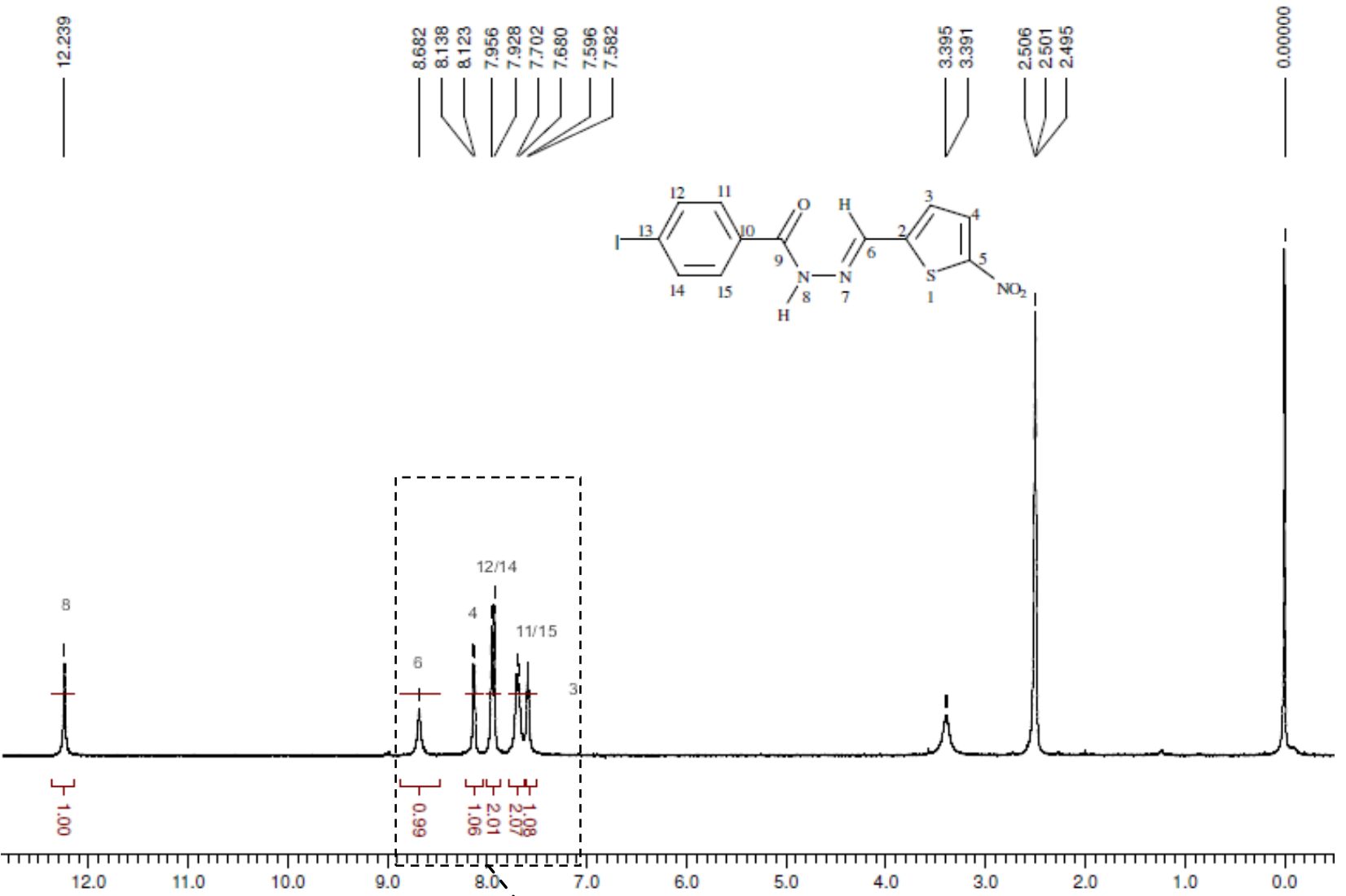
$\mathrm{ppm}(\mathrm{t} 1)$
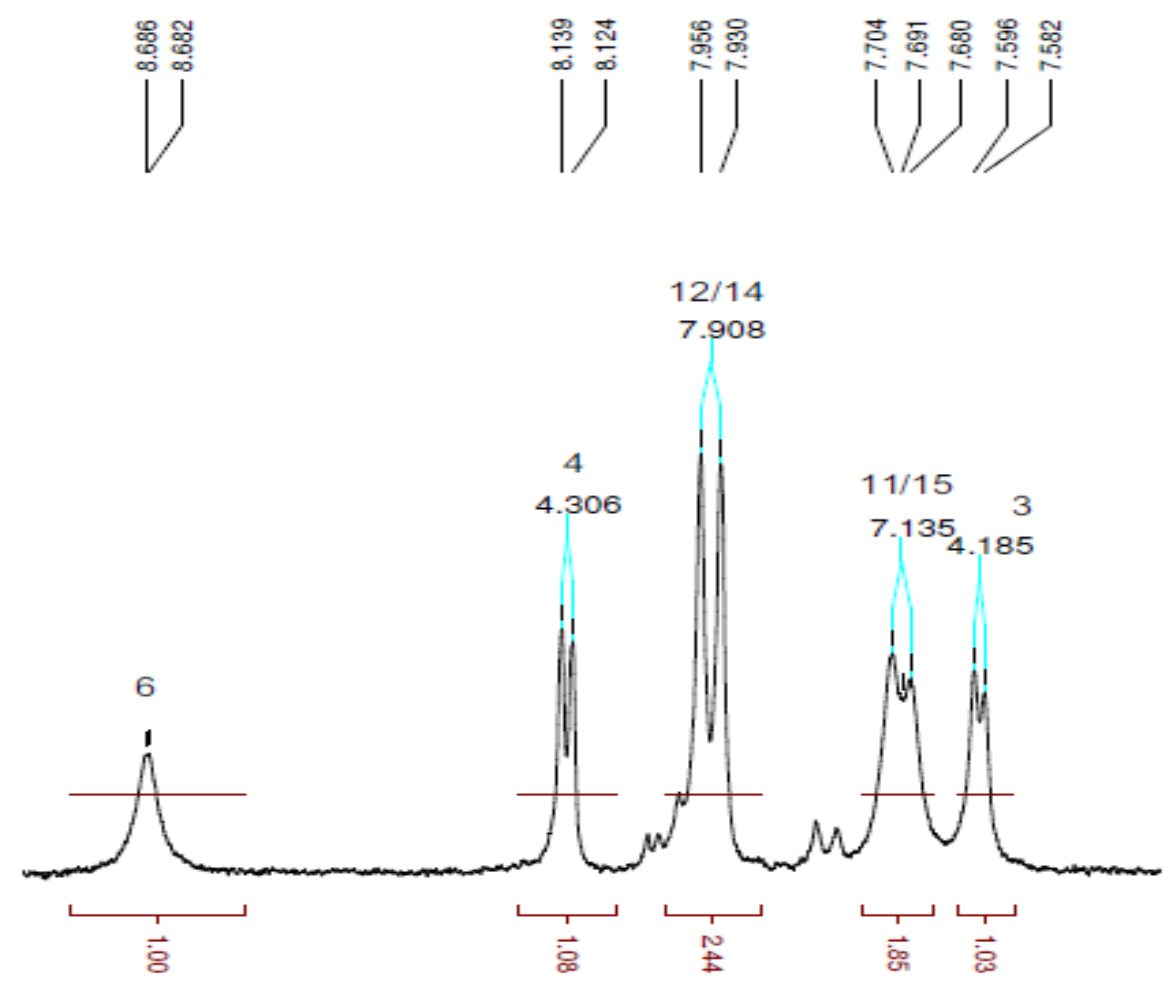

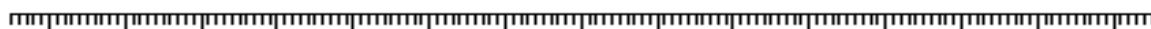
$\begin{array}{lllllllllllllllllll}8.80 & 8.70 & 8.60 & 8.50 & 8.40 & 8.30 & 8.20 & 8.10 & 8.00 & 7.90 & 7.80 & 7.70 & 7.60 & 7.50 & 7.40\end{array}$ pom (t1) 
RMN ${ }^{13} \mathrm{C}:$ 4-iodo-[N'-(5-nitrotiofen-2- il)metileno]benzidrazida
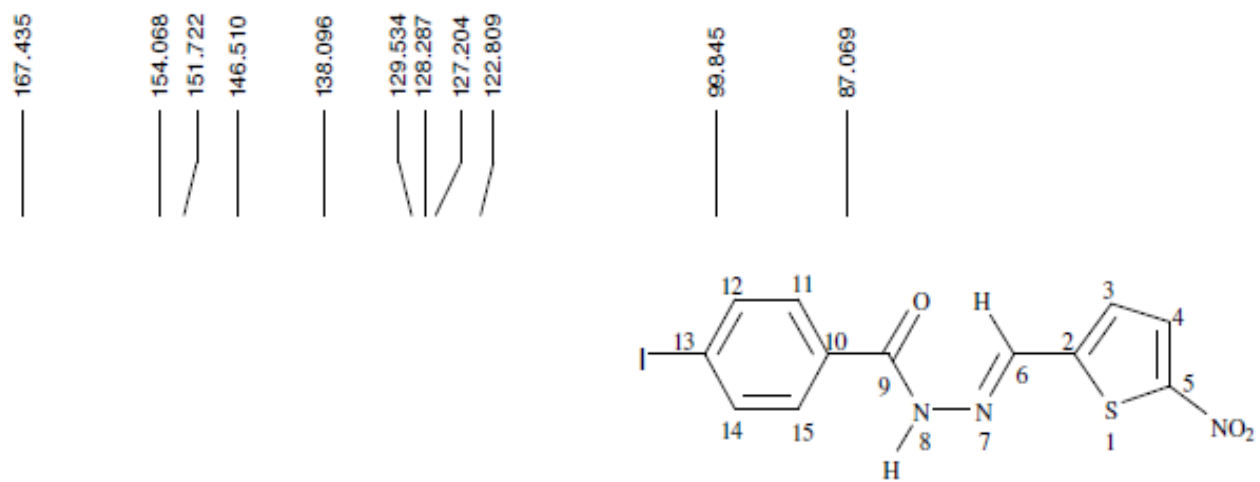

$10 \quad 3 / 4 / 11 / 15$

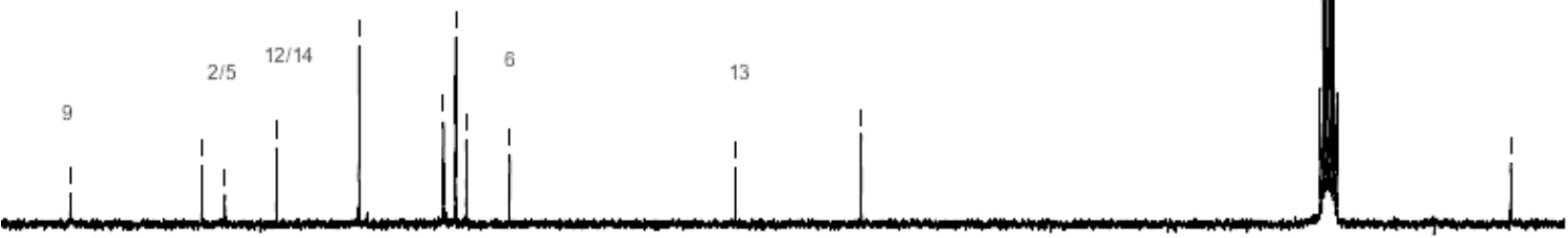

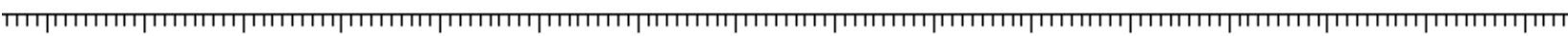

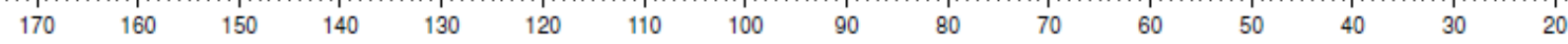
ppm (t1) 
RMN ${ }^{1} \mathrm{H}$ : 4-butoxi-[N'-(5-nitrotiofen-2- il)metileno]benzidrazida

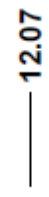

包
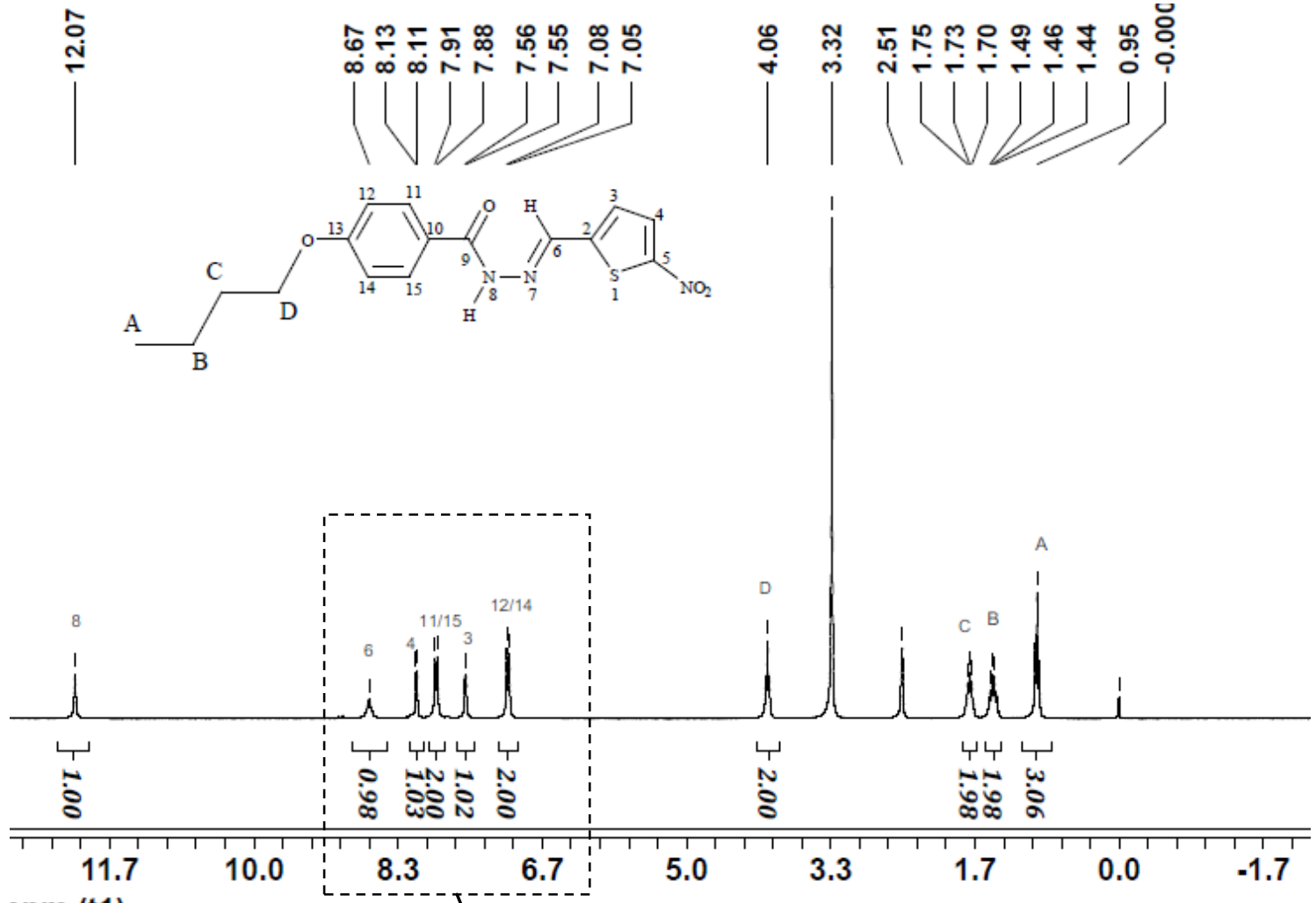

Jpm (t1)
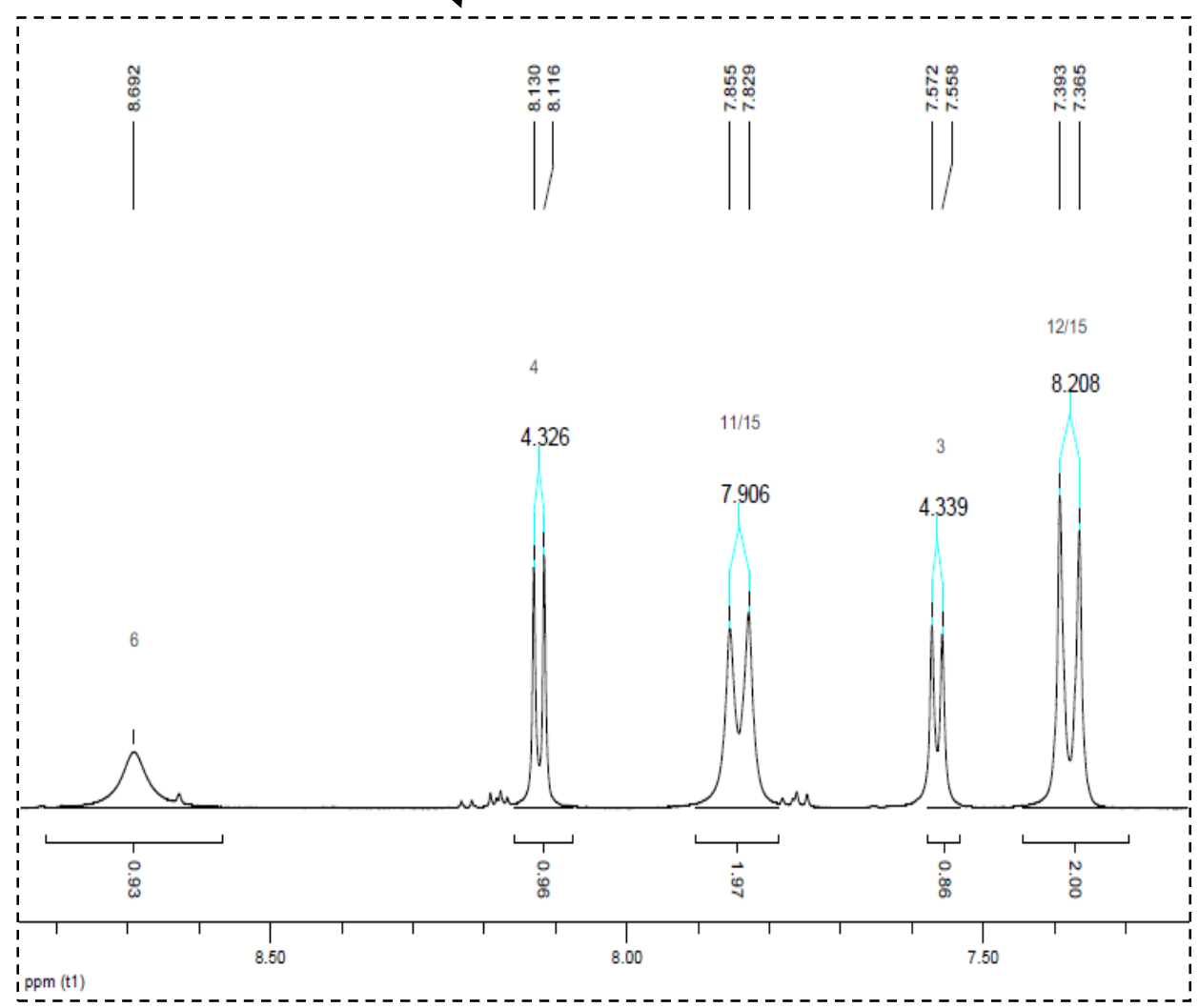
RMN ${ }^{13} \mathrm{C}$ :4-butoxi-[N'-(5-nitrotiofen-2- il)metileno]benzidrazida
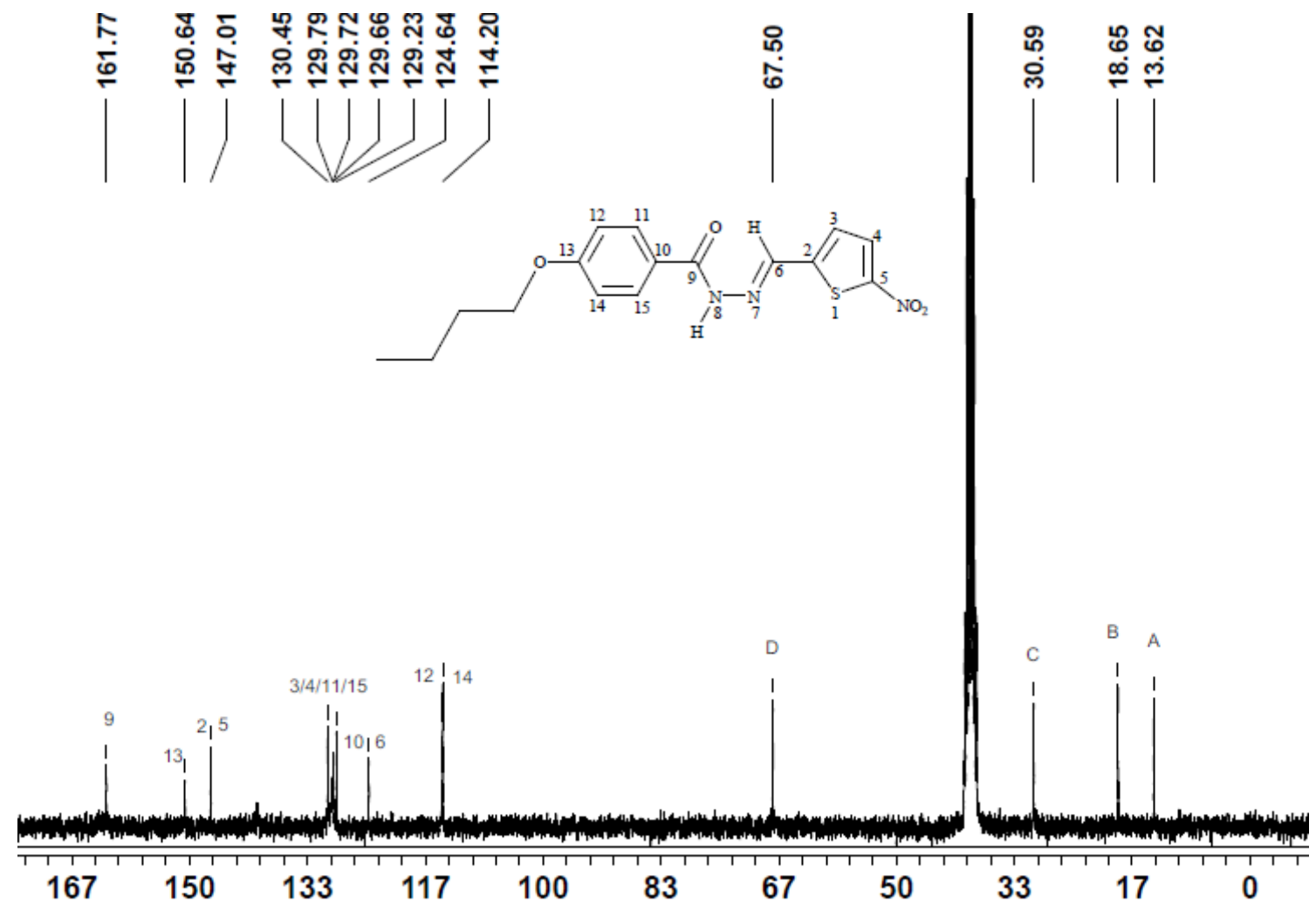

ppm (t1) 
RMN ${ }^{1} \mathrm{H}$ : 4-etil-[N'-(5-nitrotiofen-2- il)metileno]benzidrazida
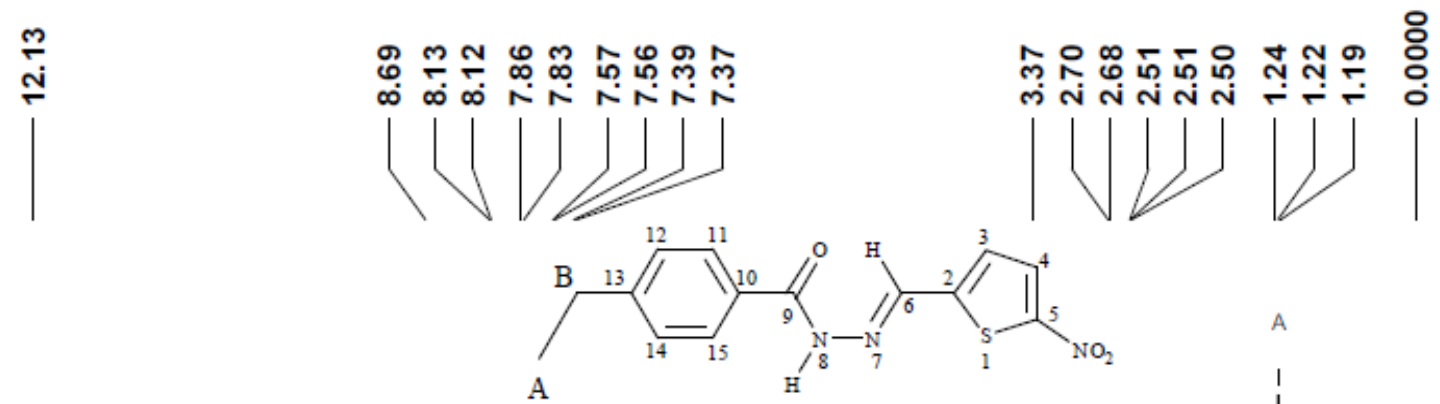

लु่

ํำ 冓
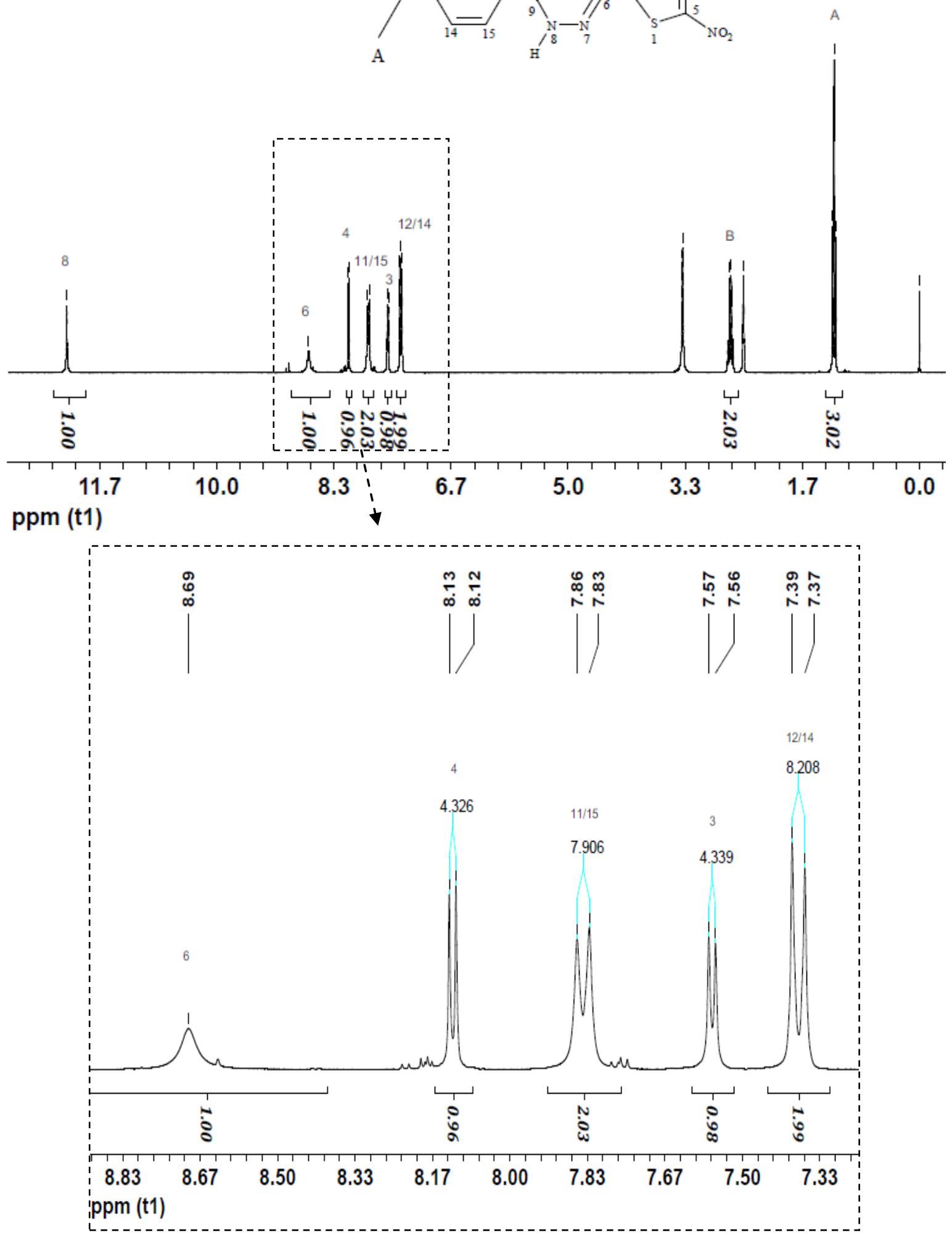
RMN ${ }^{13} \mathrm{C}:$ 4-etil-[N'-(5-nitrotiofen-2- il)metileno]benzidrazida

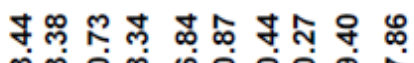
约

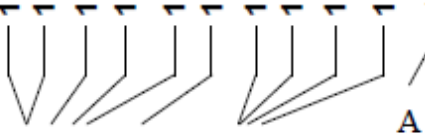

A
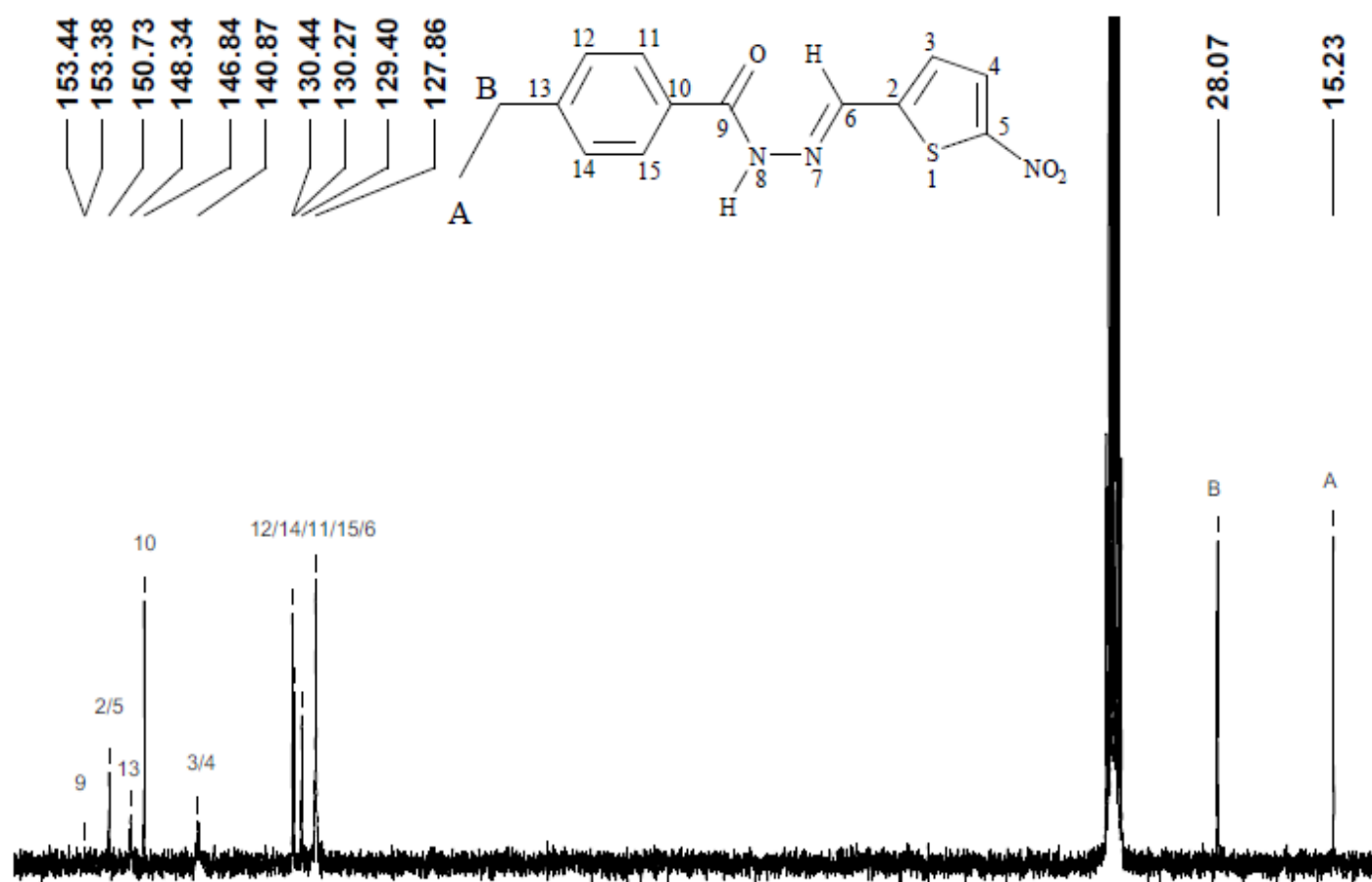

150 133 117 100 83 67 50 33 17 ppm (t1) 
Anexo2. Espectros de $R M N{ }^{1} \mathrm{H}$ e $R M N{ }^{13} \mathrm{C}$ dos compostos derivados tiofilidênicos oxadiazolínicos.

RMN ${ }^{1} \mathrm{H}$ : 2-[5-nitro-tiofiliden-2-il]-3-acetil-5-[fenil]-2,3-diidro-1,3,4oxadiazolinas
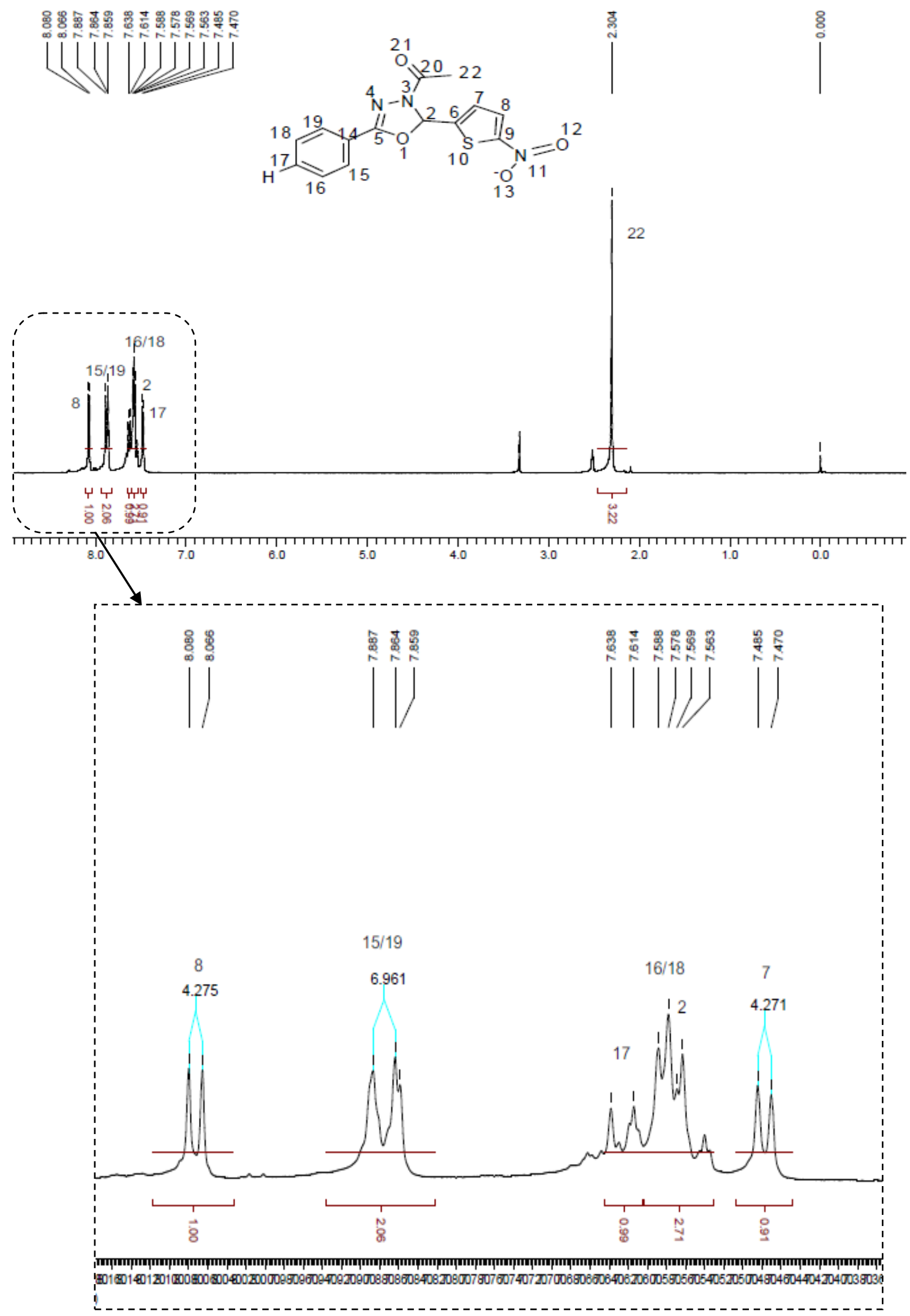
$\mathrm{RMN}{ }^{13} \mathrm{C}$ : 2-[5-nitro-tiofiliden-2-il]-3-acetil-5-[fenil]-2,3-diidro-1,3,4-oxadiazolinas
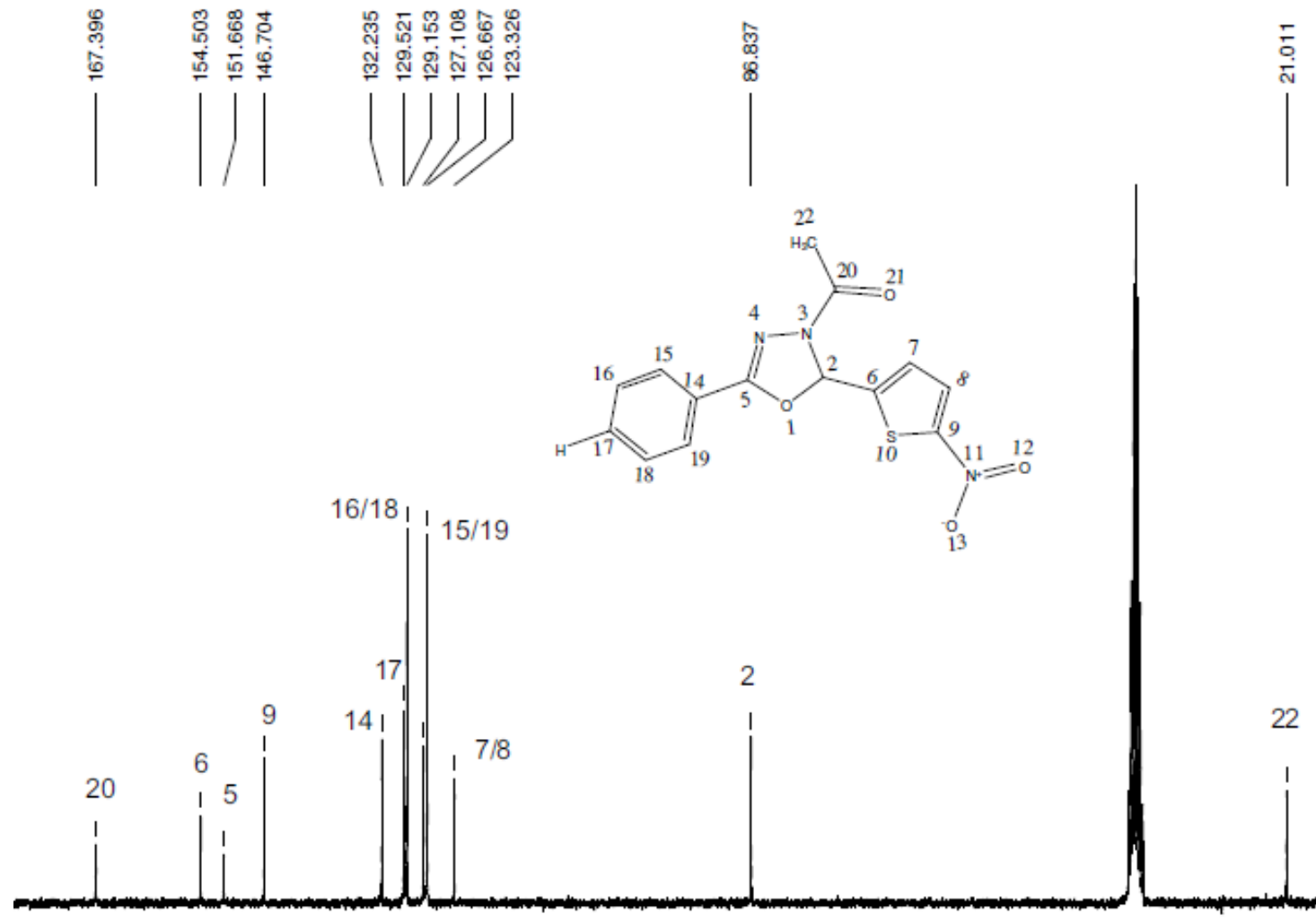

22

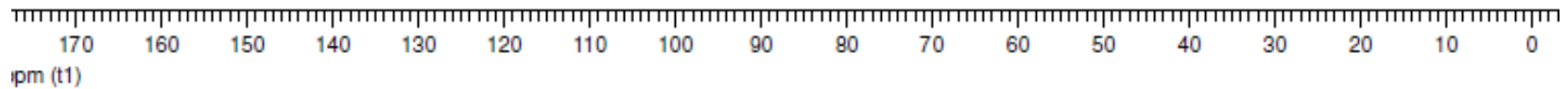


RMN ${ }^{1} \mathrm{H}:$ :2-[5-nitro-tiofiliden-2-il]-3-acetil-5-[4-cloro-fenil]-2,3-diidro-1,3,4oxadiazolinas
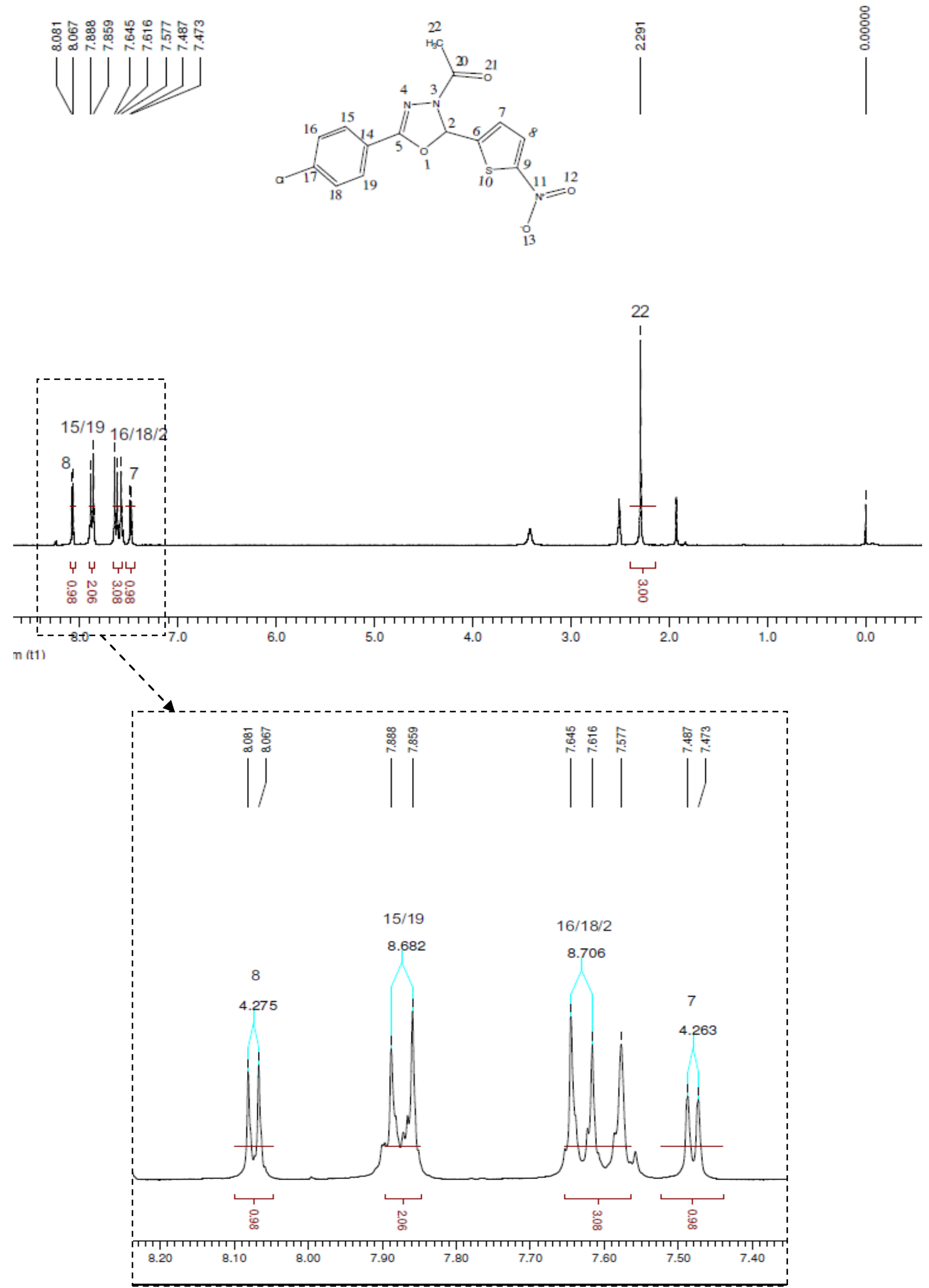
RMN $\quad{ }^{13} \mathrm{C}: \quad$ 2-[5-nitro-tiofiliden-2-il]-3-acetil-5-[4-cloro-fenil]-2,3-diidro-1,3,4oxadiazolinas
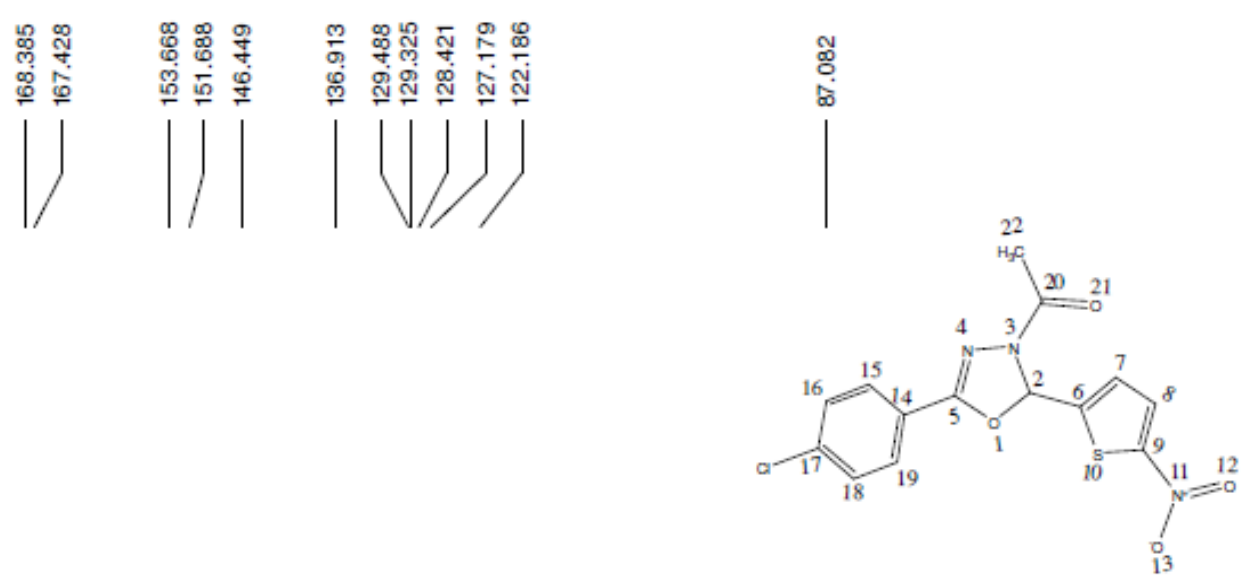

$14 / 15 / 19 / 16 / 18$

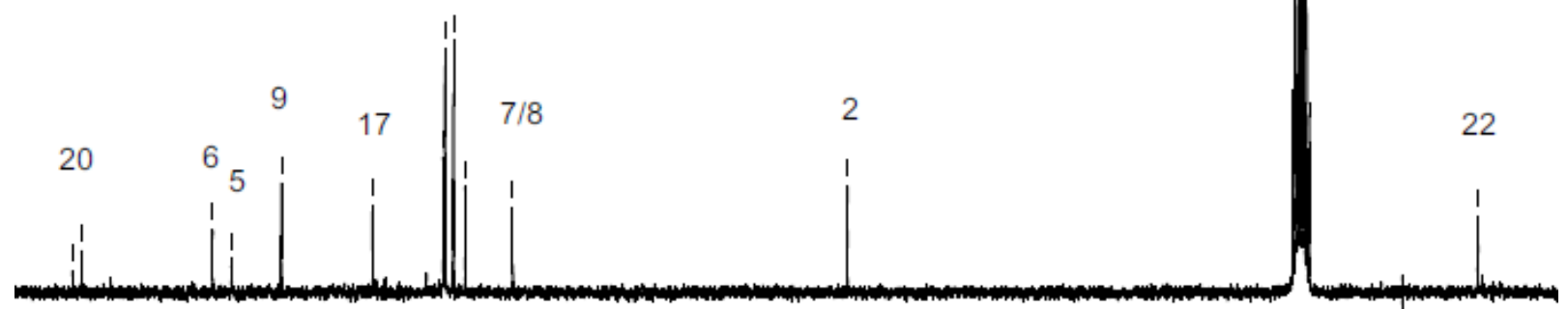

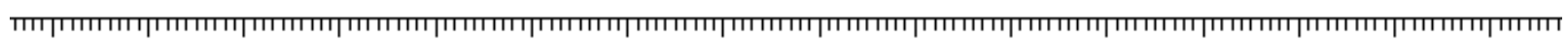

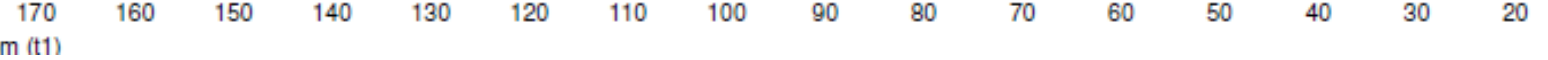


RMN $\quad{ }^{1} \mathrm{H}: \quad$ 2-[5-nitro-tiofiliden-2-il]-3-acetil-5-[4-ciano-fenil]-2,3-diidro-1,3,4oxadiazolinas

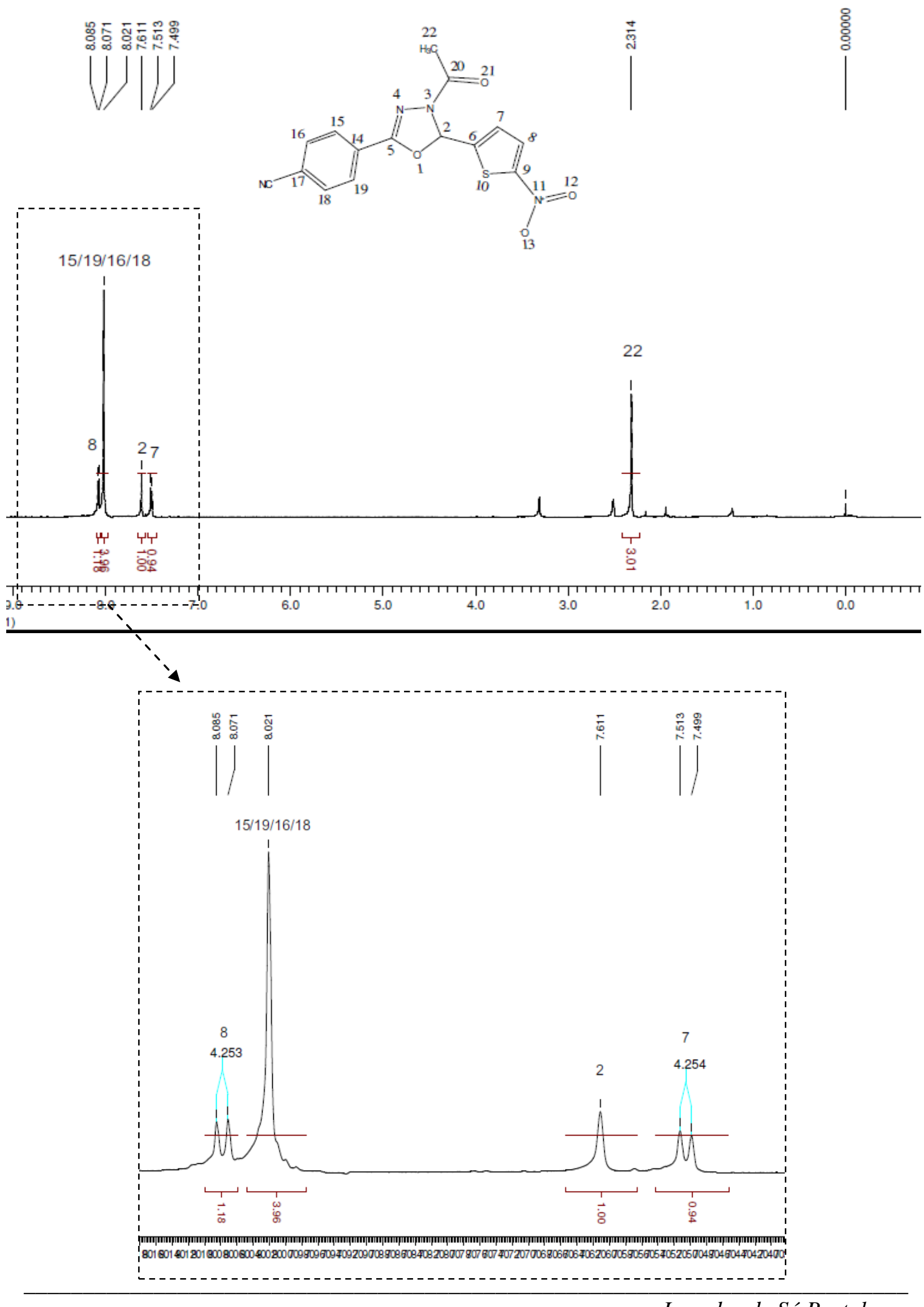


RMN $\quad{ }^{1} \mathrm{C}: \quad$ 2-[5-nitro-tiofiliden-2-il]-3-acetil-5-[4-ciano-fenil]-2,3-diidro-1,3,4oxadiazolinas
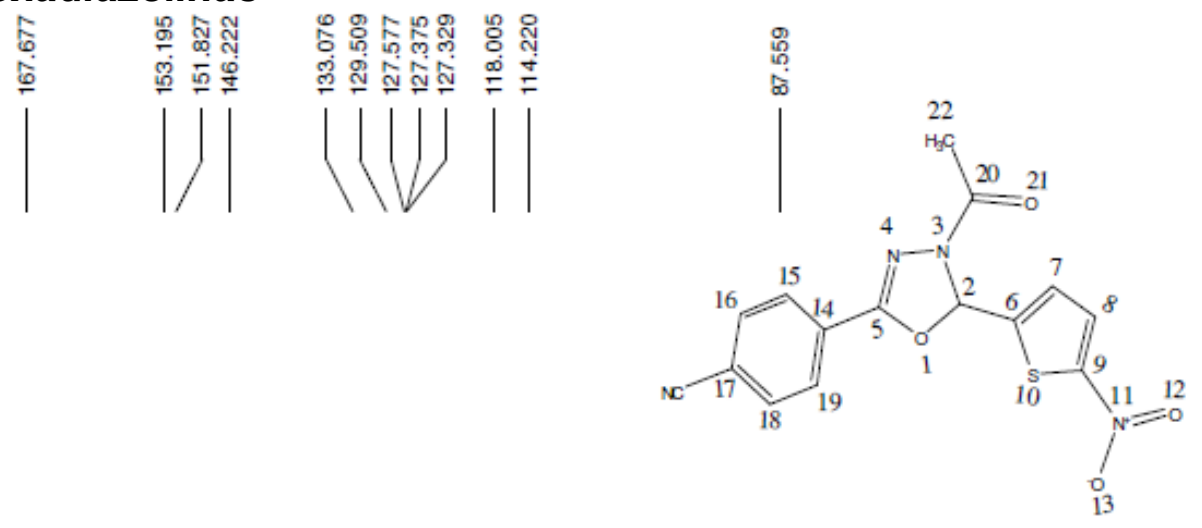

$14 / 15 / 19 / 16 / 18$

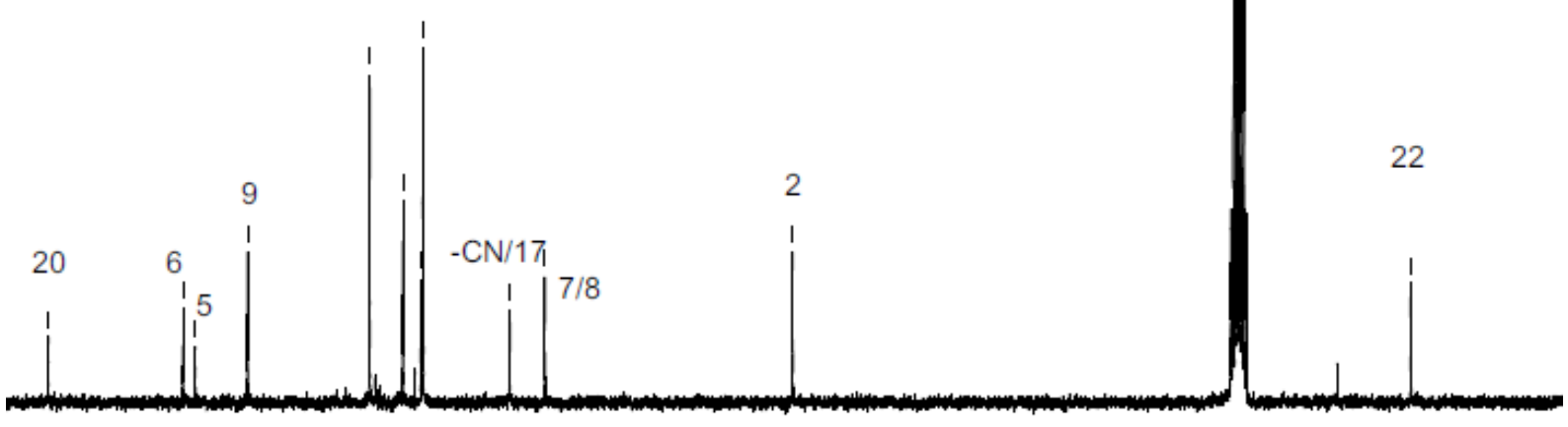

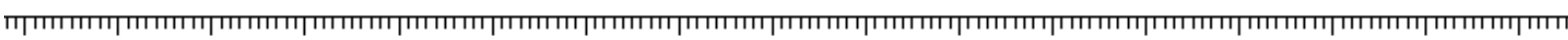

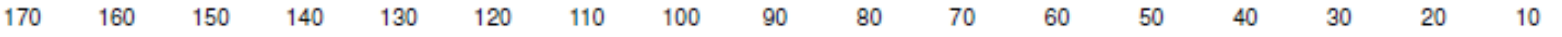
$\mathrm{m}$ (t1) 
RMN ${ }^{1} \mathrm{H}:$ 2-[5-nitro-tiofiliden-2-il]-3-acetil-5-[4-trifluormetil-fenil]-2,3-diidro-1,3,4oxadiazolinas

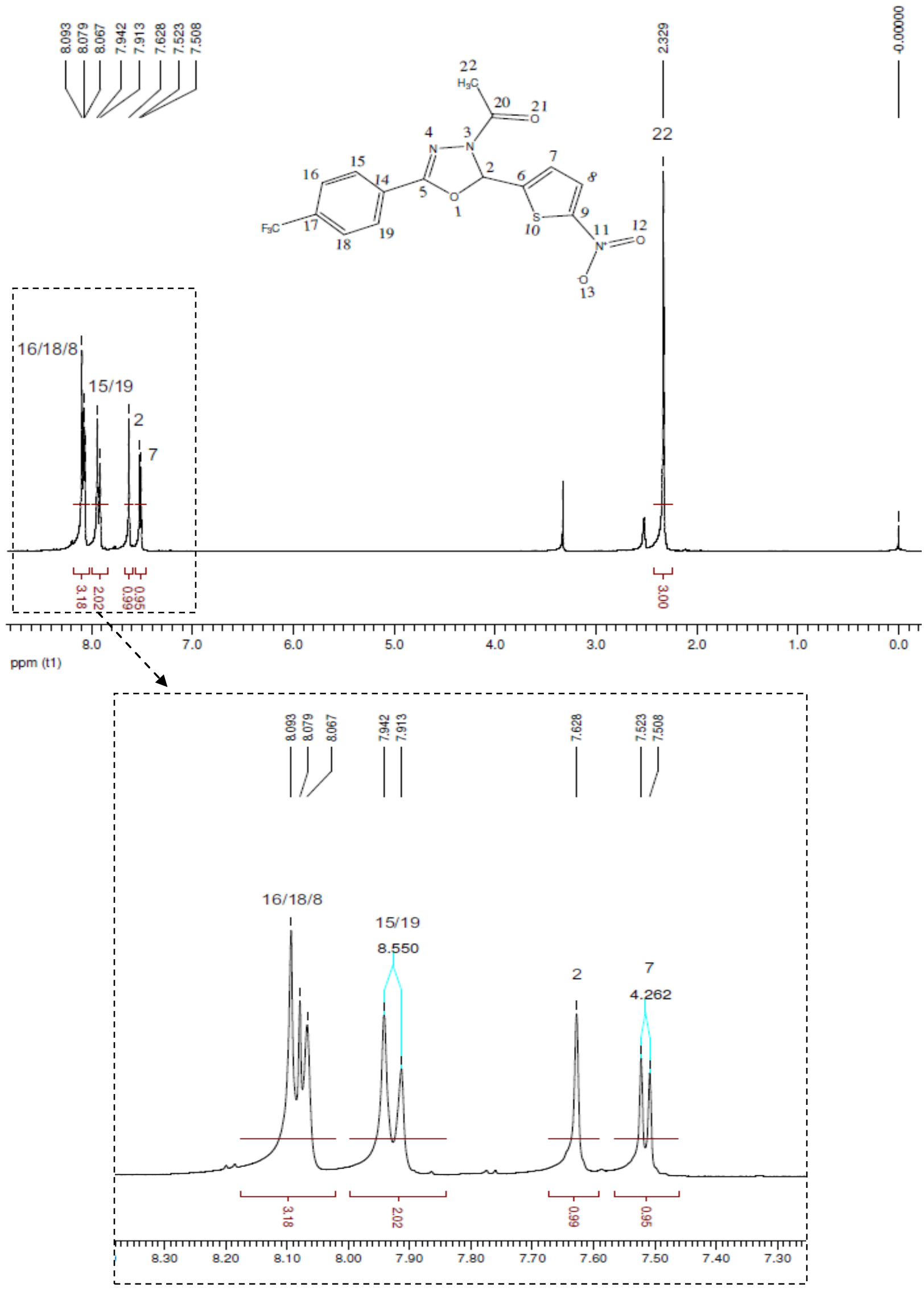


RMN ${ }^{13} \mathrm{C}$ : 2-[5-nitro-tiofiliden-2-il]-3-acetil-5-[4-trifluormetil-fenil]-2,3-diidro-1,3,4oxadiazolinas

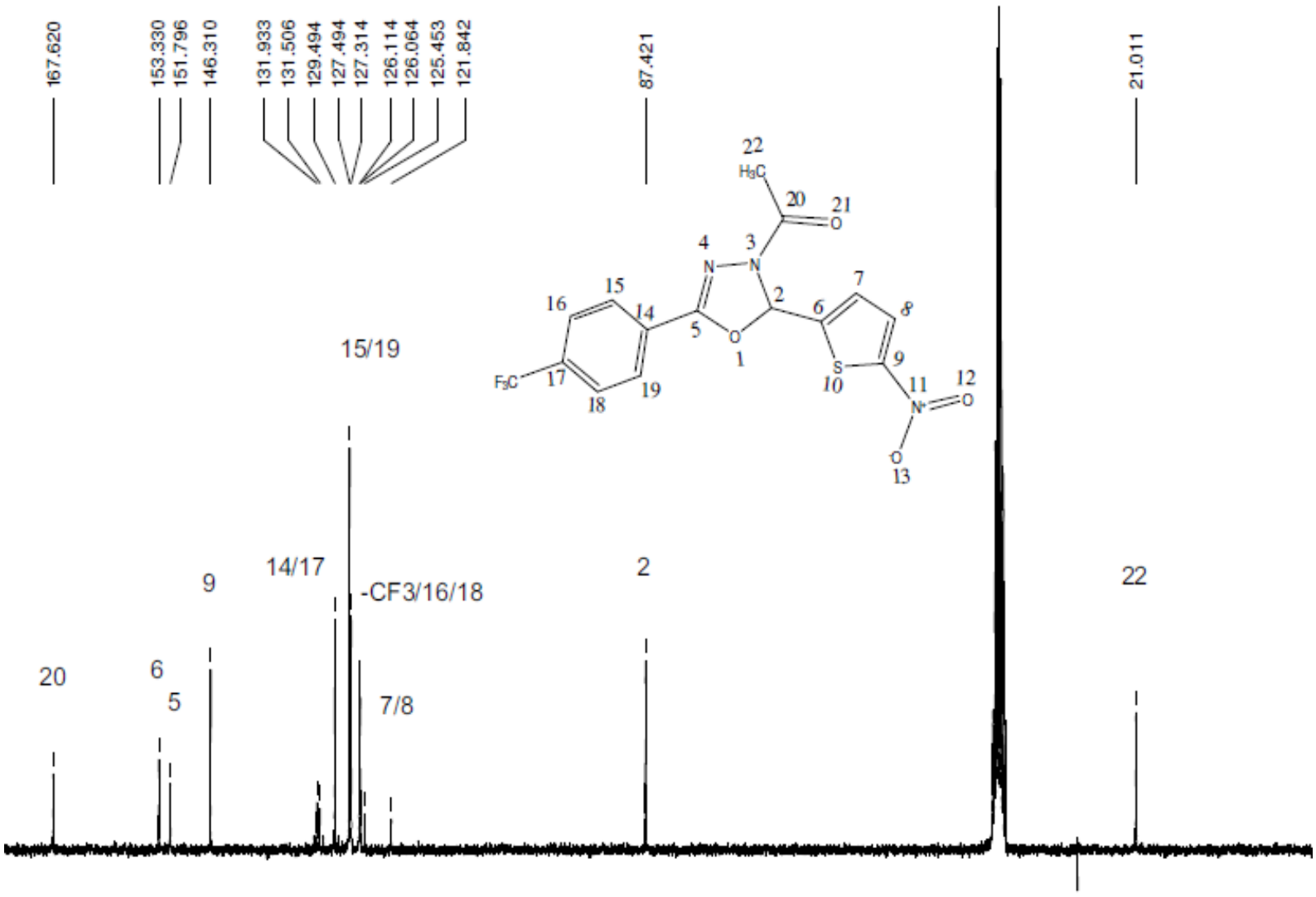

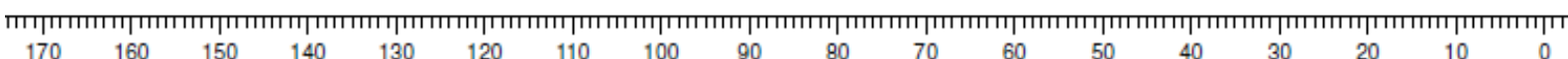


RMN ${ }^{1} \mathrm{H}: \quad$ 2-[5-nitro-tiofiliden-2-il]-3-acetil-5-[4-metoxi-fenil]-2,3-diidro-1,3,4oxadiazolinas
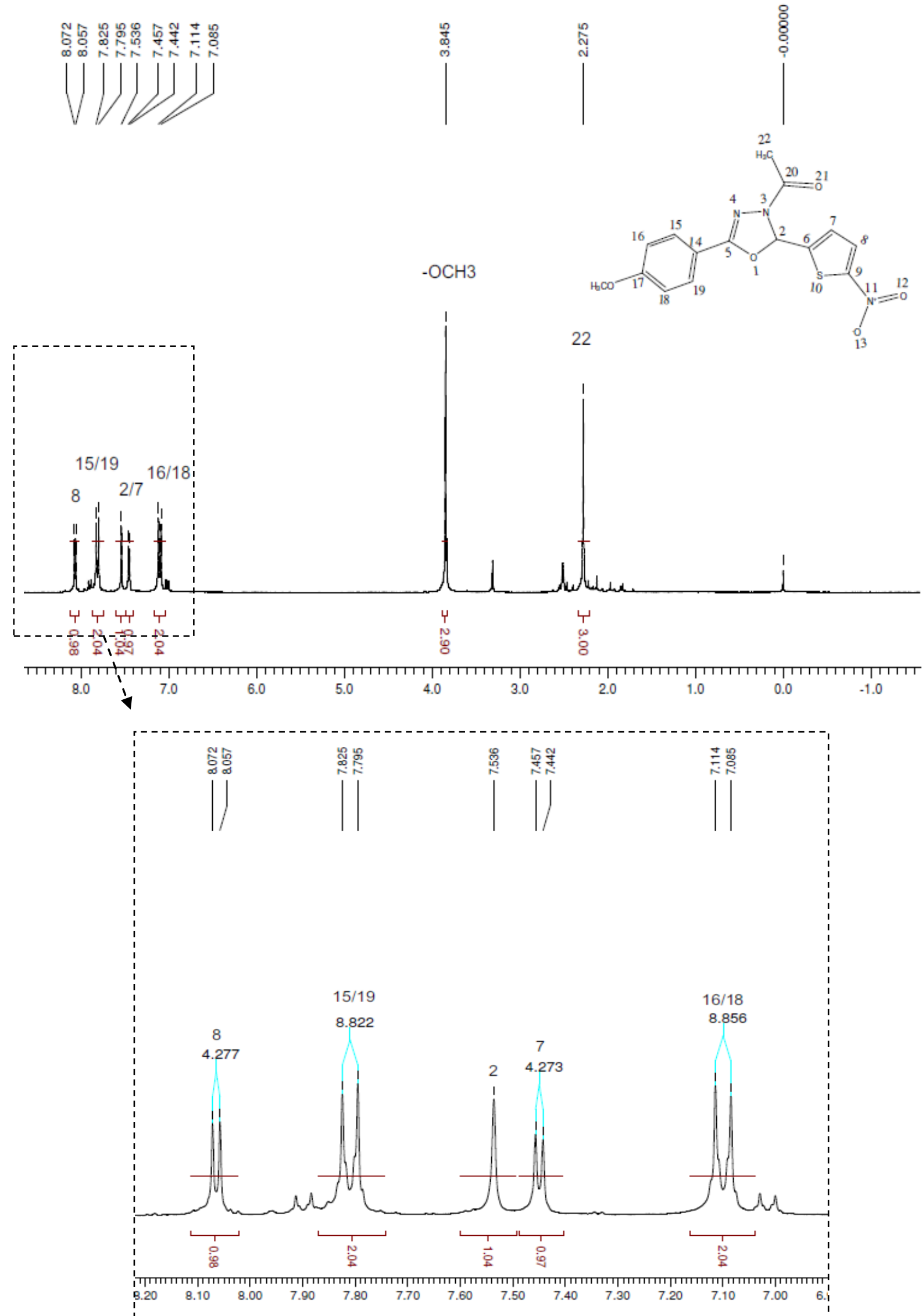
RMN $\quad{ }^{13} \mathrm{C}: \quad$ 2-[5-nitro-tiofiliden-2-il]-3-acetil-5-[4-metoxi-fenil]-2,3-diidro-1,3,4oxadiazolinas
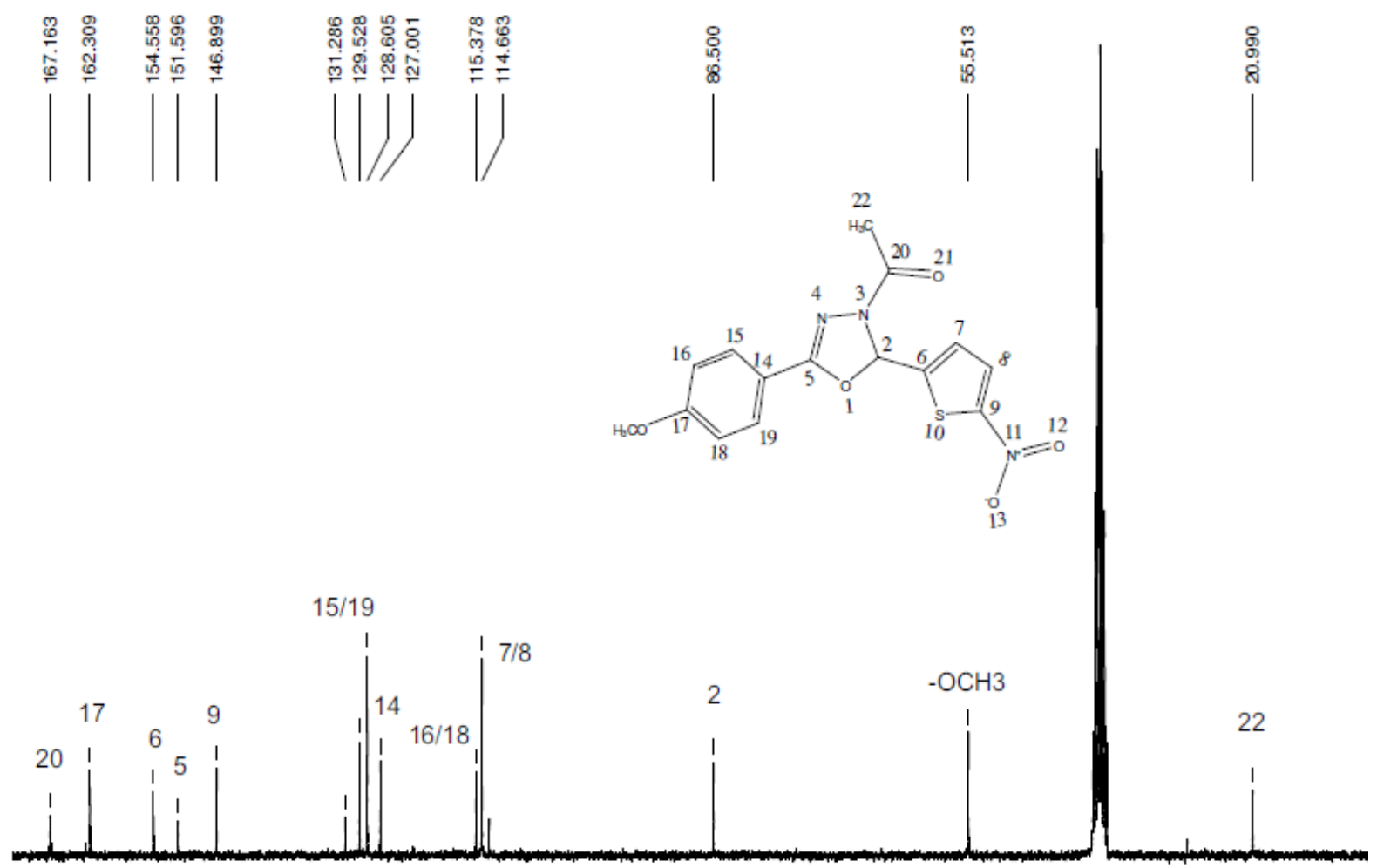

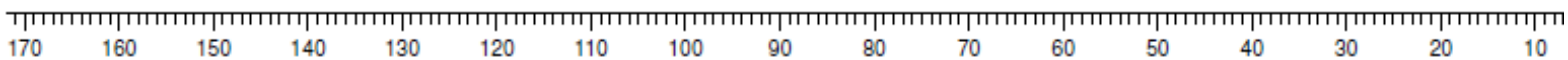
$\mathrm{ppm}(\mathrm{t} 1)$ 
RMN $\quad{ }^{1} \mathrm{H}: \quad$ 2-[5-nitro-tiofiliden-2-il]-3-acetil-5-[4-nitro-fenil]-2,3-diidro-1,3,4oxadiazolinas

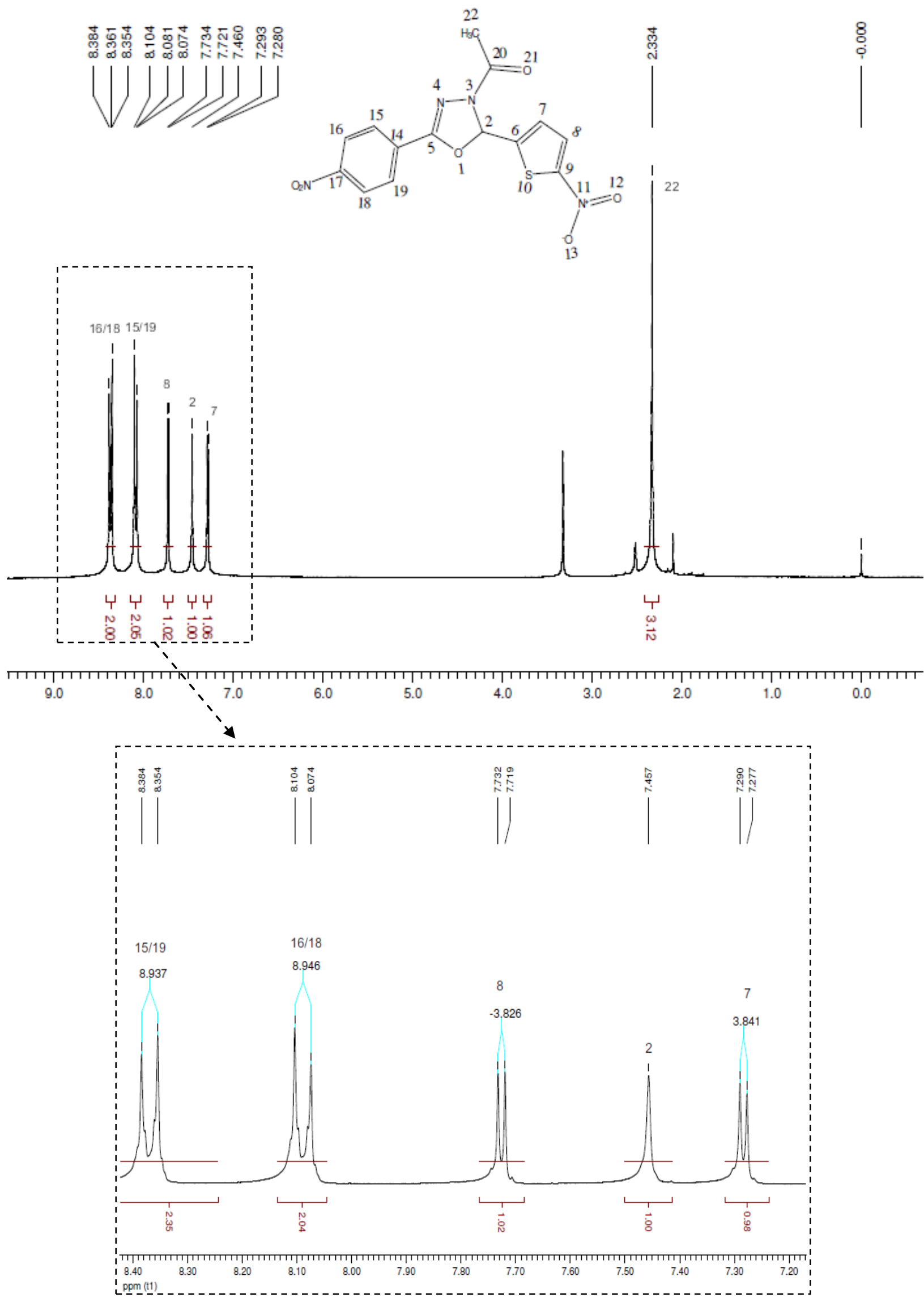


RMN ${ }^{13} \mathrm{C}$ : 2-[5-nitro-tiofiliden-2-il]-3-acetil-5-[4-nitro-fenil]-2,3-diidro-1,3,4oxadiazolinas
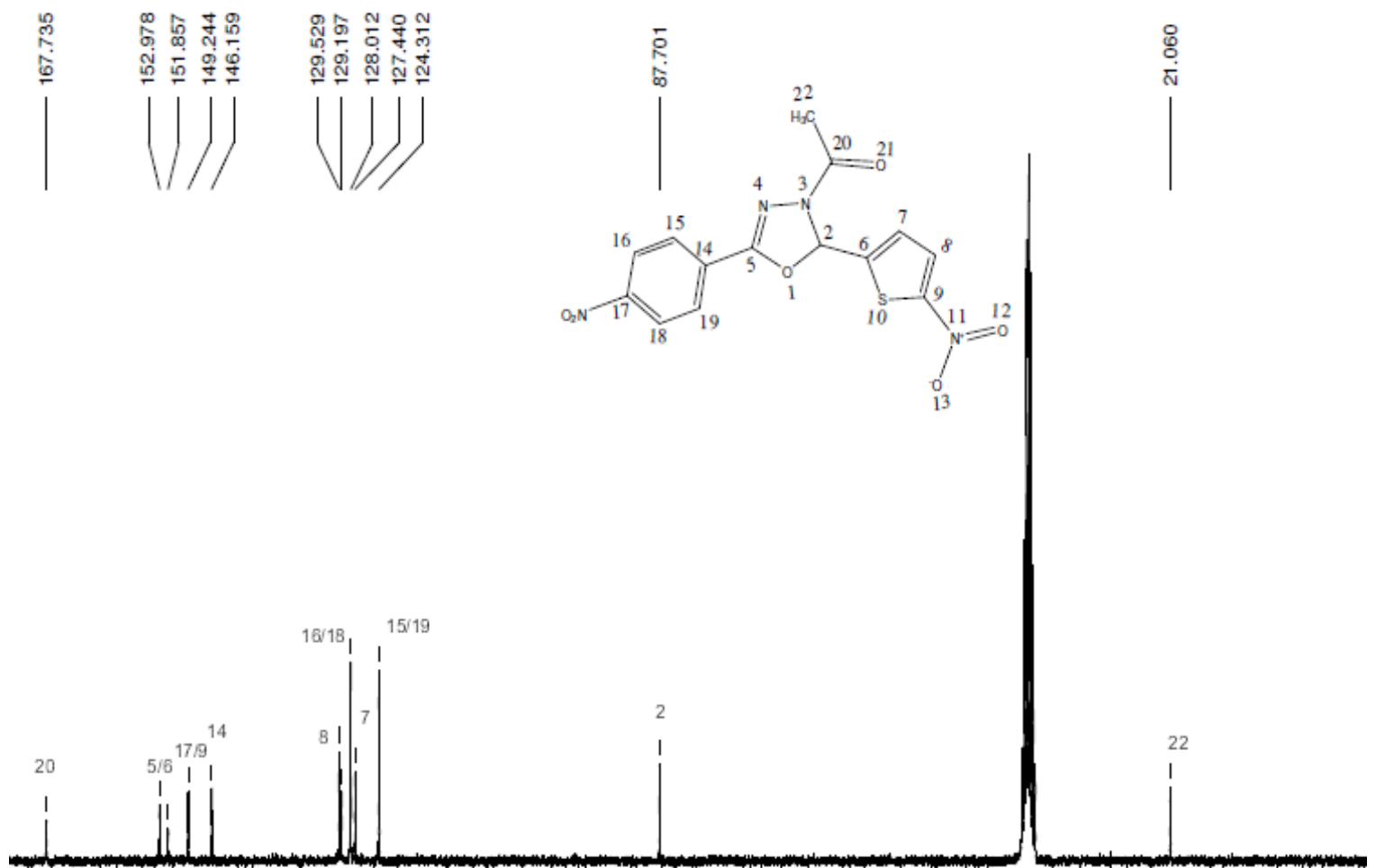

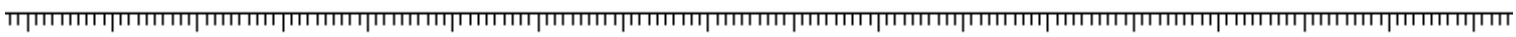

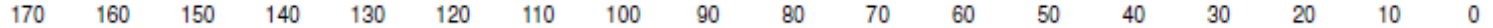
$\mathrm{ppm}(\mathrm{t} 1)$ 
RMN $\quad{ }^{1} \mathrm{H}: \quad$ 2-[5-nitro-tiofiliden-2-il]-3-acetil-5-[4-iodo-fenil]-2,3-diidro-1,3,4oxadiazolinas

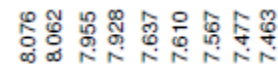
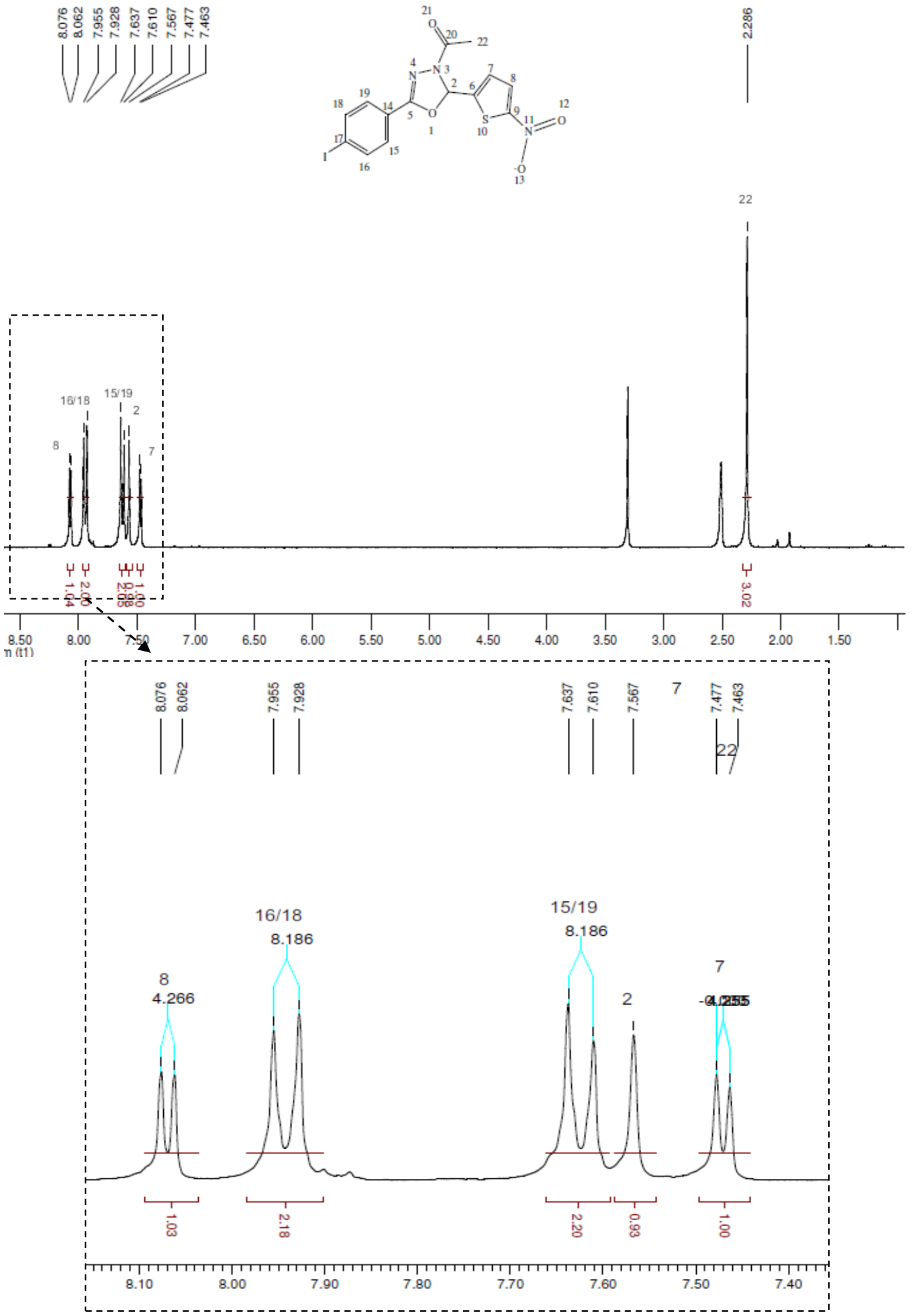
RMN $\quad{ }^{13} \mathrm{C}: \quad$ 2-[5-nitro-tiofiliden-2-il]-3-acetil-5-[4-iodo-fenil]-2,3-diidro-1,3,4oxadiazolinas
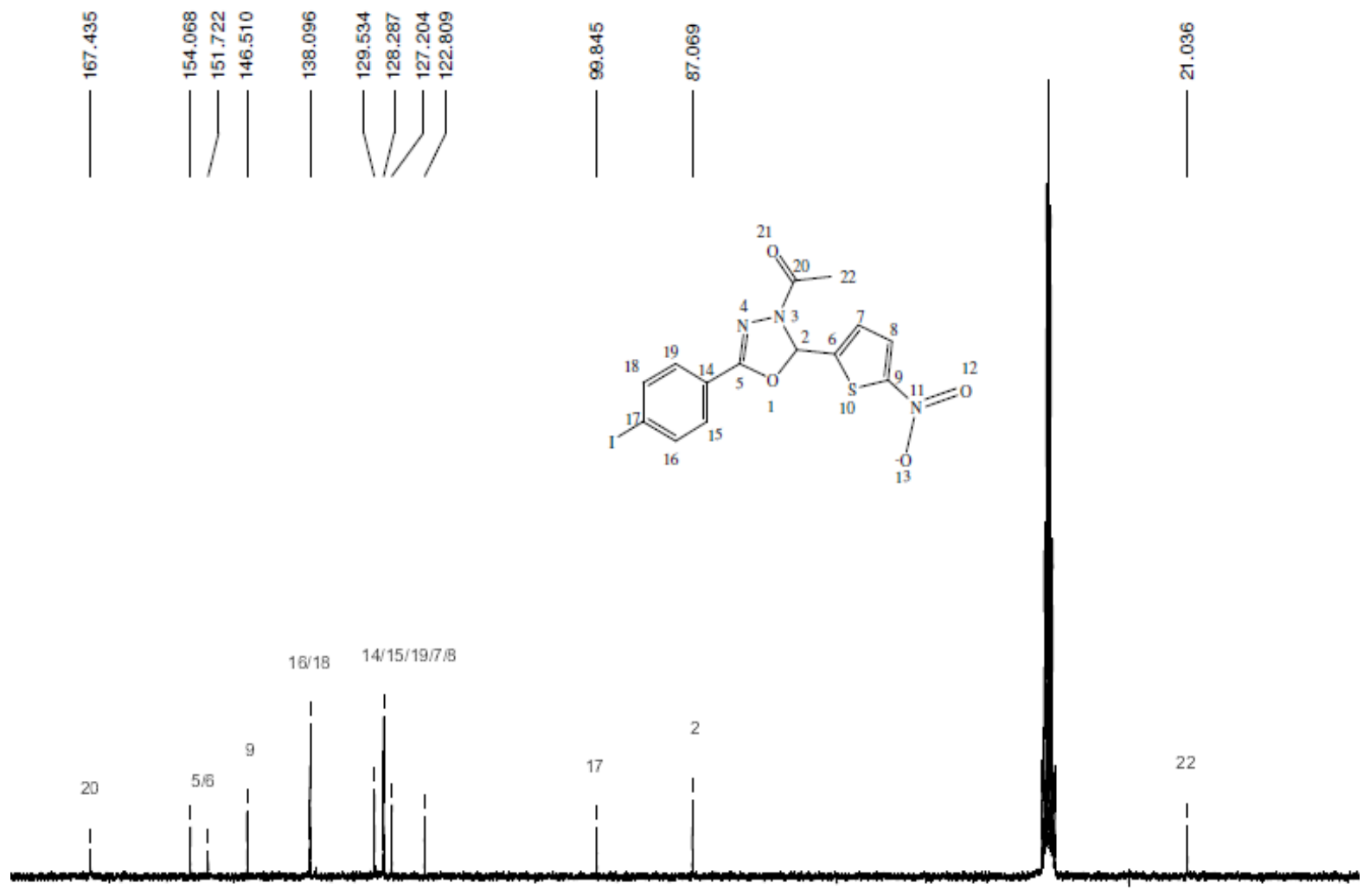

ताmापाए

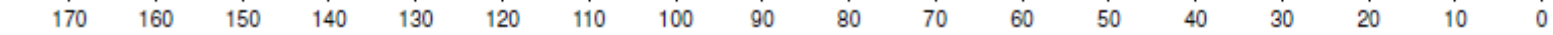
$\mathrm{ppm}(\mathrm{t} 1)$ 
${ }_{\mathrm{RMN}}{ }^{1} \mathrm{H}: \quad$ 2-[5-nitro-tiofiliden-2-il]-3-acetil-5-[4-butoxi-fenil]-2,3-diidro-1,3,4oxadiazolinas

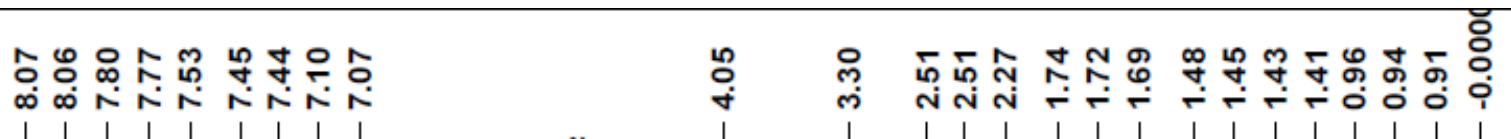
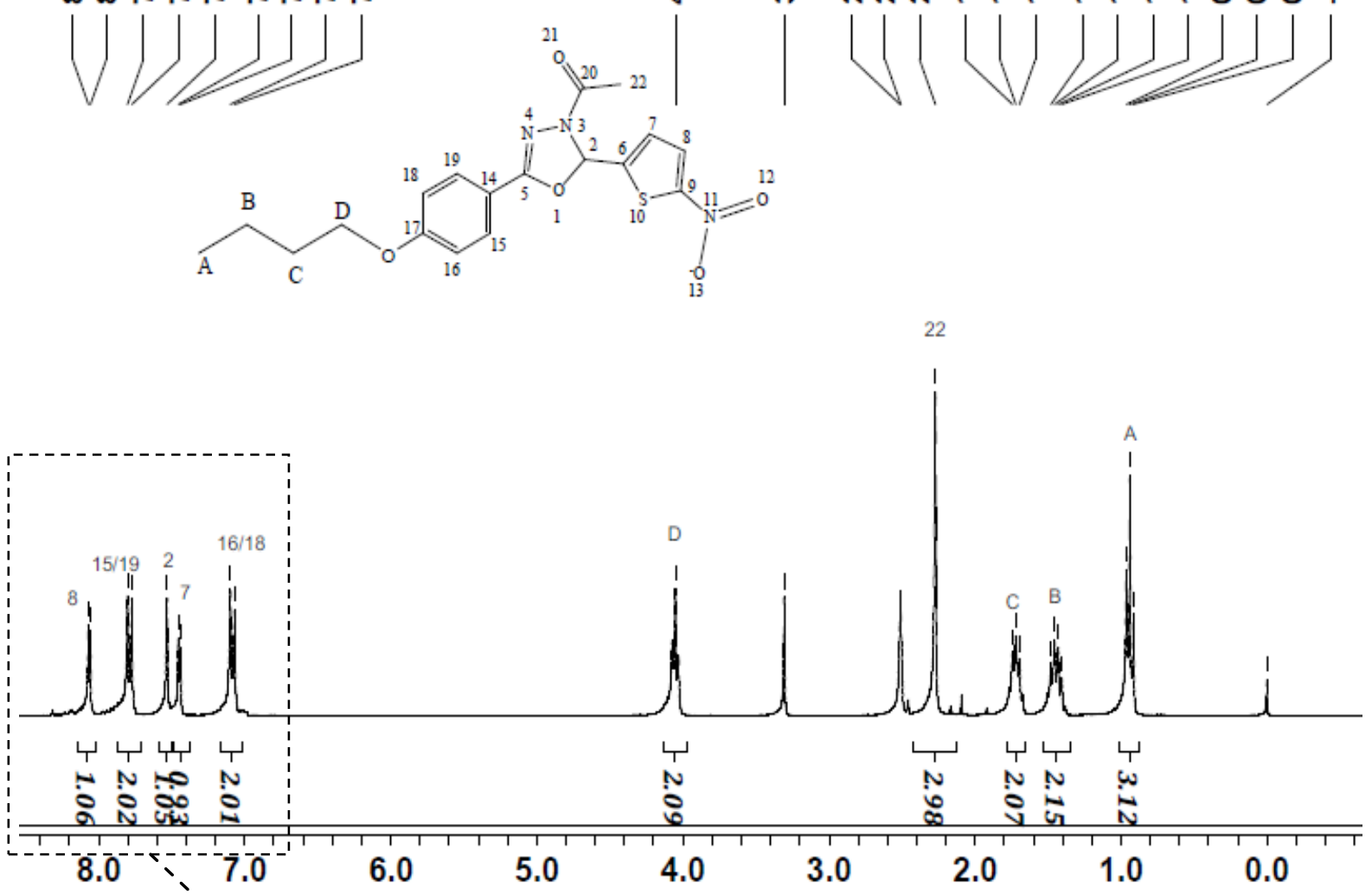
ppm (t1)
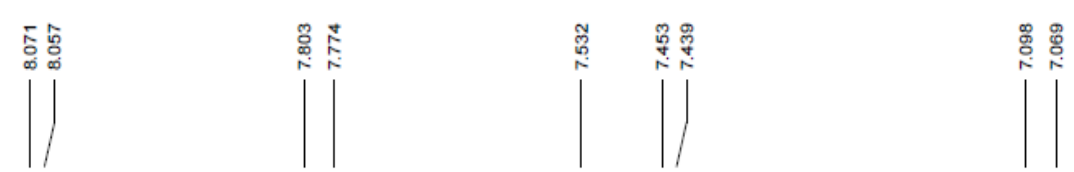

$5 / 19$

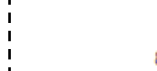

8.809

8.838

4.254

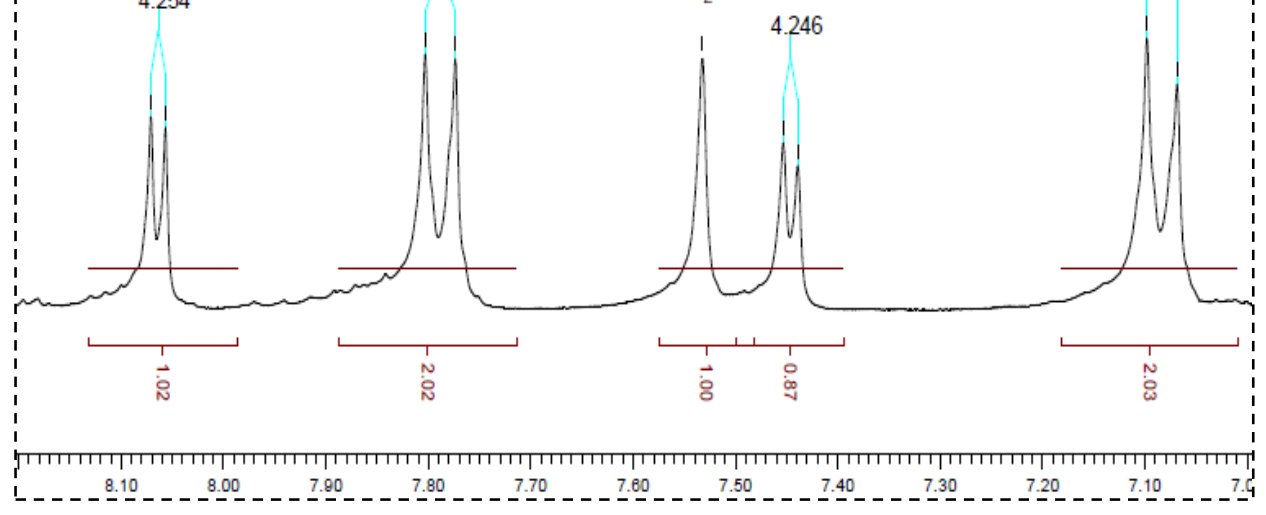


RMN $\quad{ }^{13} \mathrm{C}: \quad$ 2-[5-nitro-tiofiliden-2-il]-3-acetil-5-[4-butoxi-fenil]-2,3-diidro-1,3,4oxadiazolinas
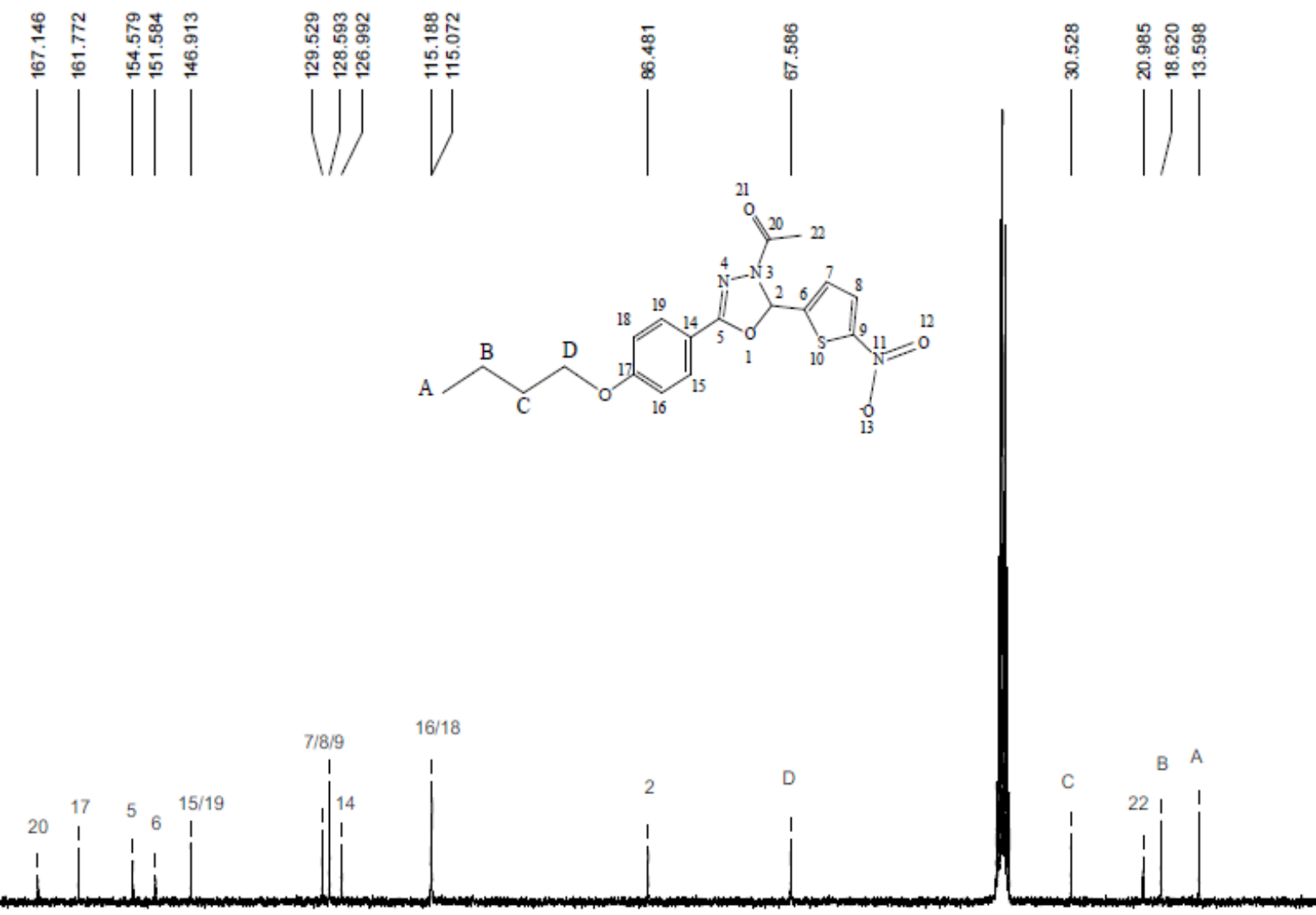

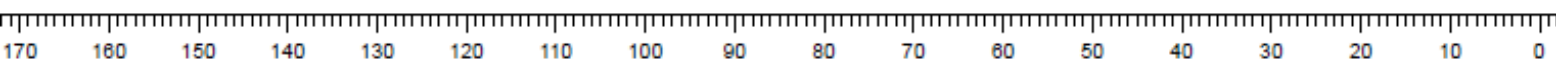
spm (t1) 
RMN $\quad{ }^{1} \mathrm{H}: \quad$ 2-[5-nitro-tiofiliden-2-il]-3-acetil-5-[4-etil-fenil]-2,3-diidro-1,3,4oxadiazolinas
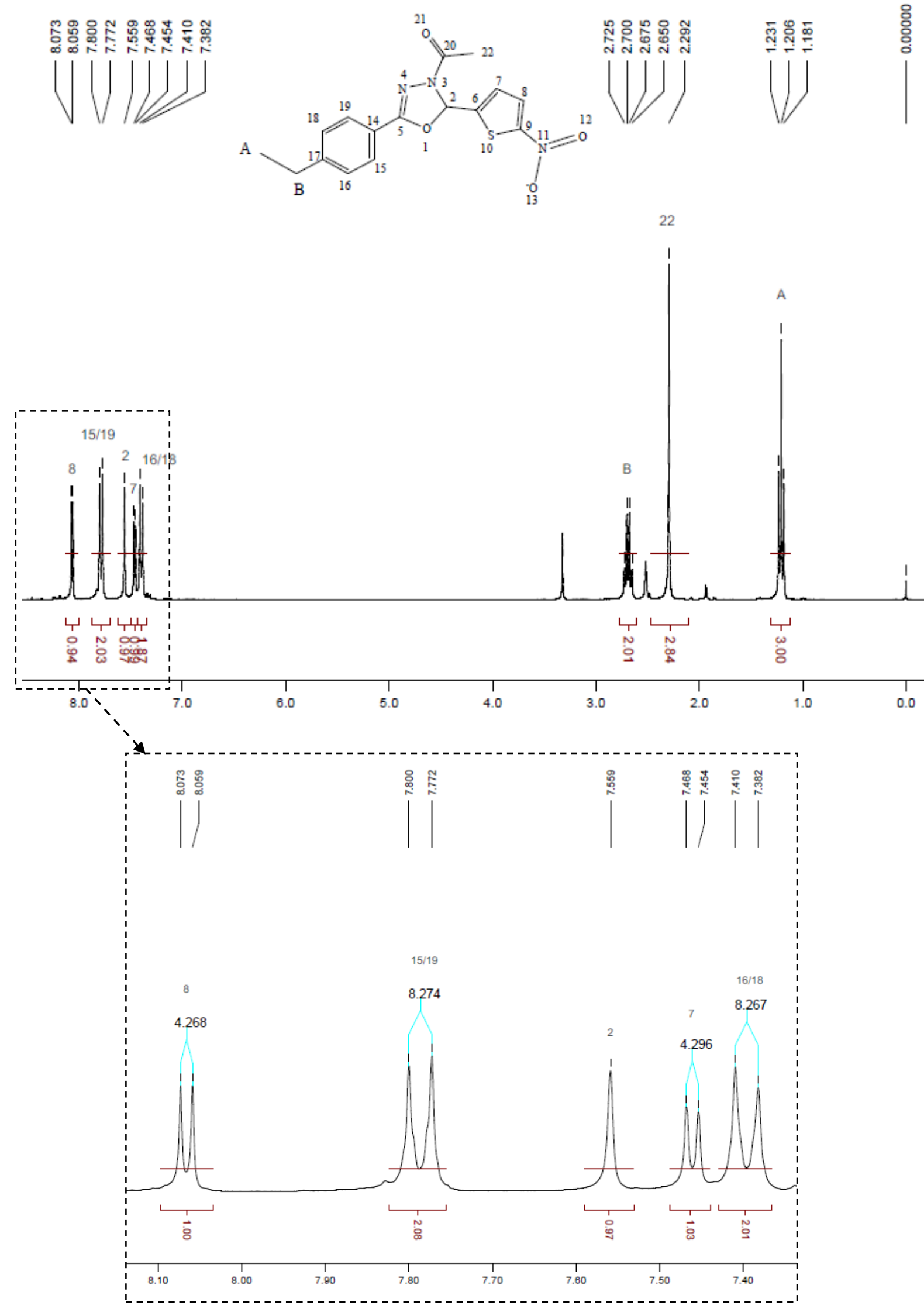
$\mathrm{RMN} \quad{ }^{13} \mathrm{C}: \quad$ 2-[5-nitro-tiofiliden-2-il]-3-acetil-5-[4-butoxi-fenil]-2,3-diidro-1,3,4oxadiazolinas
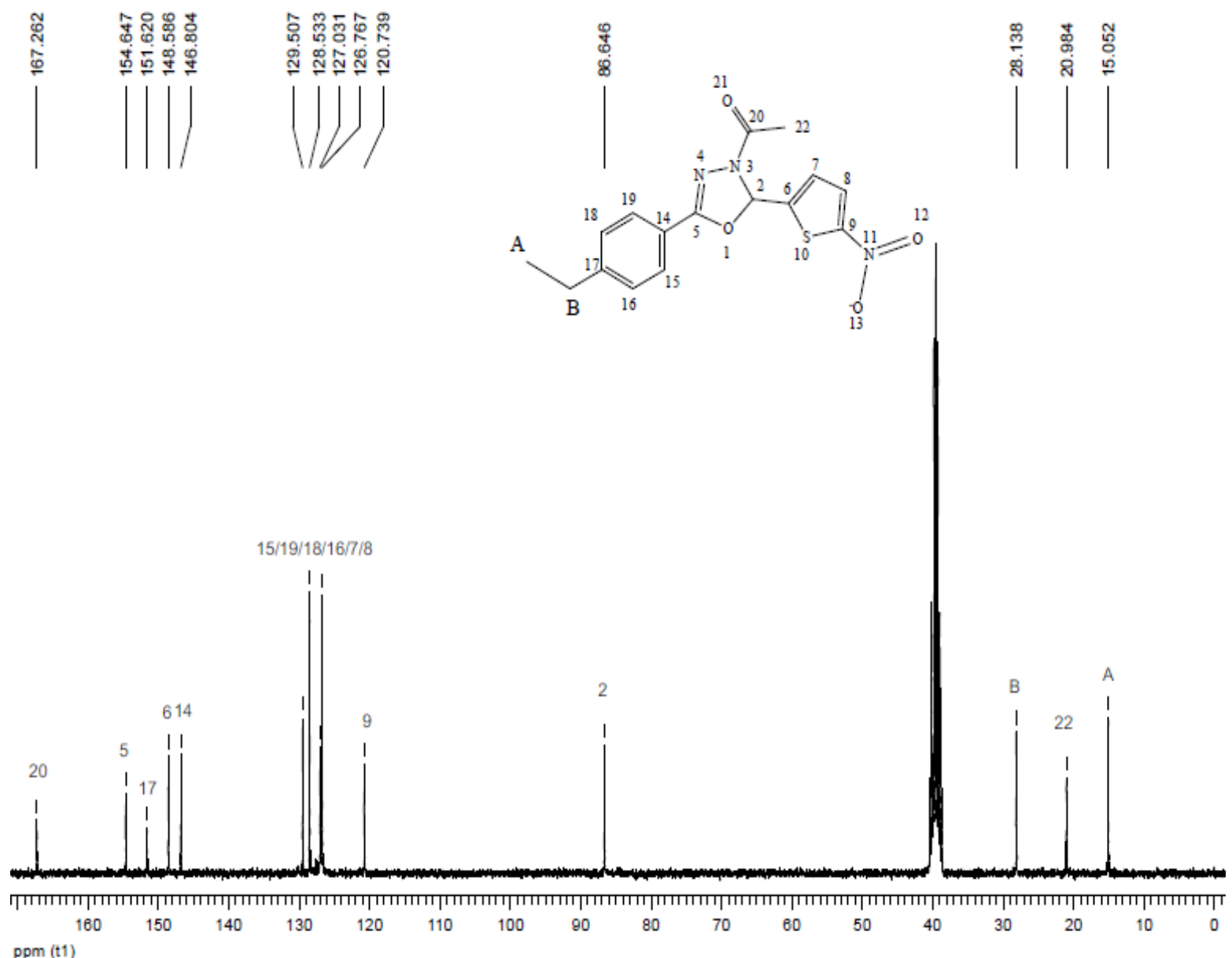
ppm (t1) 
Anexo 3. Representação gráfica dos confôrmeros e suas energias totais da simulação de dinâmica molecular 


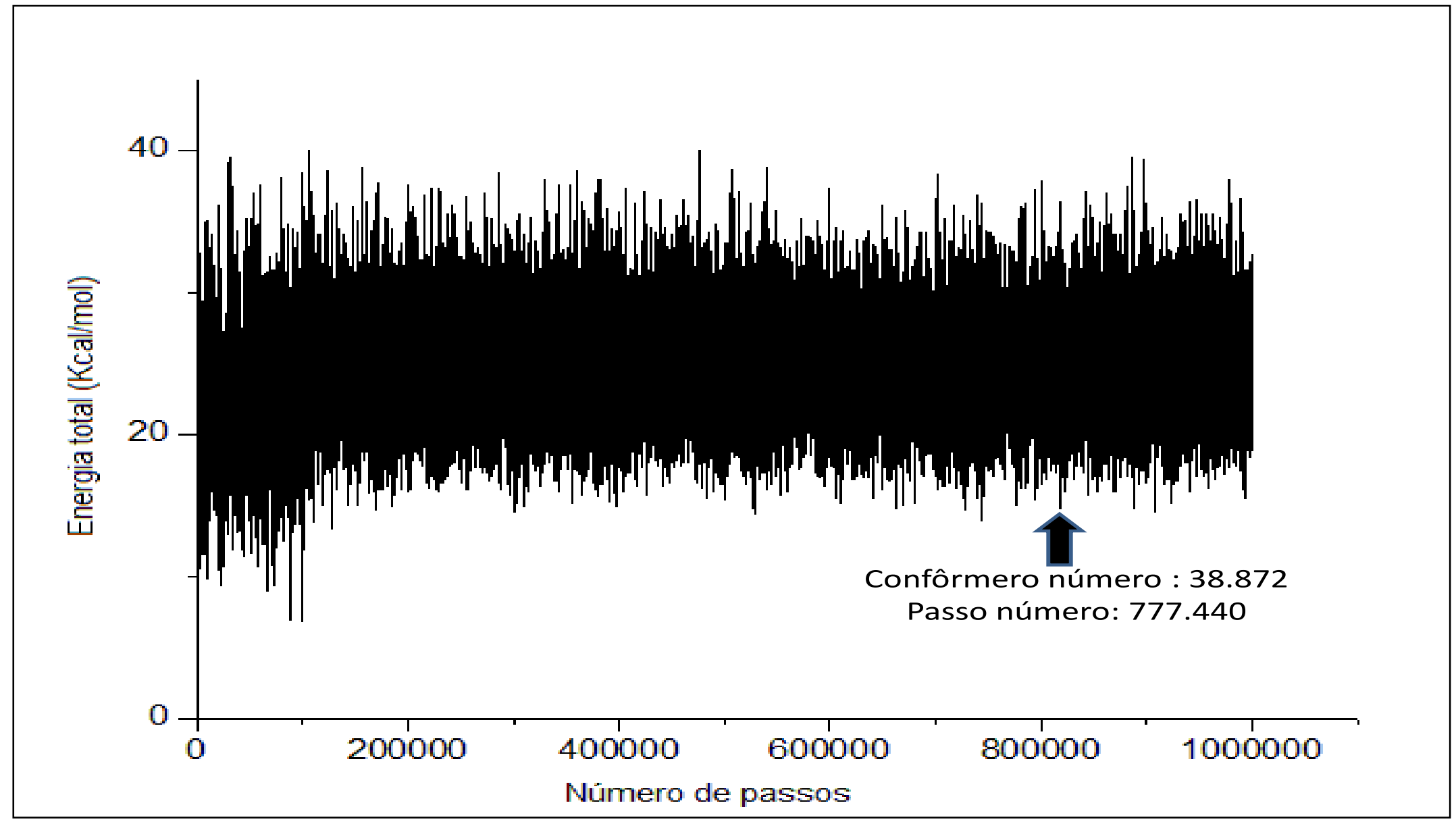

Representação gráfica do perfil de amostragem conformacional com 50.000 confôrmeros do composto série $\boldsymbol{A}-\boldsymbol{H}(\boldsymbol{A}-\boldsymbol{I})$, resultante da simulação de DM ( $1 \mathrm{~ns}, 310 \mathrm{~K})$ versus a energia total $(\mathrm{kcal} / \mathrm{mol})$. A energia total corresponde a somatória da contribuição das energias de

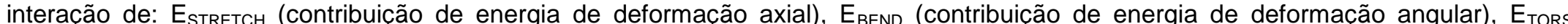
(contribuição de energia de deformação torsional), $E_{1-4}$ (contribuição de energia de interações do tipo 1-4), $E_{v a w}$ (contribuição de energia de van der Waals), $E_{\text {CHARGE }}$ (contribuição de energia eletrostática). 


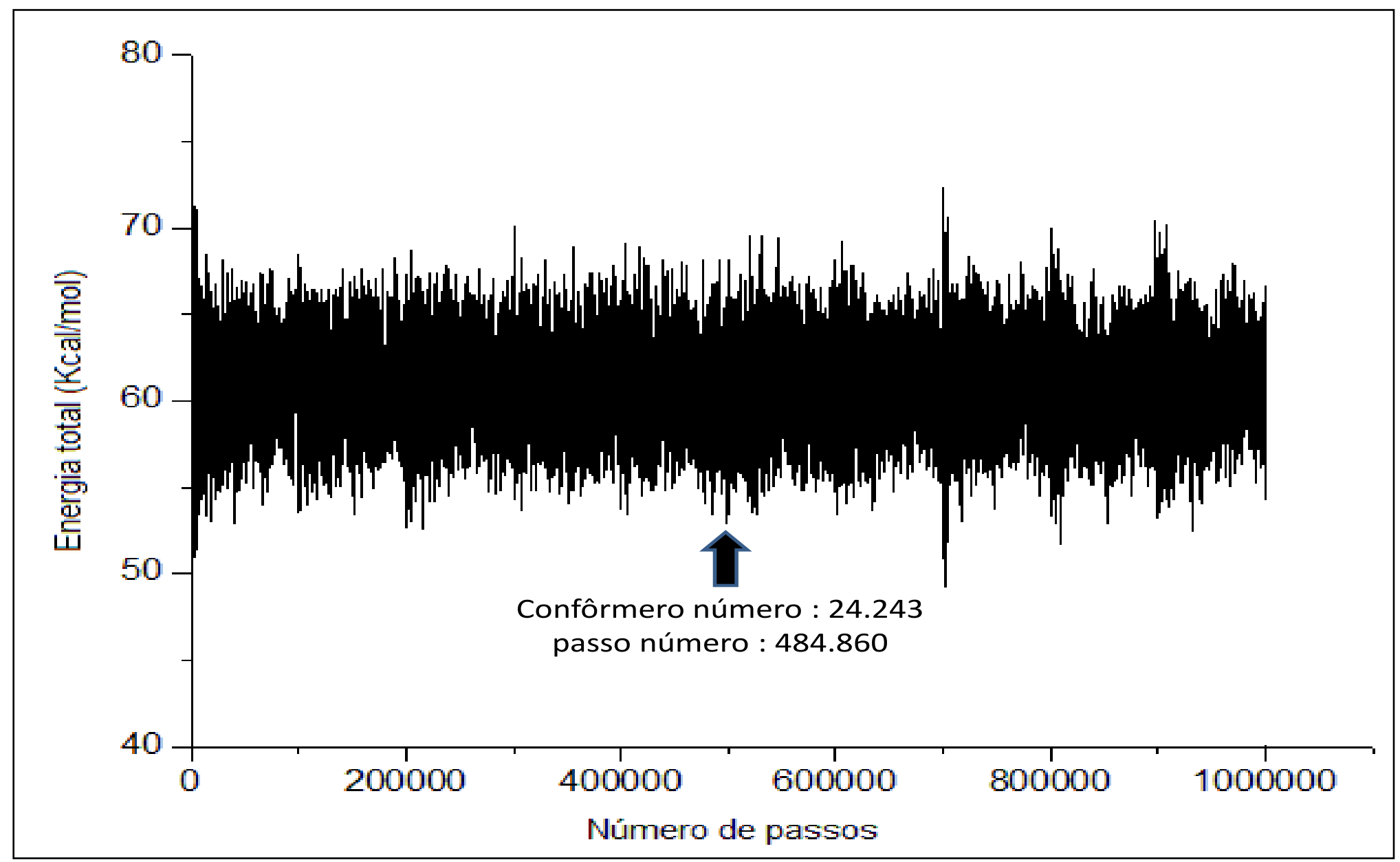

Representação gráfica do perfil de amostragem conformacional com 50.000 confôrmeros do composto série $\boldsymbol{B}$ - $\boldsymbol{H}$ (B-I), resultante da simulação de DM ( $1 \mathrm{~ns}, 310 \mathrm{~K})$ versus a energia total $(\mathrm{kcal} / \mathrm{mol})$. A energia total corresponde a somatória da contribuição das energias de interação de: $E_{\text {STRETCH }}$ (contribuição de energia de deformação axial), $E_{\text {BEND }}$ (contribuição de energia de deformação angular), $E_{\text {TORS }}$ (contribuição de energia de deformação torsional), $E_{1-4}$ (contribuição de energia de interações do tipo 1-4), $E_{\mathrm{vdW}}$ (contribuição de energia de van der Waals), $\mathrm{E}_{\text {CHARGE }}$ (contribuição de energia eletrostática). 
Anexo 4. Propriedades calculadas e obtidas em literatura dos compostos das séries A e B 


\begin{tabular}{|c|c|c|c|c|c|c|c|c|c|c|c|c|c|c|c|c|c|c|}
\hline & & $x 1$ & $\mathrm{x} 2$ & $x 3$ & $x 4$ & $x 5$ & $x 6$ & $x 7$ & $x 8$ & $x 9$ & $\mathrm{x} 10$ & $\mathrm{x} 11$ & $\mathrm{x} 12$ & $\mathrm{x} 13$ & $\mathrm{x} 14$ & $\mathrm{x} 15$ & $\mathrm{x} 16$ & $\mathrm{x} 17$ \\
\hline Composto & Código & $\mu$ & O 1-14 & S 2-10 & N 6-15 & N 5-16 & $\begin{array}{l}\text { N 7- } \\
20\end{array}$ & C 11-1 & C19-11 & homo & lumo & GAP & Platt & Randic & Balaban & Harary & $\begin{array}{l}\text { Hyper } \\
\text { wiener }\end{array}$ & Szeged \\
\hline H & A-I & 12,26 & $-0,55$ & $-0,03$ & $-0,18$ & $-0,36$ & 0,61 & $-0,02$ & 0,04 & $-211,32$ & $-12,41$ & $-198,91$ & 88 & 12,89 & 1,43 & 57,13 & 3,271 & 1,055 \\
\hline $\mathrm{n}-\mathrm{C}_{4} \mathrm{H}_{9}$ & A-II & 12,96 & $-0,56$ & $-0,02$ & $-0,18$ & $-0,37$ & 0,6 & 0,31 & 0,04 & $-210,01$ & $-11,44$ & $-198,57$ & 136 & 17,86 & 1,56 & 73,99 & 7,08 & 1,935 \\
\hline $\mathrm{Cl}$ & A-III & 10,19 & $-0,55$ & $-0,03$ & $-0,18$ & $-0,37$ & 0,6 & 0,11 & 0,06 & $-213,91$ & $-14,39$ & $-199,52$ & 88 & 12,89 & 1,59 & 61,58 & 3,968 & 1,244 \\
\hline CN & A-IV & 8,38 & $-0,54$ & $-0,02$ & $-0,18$ & $-0,36$ & 0,6 & 0,02 & 0,06 & $-216,18$ & $-16,25$ & $-199,93$ & 90 & 13,43 & 1,51 & 65,8 & 4,821 & 1,453 \\
\hline $\mathrm{OCH}_{3}$ & $A-V$ & 11,65 & $-0,57$ & $-0,03$ & $-0,18$ & $-0,39$ & 0,6 & 0,63 & 0,05 & $-210,59$ & $-11,84$ & $-198,75$ & 102 & 14,58 & 1,51 & 65,8 & 4,821 & 1,453 \\
\hline $\mathrm{NO}_{2}$ & $A-V I I$ & 6,69 & $-0,53$ & $-0,02$ & $-0,18$ & $-0,39$ & 0,59 & 0,27 & 0,07 & $-220,24$ & $-38,48$ & $-181,76$ & 94 & 13,81 & 1,46 & 70,52 & 5,677 & 1,664 \\
\hline I & A-VIII & 10,96 & $-0,55$ & $-0,02$ & $-0,17$ & $-0,38$ & 0,61 & 0,02 & 0,05 & -213 & $-14,45$ & $-198,55$ & 88 & 12,89 & 1,59 & 61,58 & 3,968 & 1,244 \\
\hline $\mathrm{CF}_{3}$ & A-IX & 9,31 & $-0,54$ & $-0,02$ & $-0,19$ & $-0,35$ & 0,6 & $-0,13$ & 0,05 & $-215,22$ & $-15,43$ & $-199,79$ & 100 & 14,11 & 1,62 & 75,75 & 6,536 & 1,877 \\
\hline $\mathrm{OC}_{4} \mathrm{H}_{9}$ & $A-X$ & 12,06 & $-0,57$ & $-0,03$ & $-0,17$ & $-0,39$ & 0,6 & 0,63 & 0,05 & $-210,19$ & $-11,54$ & $-198,65$ & 138 & 18,33 & 1,48 & 78,04 & 8,531 & 2,210 \\
\hline $\mathrm{C}_{2} \mathrm{H}_{5}$ & $A-X I$ & 12,82 & $-0,56$ & $-0,02$ & $-0,18$ & $-0,37$ & 0,6 & 0,17 & 0,04 & $-210,2$ & $-11,59$ & $-198,61$ & 112 & 15,36 & 1,51 & 65,8 & 4,821 & 1,453 \\
\hline H & B-I & 7,29 & $-0,59$ & 0,15 & $-0,55$ & $-0,15$ & 0,52 & $-0,08$ & $-0,08$ & $-200,79$ & 4,61 & $-205,4$ & 114 & 15,03 & 1,64 & 76,62 & 3,612 & 1,408 \\
\hline $\mathrm{Cl}$ & B-III & 6,05 & $-0,56$ & 0,08 & $-0,56$ & $-0,14$ & 0,52 & 0,13 & $-0,03$ & -205 & 1,46 & $-206,46$ & 114 & 15,03 & 1,56 & 81,51 & 4,338 & 1,636 \\
\hline $\mathrm{OCH}_{3}$ & B-V & 7,44 & $-0,62$ & 0,15 & $-0,59$ & $-0,18$ & 0,52 & 0,6 & $-0,08$ & $-193,82$ & 5,39 & $-199,21$ & 128 & 16,72 & 1,48 & 86,12 & 5,24 & 1,887 \\
\hline $\mathrm{NO}_{2}$ & B-VII & 7,34 & $-0,6$ & 0,15 & $-0,52$ & $-0,16$ & 0,51 & 0,24 & $-0,07$ & $-221,76$ & $-37,29$ & $-184,47$ & 120 & 15,95 & 1,42 & 91,23 & 6,145 & 2,14 \\
\hline 1 & B-VIII & 6,63 & $-0,6$ & 0,15 & $-0,56$ & $-0,16$ & 0,53 & $-0,05$ & $-0,08$ & $-200,11$ & 2,5 & $-202,61$ & 114 & 15,03 & 1,56 & 81,51 & 4,338 & 1,636 \\
\hline $\mathrm{CF}_{3}$ & B-IX & 5,75 & $-0,59$ & 0,14 & $-0,54$ & $-0,15$ & 0,51 & $-0,2$ & $-0,05$ & $-210,83$ & 1,07 & $-211,9$ & 126 & 16,25 & 1,6 & 96,84 & 7,053 & 2,395 \\
\hline $\mathrm{OC}_{4} \mathrm{H}_{9}$ & $B-X$ & 7,75 & $-0,61$ & 0,15 & $-0,6$ & $-0,16$ & 0,53 & 0,59 & $-0,08$ & $-192,76$ & 5,77 & $-198,53$ & 164 & 20,47 & 1,46 & 99,3 & 9,247 & 2,788 \\
\hline $\mathrm{C}_{2} \mathrm{H}_{5}$ & B-XI & 7,83 & $-0,61$ & 0,14 & $-0,57$ & $-0,17$ & 0,52 & 0,14 & $-0,07$ & $-196,05$ & 5,62 & $-201,67$ & 138 & 17,5 & 1,48 & 86,12 & 5,24 & 1,887 \\
\hline
\end{tabular}

$\mu$ : momento de dipolo; O 1-14: carga do potencial eletrostático do átomo de oxigênio carbonílico para série A e do oxigênio do anel oxadiazolínico para série B, calculados por ChelpG; S 2-10: carga do potencial eletrostático do átomo de oxigênio do anel tiofênico para as séries $A$ e B,calculados por ChelpG; $N$ 6-1: carga do potencial eletrostático do átomo de nitrogênio de ligação $\mathrm{N}=\mathrm{C}$ na porção azometínica para série $\mathrm{A}$ e no anel oxadiazolínico para série $\mathrm{B}$, calculados por ChelpG; N 5-16: carga do potencial eletrostático do átomo de nitrogênio de ligação N-H na porção amídica para série A e no anel oxadiazolínico para série B, calculados por ChelpG; N 7-20: carga do potencial eletrostático do átomo de nitrogênio do grupo nitro ligado ao anel tiofênico para as séries A e B, calculados por ChelpG; C 11-1: carga do potencial eletrostático do átomo de carbono do anel benzênico realizando ligação com substituintes na posição 4 para as séries A e B, calculados por ChelpG; C 19-11: carga do potencial eletrostático do átomo de carbono do anel tiofênico ligado ao grupo nitro para as séries A e B, calculados por ChelpG; $E_{\text {HOM० }}$ energia do orbital de fronteira HOMO; $E_{\text {Lumo }}$ energia do orbital de fronteira LUMO; GAP: diferença entre E HOMO e E LUMO; Platt: índice que descreve a soma dos graus de contorno da superfície molecular: Randic: índice que descreve a soma harmônica das médias geométricas dos graus dos vértices; Balaban: índice que descreve a média da somatória da distância de conectividade da molécula; Harary: índice que descreve a metade da somatória da diagonal externa, distância matricial recíproca dos elementos da molécula; Hyper wiener: descreve uma variação do índice de Wiener; Szeged: estende o índice de Wiener para gráficos cíclicos pela contagem do número de átomos em ambos os lados de cada ligação (considera aqueles átomos que estão mais perto de um lado da ligação do que do outro). 


\begin{tabular}{|c|c|c|c|c|c|c|c|c|c|c|c|c|c|c|c|c|c|c|c|c|}
\hline & x18 & x19 & x20 & x21 & x22 & $x 23$ & x24 & $x 25$ & $x 26$ & x27 & x28 & x29 & x30 & x31 & x32 & x33 & x34 & x35 & x36 & $x 37$ \\
\hline Codigo & Wiener & Dreiding & VW & ASA & ASA+ & ASA- & ASA_H & ASA_P & PSA & ${ }^{C} \log P_{M B}$ & $\pi$ & $p$ & $\mathrm{~F}$ & $\mathrm{R}$ & L & B1 & B5 & $\mathrm{MR}$ & $\begin{array}{l}\text { ClogP } \\
\text { SG-SLN }\end{array}$ & $\begin{array}{c}\text { ClogP } \\
\text { Sv }\end{array}$ \\
\hline A-I & 845 & 162,15 & 224,63 & 522,01 & 270,51 & 251,51 & 352,37 & 169,64 & 115,52 & 2,98 & 0 & 0 & 0 & 0 & 2,06 & 1 & 1 & 0,1 & 1,25 & 3,54 \\
\hline A-II & 1,513 & 184,71 & 291,84 & 640,73 & 377,71 & 263,71 & 471,09 & 169,64 & 115,52 & 4,83 & 2,13 & $-0,16$ & $-0,01$ & $-0,15$ & 6,17 & 1,52 & 4,54 & 1,96 & 3,1 & 5,2 \\
\hline A-III & 981 & 160,94 & 238,59 & 539,77 & 246,3 & 293,47 & 370,12 & 169,64 & 115,52 & 3,59 & 0,71 & 0,23 & 0,42 & $-0,19$ & 3,52 & 1,8 & 1,8 & 0,6 & 1,91 & 4,06 \\
\hline A-IV & 1,137 & 168,44 & 241,89 & 535,23 & 251,92 & 283,31 & 325,78 & 209,45 & 139,31 & 2,84 & $-0,57$ & 0,66 & 0,51 & 0,15 & 4,23 & 1,6 & 1,6 & 0,63 & 1,13 & 3,58 \\
\hline$A-V$ & 1,137 & 210,69 & 250,12 & 575,95 & 335,84 & 240,11 & 387,92 & 188,02 & 124,75 & 2,82 & $-0,02$ & $-0,27$ & 0,29 & $-0,56$ & 3,98 & 1,35 & 3,07 & 0,79 & 1,23 & 3,29 \\
\hline$A-V I$ & 1,455 & 192,48 & 291,85 & 603,26 & 349,97 & 253,29 & 433,61 & 169,64 & 115,52 & 4,53 & 1,98 & $-0,2$ & $-0,02$ & $-0,18$ & 4,11 & 2,6 & 3,17 & 1,96 & 2,65 & 5,17 \\
\hline$A-V I I$ & 1,295 & 305,33 & 249,97 & 575,13 & 302,22 & 272,91 & 319,94 & 255,19 & 161,34 & 2,92 & $-0,28$ & 0,78 & 0,65 & 0,13 & 3,44 & 1,7 & 2,44 & 0,74 & -1 & 3,5 \\
\hline A-VIII & 981 & 159,39 & 249,02 & 550,64 & 246,83 & 303,8 & 380,99 & 169,64 & 115,52 & 3,91 & 1,12 & 0,18 & 0,42 & $-0,24$ & 4,23 & 2,15 & 2,15 & 1,39 & 1,83 & 4,8 \\
\hline A-IX & 1,455 & 166,9 & 255,9 & 570,72 & 249,46 & 321,26 & 298,79 & 271,93 & 115,52 & 3,86 & 0,88 & 0,54 & 0,38 & 0,16 & 3,3 & 1,99 & 2,61 & 0,5 & 2,19 & 4,43 \\
\hline$A-X$ & 1,735 & 215,92 & 300,71 & 671,38 & 391,62 & 279,76 & 489,34 & 182,04 & 124,75 & 4,15 & 1,8 & $-0,32$ & 0,29 & $-0,61$ & 6,86 & 1,35 & 4,79 & 2,17 & 2,56 & 4,5 \\
\hline$A-X I$ & 1,137 & 180,32 & 258,12 & 581,78 & 335 & 246,78 & 412,14 & 169,64 & 115,52 & 3,94 & 1,02 & $-0,15$ & 0 & $-0,15$ & 4,11 & 1,52 & 3,17 & 1,03 & 2,19 & 4,41 \\
\hline B-I & 1,051 & 477,32 & 255,06 & 528,77 & 301,46 & 227,3 & 384,75 & 144,01 & 115,96 & 3,29 & 0 & 0 & 0 & 0 & 2,06 & 1 & 1 & 0,1 & 0,93 & 3,77 \\
\hline B-III & 1,204 & 477,5 & 269,15 & 546,78 & 290,99 & 255,79 & 402,75 & 144,02 & 115,96 & 3,89 & 0,71 & 0,23 & 0,42 & $-0,19$ & 3,52 & 1,8 & 1,8 & 0,6 & 1,6 & 4,29 \\
\hline B-IV & 1,38 & 485,12 & 272,44 & 542,61 & 294,65 & 247,96 & 358,65 & 183,96 & 139,75 & 3,14 & $-0,57$ & 0,66 & 0,51 & 0,15 & 4,23 & 1,6 & 1,6 & 0,63 & 0,81 & 3,81 \\
\hline$B-V$ & 1,38 & 534,3 & 280,67 & 583,98 & 367,52 & 216,46 & 421,57 & 162,4 & 125,19 & 3,13 & $-0,02$ & $-0,27$ & 0,29 & $-0,56$ & 3,98 & 1,35 & 3,07 & 0,79 & 0,92 & 3,52 \\
\hline B-VII & 1,558 & 621,16 & 280,53 & 582,95 & 329 & 253,96 & 351,69 & 231,27 & 161,78 & 3,23 & $-0,28$ & 0,78 & 0,65 & 0,13 & 3,44 & 1,7 & 2,44 & 0,74 & $-1,31$ & 3,72 \\
\hline B-VIII & 1,204 & 475,85 & 279,58 & 557,61 & 278,31 & 279,29 & 413,59 & 144,02 & 115,96 & 4,22 & 1,12 & 0,18 & 0,42 & $-0,24$ & 4,23 & 2,15 & 2,15 & 1,39 & 1,51 & 5,03 \\
\hline B-IX & 1,738 & 483,27 & 286,46 & 578,66 & 289,59 & 289,07 & 332,14 & 246,52 & 115,96 & 4,17 & 0,88 & 0,54 & 0,38 & 0,16 & 3,3 & 1,99 & 2,61 & 0,5 & 1,87 & 4,65 \\
\hline B-X & 2,056 & 539,54 & 331,27 & 679,48 & 423,1 & 256,38 & 523,06 & 156,42 & 125,19 & 4,45 & 1,8 & $-0,32$ & 0,29 & $-0,61$ & 6,86 & 1,35 & 4,79 & 2,17 & 2,24 & 4,72 \\
\hline B-XI & 1,38 & 499,49 & 288,67 & 590,2 & 366,39 & 223,8 & 446,18 & 144,02 & 115,96 & 4,25 & 1,02 & $-0,15$ & 0 & $-0,15$ & 4,11 & 1,52 & 3,17 & 1,03 & 1,87 & 4,63 \\
\hline
\end{tabular}

Wiener: índice que descreve a distância atômica topológica média (metade da soma de todas as distâncias atômicas) na molécula; Dreiding: energia relacionada com a estabilidade da conformação da molécula; VW: volume de van der Waals; ASA: superfície acessível a solvente, calculada usando o raio do solvente (1,4 Å para a molécula de água); ASA+: superfície acessível a solvente de todos os átomos com carga parcial positiva; ASA-; superfície acessível a solvente de todos os átomos com carga parcial negativa; ASA_H: superfície acessível a solvente de todos os átomos hidrofóbicos; ASA_P: superfície acessível a solvente de todos os átomos hidrofílicos; PSA: area de superficie polar; ClogP MB: Coeficiente de partiça calculado pelo método de pesos do programa, considerado pesos iguais para os métodos de VISVANADHAN et al ., 1989, efeito de ressonância de Swain e Lupton; L, B1, B5: parâmetros de STERIMOL (VERLOOP, 1987); MR: refratividade molar; ClogP SG-SLN: coeficiente de partição calculado pelo método GHOSE et al., 1998 - SLN; ClogP sv: coeficiente de partição calculado pelo método VISVANADHAN et al. , 1989. 